US Army Corps

of Engineers $s_{\circledast}$

Engineer Research and

Development Center
INNOVATIVE SOLUTIONS for a safer, better world

Great Lakes and Mississippi River Interbasin Study

\title{
Analytical and Numerical Model Study on Reducing the Risk of Aquatic Nuisance Species Transfer through Brandon Road Lock
}

E. Allen Hammack, David S. Smith, Richard Styles,

July 2018 and Richard L. Stockstill

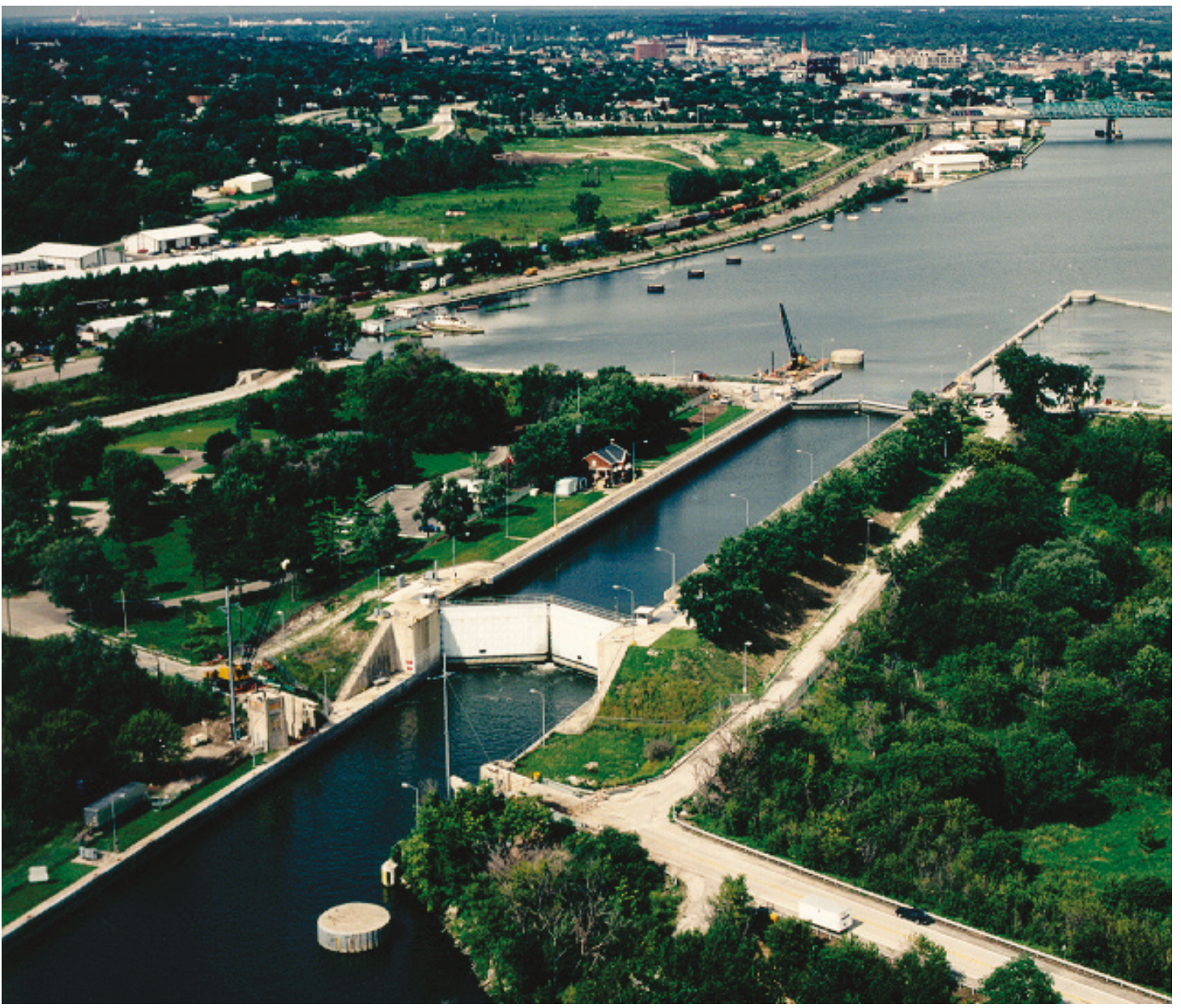


The U.S. Army Engineer Research and Development Center (ERDC) solves the nation's toughest engineering and environmental challenges. ERDC develops innovative solutions in civil and military engineering, geospatial sciences, water resources, and environmental sciences for the Army, the Department of Defense, civilian agencies, and our nation's public good. Find out more at www.erdc.usace.army.mil.

To search for other technical reports published by ERDC, visit the ERDC online library at http://acwc.sdp.sirsi.net/client/default. 


\section{Analytical and Numerical Model Study on Reducing the Risk of Aquatic Nuisance Species Transfer through Brandon Road Lock}

E. Allen Hammack, David S. Smith, Richard B. Styles, and Richard L. Stockstill

Coastal and Hydraulics Laboratory

U.S. Army Engineer Research and Development Center

3909 Halls Ferry Rd.

Vicksburg, MS 39180-6199

Final report

Approved for public release; distribution is unlimited.

Prepared for U.S. Army Corps of Engineers, Chicago District

231 S LaSalle St. \#1500, Chicago, IL 60604

U.S. Army Corps of Engineers, Rock Island District 1500 Rock Island Dr., Rock Island, IL 61201

Under Project 451647, "Brandon Rd - Great Lakes/Miss RVR Interbasin Study (GLMRIS)"

Project 451617, "Brandon Rd. Lock Flushing Numerical Model"

Project 114597, "Interbasin Control GL, MR Species" 


\section{Abstract}

The Great Lakes and Mississippi River Interbasin Study (GLMRIS) is a U.S. Army Corps of Engineers study to evaluate methods of preventing the movement of aquatic nuisance species (ANS) movement between the Great Lakes and Mississippi River basins through aquatic connections. This report is an assemblage of ideas, preliminary hydraulic calculations, and numerical model evaluations that serve as part of the development of an ANS flushing system for Brandon Road Lock on the Illinois Waterway. Four flushing system designs and operations are presented. An analytical description of each lock flushing system design and numerical model results of those designs when applied to Brandon Road Lock are presented. Further, justifications and considerations of a physical model study of any lock flushing design that is chosen for construction are presented. This report is an overall commentary on design ideas and considerations for modeling the flushing rate of the lock chamber. The hydraulic details of lock flushing are outlined with the significant parameters of each lock flushing alternative highlighted. Numerical model results are presented to quantify the effectiveness of each lock flushing concept considered in this study.

DISCLAIMER: The contents of this report are not to be used for advertising, publication, or promotional purposes. Citation of trade names does not constitute an official endorsement or approval of the use of such commercial products. All product names and trademarks cited are the property of their respective owners. The findings of this report are not to be construed as an official Department of the Army position unless so designated by other authorized documents. 


\section{Contents}

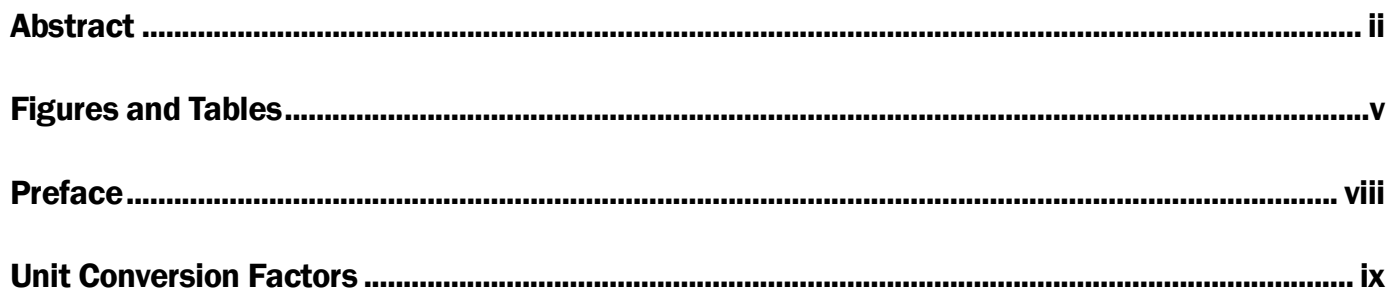

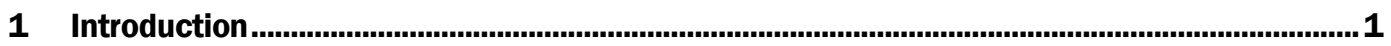

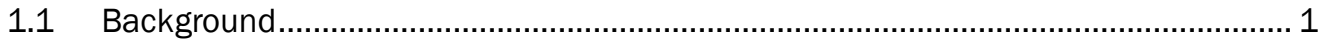

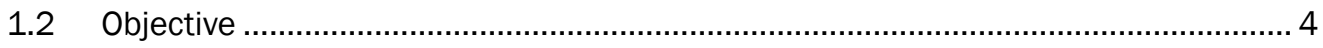

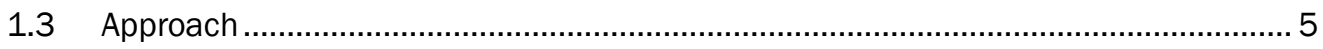

1.4 Other flushing considerations......................................................................... 5

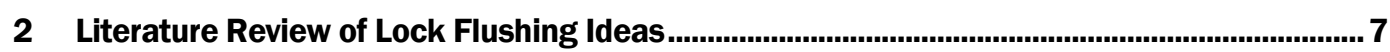

2.1 Previous lock flushing ideas .............................................................................. 7

2.2 Considerations for flushing aquatic nuisance species (ANS) .................................. 8

2.3 Brandon Road Lock details............................................................................. 8

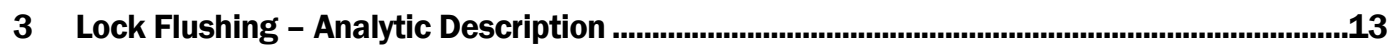

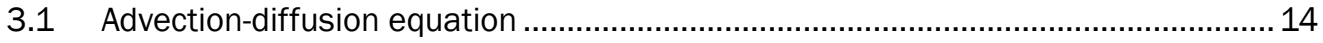

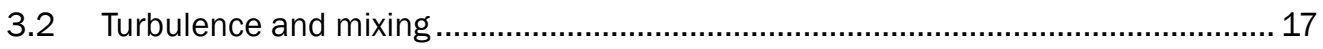

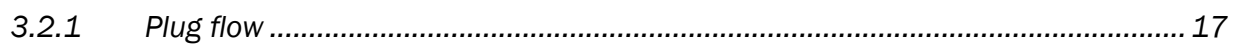

3.2.2 Well-mixed flow .................................................................................... 19

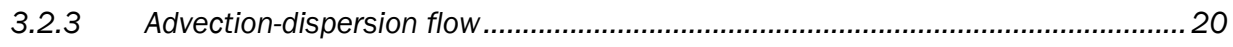

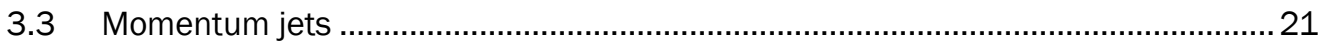

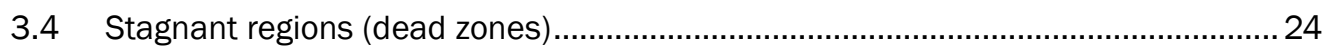

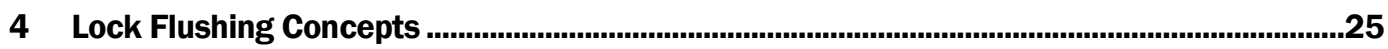

4.1 Hydraulic design of flushing systems ............................................................ 25

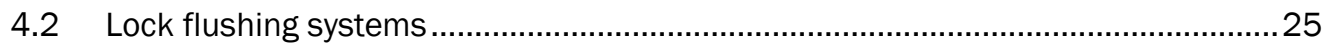

4.2.1 Type 1 lock flushing concept (existing filling and emptying system) ....................26

4.2.2 Type 2 lock flushing concept (lateral flushing manifold) ..................................... 30

4.2.3 Type 3 lock flushing concept (culverts through sill).............................................32

4.2.4 Type 4 lock flushing concept (continuous flow below chamber)............................35

4.2.5 Type 5 lock flushing concept (redesigned filling and emptying system)................ 36

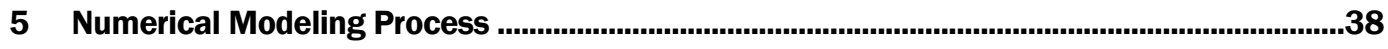

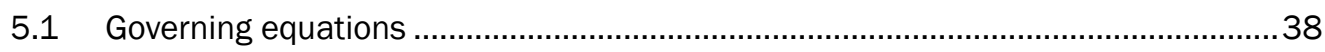

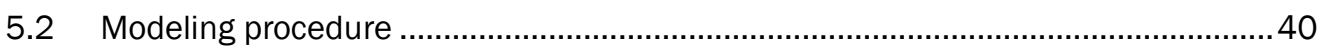

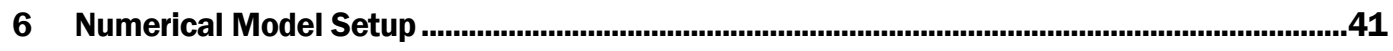

6.1 Type 1 lock flushing concept model geometry ……............................................. 42

6.2 Type 2 lock flushing concept model geometry ...................................................... 43

6.3 Type 3 lock flushing concept model geometry …................................................. 44 
6.4 Type $3 r$ lock flushing concept model geometry ..............................................45

6.5 Type 5 lock flushing concept ....................................................................... 46

7 Numerical Model Results ........................................................................................................47

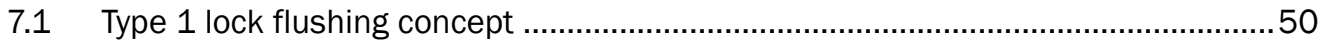

7.2 Type 2 lock flushing concept ................................................................................ 59

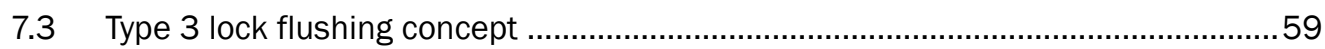

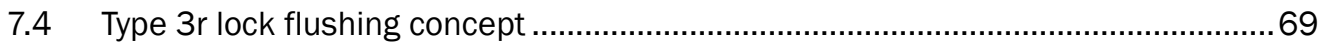

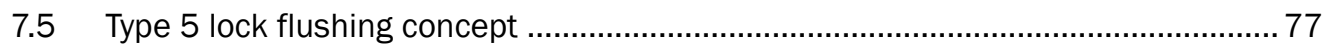

7.6 Lock flushing numerical model results summary............................................... 87

8 Physical Model Considerations...............................................................................................89

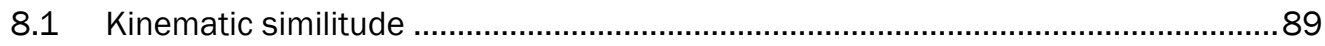

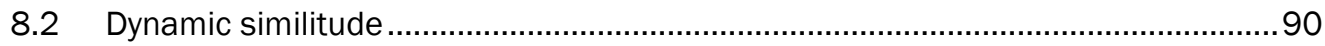

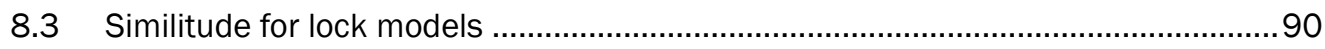

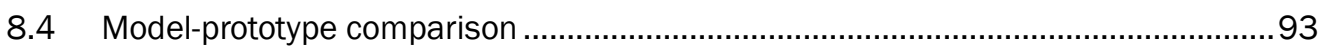

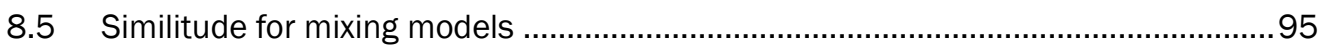

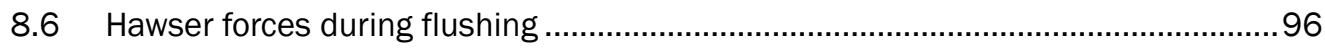

9 Further Research - Prototype and Physical Model Testing ....................................................100

9.1 Prototype tests ................................................................................................. 100

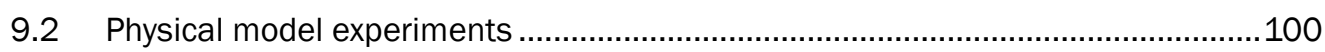

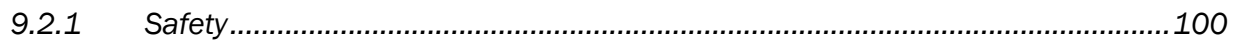

9.2.2 U.S. Army Corps of Engineers (USACE) regulations ..........................................101

9.2.3 Numerical modeling uncertainties...................................................................101

9.2.4 Physical model tests ......................................................................................... 102

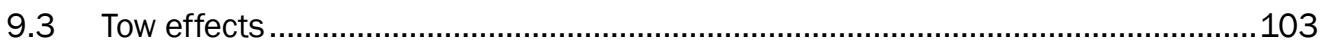

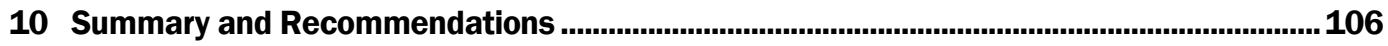

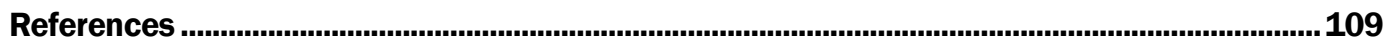

Appendix A: Eisenhower Lock Flushing System Drawings....................................................112

Appendix B: Computational Meshes ...................................................................................114

Appendix C: Type 2 Fixed Lid Model Results.....................................................................................123

Report Documentation Page 


\section{Figures and Tables}

\section{Figures}

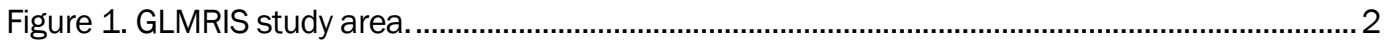

Figure 2. Des Plaines River showing Brandon Road Lock and Chicago area.................................... 3

Figure 3. Aerial view of Brandon Road Lock.............................................................................. 4

Figure 4. Brandon Road Lock, sidewall port filling and emptying system (elevations are in feet referred to mean sea level 1912). .........................................................................................10

Figure 5. Schematic of inflow source descriptions........................................................................

Figure 6. Advection-dominated plug flow....................................................................................

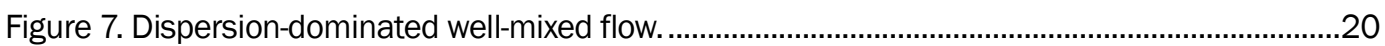

Figure 8. Concentration resulting from transport and dispersion.....................................................21

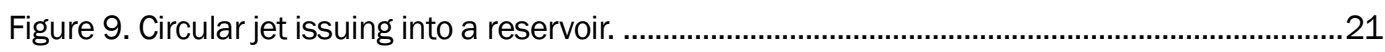

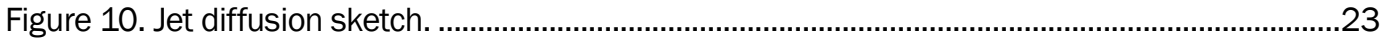

Figure 11. 2D jet issuing into a reservoir. ...................................................................................2

Figure 12. Type 1 (existing) lock flushing concept schematic...........................................................26

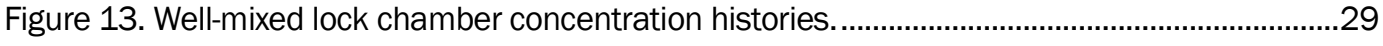

Figure 14. Well-mixed system flushing times for various dilutions....................................................30

Figure 15. Type 2 design flushing system schematic. ……….............................................................31

Figure 16. Type 3 lock flushing concept schematic. ………........................................................33

Figure 17. Plug-flow system flushing time for various tailwater elevations. ......................................35

Figure 18. Type 4 concept schematic. ........................................................................................36

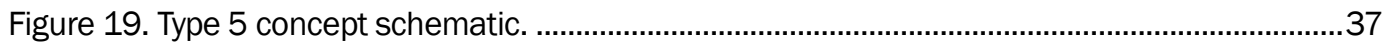

Figure 20. CAD model of Type 1 lock flushing concept..................................................................42

Figure 21. CAD model of Type 2 lock flushing concept...................................................................43

Figure 22. CAD model of Type 3 lock flushing concept....................................................................4

Figure 23. CAD model of Type 3r lock flushing concept. ................................................................45

Figure 24. CAD model of Type 5 lock flushing concept....................................................................46

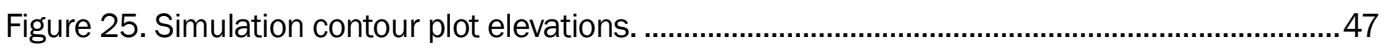

Figure 26. Sample lock flushing volume plot - single curve explanation..........................................48

Figure 27. Sample lock flushing volume plot - single flushing time explanation. ..............................49

Figure 28. Type 1 velocity magnitude contours at $3 \mathrm{ft}$ from chamber floor......................................51

Figure 29. Type 1 velocity magnitude contours $10 \mathrm{ft}$ from chamber floor. .......................................52

Figure 30. Type 1 velocity magnitude contours at lock chamber surface. ........................................53

Figure 31. Type 1 original lock chamber water concentration contours $3 \mathrm{ft}$ from chamber

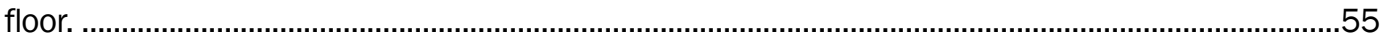

Figure 32. Type 1 original lock chamber water concentration contours $10 \mathrm{ft}$ from chamber floor.

Figure 33. Type 1 original lock chamber water concentration contours at lock chamber surface. 
Figure 34. Type 1 lock chamber flushing performance. ……......................................................

Figure 35. Type 3 velocity magnitude contours $3 \mathrm{ft}$ from chamber floor...........................................61

Figure 36. Type 3 velocity magnitude contours $10 \mathrm{ft}$ from chamber floor. ........................................62

Figure 37. Type 3 velocity magnitude contours at lock chamber surface. .......................................63

Figure 38. Type 3 original lock chamber water concentration contours at $3 \mathrm{ft}$ from chamber floor.

Figure 39. Type 3 original lock chamber water concentration contours at $10 \mathrm{ft}$ from chamber floor.

Figure 40. Type 3 original lock chamber water concentration contours at lock chamber surface.

Figure 41. Type 3 lock chamber flushing performance. .68

Figure 42. Type $3 r$ velocity magnitude contours $3 \mathrm{ft}$ from chamber floor. ........................................70

Figure 43. Type $3 r$ velocity magnitude contours $10 \mathrm{ft}$ from chamber floor........................................ 71

Figure 44. Type $3 r$ velocity magnitude contours at lock chamber surface.........................................72

Figure 45. Type $3 r$ original lock chamber water concentration contours $3 \mathrm{ft}$ from chamber floor.

Figure 46. Type $3 r$ original lock chamber water concentration contours $10 \mathrm{ft}$ from chamber floor.

Figure 47. Type 3r original lock chamber water concentration contours at lock chamber surface.

Figure 48. Type $3 r$ lock chamber flushing performance......................................................................76

Figure 49. Type 5 velocity magnitude contours $3 \mathrm{ft}$ from chamber floor...........................................79

Figure 50. Type 5 velocity magnitude contours $10 \mathrm{ft}$ from chamber floor. ........................................8

Figure 51. Type 5 velocity magnitude contours at lock chamber surface........................................81

Figure 52. Type 5 original lock chamber water concentration contours $3 \mathrm{ft}$ from chamber floor.

Figure 53. Type 5 original lock chamber water concentration contours $10 \mathrm{ft}$ from chamber floor.

Figure 54. Type 5 original lock chamber water concentration contours at lock chamber surface.

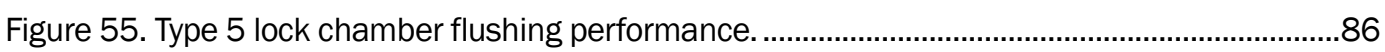

Figure 56. Whitten (Bay Springs) Lock filling curves. ......................................................................93

Figure 57. Currents generated as an upbound tow enters a lock chamber.................................... 104

Figure 58. Currents generated as a downbound tow leaves a lock chamber. ................................ 104

Figure 59. Plan and section of ice flushing system added to Eisenhower Lock,

St. Lawrence Seaway.

Figure 60. Section and elevation of ice flushing system added to Eisenhower Lock, St. Lawrence Seaway.

Figure 61. Type 1 geometry and computational mesh. ............................................................. 115

Figure 62. Type 1 geometry and computational mesh - Zoom 1................................................ 115

Figure 63. Type 1 geometry and computational mesh - Zoom 2............................................... 116

Figure 64. Type 2 geometry and computational mesh............................................................... 116

Figure 65. Type 2 geometry and computational mesh - Zoom 1.................................................117 
Figure 66. Type 2 geometry and computational mesh - Zoom 2................................................117

Figure 67. Type 3 geometry and computational mesh. ................................................................. 118

Figure 68. Type 3 geometry and computational mesh - Zoom 1................................................ 118

Figure 69. Type 3 geometry and computational mesh - Zoom 2 ................................................ 119

Figure 70. Type 3r geometry and computational mesh................................................................ 119

Figure 71. Type 3r geometry and computational mesh - Zoom 1. .................................................. 120

Figure 72. Type 3r geometry and computational mesh - Zoom 2 ................................................ 120

Figure 73. Type 5 geometry and computational mesh. .................................................................... 121

Figure 74. Type 5 geometry and computational mesh - Zoom 1. ................................................ 121

Figure 75. Type 5 geometry and computational mesh - Zoom 2............................................... 122

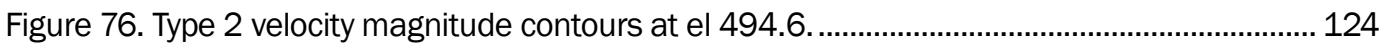

Figure 77 . Type 2 velocity magnitude contours at el 499.6 .......................................................... 125

\section{Tables}

Table 1. Brandon Road Lock, elevation information. ........................................................................11

Table 2. Brandon Road Lock, lock particulars. ...................................................................................12

Table 3. Loss coefficients for Brandon Road Lock filling system. ...................................................27

Table 4. Loss coefficients for Type 2 lock flushing concept. ............................................................32

Table 5. Loss coefficients for Type 3 lock flushing concept. ...............................................................33

Table 6. Calculated discharge for Type 3 lock flushing concept, $34 \mathrm{ft}$ normal lift. ............................34

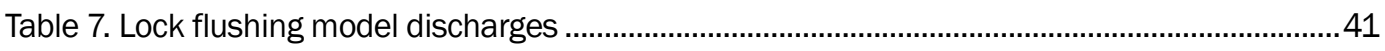

Table 8. Type 1 chamber flushing performance -5 min intervals. .....................................................59

Table 9. Type 3 chamber flushing performance -5 min intervals. ..................................................6

Table 10. Type $3 r$ chamber flushing performance -5 min intervals....................................................77

Table 11. Type 5 chamber flushing performance - 5 min intervals. ................................................86

Table 12. Model-prototype scale relations...........................................................................................91

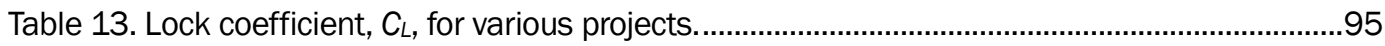

Table 14. Computational mesh sizes .......................................................................................... 114 


\section{Preface}

This study was performed for U.S. Army Corps of Engineers, Rock Island and Chicago Districts, by the Navigation Branch (CEERD-HNN) of the Navigation Division (CEERD-HN), U.S. Army Engineer Research and Development Center, Coastal and Hydraulics Laboratory (ERDC-CHL), under the following projects: "Brandon Rd - Great Lakes/Miss RVR Interbasin Study (GLMRIS)," "Brandon Rd Lock Flushing Numerical Model," and "Interbasin Control GL, MR Species." During the study, Ms. Tracy Leeser was Chief, CEERD-HNN.

At the time of publication, Mr. Tim Shelton was Chief, CEERD-HNN; Dr. Jackie S. Pettway was Chief, CEERD-HN; and Mr. W. Jeff Lillycrop was the ERDC Technical Director for Navigation (CEERD-HZT).

The Acting Deputy Director of ERDC-CHL was Mr. John T. Tucker III, and the Acting Director was Mr. Jeffrey R. Eckstein.

COL Brian S. Green was the Commander of ERDC, and Dr. David W. Pittman was the Director. 


\section{Unit Conversion Factors}

\begin{tabular}{|l|c|l|}
\hline Multiply & By & To Obtain \\
\hline cubic feet & 0.02831685 & cubic meters \\
\hline feet & 0.3048 & meters \\
\hline inches & 0.0254 & meters \\
\hline miles (U.S. statute) & $1,609.347$ & meters \\
\hline square feet & 0.09290304 & square meters \\
\hline tons (force) & $8,896.443$ & newtons \\
\hline tons (force) per square foot & 95.76052 & kilopascals \\
\hline
\end{tabular}




\section{Introduction}

\subsection{Background}

The Great Lakes and Mississippi River Interbasin Study (GLMRIS) is a multi-agency effort aimed at preventing the spread of aquatic nuisance species (ANS) from the Mississippi River basins to the Great Lakes. According to the Aquatic Nuisance Species Agency website, aquatic nuisance species are "nonindigenous species that threaten the diversity or abundance of native species, the ecological stability of infested waters, or any commercial, agricultural, aquacultural or recreational activities dependent on such waters. ANS include nonindigenous species that may occur within inland, estuarine or marine waters and that presently or potentially threaten ecological processes and natural resources. Further, invasive species are any species or other viable biological material (including its seeds, eggs, spores) that is transported into an ecosystem beyond its historic range, either intentionally or accidentally, and reproduces and spreads rapidly into new locations, causing economic or environmental harm or harm to human health. Synonyms for invasive species include introduced, foreign, exotic, alien, non-native, immigrant and transplants."1

The GLMRIS - Brandon Road effort is an assessment of the viability of establishing a single point to control the one-way, upstream transfer of ANS from the Mississippi River basin into the Great Lakes basin near Brandon Road Lock and Dam located in Joliet, IL. The Brandon Road control point was identified in the GLMRIS analyses as the only single location that can address upstream transfer of Mississippi River species through all Chicago Area Waterway System (CAWS) pathways. Implementation of technologies at the Brandon Road control point was a feature of three of the six structural alternatives presented in the GLMRIS Report (http://glmris.anl.gov/glmris-report/).

The Brandon Road site (shown in Figures 1 and 2) is located downstream of the confluence of the Des Plaines River and the Chicago Sanitary and Ship Canal (CSSC). In Figure 1, the red box shows the area of the United States where the GLMRIS study is focused, and Figure 2 shows the

\footnotetext{
1 https://www.invasivespeciesinfo.gov/aquatics/main.shtml
} 
details of the area inside that box. Brandon Road Lock is Item 10 (the green circle) in Figure 2. Previous investigations have indicated that a potential hydrologic bypass can occur during periods of high precipitation from the Des Plaines River to the CSSC. A one-way control point at the Brandon Road site would significantly lessen the likelihood of bypass of Mississippi River ANS into the Great Lakes basin during flood events.

Figure 1. GLMRIS study area.

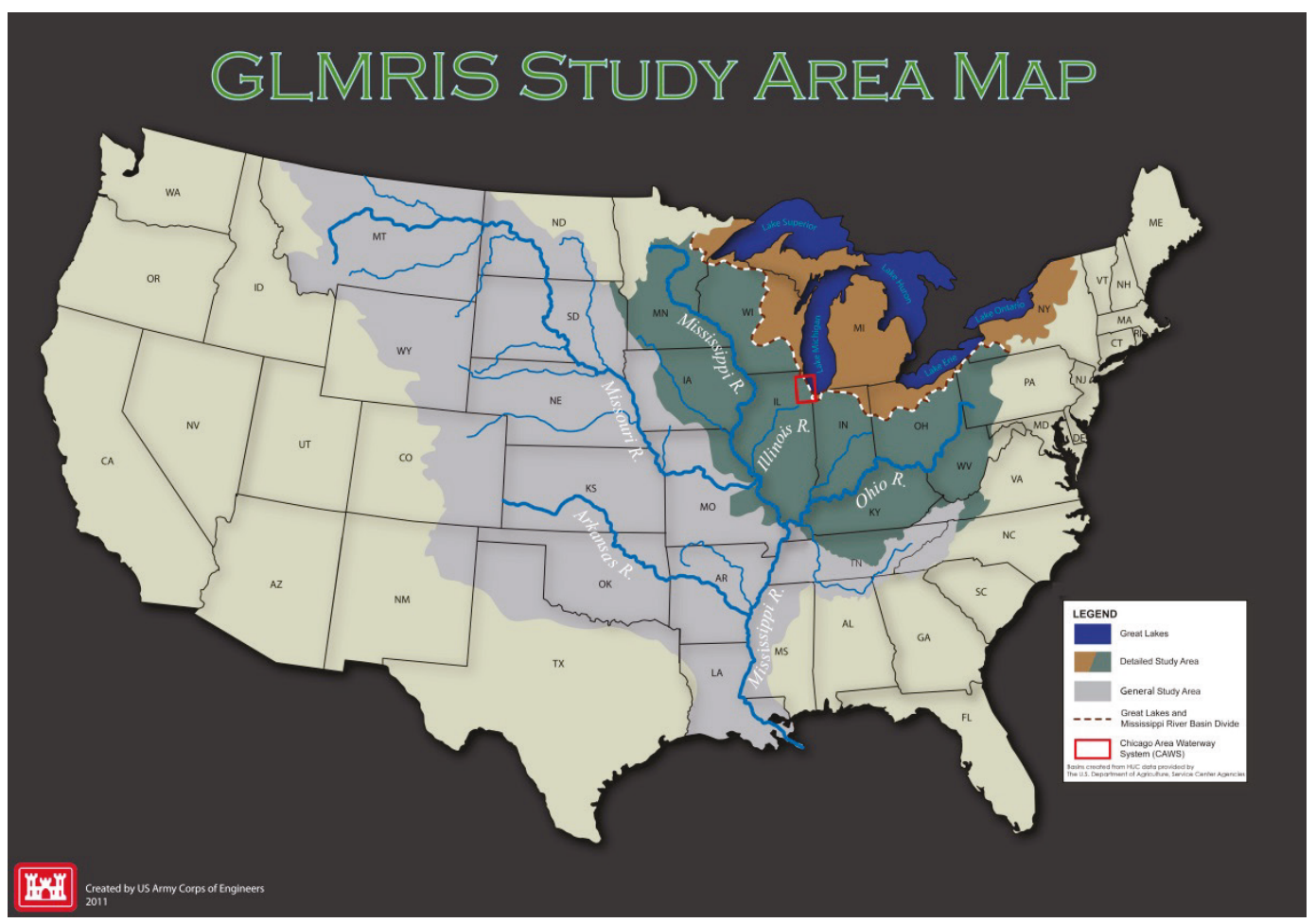


Figure 2. Des Plaines River showing Brandon Road Lock and Chicago area.

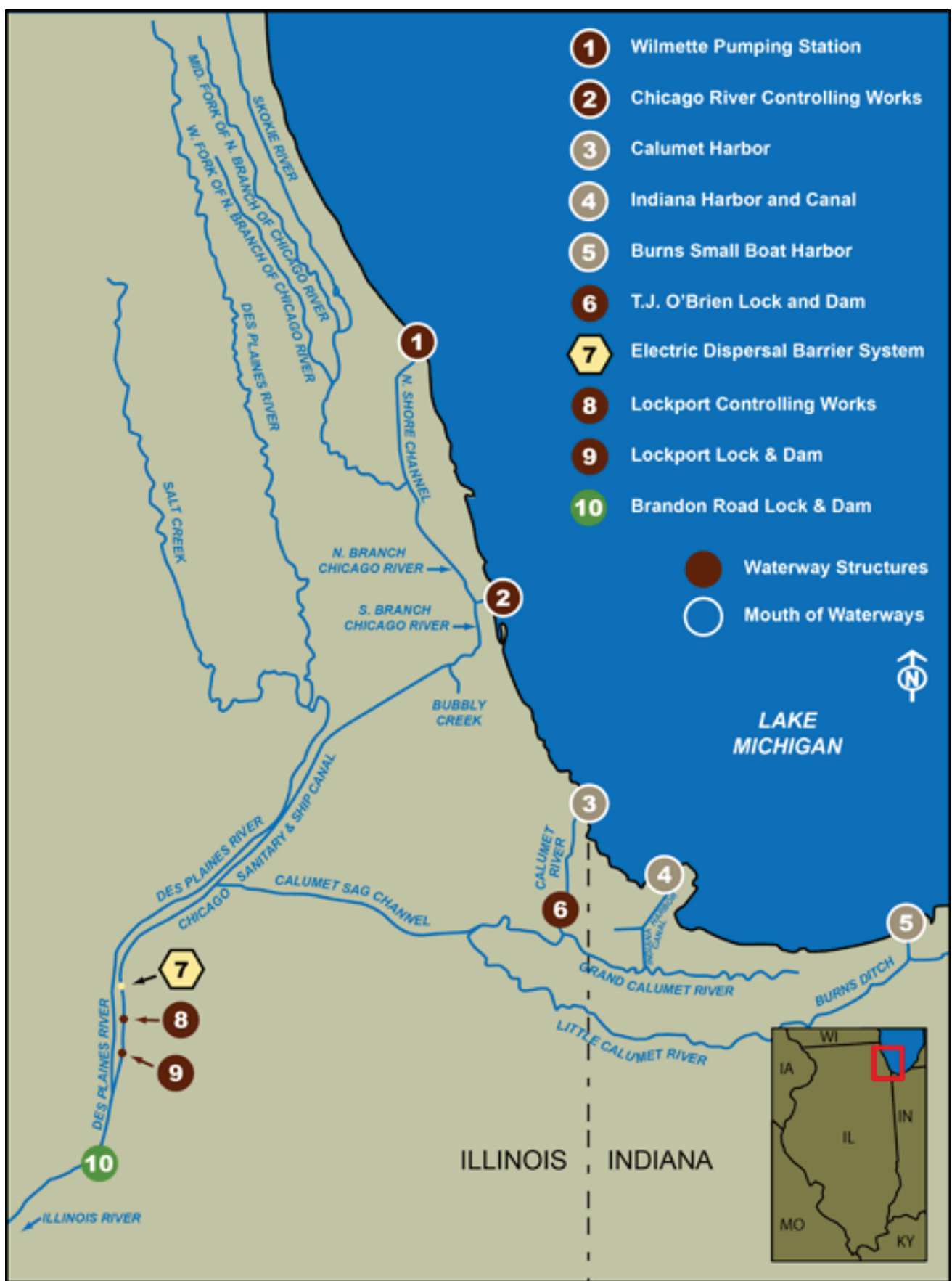

A project at the Brandon Road site is likely to reduce a number of previously identified adverse impacts to existing waterway uses and users significantly. These impacts include but are not limited to increased potential for flooding or degradation of water quality. These impacts contributed significantly to the lengthy timeframes and significant costs of the structural alternatives presented by the GLMRIS Report. 
The physical configuration of Brandon Road Dam (Figure 3) prevents the upstream transfer of Mississippi River ANS. There is a minimum 25-foot (ft) difference in water elevation from the downstream side of the dam to the upstream side, which effectively limits upstream transfer and promotes the use of gravity for flushing operations. Lock operation at this location currently provides the only known aquatic pathway that allows transfer of Mississippi River ANS to the Great Lakes through the CAWS.

Figure 3. Aerial view of Brandon Road Lock.

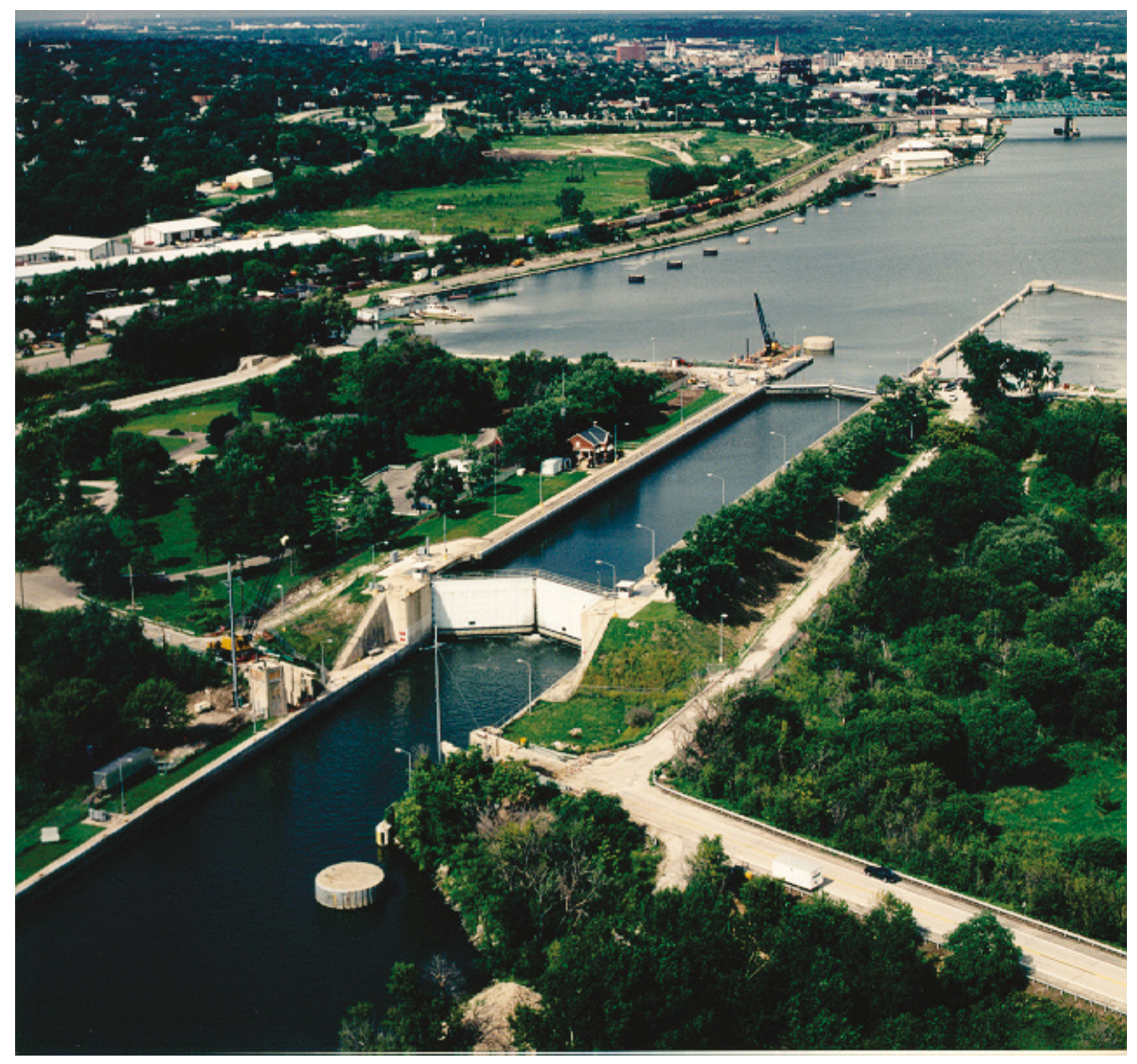

\subsection{Objective}

Preventing ANS, present in the lower pool, from reaching the upper pool requires that the chamber be flushed prior to each lock filling operation. The empty chamber (water surface at tailwater elevation) must be flushed prior to filling regardless of the presence of a tow in the chamber. Once a lock chamber is flushed and the miter gates and operation valves are closed, the chamber can be filled in a normal manner with clean water 
from the upper pool entering the chamber. Filling the lock in preparation for a down-bound tow approaching the lock must be preceded by a flushing cycle.

Different designs have been proposed for a flushing system of Brandon Road Lock. These flushing system designs require structural and operational changes to the lock. Further, these designs introduce flushing flow into the lock chamber in different locations and at different rates, so the effectiveness and efficiency of each design must be determined before any decision can be made on which flushing system design is best suited for significantly reducing the transfer of ANS across Brandon Road Lock. The objective of this project is to determine the dominant hydraulic mechanisms for each of the proposed flushing system designs and to complete numerical models to determine how each one performs.

\subsection{Approach}

To evaluate each proposed flushing system design, the hydraulics of each proposed flushing system design have been explored, and numerical hydraulic models of each system as applied to Brandon Road Lock have been completed. The literature has been reviewed to determine the relevant hydraulic considerations for each design. This information provides qualitative estimates of how each design will perform. Threedimensional (3D) numerical hydraulic models of each flushing system have been performed to determine how effectively and efficiently each system introduces flushing water into the lock chamber. The numerical model results of each design have been compared, and a recommended design is provided.

\subsection{Other flushing considerations}

This study does not address all the relevant hydraulic considerations of the modification of Brandon Road Lock for ANS transfer. Other considerations include the safety associated with navigation. Safety assurance will most likely require longer flushing times when a tow is in the chamber as compared to an empty chamber. These questions are best answered with a physical model study that includes hawser force measurements.

This report presents design concepts for flushing Brandon Road Lock as part of the overall study to answer how a navigation lock and dam can be 
used as a barrier to the upstream passage of ANS. These ideas were generated during discussions among personnel of the U. S. Army Corps of Engineers (USACE), Chicago District; Rock Island District; Inland Navigation Design Center (INDC); and the U.S. Army Engineer Research and Development Center (ERDC), Coastal and Hydraulics Laboratory (CHL). Initial estimates of flushing efficiency for various design ideas are provided. Before implementation, any chosen design should be further evaluated with a physical model study. The physical model will provide the flushing information and ensure that navigation safety is maintained after modifications are made to the lock's filling and emptying system. Therefore, a description of the physical model is also provided in this report.

This report is a commentary on design ideas and considerations for modeling the flushing of a lock chamber. First, previous studies that may provide design ideas are reviewed. This literature review is followed by a brief description of Brandon Road Lock. Then the mechanics of hydraulic mixing with application to flushing a lock chamber are discussed. Five design and operation ideas are presented with estimates of component sizes and efficiencies. Finally, descriptions of further evaluation needed for design refinement are presented including but not limited to a physical model study, the associated modeling considerations, and safety concerns associated with the operation of a modified lock. 


\section{Literature Review of Lock Flushing Ideas}

Operations of navigation locks are hindered when floating or submerged substances in the water require consideration. The most common substances are floating objects such as debris and ice, which must be flushed from the chamber to allow room for vessel passage. Salt water is another substance that must be addressed daily at certain projects. Locks are used to arrest salt-water wedges at some projects that separate the forebay's fresh water from the tailwater's saline water. Studies have been directed toward developing operation strategies for flushing ice and debris, as well as limiting salt water advance with bubble plumes and various structures placed on the lock floor.

Prohibiting passage of neutrally buoyant particles, such as ANS, presents a new challenge to lock operators. Ice and debris floating on the water surface will be transported from the chamber once enough flow is introduced into the chamber to develop a water-surface gradient. However, ANS flushing is more complicated because the turbulent flow will disperse the entities. Therefore, previous studies are of limited benefit to the problem faced by USACE operators of the Illinois Waterway navigation projects. However, modifications made to the Eisenhower and Snell Locks on the St. Lawrence Seaway are used in this report to demonstrate the feasibility of adding culverts in the lock upper sill and tied into one of the filling culverts.

\subsection{Previous lock flushing ideas}

Investigations have been conducted to determine how a navigation lock may be used as a conduit to facilitate passage of substances such as ice and debris. Ice and debris studies (e.g., Tuthill et al. 2004; Tuthill 2003; Tuthill and Gooch 1997) have focused on passing materials that tend to float on the water surface. Numerous studies are documented in the literature regarding how a lock may serve as a barrier to salt water intrusion. Salt water intrusion studies (e.g., Parchure et al. 2000; Mausshardt and Singleton 1995; Abraham et al. 1973; Bastian 1971; Wood 1970; Boggess 1970) have focused on preventing salt water from entering the lock chamber. The salt water problem focuses on the density differences of the fresh and salt water bodies that are to remain separated. 


\subsection{Considerations for flushing aquatic nuisance species (ANS)}

The current study differs from previous research in that the objective is to prevent passage of ANS, which, for the purposes of the current study, are assumed to be neutrally buoyant particles. The exchange of upstream and downstream waters for the CAWS is complicated by the fact that the mixing of water from these bodies is to be limited even though natural mixing processes occur during normal operations. The simple act of opening the lock gates generates turbulent mixing of the fluids on either side of the gate. Also, vessels entering and exiting the chamber generate mixing as return currents and propeller wash mix large quantities of water. These mixing processes make maintaining the ANS concentration at near-zero levels difficult.

\subsection{Brandon Road Lock details}

Brandon Road Lock and Dam is being considered for modification to make the project serve as a barrier to ANS. Brandon Road Lock and Dam is the first project downstream of the Lockport Lock and Dam, and the ANS are assumed to exist on the downstream side of Brandon Road Lock. The objective of the GLMRIS is to prevent ANS from entering the CAWS from the Lower Des Plaines River via Brandon Road Lock.

Brandon Road Lock and Dam is located 286 miles above the confluence of the Illinois River with the Mississippi River (Figure 1. GLMRIS study area. and Figure 2). Brandon Road Dam, located on the Des Plaines River just below the city of Joliet, IL (approximately 27 miles southwest of Chicago), is a fixed concrete structure, $1,569 \mathrm{ft}$ long. The dam is $2,391 \mathrm{ft}$ long (exclusive of fixed embankment and river wall). The water-surface elevation of the pool and discharge past the dam are controlled by twentyone $50 \mathrm{ft}$ tainter-type crest gates that hold the normal pool 27 inches above the crest of the masonry. Six openings through the dam, previously controlled by sluice gates, have been sealed and are no longer used. A $320 \mathrm{ft}$ section of head gates, which was designed for the future addition of a powerhouse, contains eight operating head gates used for passing water. An ice chute and two sections of earth embankment complete the dam. Most of the short pool is contained between flood walls. These walls vary with a maximum height of $35 \mathrm{ft}$.

Brandon Road Lock, opened in 1933, is of the sidewall port design filling and emptying system (HQUSACE 2006) as are the majority of locks 
operated by the USACE. It operates under a nominal lift of $34 \mathrm{ft}$ with an average 19-minute (min) lock chamber fill time and a 15 min emptying time. The lock chamber is nominally $600 \mathrm{ft}$ long and $110 \mathrm{ft}$ wide (HQUSACE 2006).

The layout of the lock filling and emptying system is shown in Figure 4. The lock features a redundant upstream miter gate and vertical-lift valves for flow control. The intakes and outlets are immediately upstream and downstream of the upper and lower miter gates, respectively. The chamber is filled and emptied with $12 \mathrm{ft}$-diameter (diam) culverts in each lock wall. Each sidewall manifold has ten ports, $5.0 \mathrm{ft}$ wide by $3.5 \mathrm{ft}$ tall. The port spacing varies from $35 \mathrm{ft}$ to $115 \mathrm{ft}$ along the chamber length. The ports in each wall are positioned directly opposite rather than staggered as specified in current lock design criteria (HQUSACE 2006). The chamber floor is at elevation (el) $489.7 \mathrm{ft}$ with $19 \mathrm{ft}$ wide aprons at el 490.7 (NGVD 29) adjacent to either lock wall.

The ratio of the sum of the cross-sectional area of the ports to the crosssectional area of the culvert (port-to-culvert area ratio) is 1.55 for Brandon Lock whereas 0.95 is the current design criteria for sidewall port systems based on USACE guidance (HQUSACE 2006). If the sum of the crosssectional area of the ports is larger than the cross-sectional area of the culvert, the flow into the lock chamber is culvert controlled instead of port controlled, and poor distribution of flow from the port manifold will result. During peak discharge of a filling operation, flow can be drawn from the lock chamber by the upstream ports (HQUSACE 2006). Conversely, if the port-to-culvert area ratio is too small, filling time will be sacrificed without a noticeable improvement in conditions in the lock chamber. 
Figure 4. Brandon Road Lock, sidewall port filling and emptying system (elevations are in feet referred to mean sea level 1912).

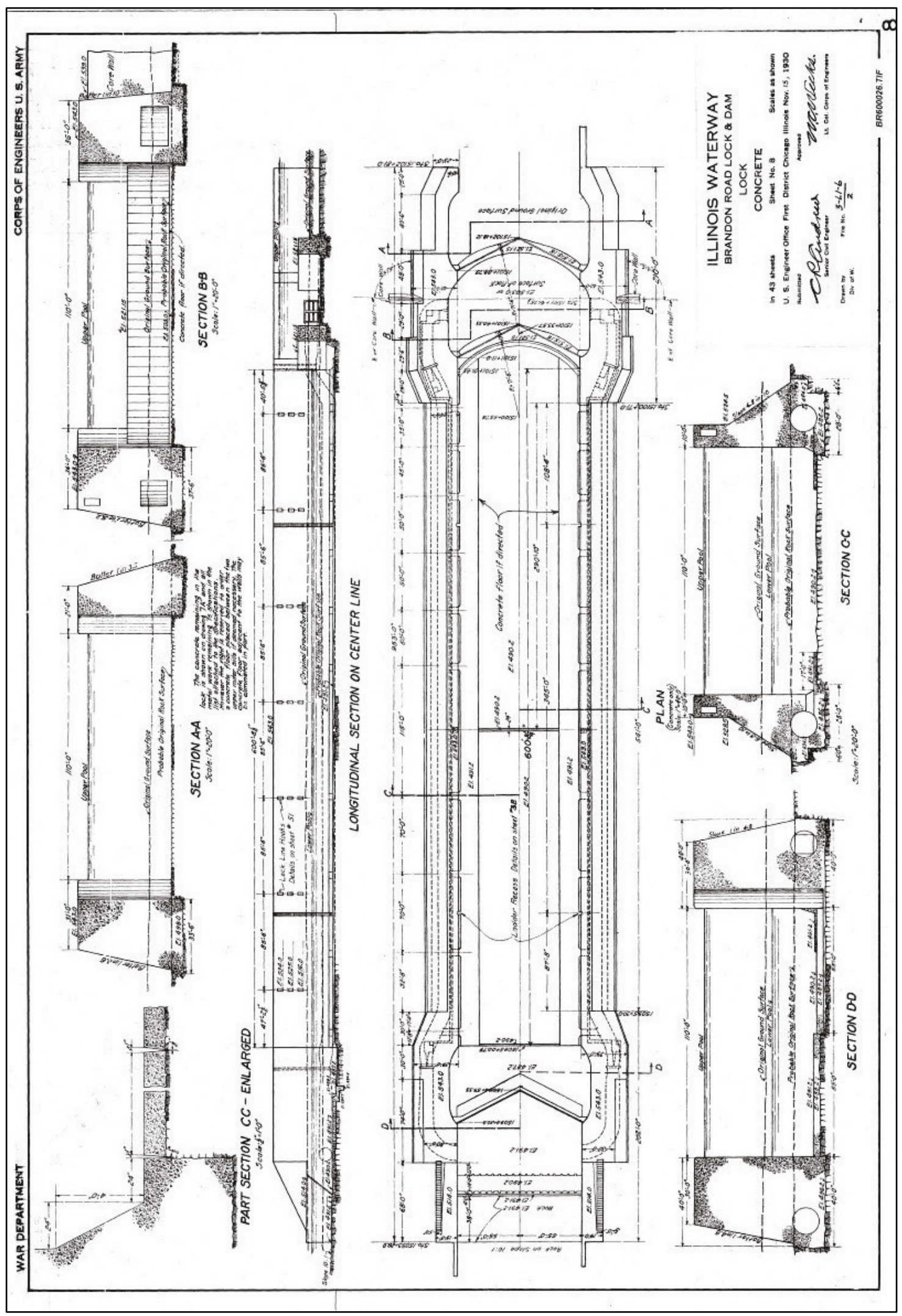


Simple volume exchange calculations can provide order-of-magnitude estimates of mixing attributed to a vessel entering or leaving a lock chamber. For the case in which a tow exits the lock into ANScontaminated water, a first approximation is to assume the volume of water displaced by the tow in the lock will be replaced by ANScontaminated water as the barge leaves the chamber. The calculations below are based on geometric parameters of the lock chamber (listed in Tables 1 and 2) and the design tow. The design tow is assumed to be a $3 \times 3$ flotilla of jumbo barges, each barge being $35 \mathrm{ft}$ wide by $195 \mathrm{ft}$ long and drafted at $9 \mathrm{ft}$. The total dimensions of the $3 \times 3$ tow are the beam width $(b=105 \mathrm{ft})$, the length $(l=585 \mathrm{ft})$, and $\operatorname{draft}(d=9 \mathrm{ft})$.

Table 1. Brandon Road Lock, elevation information.

\begin{tabular}{|l|c|}
\hline \multicolumn{2}{|c|}{ Elevations (ft, NGVD 29*) } \\
\hline Upper Pool Normal & 538.5 \\
\hline Upper Pool Minimum & 537.2 \\
\hline Upper Pool Maximum & 540.5 \\
\hline Lower Pool Normal (no flow) & 504.5 \\
\hline Lower Pool Minimum & 501.1 \\
\hline Lower Pool Maximum & 513.5 \\
\hline Chamber Floor (Average) & 490.0 \\
\hline
\end{tabular}

*National Geodetic Vertical Datum of 1929

The floor of Brandon Road Lock chamber is rock at el $489.7^{1} \mathrm{ft}$ with a concrete apron at el $490.7 \mathrm{ft}$ that is $19 \mathrm{ft}$ wide adjacent and along either chamber wall. The average elevation of the chamber floor is el $490.0(72 \mathrm{ft}$ at el 489.7 and $38 \mathrm{ft}$ at el 490.7$)$. The chamber is $110 \mathrm{ft}$ wide by $671 \mathrm{ft}$ long, pintle-to-pintle.

Although the volume to be exchanged will be less when the tailwater is at normal or minimum lower pool elevation, the higher head may be most critical regarding hawser forces if a tow is present. River conditions that provide maximum lower pool elevation will have the largest volume and the least head, both of which result in a longer flushing time. This report does not consider the volume of water in the culverts, but the volume of potentially contaminated water residing in the culverts could be included in the exchange-time determinations in a physical model study.

${ }^{1}$ All elevations included in this report are in feet referenced to NGVD 1929 datum. 
Table 2. Brandon Road Lock, lock particulars.

\begin{tabular}{|l|l|}
\hline \multicolumn{2}{|l|}{ Lock Information at Normal Upper Pool (el 538.5) and Lower Pool (el 504.5) } \\
\hline Lock filling and emptying system & Sidewall Port \\
\hline Chamber width & $110 \mathrm{ft}$ \\
\hline Chamber length & $671 \mathrm{ft}$ \\
\hline Culvert diam & $12 \mathrm{ft}$ \\
\hline Port size & $5.0 \mathrm{ft}$ wide by $3.5 \mathrm{ft}$ tall \\
\hline Number of ports (each culvert) & 10 \\
\hline Port-to-culvert area ratio & 1.55 \\
\hline Filling time & $19 \mathrm{~min}$ \\
\hline Emptying time & $15 \mathrm{~min}$ \\
\hline Chamber depth when filled & $48.5 \mathrm{ft}$ \\
\hline Volume of “filled" lock & $3,579,785 \mathrm{ft}^{3}$ \\
\hline Chamber depth when empty & $14.5 \mathrm{ft}$ \\
\hline Volume of “empty" lock & $1,070,245 \mathrm{ft}^{3}$ \\
\hline Normal lift & $34 \mathrm{ft}$ \\
\hline Normal lift volume & $2,509,540 \mathrm{ft}^{3}$ \\
\hline
\end{tabular}




\section{Lock Flushing - Analytic Description}

Flushing of Brandon Road Lock chamber will be accomplished by introducing clean water from the upper pool into the chamber, diluting ANS-contaminated water by mixing, and transporting ANS-contaminated water into the lower pool from the chamber through opened lower miter gates. This chapter provides the analytic evaluation required to estimate the time and space consequences of flushing the lock chamber.

This study focuses on concepts for flushing the lock using gravity, thus avoiding the large expenses of mechanical pumping. The energy and other operation costs as well as construction and maintenance costs over the lifespan of the pump can be avoided if a gravitational system can be developed. Flushing will bring upper pool water into the chamber, which will be at lower pool level, so the energy available will be the head from the pool differences.

The introduction of clean upper pool water at the upstream end of the chamber can be considered as either a point or line source. Schematics of each of these systems are provided in Figure 5. The red dots indicate the presence of ANS, and the blue lines indicate clean water. In the upper image, clean upper pool water is introduced at a single location, and that flow spreads into the lock chamber as a jet. In the lower image, clean upper pool water is introduced as a line of point sources. The introduction of clean water is essentially a uniform plug.

Modeling the point source conditions requires knowledge of both the lateral and the longitudinal dispersion coefficients. Point source evaluation further requires the inclusion of lateral diffusion and a multidimensional advection-diffusion equation for analysis. Rather than speculating about the effectiveness of a single outlet, this analytical evaluation will consider the clean water inflow as a steady-state line source as illustrated in Figure 5. The alternatives will be further evaluated by the design team to compare cost, operation and maintenance issues, and overall efficiency of the alternatives. 
Figure 5. Schematic of inflow source descriptions.

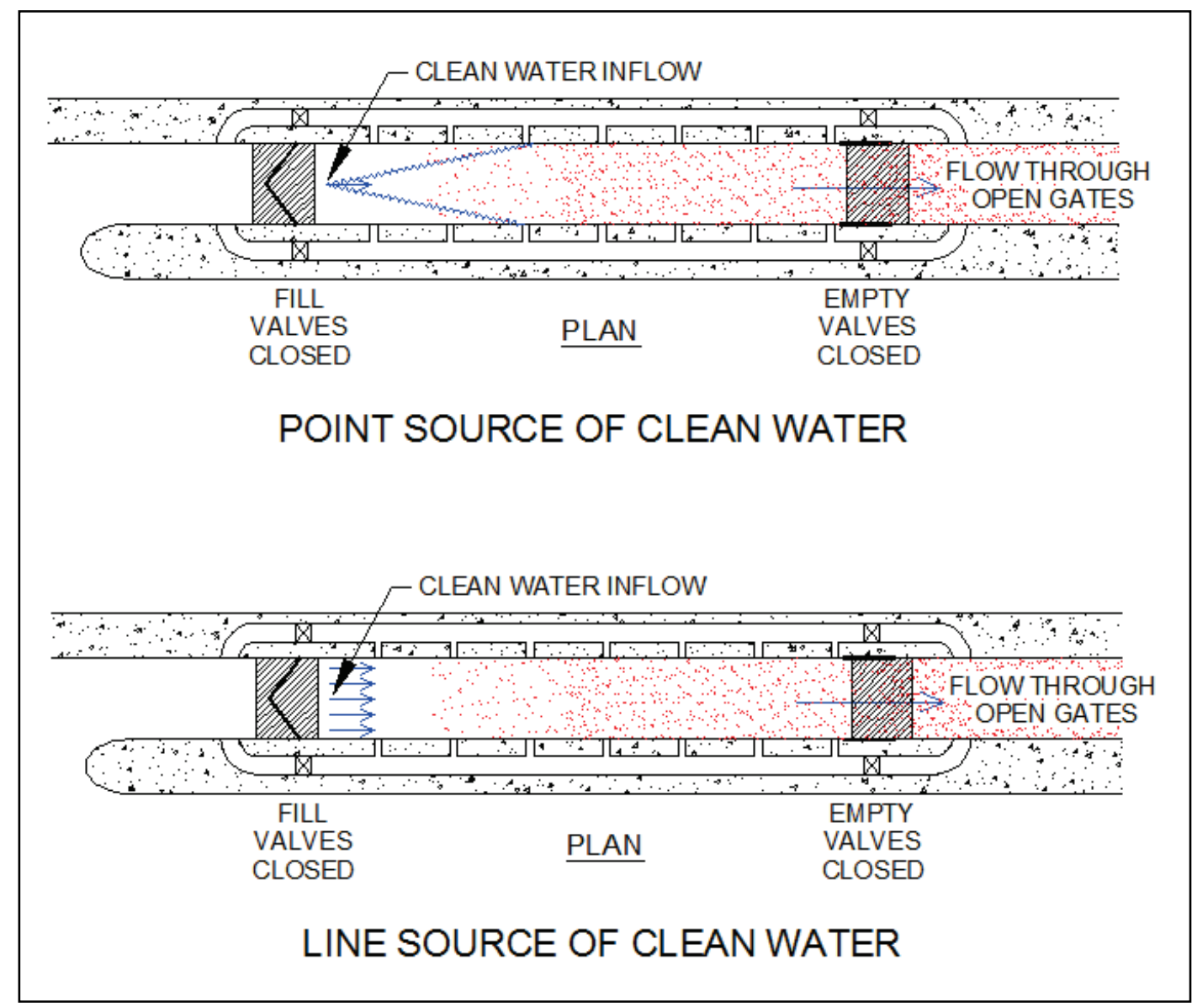

\subsection{Advection-diffusion equation}

Flushing of the lock chamber using a line source of clean water is a complex hydro-transport problem but can be explained using the simplified one-dimensional (1D) transport equation if the assumption is that flow characteristics do not change perpendicular to the flow direction. The concentration relative to position is quantified with the $1 \mathrm{D}$ advectiondiffusion equation. The advection-diffusion equation with a conservative constituent is used to estimate the rate of longitudinal dispersion. The $1 \mathrm{D}$ advection-diffusion equation is

$$
\frac{\partial C}{\partial t}+U \frac{\partial C}{\partial x}-D \frac{\partial^{2} C}{\partial x^{2}}=0
$$


where:

$$
\begin{aligned}
C= & \text { cross-sectional average concentration }\left[\mathrm{ML}^{-3}\right] \\
T= & \text { time }[\mathrm{T}] \\
U= & \text { cross-sectional average velocity }\left[\mathrm{LT}^{-1}\right] \\
x= & \text { longitudinal direction of flow }[\mathrm{L}] \\
D= & D_{x}+D_{t}+E_{x}=\text { the longitudinal dispersion coefficient }\left[\mathrm{L}^{2} \mathrm{~T}^{-1}\right] \\
D_{x}= & x \text {-direction molecular diffusion } \\
D_{t}= & \text { turbulent (eddy) diffusion (time-averaged) } \\
E_{x}= & x \text {-direction (mechanical) dispersion coefficient (space- } \\
& \quad \text { averaged). }
\end{aligned}
$$

The molecular diffusion, $\mathrm{D}_{\mathrm{x}}$, is the random motion of particles; the eddy diffusion, $\mathrm{D}_{\mathrm{t}}$, is the turbulent mixing of particles; and the mechanical dispersion, $\mathrm{E}_{\mathrm{x}}$, is the mixing caused by variations in velocities. Diffusion is the process where a constituent moves from a higher concentration to a lower concentration whereas dispersion is mixing caused by physical processes.

The flushing process consists of the initial condition that at $t=0, C=C_{o}$ for all $x$ and the boundary condition that the concentration at the inflow boundary is constant, $C=\mathrm{O}$ at $x=\mathrm{o}$ or

$$
\begin{gathered}
C(x, 0)=C_{0} \text { for } x \geq 0 \\
C(0, t)=0 \text { for } t \geq 0 \\
C(\infty, t)=C_{0} \text { for } t \geq 0
\end{gathered}
$$

The analytical solution for the advection-diffusion equation with these initial and boundary conditions is (e.g., Kumar et al. 2011; Socolofsky and Jirka 2005; Runkel 1996)

$$
C(x, t)=\frac{C_{0}}{2}\left[1-\operatorname{erf}\left(\frac{x-U t}{\sqrt{4 D_{t}}}\right)\right]
$$

where $\operatorname{erf}()$ is the Gause error function defined as the following: 


$$
\operatorname{erf}(x)=\frac{1}{\sqrt{\pi}} \int_{-x}^{x} e^{-t^{2}} d t
$$

The difficulty of solving the spatial and temporal concentration variation using this equation is that the longitudinal dispersion coefficient $(D)$ is unknown. Numerous researchers have developed methods to quantify the longitudinal dispersion coefficient. Yet, the discrepancies between the values of the observed and predicted longitudinal dispersion coefficients range from one to three orders of magnitude, and existing methods, in general, underestimate the dispersion coefficient (Deng et al. 2002).

Mixing in the lock chamber will be driven by free shear such as a jet from the clean-water source. Farther from the clean-water source, the flushing will approach uniform flow, and boundary friction will then be the primary source of shear. The longitudinal dispersion coefficient for boundary shear is estimated from the friction velocity, $U_{*}$, which is

$$
U_{*}=\sqrt{g R S_{f}}=\sqrt{\frac{f}{8} U^{2}}
$$

where:

$$
\begin{aligned}
g & =\text { acceleration due to gravity } \\
S_{f} & =\text { friction slope } \\
R & =\text { hydraulic radius } \\
F & =\text { Darcy friction factor } \\
U & =\text { average flow velocity. }
\end{aligned}
$$

The most commonly used method of determining the longitudinal dispersion coefficient is the Fischer equation (Fischer et al. 1979), which is

$$
\frac{D}{h U_{*}}=0.011\left(\frac{B}{h}\right)^{2}\left(\frac{U}{U_{*}}\right)^{2}
$$

This equation is popular because it gives the longitudinal dispersion coefficient, $D$, in terms of readily available hydraulic variables; the widthto-depth ratio $(B / h)$; and friction term $\left(U / U_{*}\right)$. The left-hand side of the Fischer equation is commonly referred to as the dimensionless dispersion coefficient. Seo and Cheong (1998) used regression analysis to develop an 
empirical form of the hydraulic and geometric variables of the Fischer equation to better represent observed values.

$$
\frac{D}{h U_{*}}=5.915\left(\frac{B}{h}\right)^{0.62}\left(\frac{U}{U_{*}}\right)^{1.428}
$$

\subsection{Turbulence and mixing}

Without knowledge of the longitudinal dispersion coefficient, the problem can be bounded as one of advection-dominated flow and one in which the flow is better characterized as dispersion dominated. Evaluation requires determination of the importance of dispersion relative to the transport of a concentration (ANS). This is done using the Peclet number, $P e$, which is the relative advection-to-dispersion ratio and is given as

$$
P e=\frac{U L}{D}=\frac{U^{2} t}{D}
$$

Note that the Peclet number is sometimes given as the ratio of dispersion to advection (reciprocal of what is defined here). As presented here the Peclet number is large when the flow is advection dominated and small when dispersion dominates. If the flow is dispersion dominated, the Peclet number goes to zero. In the case of advection domination, the Peclet goes toward infinity, and the transport is similar to plug flow.

Some simple water quality models can be developed for special cases where either advection or dispersion is dominant. As the Peclet number becomes large, the longitudinal dispersion can be neglected, and the system behaves as a plug-flow chamber

\subsubsection{Plug flow}

The plug-flow concentration is shown at a particular position for various times in Figure 6. The concentration, $C$, is normalized by the initial concentration, $C_{o}$, and the distance from the clean water source, $x$, is related to the lock chamber length, $L$. 
Figure 6. Advection-dominated plug flow.

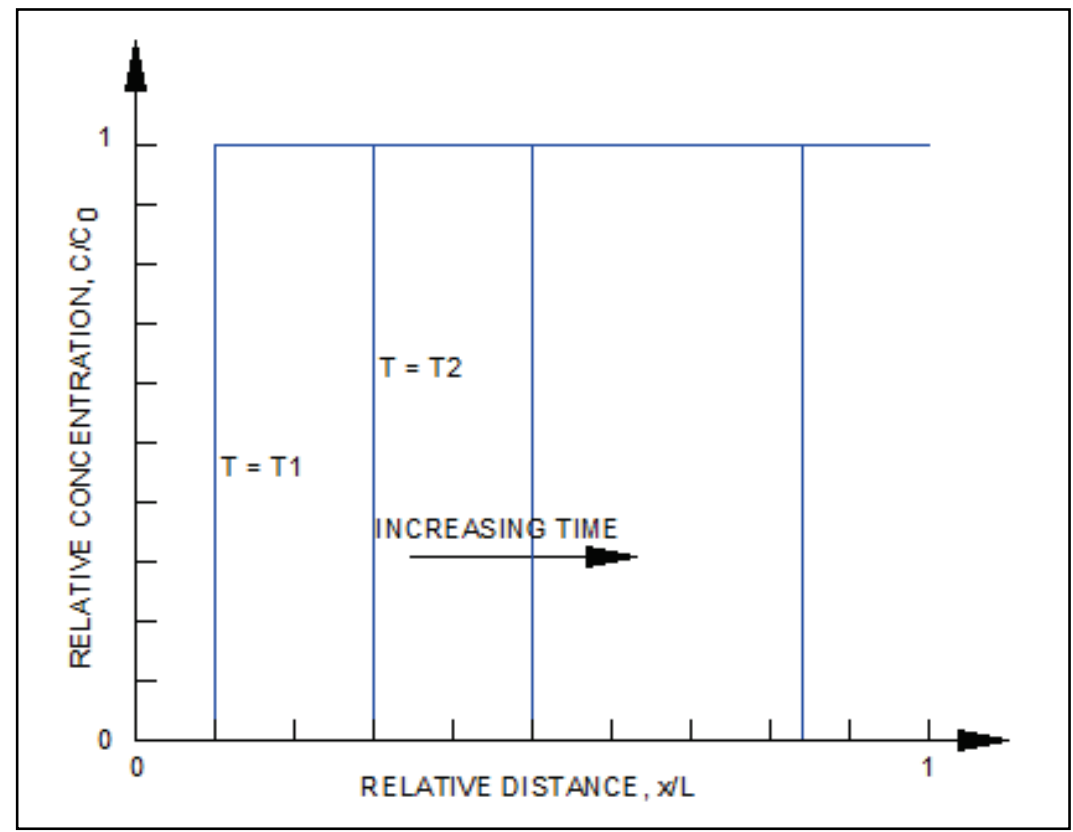

The time required flushing water into and from the chamber, $T_{f}$, is the volume to be exchanged, $V_{c}$, divided by the volumetric flow rate, $Q$.

$$
T_{f}=\frac{V_{c}}{Q}
$$

where:

$T_{f}=$ time required to flush the lock chamber assuming plug flow

$V_{c}=$ the volume of the lock chamber when the water surface is at tailwater.

The fastest time is limited by the maximum allowable discharge. Of course, the actual flow conditions in the lock chamber will not be plug flow, but the plug-flow equation provides the absolute shortest time and least volume of water required to flush the lock chamber. The actual flow volume required to flush Brandon Road Lock chamber in a reasonable time will produce high-shear turbulent conditions in the lock chamber. The turbulent dispersion in the lock chamber will require a longer time and larger volume of water to flush as compared to the plug-flow condition. 


\subsubsection{Well-mixed flow}

Dispersion-dominated problems can be treated as a well-mixed system. The dispersion-dominated case is analogous to a continuously stirred tank. Flow that enters the chamber is assumed to instantaneously mix throughout the full chamber volume. This situation is referred to as the well-mixed case wherein conservation of mass means that

$$
\frac{\partial(C V)}{\partial t}=-Q\left(C_{\text {in }}-C_{\text {out }}\right)
$$

In the case at hand, where the chamber has an ANS concentration of $C(t)$, the chamber is flushed with clean inflow having a concentration of $C_{i n}=0$. The volume of water in the chamber is constant because the volumetric flow rate into the chamber equals that flowing from the chamber, so

$$
\frac{\partial C}{\partial t}=-\frac{Q}{V} C_{\text {out }}
$$

The well-mixed case means that the concentration of water flowing from the chamber is equal to the concentration in the chamber, $C(t)$. The solution of this differential equation is

$$
C(t)=\exp \left(-\frac{Q}{V} \mathrm{t}\right)
$$

For an inflow concentration of zero, the concentration in the chamber decreases exponentially for the well-mixed case, wherein dispersion dominates advection.

The time required to flush $95 \%$ of the chamber concentration is the time required to reduce the concentration from 1.0 to 0.05 . The time required is

$$
t=-\frac{V}{Q} \ln C=-\frac{V}{Q} \ln (0.05)
$$

Temporal variation of relative concentration at a particular distance from the clean-water source is illustrated for the well-mixed case in Figure 7. This case represents the longest time required to flush the chamber, and complete flushing is theoretically never obtained because the concentration varies logarithmically (hence asymptotically) with time. 
Figure 7. Dispersion-dominated well-mixed flow.

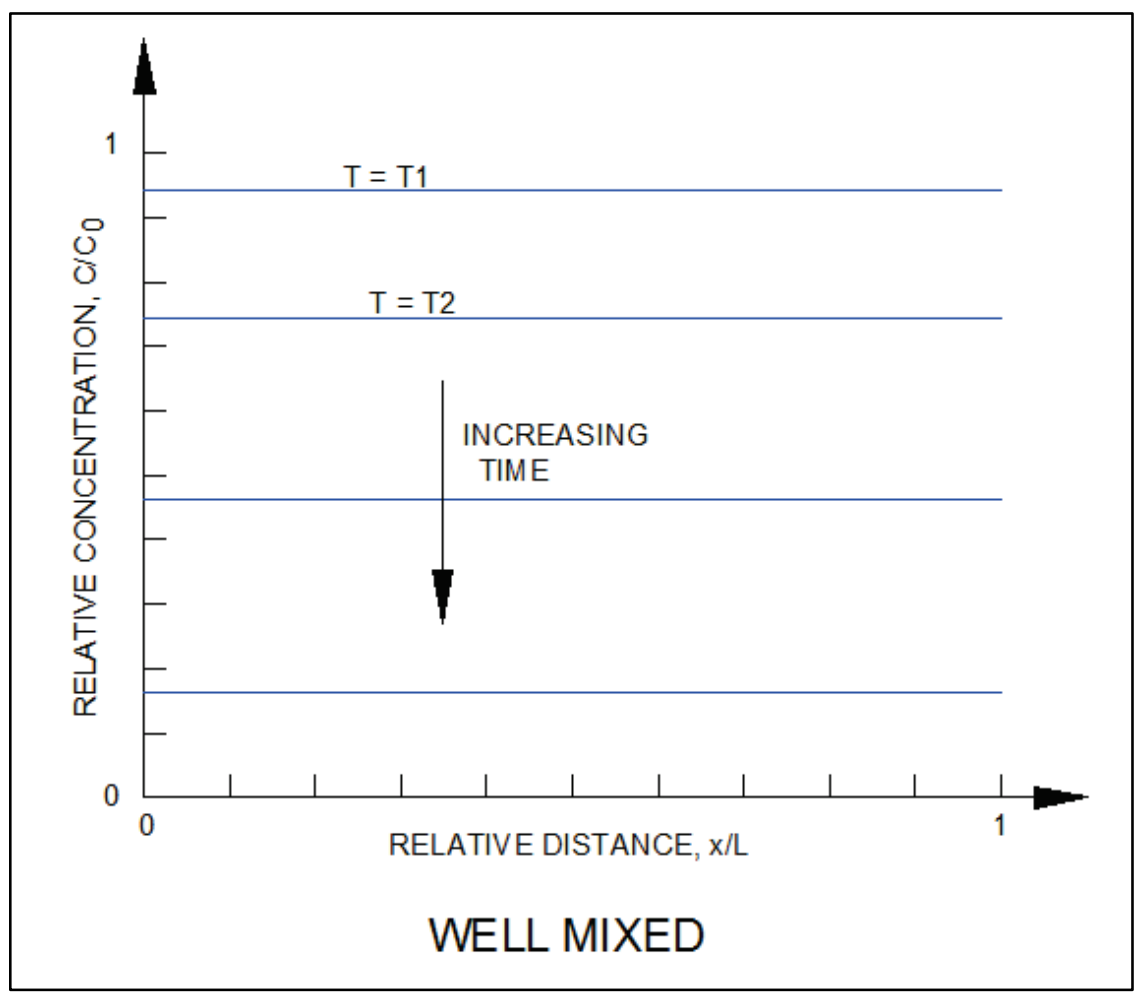

\subsubsection{Advection-dispersion flow}

A third case of flushing the lock chamber will cause the ANS to be transported downstream and their concentration dispersed (i.e., advection-dispersion flow). The problem is theoretically bound between the plug-flow situation, which is the quickest flushing time and the wellmixed case which requires the most time to flush. The actual response to the introduction of clean water via momentum jets is illustrated by the concentrations in Figure 8. 
Figure 8. Concentration resulting from transport and dispersion.

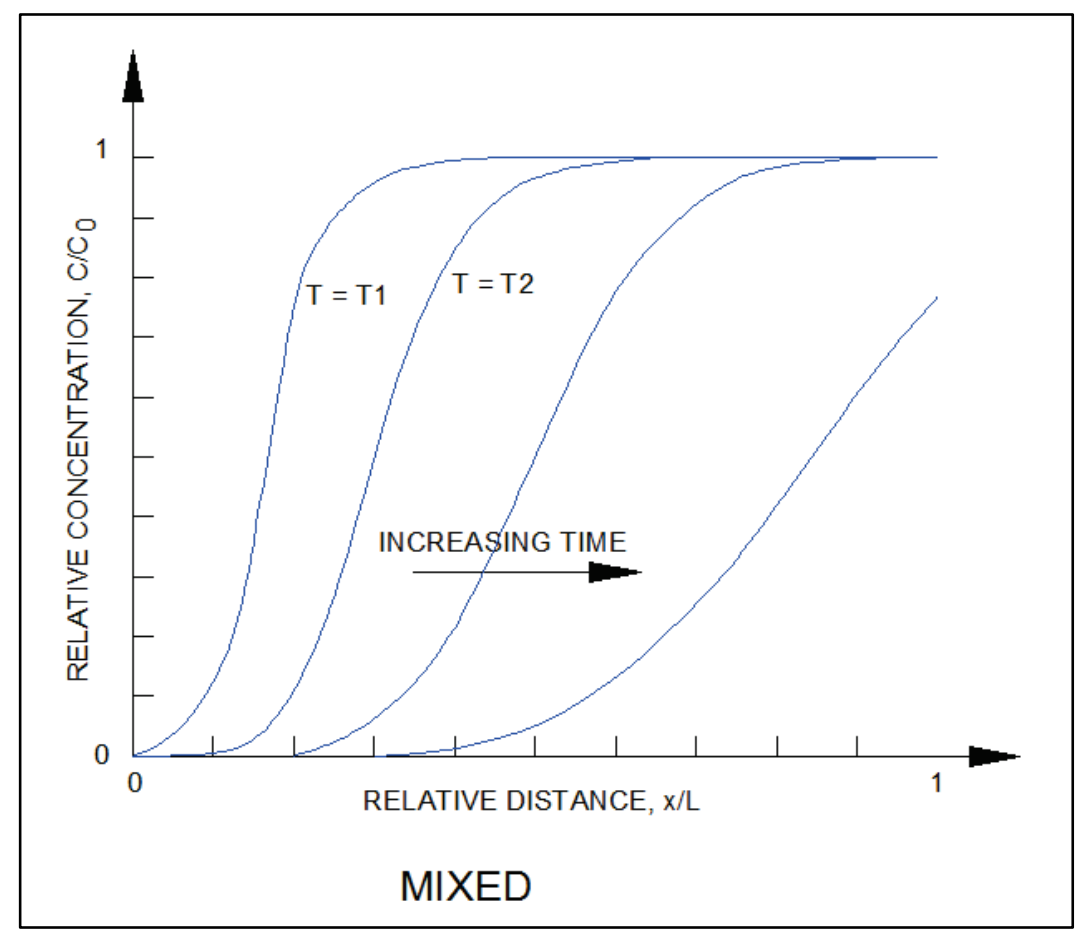

\subsection{Momentum jets}

Regardless of how clean water is introduced into Brandon Road Lock chamber, the flow will enter the chamber as a momentum jet or a set thereof. Albertson et al. (1950) describe the mechanics of a submerged jet using the assumptions of steady (but turbulent) flow, quiescent ambient fluid, and that the receiving fluid has the same density as the discharge fluid. The jet development is classified as being in two zones, the zone of flow establishment and the zone of established flow (ZEF) as illustrated in Figure 9. Further assumptions are that the jet grows linearly, that the pressure distribution is hydrostatic, and that the velocity profile is Gaussian.

Figure 9. Circular jet issuing into a reservoir.

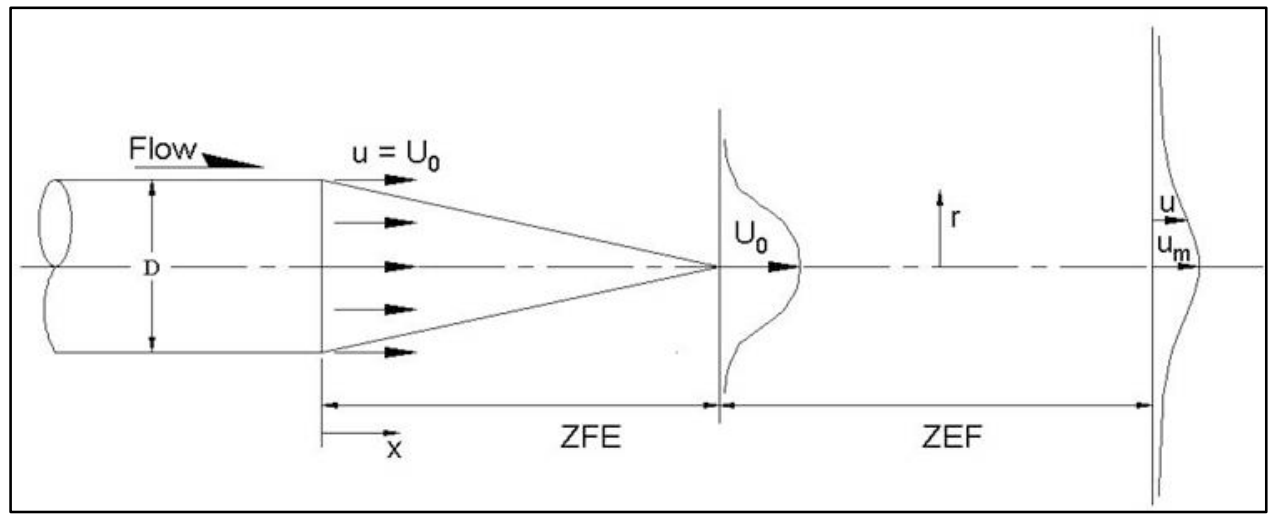


The Albertson et al. (1950) experiments were conducted at $R e \approx 5 \times 10^{4}$, so the results are valid for turbulent flow.

\subsubsection{Round (circular) jet}

Expressions for velocity and discharge in the ZEF for a round (circular) are

$$
\begin{aligned}
& \frac{u_{m}}{U_{0}}=6.2\left(\frac{D_{0}}{x}\right) \\
& \frac{Q}{Q_{0}}=0.32\left(\frac{x}{D_{0}}\right)
\end{aligned}
$$

where:

$$
\begin{aligned}
u_{m} & =\text { maximum velocity within the jet } \\
U_{o} & =\text { jet velocity at the port face } \\
D_{o} & =\text { inflow culvert diam } \\
x & =\text { distance from the port face. }
\end{aligned}
$$

As the jet spreads, it entrains flow from the surrounding fluid, growing linearly. The centerline velocity also grows linearly. The plot shown in Figure 10 illustrates the jet velocity and discharge growth. The blue lines indicate the motion of the surrounding fluid as it is entrained into the jet. Note that nominal boundaries of the submerged circular jet expand by a ratio of 1 lateral to 5 longitudinal. 
Figure 10. Jet diffusion sketch.

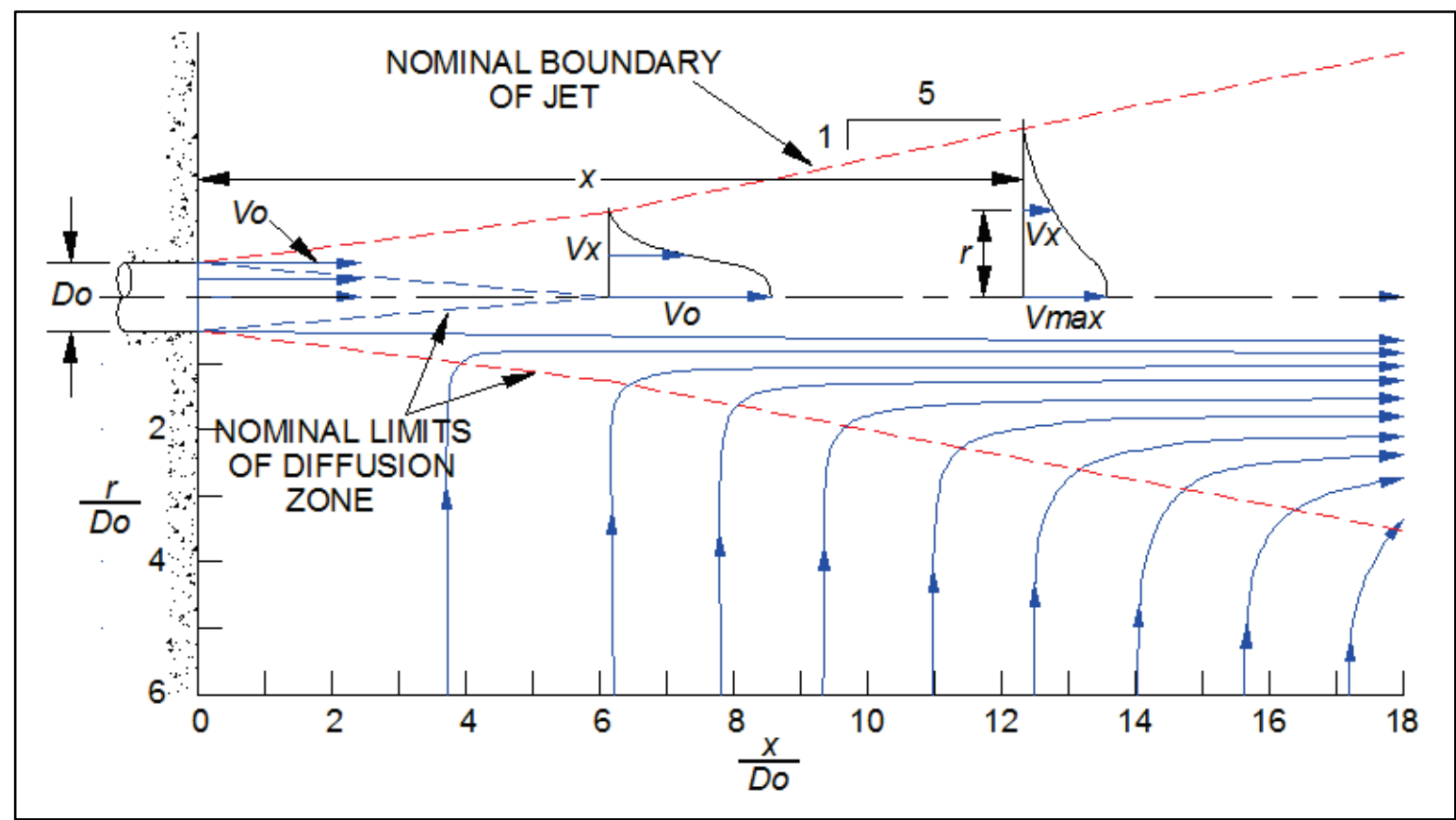

\subsubsection{Two-dimensional (2D) momentum jet}

The velocity distribution for a $2 \mathrm{D}$ jet produced from a channel of width $B_{o}$ is illustrated in Figure 11. Albertson et al. (1950) determined the upstream limit of the ZEF to be $\frac{x}{B_{0}}=5.2$ and that the velocity and discharge are given as

$$
\begin{aligned}
& \frac{u_{m}}{U_{0}}=2.28 \sqrt{\frac{B_{0}}{x}} \\
& \frac{Q}{Q_{0}}=0.62 \sqrt{\frac{x}{B_{0}}}
\end{aligned}
$$

The free shear attributed to submerged jets will be the primary source of dispersion during lock flushing operations. 
Figure 11. 2D jet issuing into a reservoir.

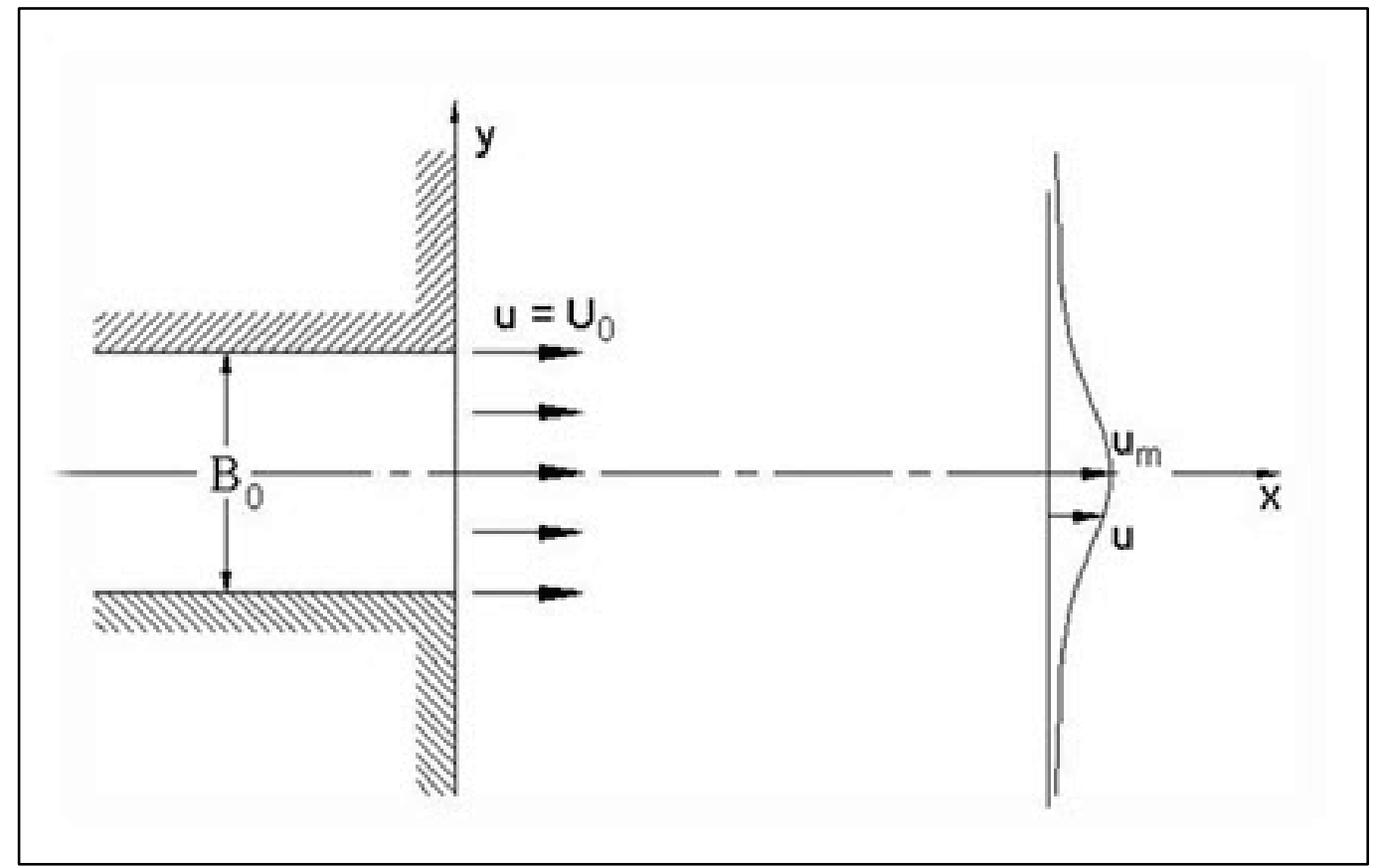

\subsection{Stagnant regions (dead zones)}

The jet diffusion sketches (Figure 9-Figure 11) illustrate that, even with the entrainment currents induced by the jet shear, there can be regions within the ambient fluid that remain unmoved, such as areas outside the spreading jet and to the immediate sides of the jet outlet. ANS will be trapped in stagnant regions referred to as "dead zones" or "storage zones" (Fernando 2013). Therefore, reduction of dead zones will in turn provide a more efficient flushing system. 


\section{Lock Flushing Concepts}

\subsection{Hydraulic design of flushing systems}

Hydraulic flushing systems have been studied and designed for many years, and basic hydraulic loss coefficients are often known.

The energy loss $H_{L}$ through each component can be expressed as

$$
H_{L_{i}}=K_{i} \frac{V_{i}^{2}}{2 g}
$$

where:

$$
\begin{aligned}
& K_{i}=\text { loss coefficient for component } i \\
& V_{i}=\text { velocity through component } i
\end{aligned}
$$

Loss coefficients for many hydraulic components are well established and are readily available in the literature (e.g., Miller 1990). However, lock culvert system components are often unique to a particular project, and the loss coefficients have not been determined for lock components of any size or configuration.

\subsection{Lock flushing systems}

The flushing process can be described as introducing clean water from the upper pool into an empty chamber. The lock flushing process that provides clean water from the upper pool into an empty chamber (chamber water surface at lower pool elevation), either using the existing filling and emptying system or a new culvert system designed specifically for flushing ANS, will be analyzed in detail for several alternatives.

Four basic concepts have been identified. The first lock flushing concept (Type 1) relies on the existing filling and emptying system to flush the lock. The second lock flushing concept (Type 2) adds a lateral manifold from one of the filling culverts across the lock chamber immediately downstream of the upper sill. The third lock flushing concept (Type 3) adds culverts from the upper pool to the chamber through the upper sill. A final concept (Type 4) considered is not designed to flush the lock chamber but rather provides a continuous flow of clean water flushing the lower 
lock approach to prevent ANS from entering the lock chamber. A fifth lock flushing concept (Type 5) has also been proposed. The Type 5 lock flushing concept is similar to the Type 1 concept in that it relies on the filling and emptying system to flush the lock. However, the Type 5 concept uses a filling and emptying system that has been modified to closely conform to current hydraulic design guidance.

\subsubsection{Type 1 lock flushing concept (existing filling and emptying system)}

The Type 1 lock flushing concept (shown in Figure 12) uses the existing lock filling and emptying system to flush the lock chamber. The system setup would have the upper miter gates closed, the lower miter gates open, the fill valves opened (perhaps partially), and the emptying valves closed. This scheme would input clean water with zero concentration along the length of the chamber, which would respond more as a well-mixed system wherein dispersion dominates the flow. The movement of flushing flow through the system is indicated by the blue arrows in the figure. The lower miter gates may need to be retrofitted with a means to secure them in the open position as the chamber is flushed.

Figure 12. Type 1 (existing) lock flushing concept schematic.

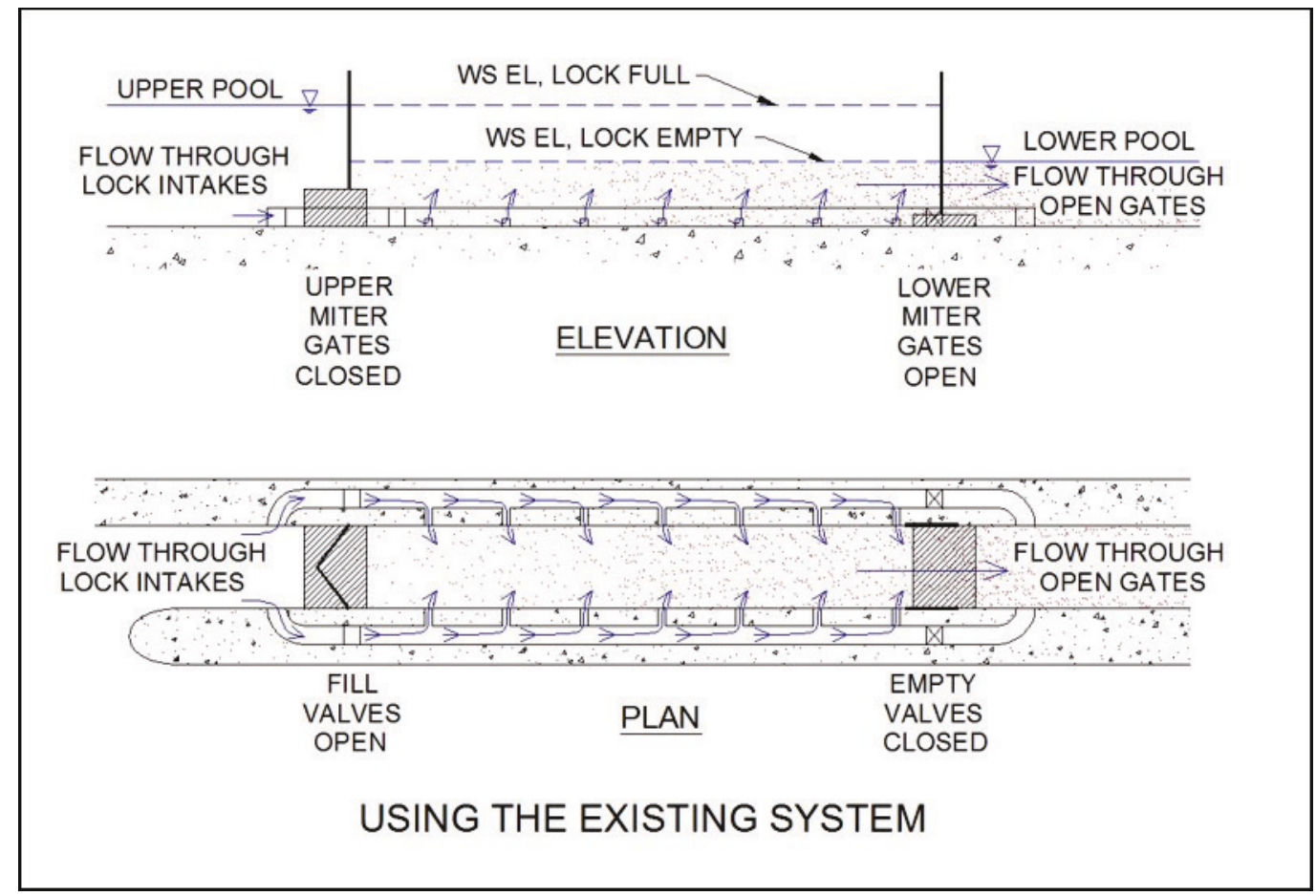


The lock coefficient for a standard design sidewall port filling system is approximately o.80 (McCartney et al. 1998). Loss coefficients for lock filling and emptying systems are customarily given in terms of the velocity head in the culvert at the valve (i.e., valve fully open). Estimates of loss coefficient values for Brandon Road Lock filling system components are provided in Table 3. These coefficients are for a standard sidewall port filling system (e.g. Murphy 1975; McCartney et al. 1998; HQUSACE 2006). Since the design standards were not developed until decades after Brandon Road Lock was constructed, the loss coefficient values will need to be validated with field or laboratory data. The head loss as flow passes a partially opened vertical-lift valve is a function of the shape of the valve lip and the valve opening. The head loss varies during a valve operation. The Hydraulic Design Chart 320-1 (HQUSACE 1988) is a plot of discharge coefficient as a function of valve position. The relation between the discharge coefficient, $C_{v}$, and a head loss coefficient for the valve, $K_{v}$, can be determined by equating the change in head across the valve:

$$
K_{v}=\left(\frac{b}{B}\right)^{-2} C_{v}^{-2}
$$

where:

$$
\begin{aligned}
& b=\text { valve opening } \\
& B=\text { culvert height at the valve, } 9 \mathrm{ft} \text { for Brandon Road Lock. }
\end{aligned}
$$

The discharge coefficient for a valve opening of $25 \%$ is given in Hydraulic Design Criteria 320-1 as 0.73 (HQUSACE 1988). This yields a loss coefficient of 30 , which is the same value given in Miller (1990) for vertical lift valves opened $25 \%$.

Table 3. Loss coefficients for Brandon Road Lock filling system.

\begin{tabular}{|l|c|c|}
\hline Lock Component & $\begin{array}{c}\text { Representative area } \\
\text { (valve area), } \mathrm{A}_{\mathrm{v}}\end{array}$ & Total Loss Coefficient, $\mathrm{K}$ \\
\hline Upper pool to valve & $9 \mathrm{ft}$ by $9 \mathrm{ft}=81 \mathrm{ft}^{2}$ & 0.45 \\
\hline Through open valve & $81 \mathrm{ft}^{2}$ & 0.11 \\
\hline Through valve 25\% open & $81 \mathrm{ft}^{2}$ & 30 \\
\hline Valve to lock chamber & $81 \mathrm{ft}^{2}$ & 1.05 \\
\hline
\end{tabular}


The sum of head loss at normal pool conditions is 1.61 (see Table 2), so the discharge is estimated to be

$$
Q=A_{v} \sqrt{\frac{2 g H}{K_{T}}}=81 \mathrm{ft}^{2} \sqrt{\frac{2\left(32.2 \mathrm{ft} / \mathrm{sec}^{2}\right)(34 f t)}{1.61}}=2987 \mathrm{ft}^{3} / \mathrm{sec}
$$

This discharge calculated from Equation 21 is the estimated discharge per culvert with the vertical-lift gates fully open. Because there are two culverts, the total discharge into the chamber is estimated to be 5,970 cubic feet per second $(\mathrm{ft} 3 / \mathrm{sec})$. This method of flushing will require that the filling valves are able to close in flowing water at the project's full $34 \mathrm{ft}$ head. Project operation personnel have indicated that the filling valves can only be opened $25 \%$ during flushing. One reason for concern is that during flushing, the open lower miter gates may slam shut. Therefore, a device to hold the lower miter gates open will need to be installed. Another consideration is that the existing vertical-lift valves may either require modification or replacement with valves that are designed specifically for flow control and are heavy enough to close under full flow. The flushing discharge with the fill valves opened $25 \%$ rather than $100 \%$ is calculated using the head loss coefficient for a vertical-lift valve opened $25 \%$ as $K_{v}=30$ (Miller 1990). Then, the total loss coefficient with the valve opened $25 \%$ is 31.5 , so the discharge through each culvert is estimated to be

$$
Q_{25 \%}=A_{v} \sqrt{\frac{2 g H}{K_{T}}}=81 \mathrm{ft}^{2} \sqrt{\frac{2\left(32.2 \mathrm{ft} / \mathrm{sec}^{2}\right)(34 \mathrm{ft})}{31.5}}=675 \mathrm{ft}^{3} / \mathrm{sec}
$$

per culvert for a total flushing discharge of about $1,350 \mathrm{ft} 3 / \mathrm{sec}$.

Concentration histories for various discharges are shown in Figure 13. The concentrations presented correspond to a $504.5 \mathrm{ft}$ normal lower pool where the concentration can be calculated with Equation 14 . 
Figure 13. Well-mixed lock chamber concentration histories.

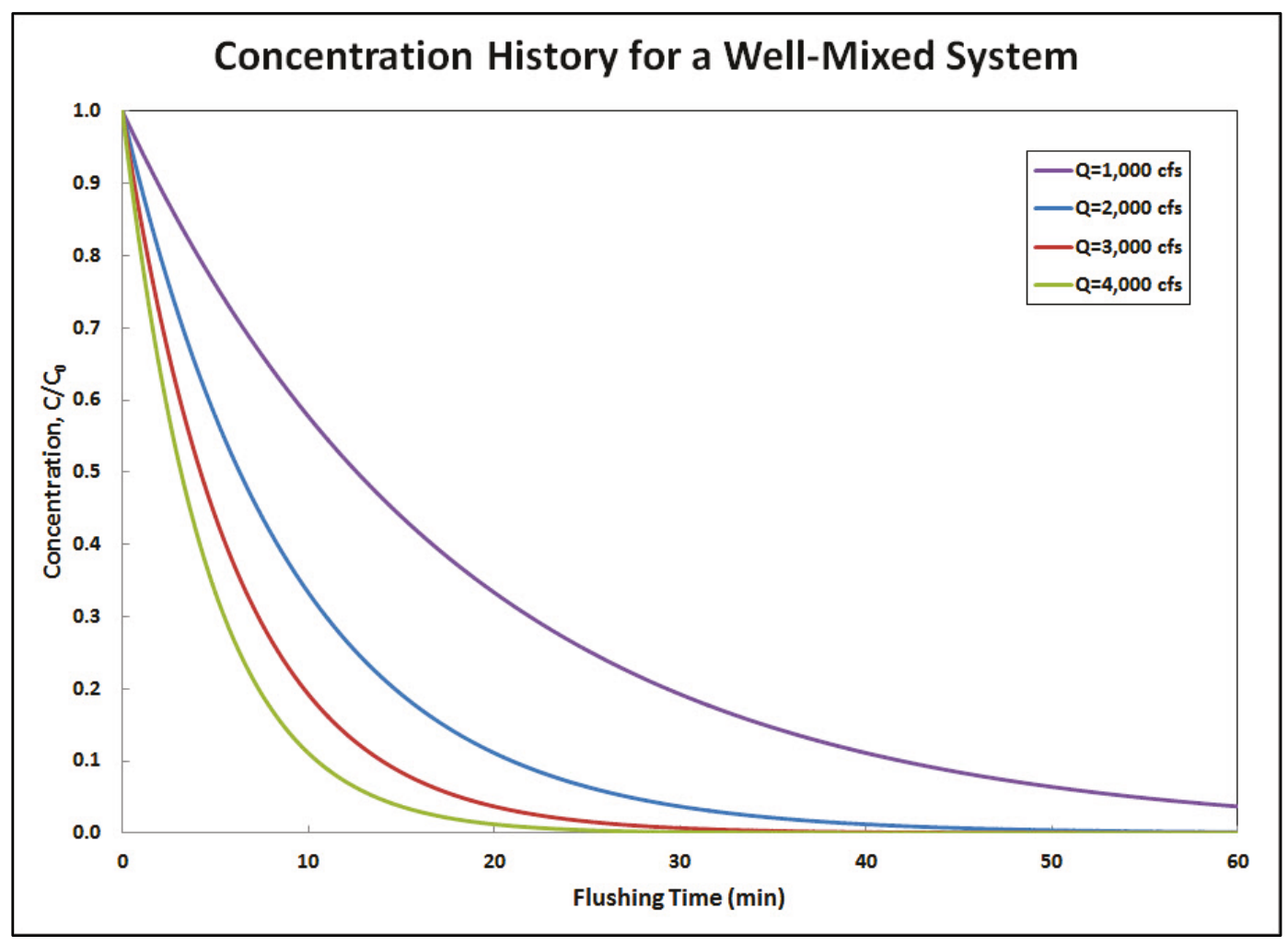

The Type 1 concept will perform more as a well-mixed flow field wherein the flushing times for various discharges are illustrated in Figure 13. Flushing of the well-mixed chamber can be evaluated as the time required for dilution to a particular concentration. The flushing times required to reduce the ANS concentration by various amounts ranging from $50 \%$ to 99\% are shown in Figure 14. The flushing times shown correspond to various dilutions at the normal tailwater elevation of $504.5 \mathrm{ft}$ where the time is given by Equation 12 . 
Figure 14. Well-mixed system flushing times for various dilutions.

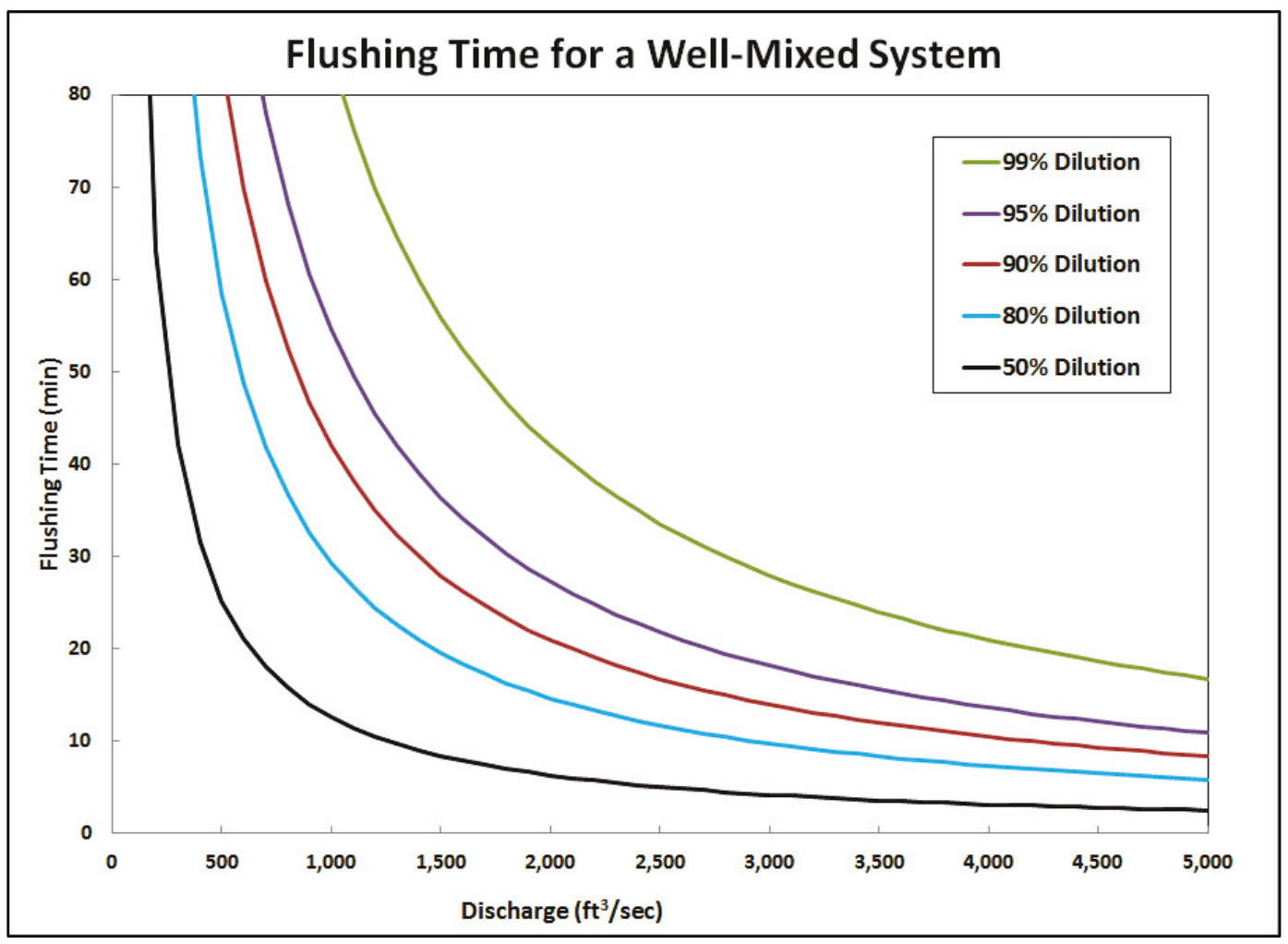

\subsubsection{Type 2 lock flushing concept (lateral flushing manifold)}

The Type 2 lock flushing concept (Figure 15) is a new culvert and manifold perpendicular to the lock walls. The movement of flushing flow through the system is indicated by the blue arrows in the figure. The flushing operation would have the upper miter gates closed, the lower miter gates open, and the filling and emptying valves closed. This scheme would require a valve on the lateral flushing manifold that would be opened during the flushing operation. This flushing manifold would be placed immediately downstream of the upper sill so that most of the chamber is downstream of the lateral's discharge and would extend into the lock chamber normal to the culvert-side lock walls. This culvert would join one of the filling culverts (either right or left wall) upstream of that culvert's fill valve. The existing culvert system of Brandon Road Lock would have to be significantly altered to accommodate this design. The culverts make rectangular-to-circular transitions, so connecting a lateral flushing manifold to an existing filling and emptying ( $\mathrm{F} / \mathrm{E}$ ) culvert will be difficult during construction. Also, the fill valve will have to be moved downstream (as indicated in the plan image of Figure 15) to allow flow from the upper pool to reach the flushing manifold but not the F/E ports. The first port on 
the lock F/E manifold may have to be closed to make room for the new fill valve and lateral culvert. Closing the first port may actually have beneficial consequences for Brandon Road Lock since the sum of the port areas is approximately 1.5 times that of the culvert area. Sidewall port design criteria calls for a ratio of 0.95 . Chamber performance during filling is enhanced when the flow control is at the ports. This requires that the port-to-culvert area ratio be less than or equal to 1.0, which is currently not the case for Brandon Road Lock.

Figure 15. Type 2 design flushing system schematic.

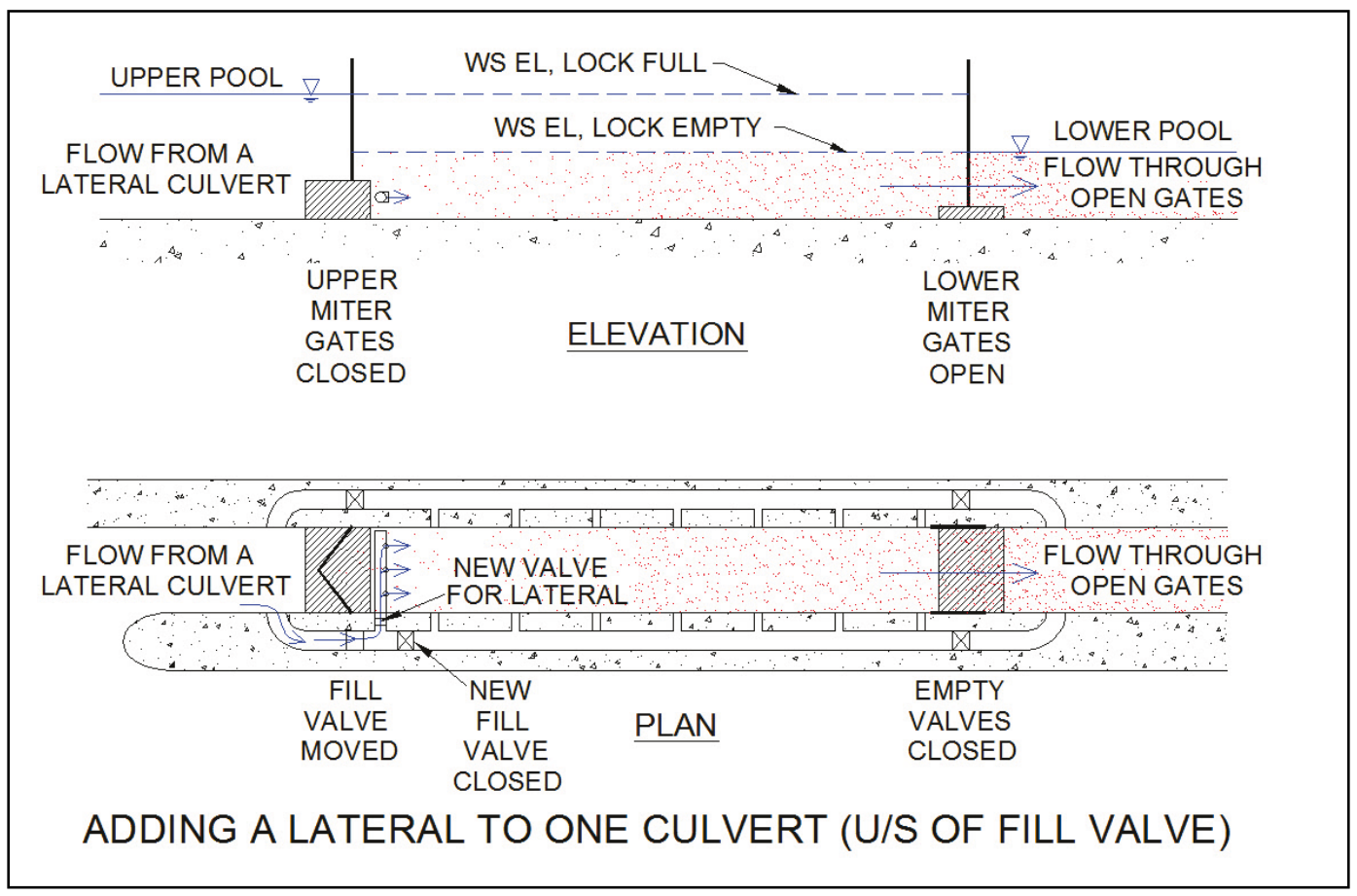

For the purposes of this report, culvert sizes and configurations were taken from the St. Lawrence Seaway Development Corporation design for the Eisenhower Lock (Appendix A). These values were chosen because a properly functioning flushing system is already in place at Eisenhower Lock, and the proposed flushing system at Brandon Road Lock is similar. The flushing culvert is $10 \mathrm{ft}$ in diam, and the lateral manifold has five pipes that tee into the lateral flushing manifold. Each pipe is $4 \mathrm{ft}$ in diam and serves as a port resulting in a sum of the port-to-culvert area ratio of o.8.

The sum of head loss at normal pool conditions is $34 \mathrm{ft}$. Equating this head loss to the losses listed in Table 4 and using Equation 21, the discharge is calculated to be $3,540 \mathrm{ft} 3 / \mathrm{sec}$. This is the estimated discharge from the Type 2 lock flushing concept at normal pool conditions with the F/E valve 
(vertical-lift valve) fully open. This concept will act somewhat as an advection-dominated system wherein the water moves downstream as plug flow. The flushing time for this system is provided in the following section.

Table 4. Loss coefficients for Type 2 lock flushing concept.

\begin{tabular}{|l|c|c|c|}
\hline System Component & Loss Coefficient, $K$ & $\begin{array}{c}\text { Representative Area, } \\
\mathrm{ft}^{2}\end{array}$ & Coefficient Value \\
\hline Lock Intake & $K_{i}$ & 216 & 0.24 \\
\hline 90 deg bend & $K_{b}$ & 216 & 0.24 \\
\hline $\begin{array}{l}\text { Open vertical-lift valve } \\
\text { (old) }\end{array}$ & $K_{g v}$ & 81 & 0.11 \\
\hline 90 deg T junction & $K_{\text {tee }}$ & 78.5 & 0.23 \\
\hline $\begin{array}{l}\text { Open flow-control } \\
\text { (butterfly) valve }\end{array}$ & $K_{b v}$ & 78.5 & 0.2 \\
\hline Dividing flow manifold & $K_{m}$ & 78.5 & 1.5 \\
\hline Outlets & $K_{0}$ & 12.6 & 1.0 \\
\hline
\end{tabular}

The Type 2 design will require at least $10.5 \mathrm{ft}$ of excavation below the existing lock floor elevation for Brandon Road Lock to provide enough clearance required by USACE guidelines (HQUSACE 2006). This limestone excavation is required for placement of the lateral culvert beneath the lock floor. ${ }^{1}$

\subsubsection{Type 3 lock flushing concept (culverts through sill)}

The Type 3 lock flushing concept (Figure 16) is the addition of conduits through the upper sill. These pipes require valves to control the flushing flow. The movement of flushing flow through the system is indicated by the blue arrows in the figure. Snell Lock on the St. Lawrence Seaway has undergone similar modifications to facilitate ice flushing from the chamber. The plug-flow analogy would be a more reasonable representative of the flushing than the well-mixed case.

\footnotetext{
1 The Type 2 flushing concept was removed from consideration before the free-surface numerical modeling effort described in detail in Chapters 5, 6, and 7. A numerical model was performed on Type 2 in an earlier stage of the modeling effort, and the flow solutions of that model are shown in Appendix C.
} 
Figure 16. Type 3 lock flushing concept schematic.

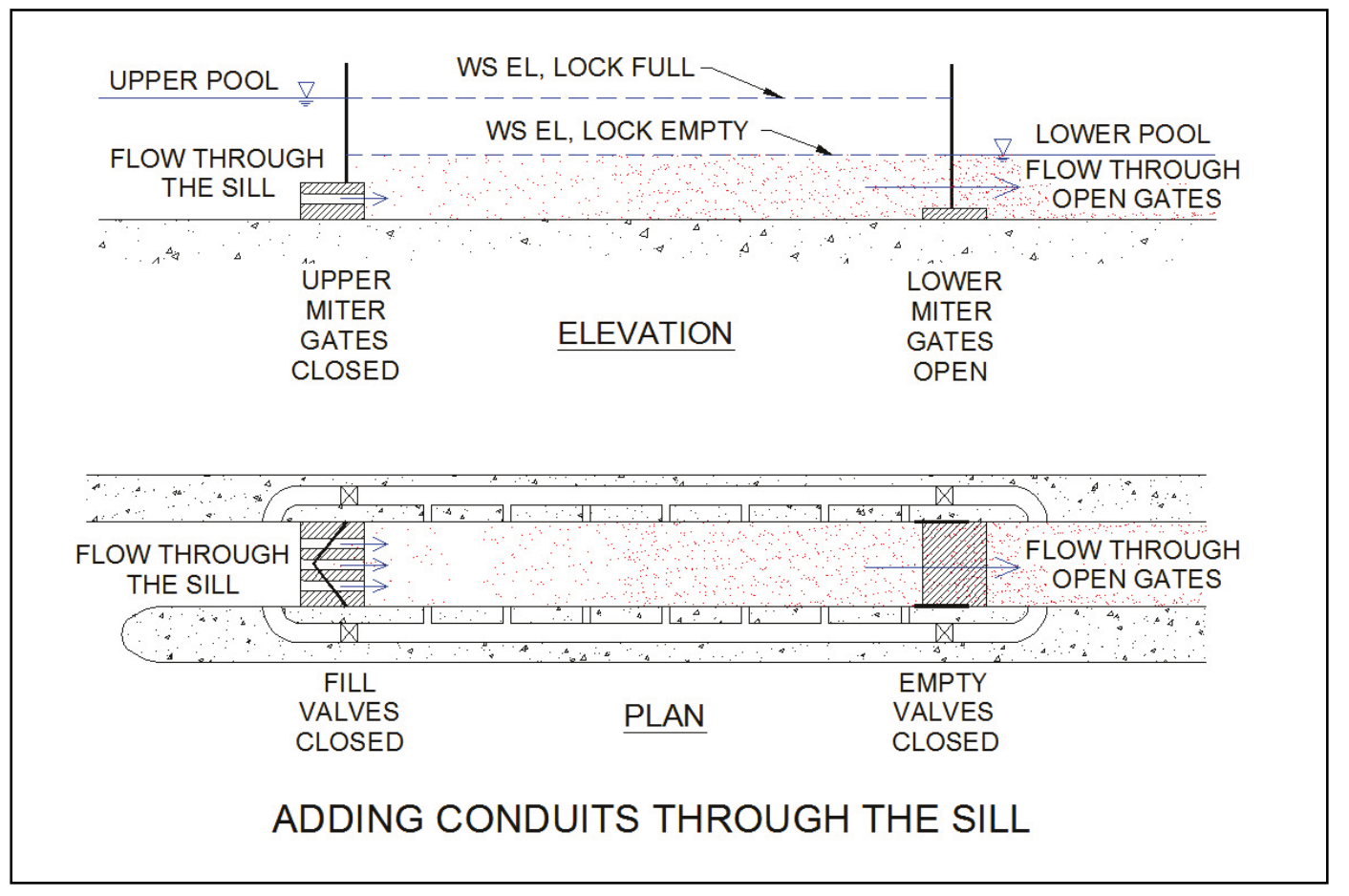

The new pipes will be long enough to pass from the upstream to downstream face of the upper sill (approximately $85 \mathrm{ft}$ ). Culverts passing through the sill will experience intake losses, friction losses, loss at the opened butterfly valve, and exit losses. The pertinent loss coefficient characteristics and values for the Type 3 lock flushing concept are listed in Table 5. The total discharges possible for Type 3 with a $34 \mathrm{ft}$ lift are shown in Table 6. Multiple pipes are required to prevent reverse eddies and motionless areas in the upper corners of the chamber (Oswalt 1976), and the total discharge for various pipe configurations and sizes are computed.

Table 5. Loss coefficients for Type 3 lock flushing concept.

\begin{tabular}{|l|c|c|c|}
\hline Conduit Segment & Loss Coefficient, $K$ & $\begin{array}{c}\text { Characteristic } \\
\text { Dimension(s) }\end{array}$ & Coefficient Value \\
\hline Inlet & $K_{i}$ & $A=\frac{\pi D^{2}}{4}$ & 0.1 \\
\hline Wall friction & $f L / D$ & $L=85 \mathrm{ft}$ & $0.014 * 85 / D$ \\
\hline Open butterfly valve & $K_{v}$ & $A=\frac{\pi D^{2}}{4}$ & 0.2 \\
\hline Exit & $K_{e}$ & $A=\frac{\pi D^{2}}{4}$ & 1.0 \\
\hline
\end{tabular}


Table 6. Calculated discharge for Type 3 lock flushing concept, $34 \mathrm{ft}$ normal lift.

\begin{tabular}{|c|c|c|}
\hline Pipe Diam, $D$, ft & Number of Pipes & Total Discharge, $\mathrm{ft}^{3} / \mathrm{sec}$ \\
\hline \multirow{5}{*}{4} & 1 & 460 \\
\hline & 2 & 930 \\
\hline & 3 & 1,390 \\
\hline & 4 & 1,860 \\
\hline & 5 & 2,320 \\
\hline \multirow{5}{*}{5} & 1 & 740 \\
\hline & 2 & 1,480 \\
\hline & 3 & 2,230 \\
\hline & 4 & 2,970 \\
\hline & 5 & 3,710 \\
\hline \multirow{5}{*}{6} & 1 & 1,080 \\
\hline & 2 & 2,170 \\
\hline & 3 & 3,250 \\
\hline & 4 & 4,340 \\
\hline & 5 & 5,420 \\
\hline
\end{tabular}

Intakes in the upper sills of locks have led to vortex formations during lock filling. Numerous physical model studies have been conducted to reduce vortex tendencies (e.g., Ables 1979; Hite 1999; Hite 2000; Hite and Tuthill 2005; Hite and Bislip-Morales 2012). During previous model studies, conducted with through-the-sill intakes, modifications in the approach were developed to reduce the tendency for strong vortices to form. Streamlining the flow into the intakes by modifying the miter gate recesses have helped reduce vortex formation. Reducing the approach velocities by deepening the approach also helps improve flow conditions. Therefore, the Type 3 concept will most likely induce vortices in the upper approach during flushing operations. The tendency for vortex formation is due to the relatively small intake area in conjunction with the culvert intakes being relatively shallow.

Vortices will not only inhibit the efficiency of the culverts thereby reducing the discharge, they can also be a safety hazard and draw debris down to the culvert intakes. Intake trash racks can then become clogged with submerged debris, further restricting the intake area and discharge. 
The Type 3 concept, as with Type 2, will serve more as advectiondominated flow fields, and the plug-flow analogy provides an order of magnitude estimate of the time required to flush ANS from the lock chamber. The flushing times for multiple flushing discharges are shown in Figure 17. The discharges shown are given by Equation 10.

Figure 17. Plug-flow system flushing time for various tailwater elevations.

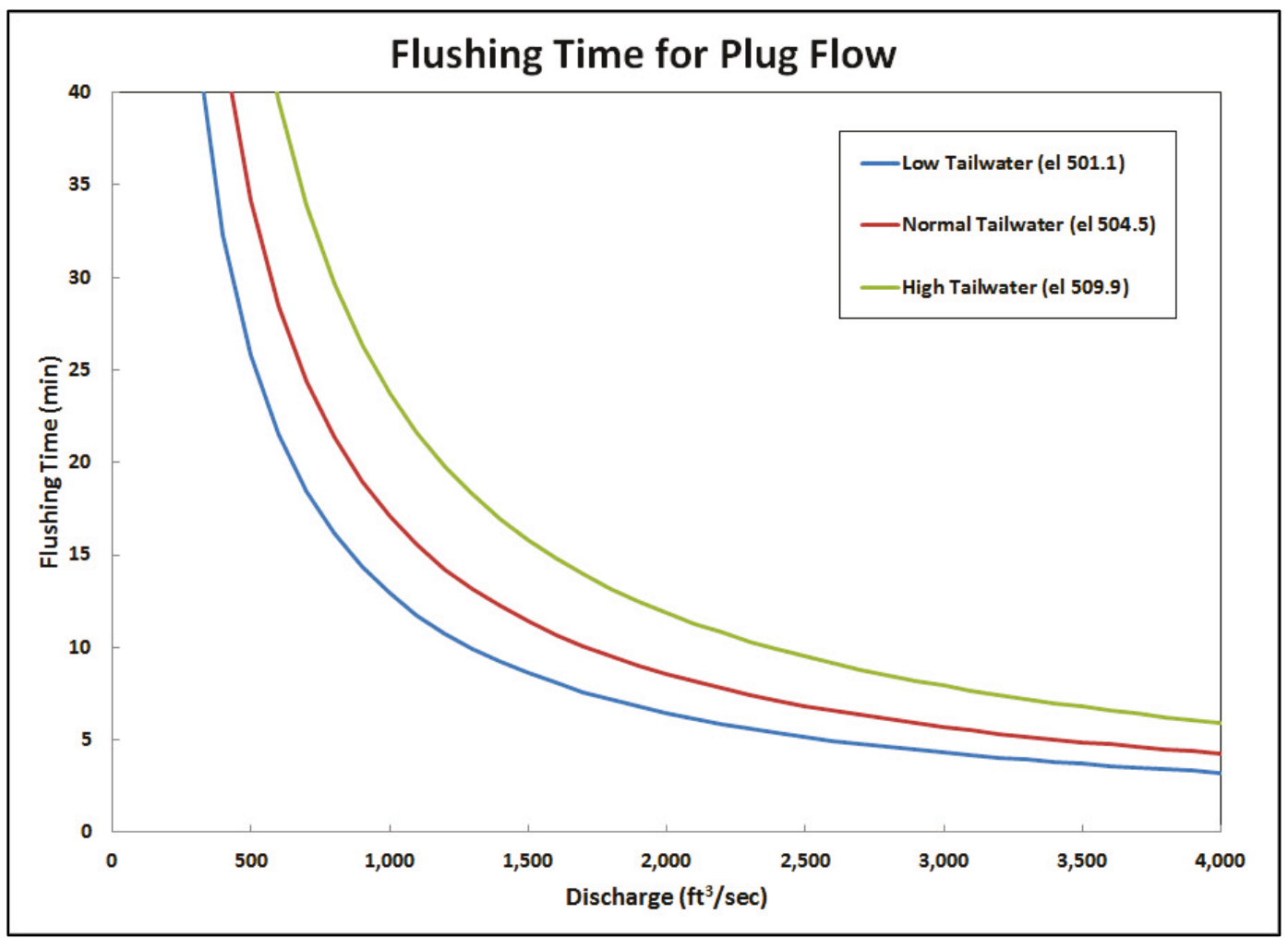

\subsubsection{Type 4 lock flushing concept (continuous flow below chamber)}

The Type 4 concept is not a configuration of Brandon Road Lock but rather relies on keeping ANS from ever entering the lock chamber. The barrier is a lateral manifold across the lower approach channel downstream of the lock providing continuous flow. The clean water is taken from the upper pool, and the flow is distributed across the channel with a multi-ported manifold as illustrated by the sketch in Figure 18.

One shortcoming of this concept is that it does not address the ANS that can be carried into the lock chamber as upbound and downbound tows traverse the lock. Propeller wash from tow boats and return currents generated as downbound tows leave the chamber may transport ANS over the continuous flow manifold. Also, the water pushed ahead of upbound 
tows may also overcome the hydraulic gradient that the manifold maintains. Once ANS are upstream of the manifold, there is no means to flush them using the Type 4 concept.

Figure 18. Type 4 concept schematic.

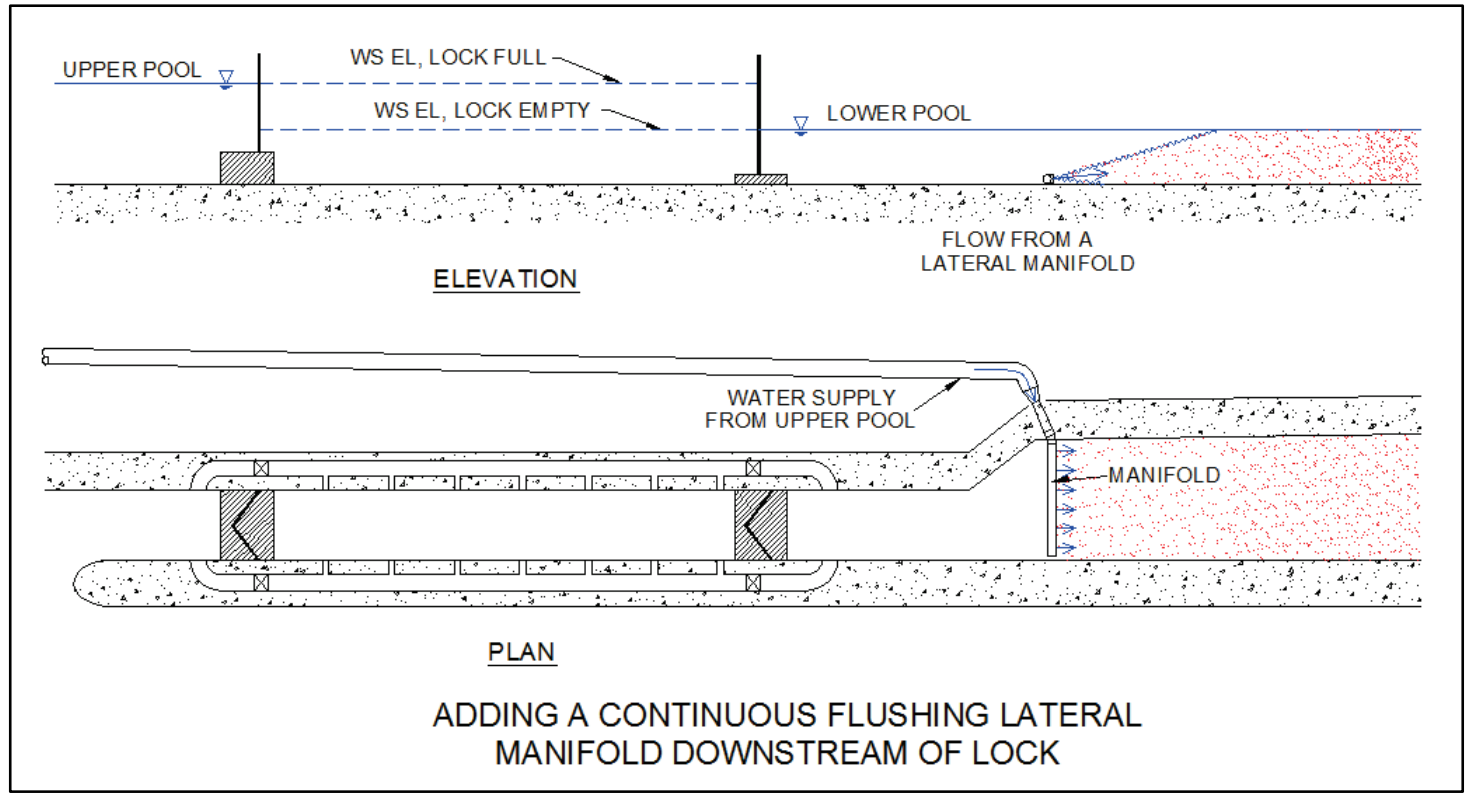

A physical model can be designed to accommodate experiments to evaluate the Type 4 concept. Particular questions can be answered such as the effectiveness of the Type 4 concept as tows pass over it.

\subsubsection{Type 5 lock flushing concept (redesigned filling and emptying system)}

The Type 5 lock flushing concept, shown in Figure 19, uses a redesigned lock filling and emptying system to flush the lock chamber. This system will be set up and operate similarly to the Type 1 system. For details of this setup, see Section 4.2.1. This concept basically adheres to the current USACE hydraulic design guidance for lock filling and emptying systems (HQUSACE 2006). Each culvert consists of twelve $3.54 \mathrm{ft}$ tall ports that are $2.54 \mathrm{ft}$ wide at the culvert with a 1-on-20 taper to the culvert. These ports have a $28 \mathrm{ft}$ spacing (center to center). Unlike the ports with the existing design that face one another directly, the ports in the redesigned system are offset by $14 \mathrm{ft}$. This offset is included so the jets extending from the ports on one culvert do not interfere with those from the ports in the opposite culvert. Removing any such interference should reduce any bulking at the chamber water surface. Triangular flow deflectors are 
included in the lock chamber for the first four ports on each culvert. These deflectors are included on the upstream third of the ports on each culvert to direct the jets (from each port) toward the opposite lock chamber wall instead of more toward the downstream gates. Having the jets oriented that way reduces the likelihood of bulking at the lock chamber surface, which would increase the hawser forces on a vessel in the chamber.

The only deviation from the current design guidance is the inclusion of a $6 \times 6 \mathrm{ft}$ port (shown in Figure 24 in Section 6.5) at the upstream end of each filling and emptying culvert. These two ports are included in the design solely to improve the flushing performance of the upstream end of the lock chamber. These ports are positioned at the location of the first port in the existing filling and emptying system (Figure 20 in Section 6.5).

Figure 19. Type 5 concept schematic.

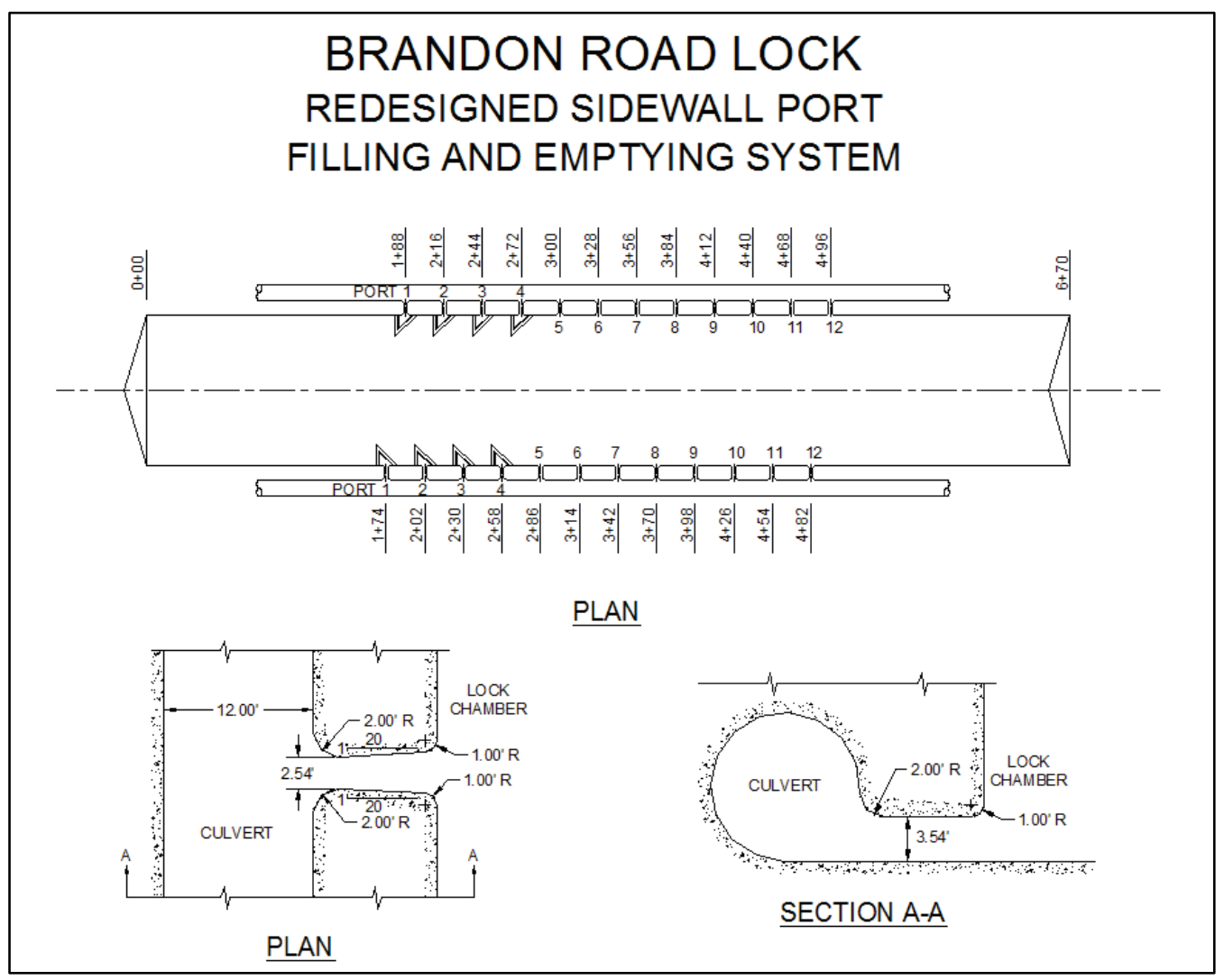




\section{Numerical Modeling Process}

Dead zones, defined as regions that are not directly affected by the momentum exchange from the flushing jets, are an issue that the total loss and discharge calculations previously performed cannot determine. However, these regions can be recreated with numerical models. Therefore, a numerical model has been developed for each of four lock flushing concepts to determine the location and size of dead zones produced by each lock flushing concept. Each numerical model includes details of the flushing evaluation such as the complete geometry, something not used in the purely analytic approach. Also, only the numerical model produces flow distributions and patterns that are needed to better evaluate flushing efficiency.

A $3 \mathrm{D}$ Navier-Stokes (non-hydrostatic) numerical flow model of the lock is a useful predictive tool to explore lock flushing concepts. The ERDC $3 \mathrm{D}$ Navier-Stokes module of the Adaptive Hydraulics (AdH) code has been used to model the complicated turbulent exchange processes as flow passes into and from the lock chamber and is an appropriate tool for this modeling effort. AdH produces time-varying flow solutions, and steadystate solutions are obtained by simulating time until the dynamic variation in the flow field ceases.

\subsection{Governing equations}

The Reynolds-Averaged Navier-Stokes (RANS) equations are employed to model the flow field approaching, interacting with, and passing by hydraulic structures. The RANS equations are $3 \mathrm{D}$ with 4 degrees of freedom: the pressure and the three components of fluid velocity. These equations make no assumptions about pressure distributions. Since many hydraulic flow models assume the flow is hydrostatic, RANS models are referred to as non-hydrostatic models.

The RANS equations are derived from the conservation of mass and conservation of momentum applied to fluid flow by decomposing the instantaneous flow velocity into a mean component, $\boldsymbol{U}$, and a fluctuating component, $\boldsymbol{u}$, and averaging these equations over time periods that are long compared to the periods of the fluctuations. Mathematically, the conservation of mass for an incompressible fluid is described as 


$$
\nabla \cdot \boldsymbol{U}=0
$$

and the conservation of momentum is given as

$$
\rho\left(\frac{\partial U}{\partial t}+\boldsymbol{U} \cdot \nabla \boldsymbol{U}\right)-\nabla \cdot \sigma+\nabla \cdot(\rho \boldsymbol{u u})=0
$$

where:

$$
\begin{gathered}
t=\text { time } \\
\rho=\text { fluid density } \\
\sigma=-p \boldsymbol{I}+\tau \\
\boldsymbol{I}=\text { identity matrix } \\
\tau=2 \mu \boldsymbol{\Gamma} \\
\boldsymbol{\Gamma}=\frac{1}{2}\left(\nabla \boldsymbol{u}+\nabla \boldsymbol{u}^{\boldsymbol{T}}\right) \\
\mu=\text { fluid viscosity. }
\end{gathered}
$$

The RANS equations are written in terms of the mean velocity, $\boldsymbol{U}(x, t)$, and pressure, $p(x, t)$, to reduce the modeling of turbulence to a set of quasisteady-state equations that incorporate terms to model the effects of turbulence on the main flow. In a RANS approach, the term $\nabla \cdot(\rho \boldsymbol{u} \boldsymbol{u})$ is used to represent the effect of turbulence on the mean flow.

Following the suggestion of Boussinesq, an eddy viscosity is added to the molecular viscosity in the momentum equations to account for the effects of turbulence. A constant eddy viscosity model was used to replicate the turbulent effects. The eddy viscosity value was reduced until the velocity magnitudes no longer changed with decreasing values of the eddy viscosity. This threshold value of eddy viscosity was used for all simulations.

The effectiveness and efficiency of each lock flushing concept is modeled by direct calculation of the concentration of the flushing flow throughout the flow domain. These concentrations are treated as being composed of neutrally buoyant concentrations. The behavior of the concentration is described by the advection-diffusion equation (shown in the $1 \mathrm{D}$ form as Equation 1 in Section 3.1). For the numerical modeling, the 3D form of the advection-diffusion equations assuming a constant diffusion coefficient is used: 


$$
\frac{\partial C}{\partial t}+\boldsymbol{U} \cdot(\nabla C)-D \nabla^{2} C=0
$$

where $\boldsymbol{U}=$ mean velocity vector at a point.

The diffusion coefficient, $D$, is assumed to be equal in all directions.

\subsection{Modeling procedure}

Before the equations of motion can be applied, the domain must be discretized into numerical elements. This process includes the construction of a $3 \mathrm{D}$ computer-aided design (CAD) representation of the flow boundaries including the geometric features of the hydraulic structure, the bathymetry of the approaching river, and the water surface. The CAD model is then used as input for a mesh generator.

A computational mesh is constructed to fill the volume enclosed by the CAD model surfaces. For AdH simulations, the computational mesh must only sufficiently describe the boundaries of the flow domain because automatic mesh refinement is used to ensure that the flow features interior to the domain are reproduced correctly. The mesh of the CAD surface will be composed of individual faces of the elements that form the lock boundaries and the water surface. The boundary conditions such as velocity, discharge, and pressure are needed on these faces and their nodes to determine a particular solution to the governing partial differential (RANS) equations. 


\section{Numerical Model Setup}

A numerical model was created for each lock flushing concept, except Type 4 since it only includes changes to the flow downstream of the lock itself (the lock is bypassed). For each lock flushing concept, the upper pool elevation is $538.5 \mathrm{ft} \mathrm{NGVD}$, and the lower pool (chamber) elevation is $504.5 \mathrm{ft} \mathrm{NGVD}$. These elevations are the average normal pool elevations present at Brandon Road Lock from 2005-2014. Additional information about the computational meshes is included in Appendix B.

Each model has two flux boundaries - one inflow and one outflow. The model discharge, listed in Table 7, is applied as an average inflow velocity at the inflow boundary. Initially for Type 3, a flushing discharge of $3,000 \mathrm{ft} 3 / \mathrm{sec}$ is used. This discharge was based on the maximum available flushing discharge outlined in Section 4.2.3 (Table 6). However, this discharge produced such high velocities in the upstream end of the chamber near the flushing pipe outlets that the water surface drawdown in that area was approximately $5 \mathrm{ft}$. Such a large drawdown will likely not satisfy safety concerns when barges are moored in the lock chamber, so the flushing discharge is reduced to $1,000 \mathrm{ft} 3 / \mathrm{sec}$. The new flushing discharge produces average velocities in the flushing pipes that are similar to the largest average velocities through the filling and emptying ports in Type 1 . An additional concept, Type $3 \mathrm{r}$, is based on the Type 3 design and includes rectangular flushing pipes. This concept allows for the higher $3,000 \mathrm{ft} 3 / \mathrm{sec}$ discharge to be tested.

The 2,600 $\mathrm{ft} 3 / \mathrm{sec}$ flushing discharge for Type 5 is based on a redesigned (stronger) intake valve and gate that can be opened to half open when under full head; currently the existing valves can only be lifted a quarter open under full head without excessive vibration and chance of being pinned shut.

Table 7. Lock flushing model discharges.

\begin{tabular}{|c|c|}
\hline Flushing Concept & Flushing Discharge $\left(\mathrm{ft}^{3}\right.$ /sec) \\
\hline Type 1 & 1,350 \\
\hline Type 2 & 3,540 \\
\hline Type 3 & 1,000 \\
\hline Type 3r & 3,000 \\
\hline Type 5 & 2,600 \\
\hline
\end{tabular}


For each model, a hydrostatic pressure distribution was applied to the nodes on the downstream boundary such that zero pressure was applied to the nodes at the water surface on the downstream boundary. Details of each lock flushing concept configuration are discussed in Chapter 4. The diffusion coefficient of $0.0003 \mathrm{ft}^{2} / \mathrm{sec}$ was used for all simulations.

\subsection{Type 1 lock flushing concept model geometry}

The Type 1 lock flushing concept is the existing filling and emptying system. Figure 20 shows a CAD model of Brandon Road Lock filling and emptying system. The CAD model was constructed from the line drawings provided by the INDC. The flow domain includes a portion of the lock upstream of the upper miter gates, both filling and emptying culverts with both the intakes and ports, and the lock chamber. The downstream end of the flow domain is located at the pintle of the downstream miter gates. The culvert is terminated downstream of the last (tenth) port.

Figure 20. CAD model of Type 1 lock flushing concept.

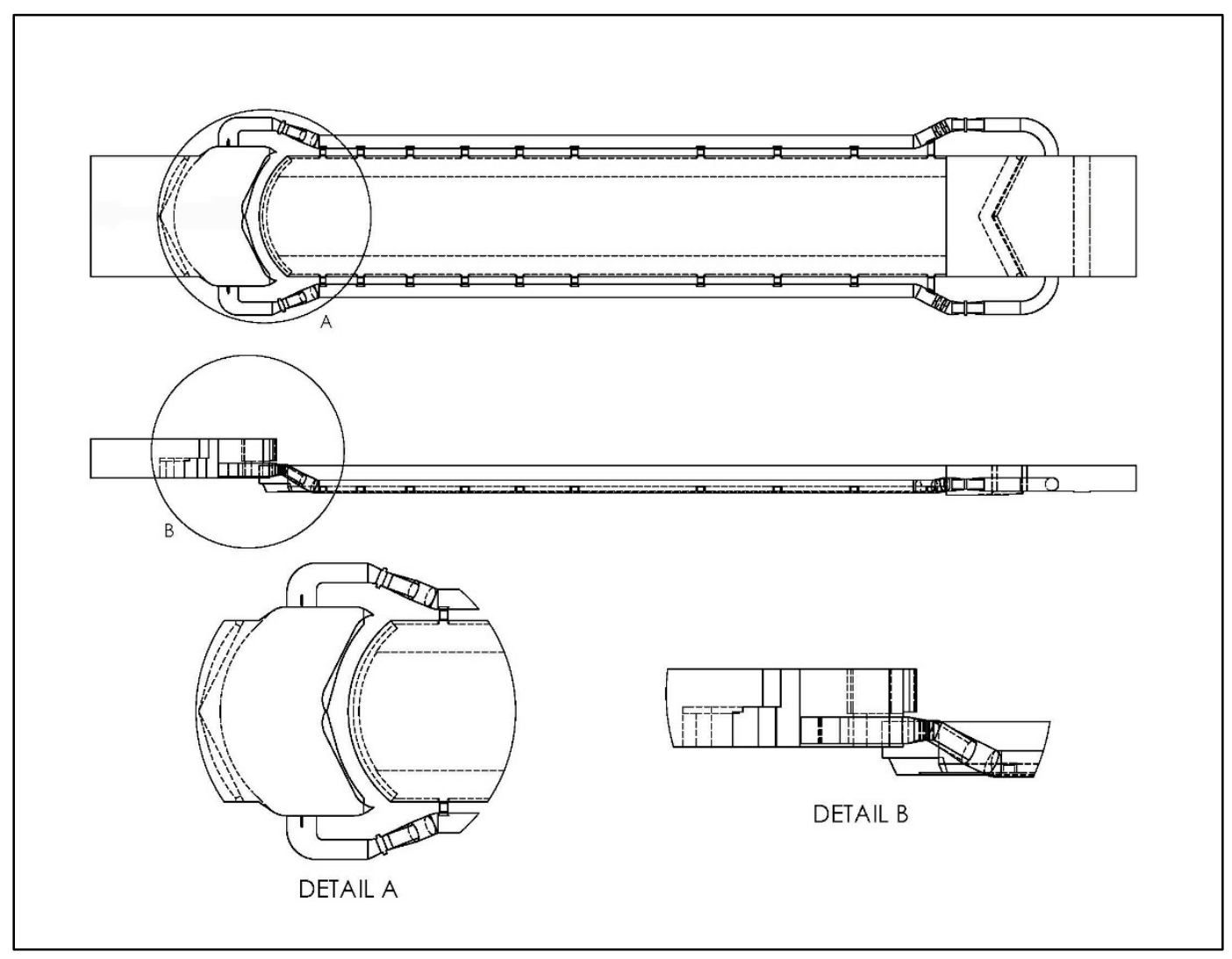




\subsection{Type 2 lock flushing concept model geometry}

The Type 2 lock flushing concept is an additional lateral flushing manifold positioned near the upstream end of the lock chamber. The CAD model for this concept is shown in Figure 21. The flushing manifold is connected to the right of the existing filling and emptying culvert at the first port. This manifold culvert has a uniform $10 \mathrm{ft}$ circular diam cross section with five $4 \mathrm{ft}$ diam ports. These ports are connected to the top of the flushing culvert and are directed vertically. The center of the first port is $15 \mathrm{ft}$ from the lock wall, and the ports are at $20 \mathrm{ft}$ spacings (center to center). To satisfy USACE design criteria on clearance, the lock flushing culvert is $10.5 \mathrm{ft}$ below the lock chamber floor. The flushing ports connect the top of the flushing culvert to the lock floor. The flushing manifold requires all the flow entering one of the existing filling and emptying culverts to be directed completely through the manifold, so the filling and emptying culvert downstream of the flushing manifold is not included in the flow domain. The opposite filling and emptying culvert (the one not involved in the lock chamber flushing) is also excluded from the flow domain.

Figure 21. CAD model of Type 2 lock flushing concept.

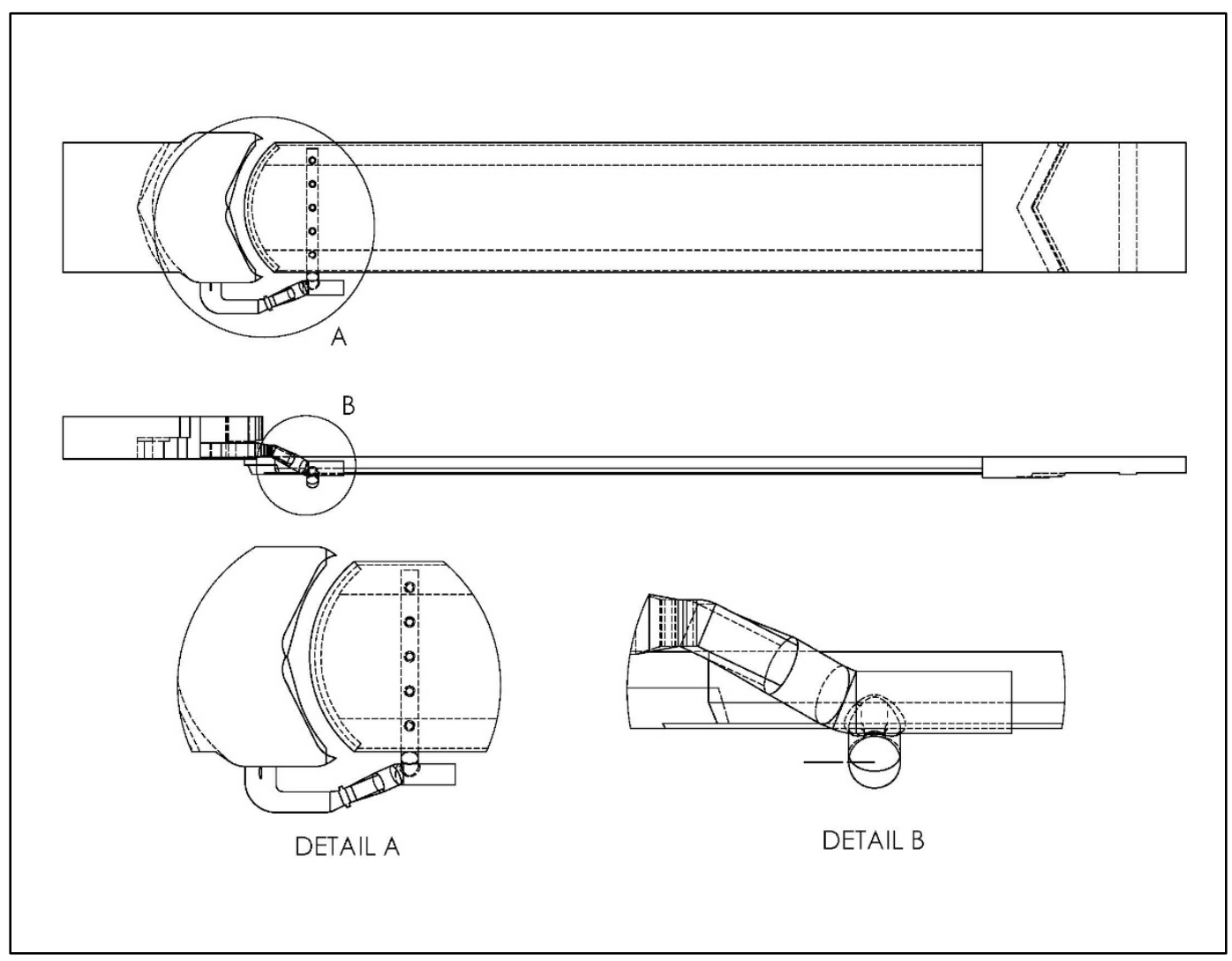




\subsection{Type 3 lock flushing concept model geometry}

The Type 3 lock flushing concept is a series of pipes in the upstream gate sill that connect the upper pool with the lock chamber. The configuration chosen for the computation model, shown in Figure 22, has four $5 \mathrm{ft}$ diam pipes positioned laterally at a $19.2 \mathrm{ft}$ spacing (center to center) along the gate sill over the deepest portion of the lock chamber. The center of these pipes is at el 494, which corresponds to a submergence of $10.4 \mathrm{ft}$ when the lower pool water surface is at el 504.5. The filling and emptying culverts play no role in the lock flushing for this concept, so they are not included in the flow domain. The Type 3 numerical model flow domain includes a portion of the lock upstream of the upper miter gates, the gate sill pipes, and the lock chamber terminated at the downstream miter gates. The lock chamber for the Type 3 concept differs from that of Types 1 and 5 in that a portion of the upstream end (upstream of the first port in the existing filling and emptying system) is removed. This removal is a structural requirement for the flushing pipes.

Figure 22. CAD model of Type 3 lock flushing concept.

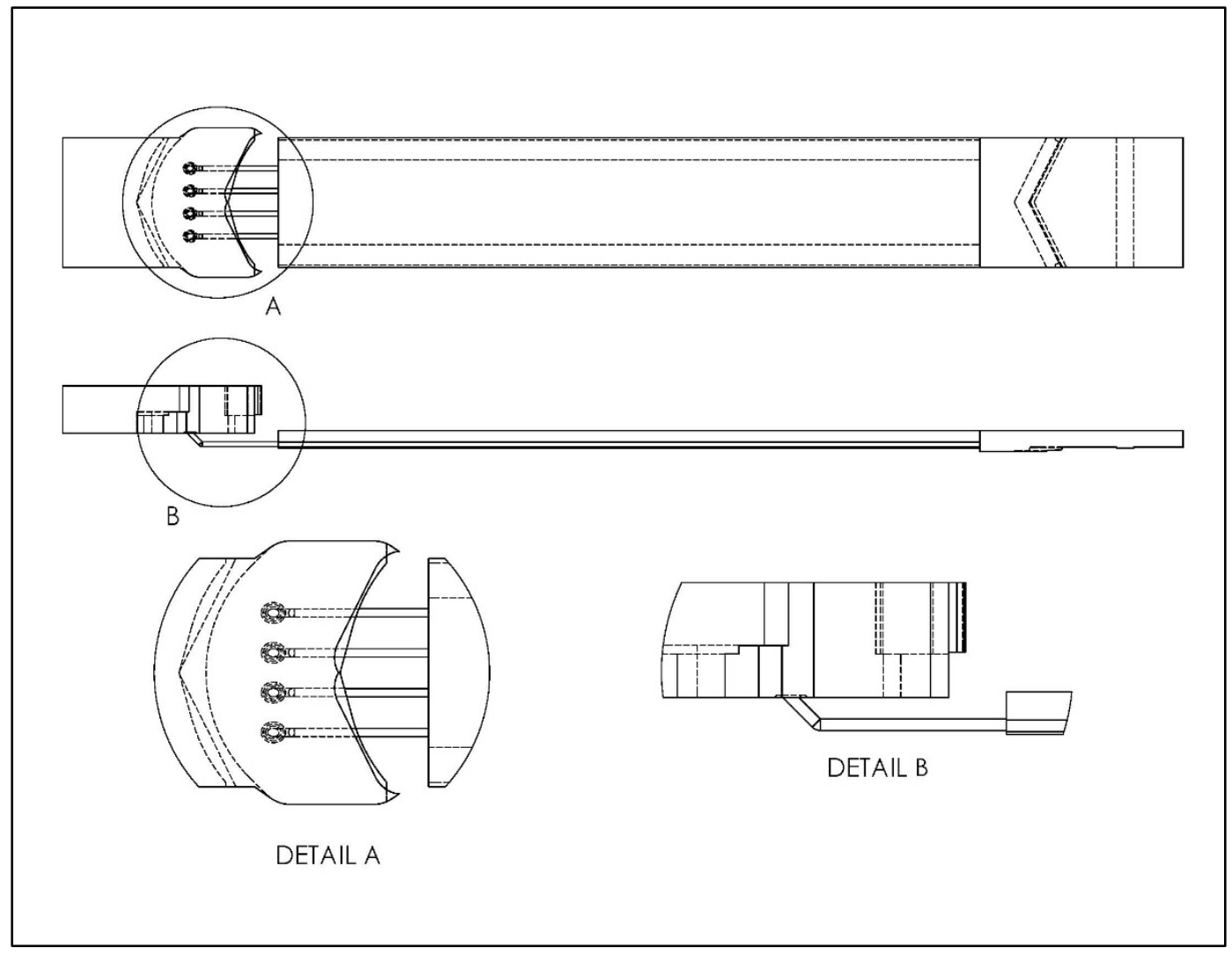




\subsection{Type 3r lock flushing concept model geometry}

The Type $3 \mathrm{r}$ lock flushing concept, shown in Figure 23, was developed as a result of the reduced discharge in the Type 3 model. For the Type 3 numerical model, the discharge was reduced because of the high velocities in the upstream side of the lock chamber. For the Type $3 \mathrm{r}$ model, the size of the conduit that introduces flushing flow into the lock chamber was increased such that the average flushing velocity introduced into the lock chamber is close to $15 \mathrm{ft} / \mathrm{sec}$. This average velocity corresponds to the largest average velocity of flow through the filling and emptying ports in the Type 1 lock flushing concept. This new conduit, referred to as the "rectangular slot," is a constant $72 \mathrm{ft}$ wide by $3 \mathrm{ft}$ tall cross section that connects to the lock chamber at the same centerline elevation as the gate sill pipes in Type 3. The rectangular slot is centered laterally in the lock chamber. Constructing such a large conduit though the upstream gate sill is highly improbable, so this lock flushing concept is largely just to show how well a gate sill lock flushing concept could perform if only the hydraulics of the system are considered.

Figure 23. CAD model of Type 3r lock flushing concept.

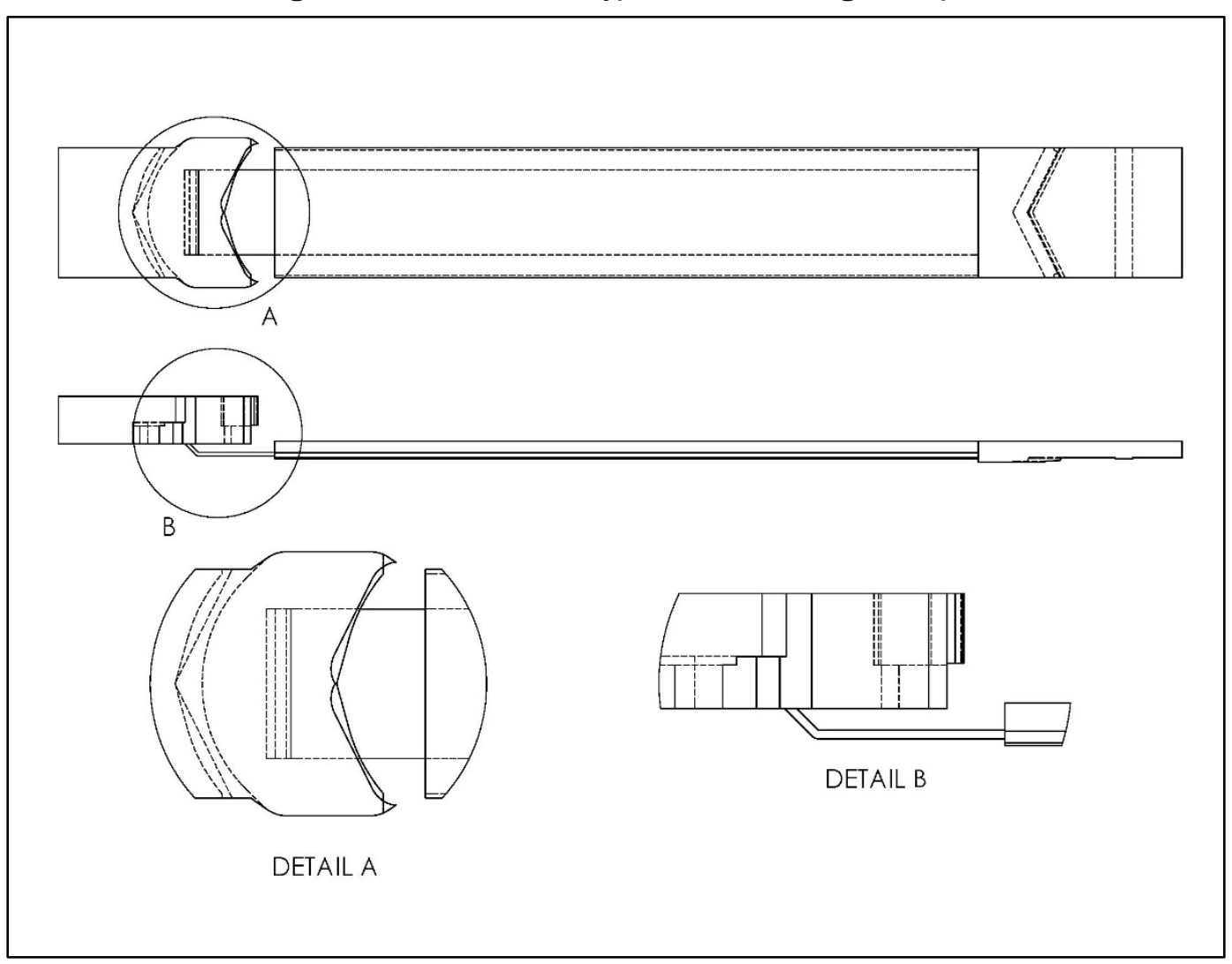




\subsection{Type 5 lock flushing concept}

The Type 5 lock flushing concept, shown in Figure 24, is a redesign of the filling and emptying system at Brandon Road Lock. The flow domain includes a portion of the lock upstream of the upper miter gates, both filling and emptying culverts with both the intakes and ports, and the lock chamber. The downstream end of the flow domain is located at the pintle of the downstream miter gates. The culvert is terminated downstream of the last (twelfth) port. One of the flushing ports mentioned in Section 4.2.5 is shown in Figure 24, Detail A. The upstream four ports on either side of the lock include deflectors as shown in Detail C. The port positioning and deflector geometry follow the guidelines set forth in EM 1110-2-1604 (HQUSACE 2006).

Figure 24. CAD model of Type 5 lock flushing concept.
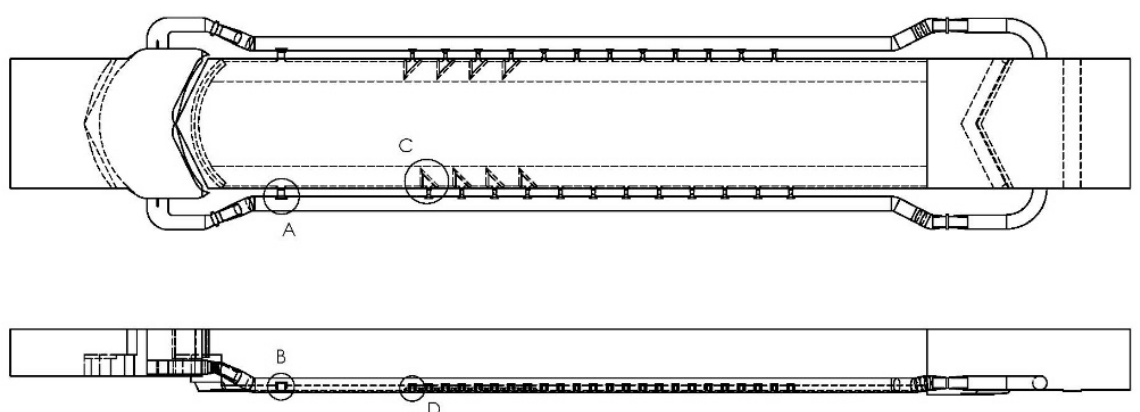

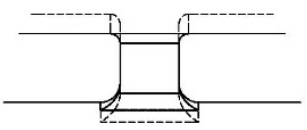

DETAIL A

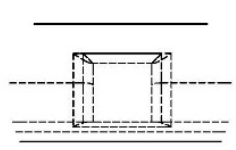

DETAIL B

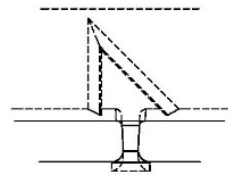

DETAIL C

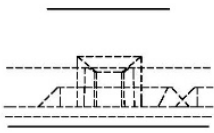

DETAIL D 


\section{Numerical Model Results}

The results of each numerical model are shown and discussed in this chapter. Contour plots of the flow velocity and the original lock water concentration of each lock flushing concept during a simulated lock flushing operation are presented.

The flow results are presented with the velocity magnitude, $V$, which is defined as

$$
V=\sqrt{u^{2}+v^{2}+w^{2}}
$$

where:

$$
\begin{aligned}
u & =x \text {-component of flow velocity } \\
v & =y \text {-component of flow velocity } \\
w & =z \text {-component of flow velocity. }
\end{aligned}
$$

The simulation results are shown via contour plots that show the spatial distribution of the flow variables during lock flushing. These contour plots are presented for each of three different vertical slices in the lock chamber. As indicated in Figure 25, these three slices are located $3 \mathrm{ft}$ from the lock chamber floor, $10 \mathrm{ft}$ from the lock chamber floor, and at the lock chamber surface. Figure 25 has been stretched vertically by a factor of five, so the different slice locations can be seen more easily.

Figure 25. Simulation contour plot elevations.

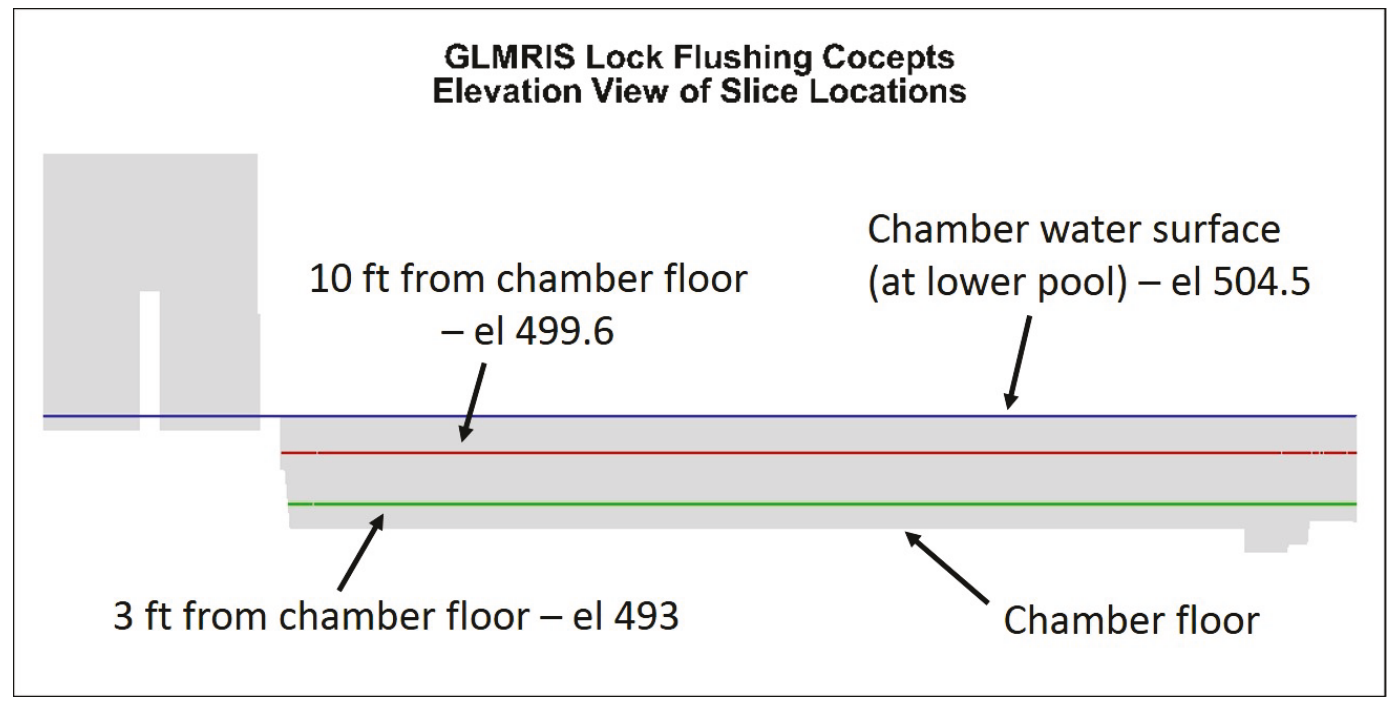


The effectiveness and efficiency of each flushing operation is quantified by calculating the reduction of the original lock chamber water concentration during the flushing operation. The volume of the lock chamber where the original lock chamber water concentration reduces to pre-chosen levels is shown as different curves on the dilution plots. These flushing volume results are reported as percentages of the total lock chamber volume throughout the lock flushing operation.

Figure 26 shows an example plot of how the lock flushing performance is quantified. The horizontal axis represents the flushing time, and the vertical axis represents the percentage of the lock chamber volume that is reduced to certain concentration levels. In the example plot, the green curve shows the volume of the lock chamber that has been flushed to $60 \%$ of the concentration of water in the lock chamber during flushing. Two points on the curve are indicated. The red point on the plot represents 10 min of flushing flow. Moving vertically from the horizontal axis at 10 min to the red point, then proceeding to the left to the vertical axis shows that $27 \%$ of the lock chamber volume has been reduced to $60 \%$ concentration of the original lock chamber water. The blue point on the plot represents $15 \mathrm{~min}$ of flushing flow. Moving vertically from the horizontal axis at $15 \mathrm{~min}$ to the blue point, then proceeding to the left to the vertical axis shows that $92 \%$ of the lock chamber volume has been reduced to $60 \%$ concentration of the original lock chamber water.

Figure 26. Sample lock flushing volume plot - single curve explanation.

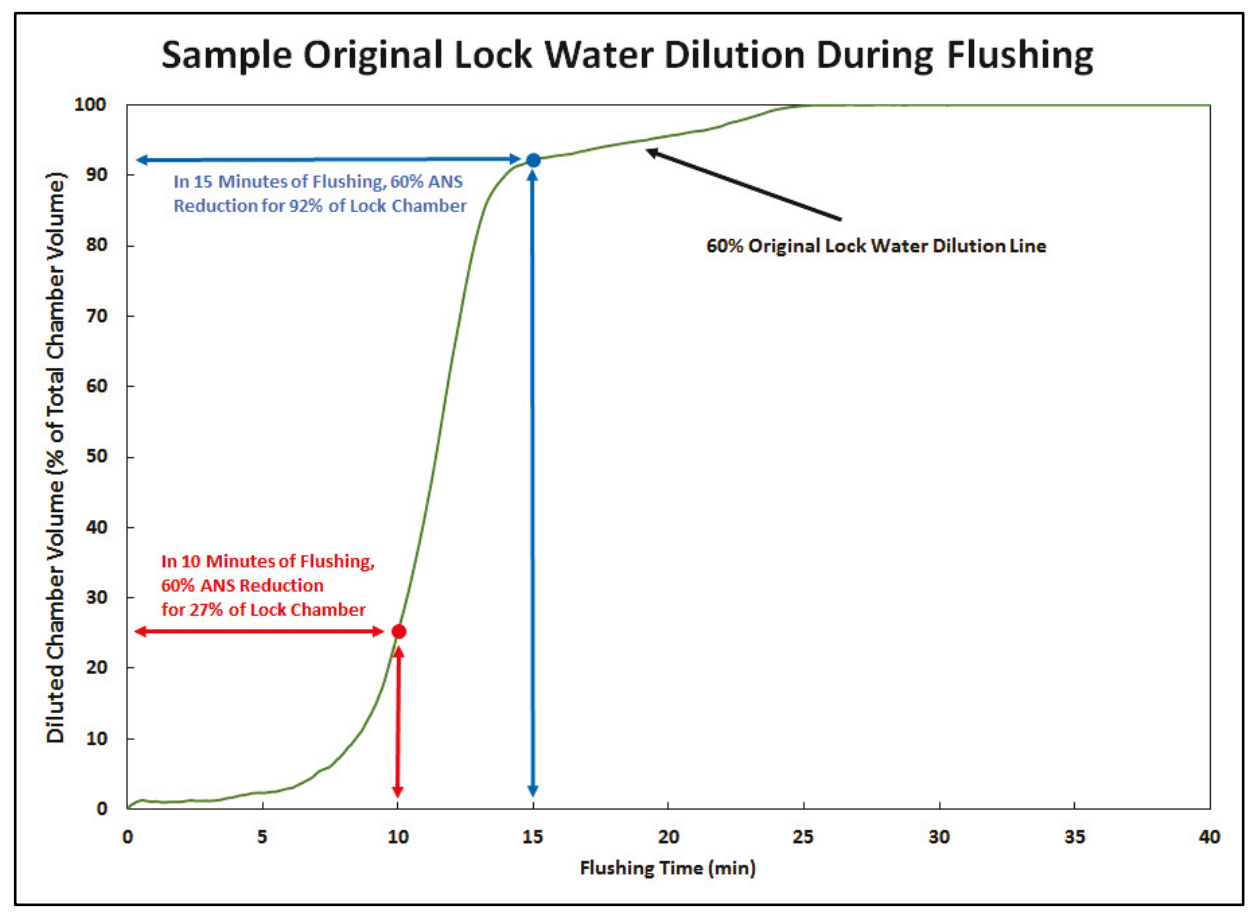


Additionally, the plots can be read to show how much of the lock chamber has been reduced to multiple concentration levels at a single flushing time. In Figure 27, the blue, red, and green curves represent 70\%, 60\%, and 50\% concentrations, respectively, of water in the lock chamber during flushing. The black dashed line indicates $10 \mathrm{~min}$ of flushing flow. The plot is read by picking a flushing time and moving vertically from the horizontal, flushing time axis to each time the black dashed line intersects a concentration curve. For each concentration curve, move left to the horizontal axis to read the percentage of the lock chamber that has been flushed to the concentration indicated by the intersected concentration curve. For instance, the black dashed line first intersects the blue line, which indicates that after 10 min of flushing flow, $4 \%$ of the lock chamber has been reduced to $70 \%$ of the original concentration. Similarly, the red curve indicates that $25 \%$ of the chamber is reduced to $60 \%$ of the original concentration in 10 min of flushing. Also, the green curve indicates that $74 \%$ of the lock chamber has been reduced to $50 \%$ of the original concentration in $10 \mathrm{~min}$ of flushing.

Figure 27. Sample lock flushing volume plot - single flushing time explanation.

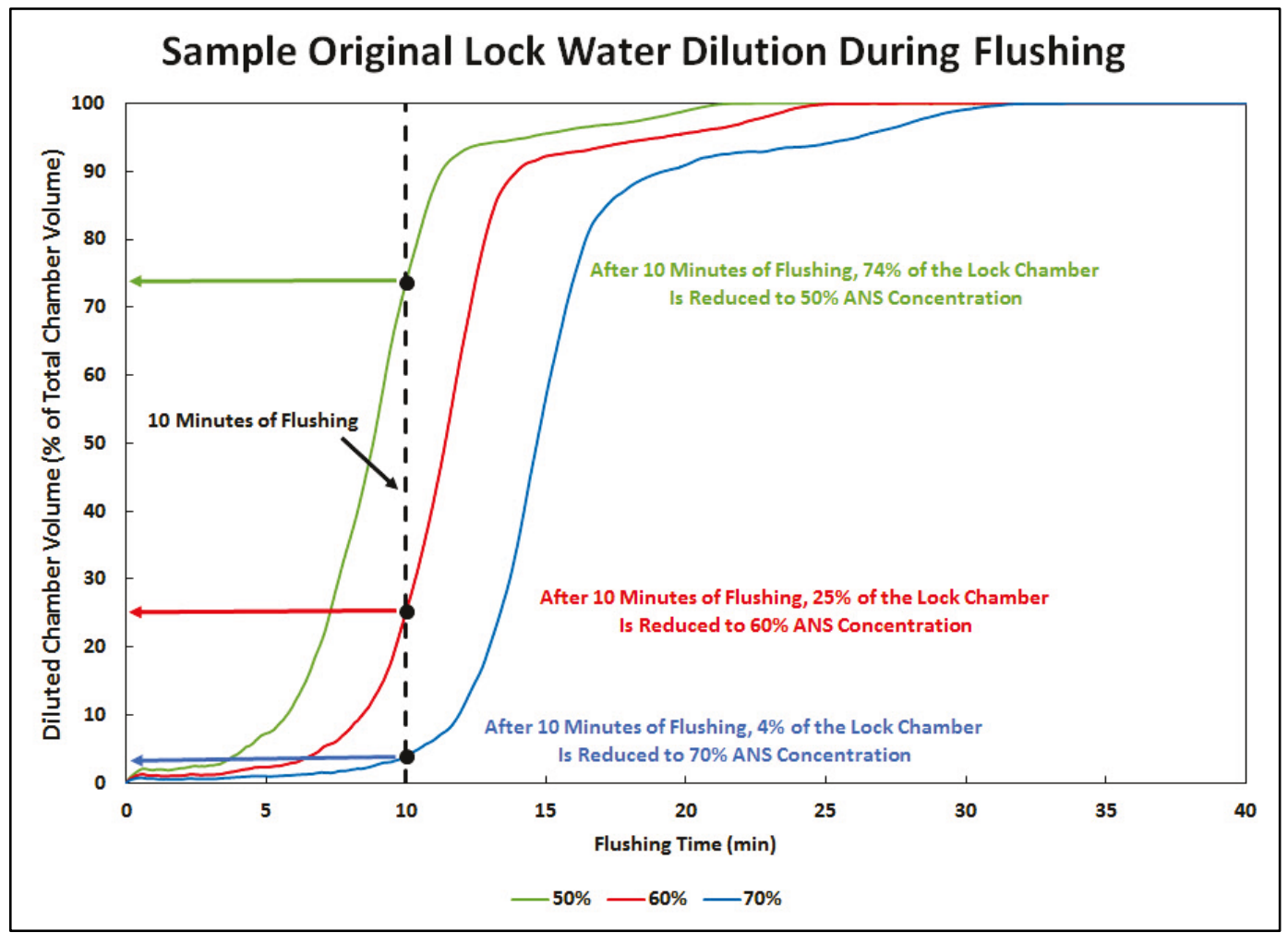




\subsection{Type 1 lock flushing concept}

The contour plots of the velocity magnitudes for the Type 1 lock flushing concept are shown in Figure 28-Figure 30. In each figure, the velocity contours are shown at the beginning of flushing, at $5 \mathrm{~min}$ of flushing, and at 10 min of flushing. The flushing discharge remains constant throughout the simulation. Flushing flow is introduced into the lock chamber at several locations via the filling and emptying ports. Viewing the contours closest to the chamber floor, the velocity magnitudes vary in both time and space. The jets that extend from each port have a maximum velocity of approximately $4 \mathrm{ft} / \mathrm{sec}$. Each jet extends approximately halfway across the lock chamber. The jets are directed more toward the downstream miter gates for the ports that are farthest downstream. The contours $10 \mathrm{ft}$ from the chamber floor show that the variation in velocity magnitude is much smaller farther away from the ports. At that elevation the maximum velocity magnitude is approximately $3 \mathrm{ft} / \mathrm{sec}$. At the lock chamber surface, the velocity magnitudes vary more than near the center of the lock chamber water column. The largest velocity magnitudes at the water surface are approximately $3 \mathrm{ft} / \mathrm{sec}$. 
Figure 28. Type 1 velocity magnitude contours at $3 \mathrm{ft}$ from chamber floor.

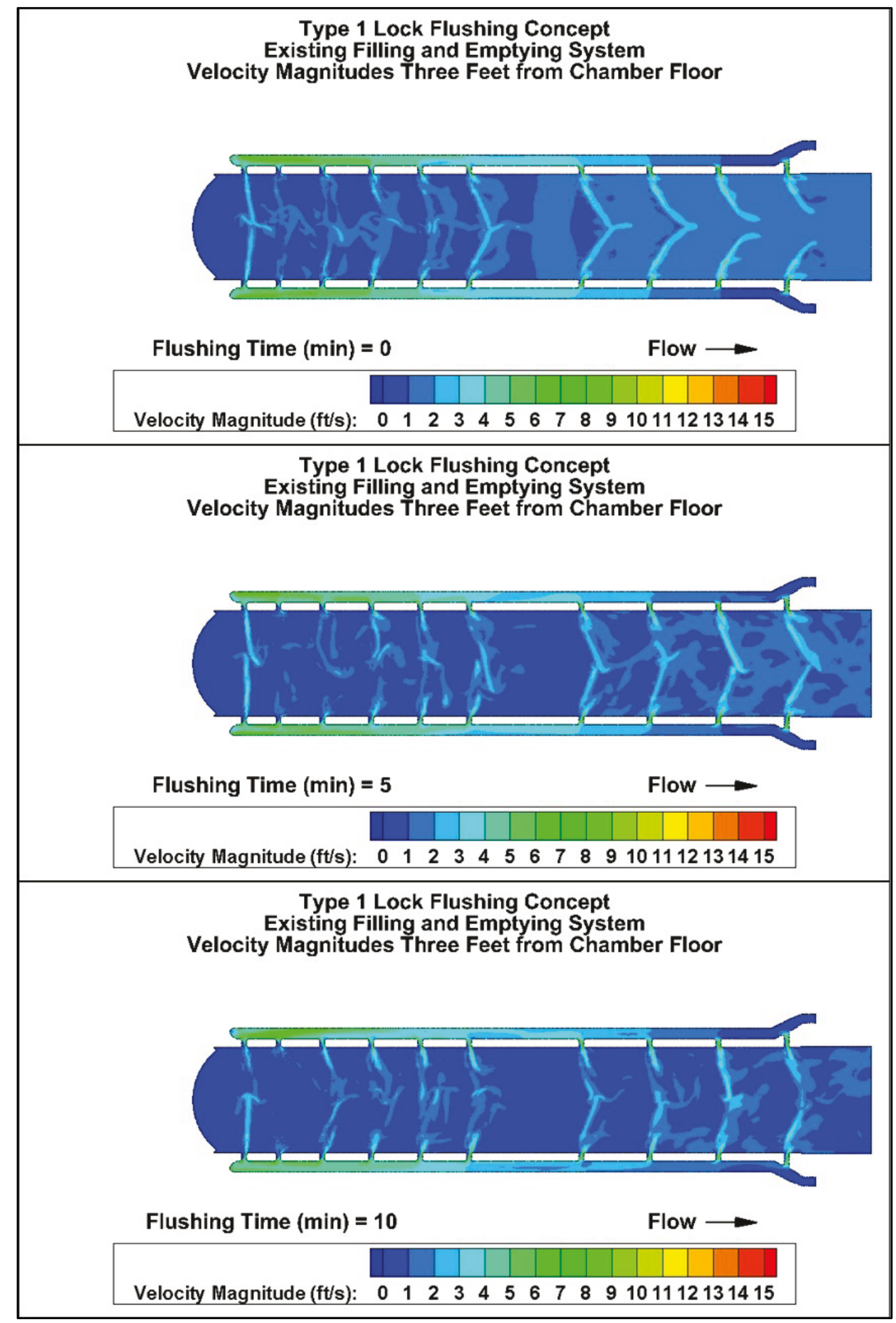


Figure 29. Type 1 velocity magnitude contours $10 \mathrm{ft}$ from chamber floor.

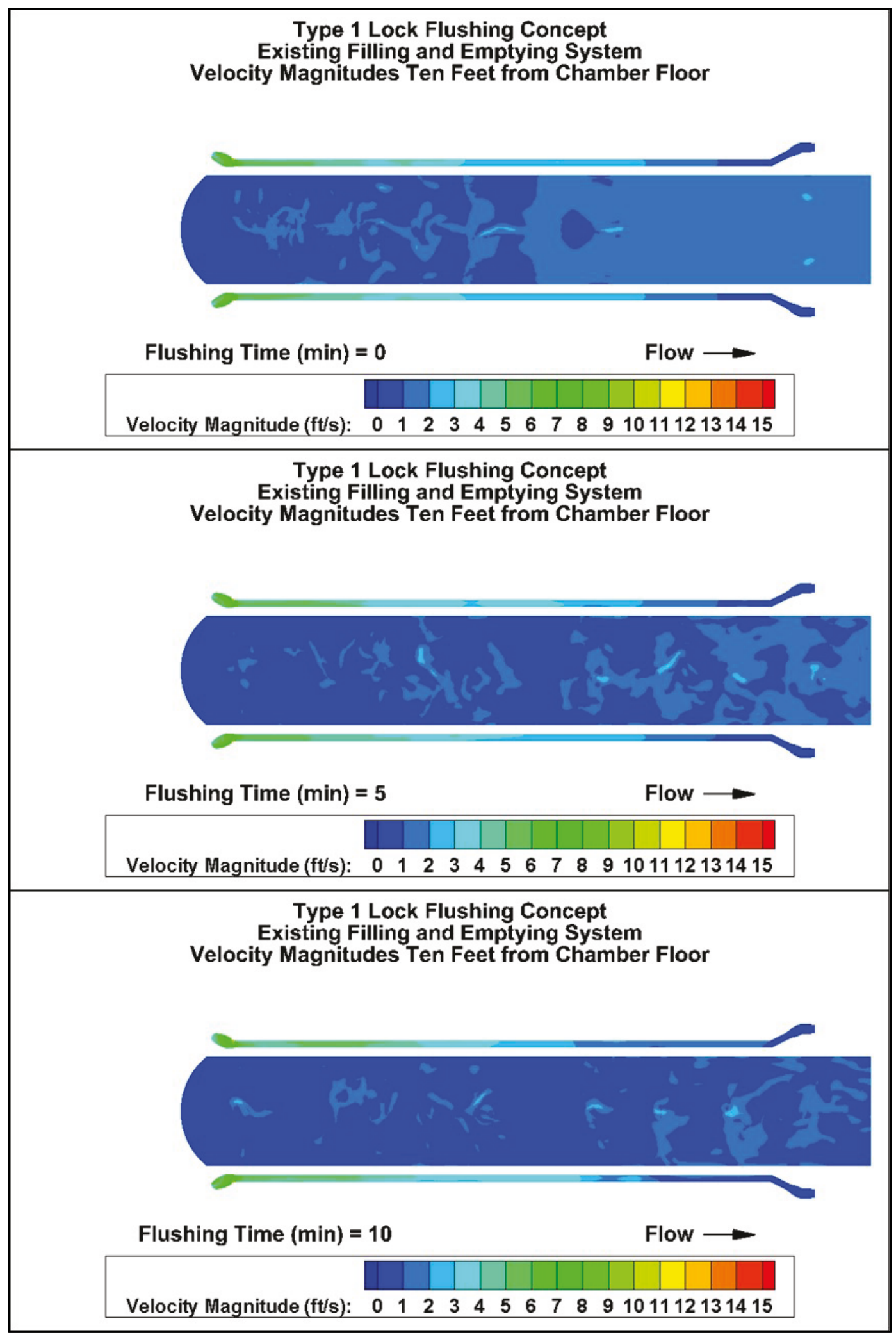


Figure 30. Type 1 velocity magnitude contours at lock chamber surface.

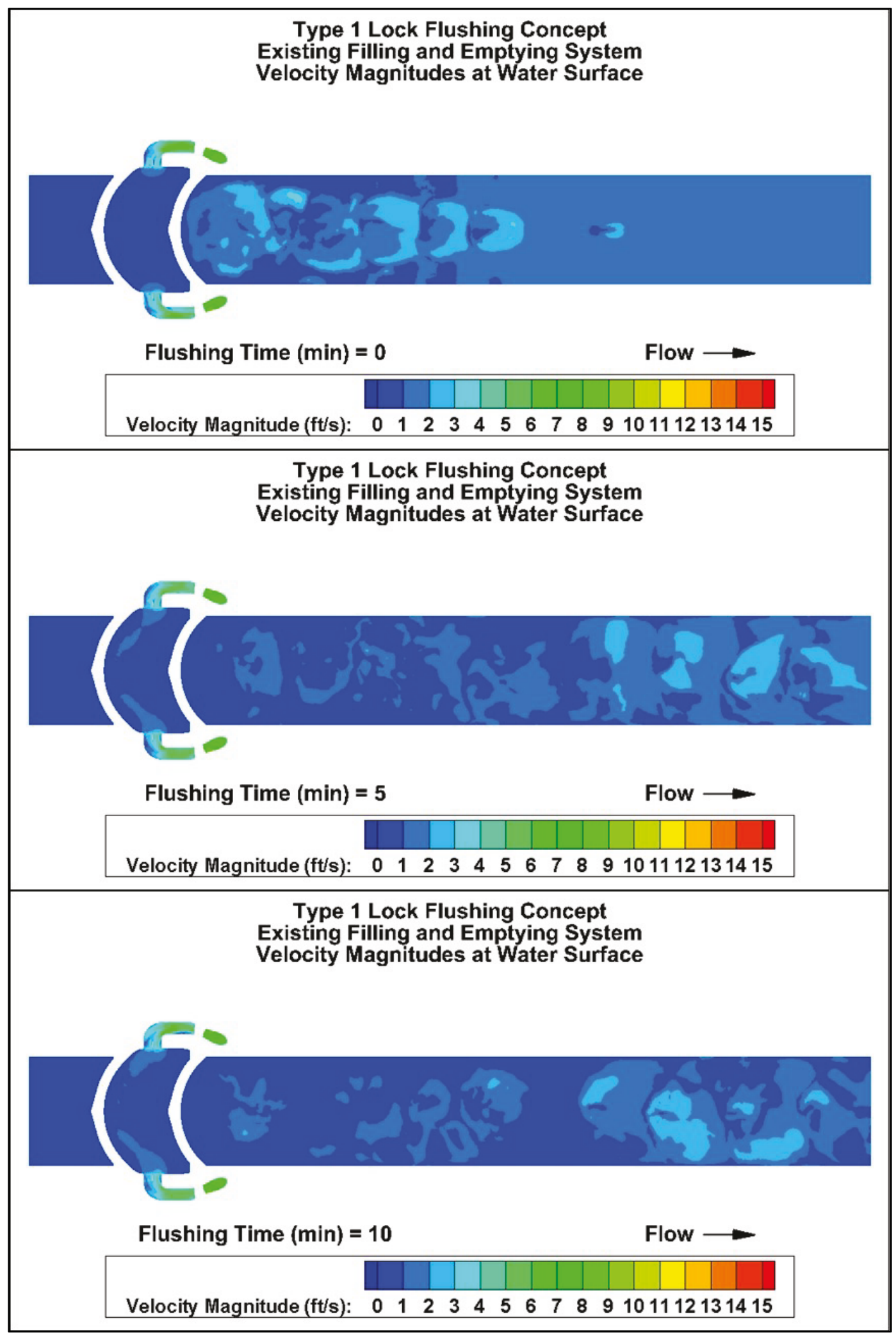


Contour plots of the original lock chamber water concentration for the Type 1 flushing concept are shown in Figure 31-Figure 33. The purpose of these figures is to show how much the concentration in the lock chamber varies in both time and space in the lock chamber during a lock filling operation. At the beginning of flushing (flushing time $=0$ ), the entire lock chamber is orange/red indicating a uniform concentration of $100 \%$ of the original lock chamber water. During flushing, the contours in the lock chamber change from orange/red to green to blue. These changes show that the lock chamber flushing is reducing the concentration of original lock chamber water. Since flushing flow is introduced at multiple locations in the lock chamber, the original lock chamber water concentration is reduced gradually throughout the lock chamber. At $3 \mathrm{ft}$ from the chamber floor, the effect of the ports is noticeable, and the reduction in chamber concentration varies dramatically in both time and space. Moving farther up the water column, the reduction in concentration is more gradual. After 15 min of lock flushing, the concentration of original lock chamber water for each elevation is approximately $50 \%$ for the entire chamber. Upstream of the first filling port, the original lock chamber concentration is even higher. 
Figure 31. Type 1 original lock chamber water concentration contours $3 \mathrm{ft}$ from chamber floor.

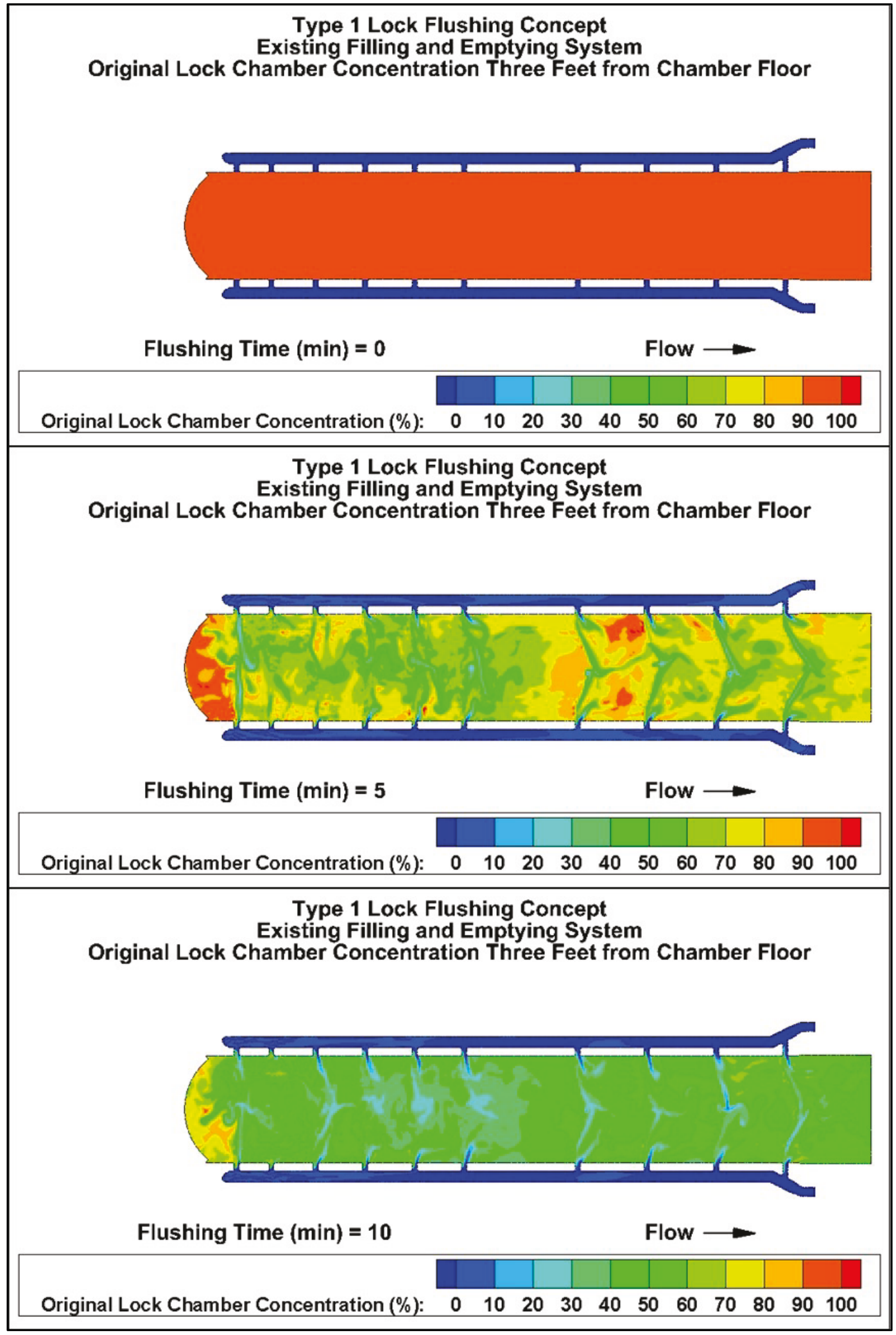


Figure 32. Type 1 original lock chamber water concentration contours $10 \mathrm{ft}$ from chamber floor.

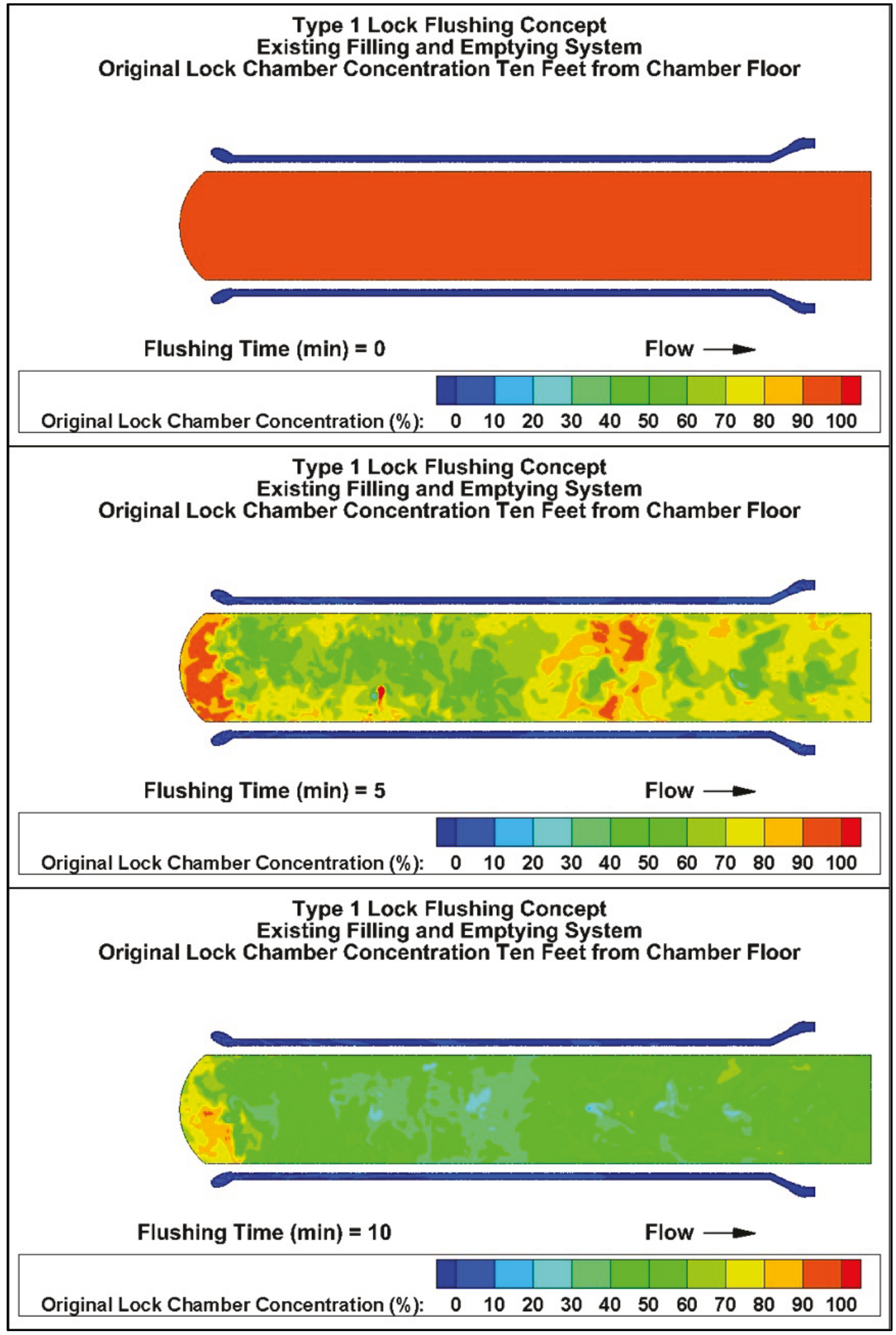


Figure 33. Type 1 original lock chamber water concentration contours at lock chamber surface.

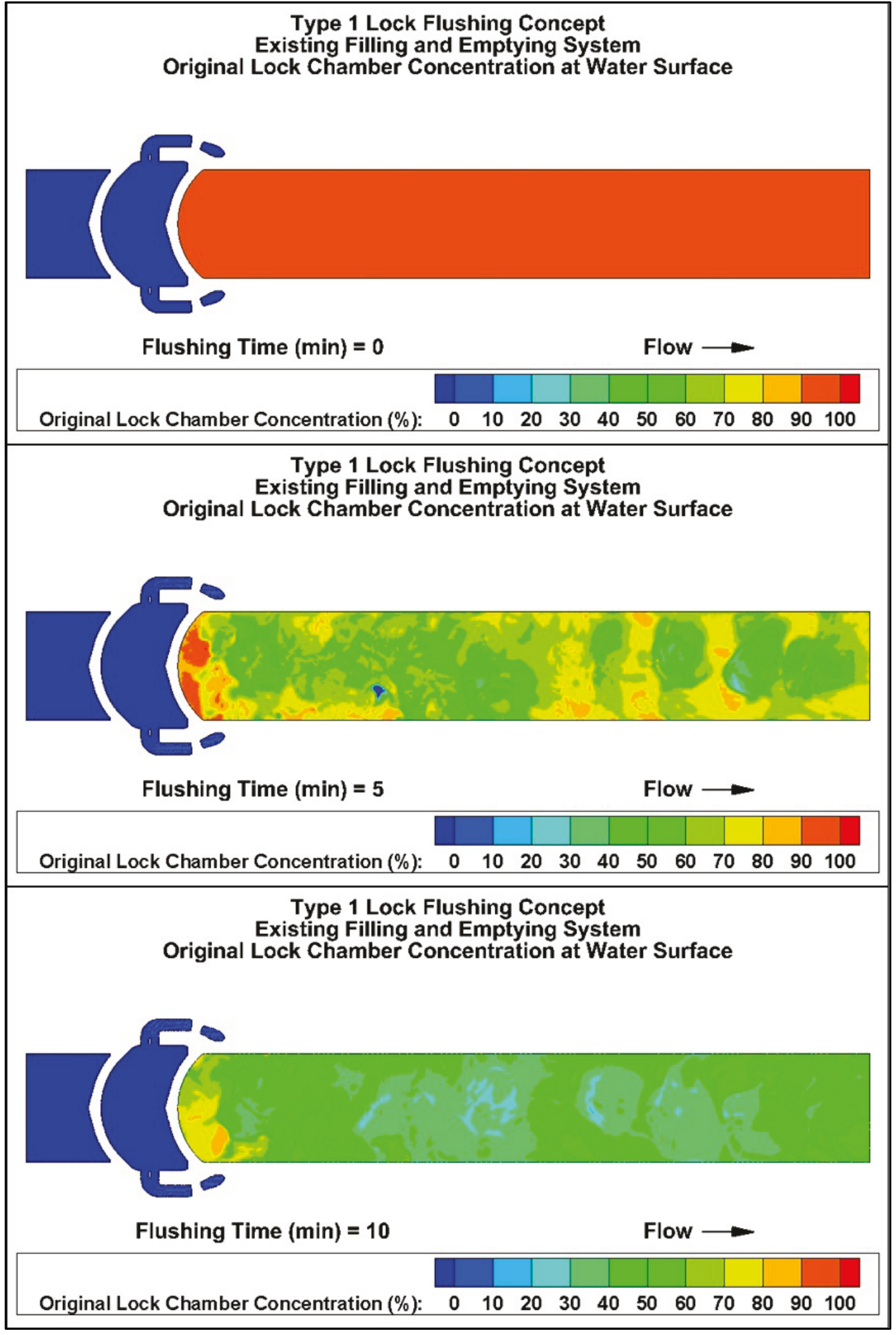


The flushing effectiveness and efficiency for Type 1 are shown in Figure 34 and Table 8. In the figure, the original lock water concentration is plotted against the flushing time. The different curves indicate how much of the lock chamber has reached different levels of original lock chamber water concentration during a flushing operation, with red indicating at most a $10 \%$ reduction in the original lock chamber concentration, green indicating at most a 50\% reduction, and dark blue indicating a $99.9 \%$ reduction (essentially portions of the chamber where the water has been completely replaced by flushing water).

Most of the curves show a slow volume change initially, a period of rapid volume change, and finally a return to a slow volume change as the curves approach $100 \%$ of the lock chamber. The desired amount of flushing (99.9\% reduction) as indicated by the dark blue line (which is essentially on top of the horizontal axis) is not attained in $40 \mathrm{~min}$ of flushing. After $15 \mathrm{~min}$, indicated by the dashed black line, $80 \%$ reduction of the flow has only occurred in $4 \%$ of the lock chamber. Lock chamber volume percentages at 5 min increments of flushing are listed in Table 8. The values listed correspond to values that can be read directly from Figure 33, but the table values provide more precision in the percent volumes.

Figure 34. Type 1 lock chamber flushing performance.

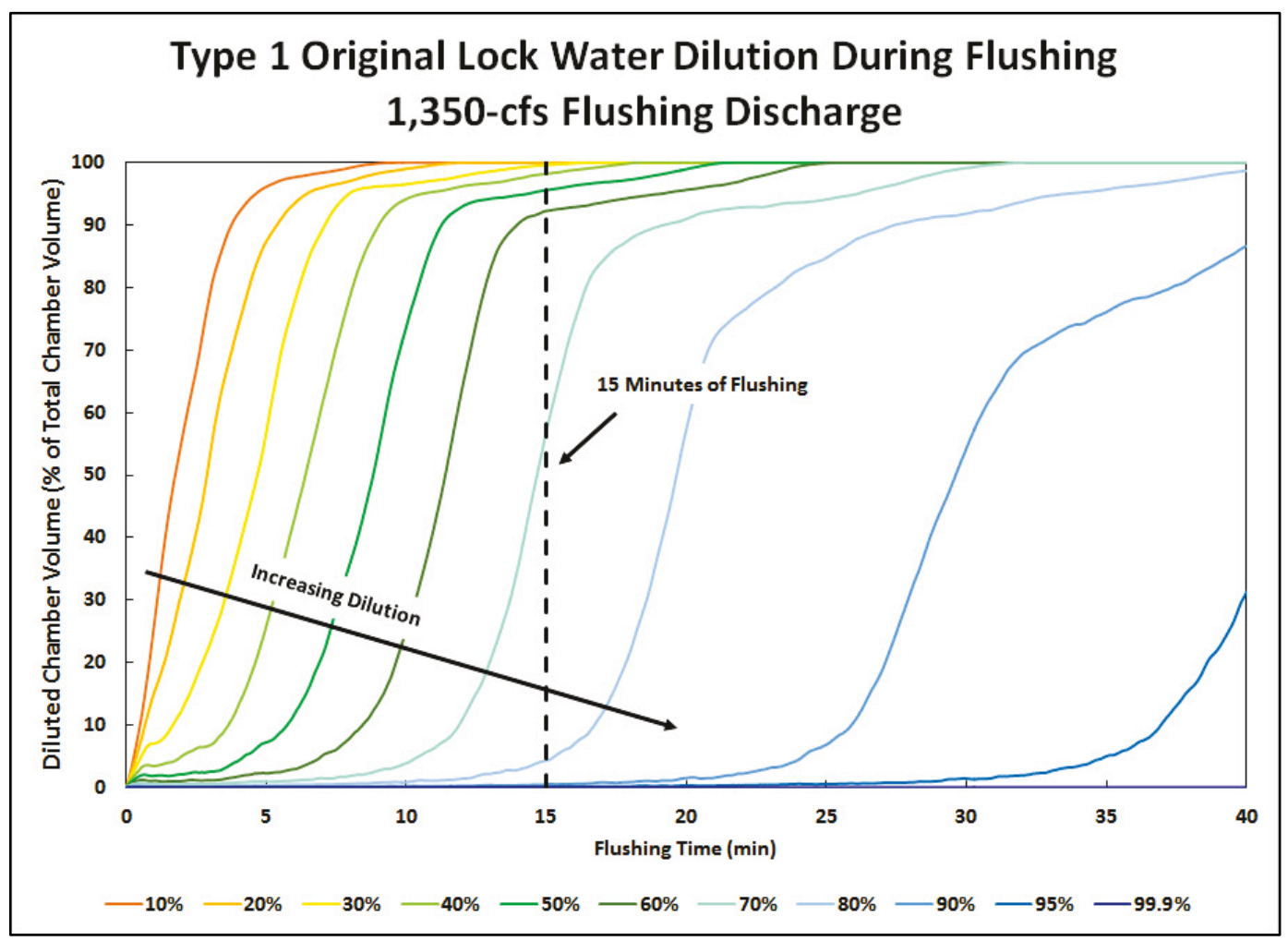


Table 8. Type 1 chamber flushing performance $-5 \mathrm{~min}$ intervals.

\begin{tabular}{|c|c|c|c|c|c|c|c|c|c|}
\hline \multirow{2}{*}{\multicolumn{2}{|c|}{ Flushing Time (min) }} & \multicolumn{8}{|c|}{ Flushed chamber volume (\% of total lock chamber volume) } \\
\hline & & 5 & 10 & 15 & 20 & 25 & 30 & 35 & 40 \\
\hline \multirow{10}{*}{ 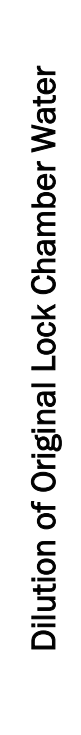 } & $99.9 \%$ & $<1$ & $<1$ & $<1$ & $<1$ & $<1$ & $<1$ & $<1$ & $<1$ \\
\hline & $90 \%$ & $<1$ & $<1$ & 1 & 2 & 7 & 54 & 76 & 87 \\
\hline & $80 \%$ & $<1$ & 1 & 4 & 57 & 85 & 92 & 96 & 99 \\
\hline & $70 \%$ & 1 & 4 & 57 & 91 & 94 & 99 & 100 & 100 \\
\hline & $60 \%$ & 2 & 25 & 92 & 96 & 100 & 100 & 100 & 100 \\
\hline & $50 \%$ & 7 & 74 & 96 & 99 & 100 & 100 & 100 & 100 \\
\hline & $40 \%$ & 26 & 94 & 98 & 100 & 100 & 100 & 100 & 100 \\
\hline & $30 \%$ & 57 & 97 & 100 & 100 & 100 & 100 & 100 & 100 \\
\hline & $20 \%$ & 87 & 99 & 100 & 100 & 100 & 100 & 100 & 100 \\
\hline & $10 \%$ & 96 & 100 & 100 & 100 & 100 & 100 & 100 & 100 \\
\hline
\end{tabular}

\subsection{Type 2 lock flushing concept}

The Type 2 lock flushing concept was simulated in a previous phase of numerical modeling work for the GLMRIS project. Between the completion of the first phase of numerical modeling effort and the beginning of the phase being reported in this report, the Type 2 lock flushing concept was removed from further consideration. The decision to remove the Type 2 concept is based on a combination of factors including high vertical velocities it produced in the lock chamber and construction (excavation) requirements for the new lateral manifold. The Type 2 numerical models used a fixed-lid boundary condition instead of a free-service boundary, and contour plots of the velocity magnitudes are included in Appendix C. No direct calculation of original lock water concentration was included in that phase of the numerical modeling work. The velocity magnitude contour plots for the Type 2 concept would perform, but these results should not be used as a direct comparison with the results shown and discussed in this chapter because extra degrees of freedom were included in those models, which can significantly affect the flow solution.

\subsection{Type 3 lock flushing concept}

The contour plots of the velocity magnitudes for Type 3 concept are shown in Figure 35-Figure 37. In each figure, the velocity contours are shown at 
the beginning of flushing, at $5 \mathrm{~min}$ of flushing, and at $10 \mathrm{~min}$ of flushing. The flushing discharge is constant throughout the simulation. Flushing flow is introduced into the lock chamber at the upstream end via four pipes through the gate sill. The outlets of these pipes are near the lock chamber floor. The jets that extend from each pipe have a maximum velocity of approximately $15 \mathrm{ft} / \mathrm{sec}$. The contours closest to the chamber floor show that the velocity magnitudes vary in both time and space in the upstream third of the lock chamber. Farther downstream, the variation of velocity magnitude is much smaller, and the maximum flow velocities are approximtely $2 \mathrm{ft} / \mathrm{sec}$. The contours $10 \mathrm{ft}$ from the chamber floor show that the variation in velocity magnitudes is smaller farther away from the ports but is still largely restricted to the upstream third of the lock chamber. At that elevation, the maximum velocity magnitude is approximately $7 \mathrm{ft} / \mathrm{sec}$. At the lock chamber surface, the velocity magnitudes vary more than near the center of the lock chamber water column. The strong effect of introducing the flushing flow through the pipes is still very apparent at the chamber surface. The largest velocity magnitudes at the water surfaces are approximately $7 \mathrm{ft} / \mathrm{sec}$.

Contour plots of the original lock chamber water concentration for Type 3 are shown in Figure 38-Figure 40. The purpose of these figures is to show how much the concentration in the lock chamber varies in both time and space in the lock chamber during a lock filling operation. At the beginning of flushing (flushing time $=0$ ), the entire lock chamber is orange/red indicating a uniform concentration of $100 \%$ of the original lock chamber water. During flushing, the contours in the lock chamber change from orange/red to green to blue. These changes show that the lock chamber flushing is reducing the concentration of original lock chamber water during flushing. Since flushing flow is introduced at the upstream end of the lock chamber, the original lock chamber water concentration is reduced first at the upstream end of the lock chamber. The original lock chamber water concentration is reduced throughout the lock chamber as the flushing flow moves toward the downstream miter gates. There is no strong vertical variation in the original lock chamber water concentration. After 15 min of lock flushing, the original lock chamber concentration at the upstream end of the lock chamber has already been reduced to approximately $10 \%$. These concentration contours indicate that Type 3 is more efficient than Type 1. Further, Type 3 does not produce any areas of the lock chamber that take significantly longer to flush than other areas. 
Figure 35. Type 3 velocity magnitude contours $3 \mathrm{ft}$ from chamber floor.

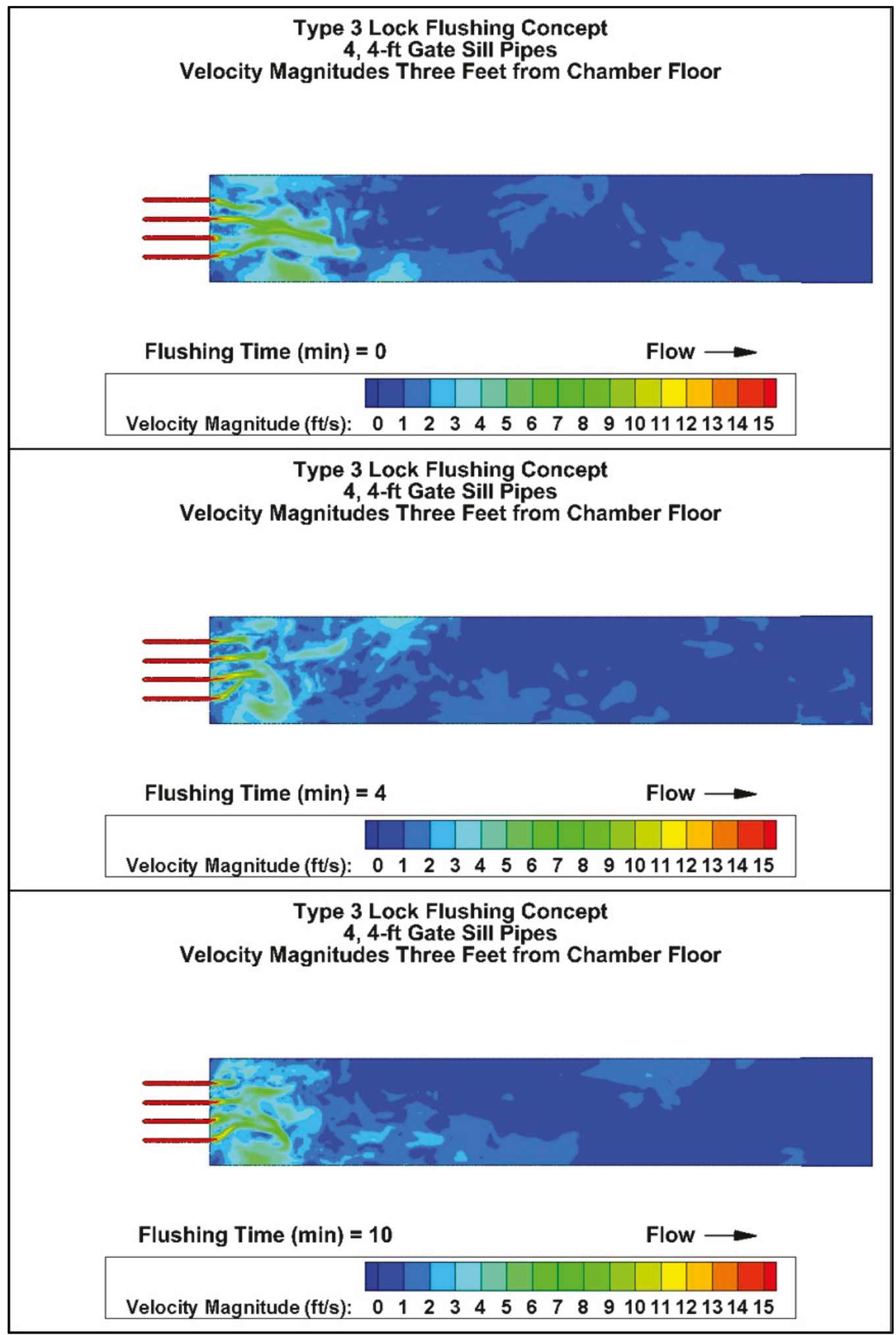


Figure 36. Type 3 velocity magnitude contours $10 \mathrm{ft}$ from chamber floor.

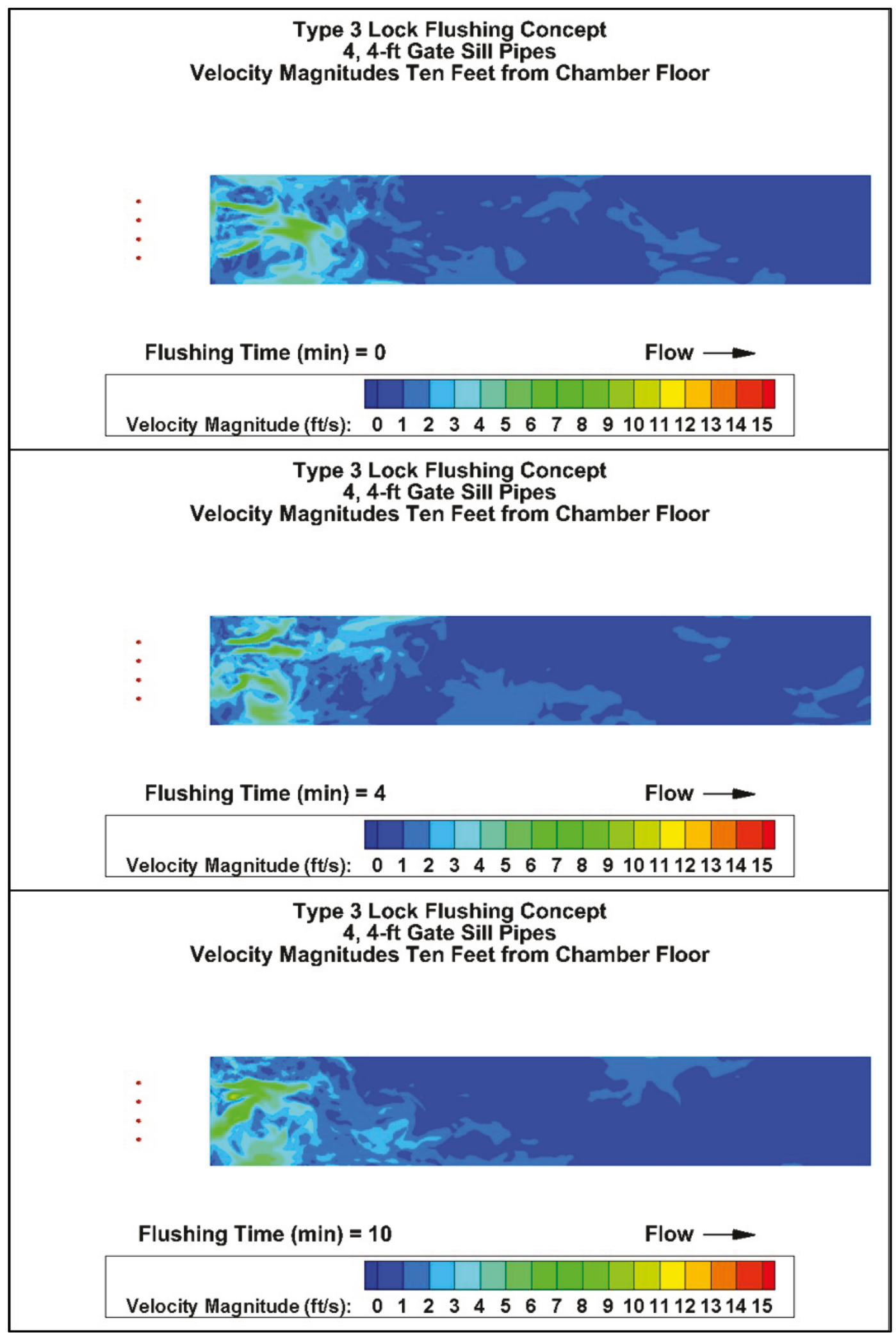


Figure 37 . Type 3 velocity magnitude contours at lock chamber surface.

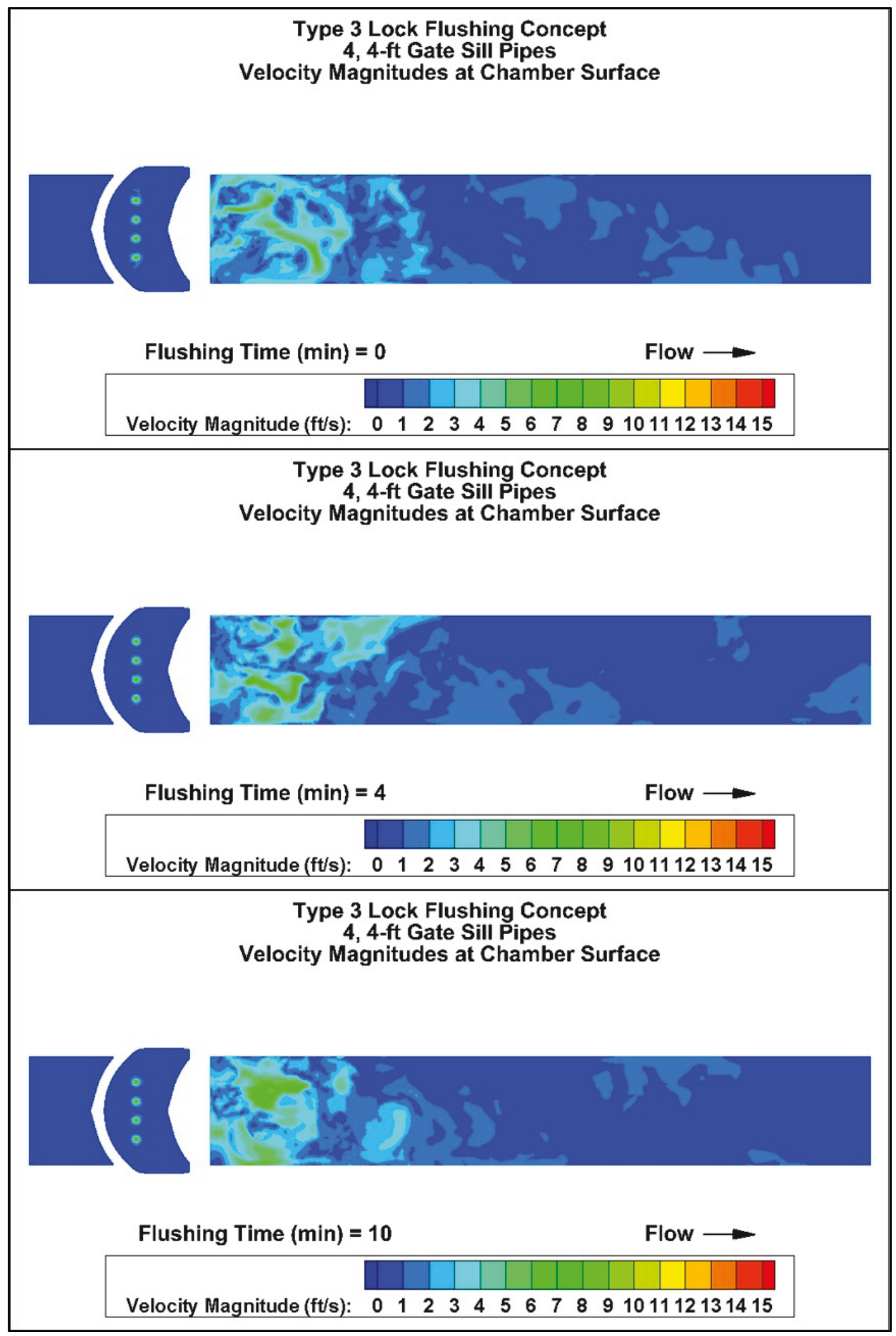


Figure 38. Type 3 original lock chamber water concentration contours at $3 \mathrm{ft}$ from chamber floor.

Type 3 Lock Flushing Concept

4, 4-ft Gate Sill Pipes

Original Lock Chamber Concentration Three Feet from Chamber Floor

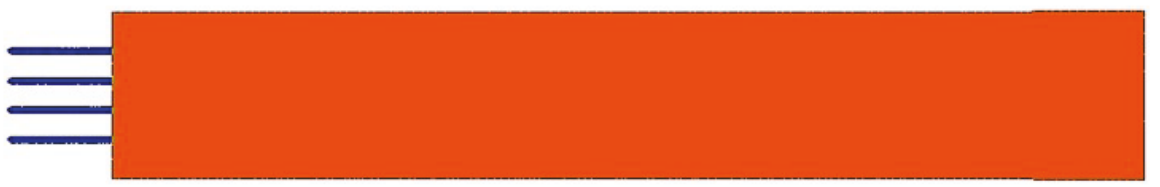

Flushing Time $(\min )=0$

Flow $\longrightarrow$

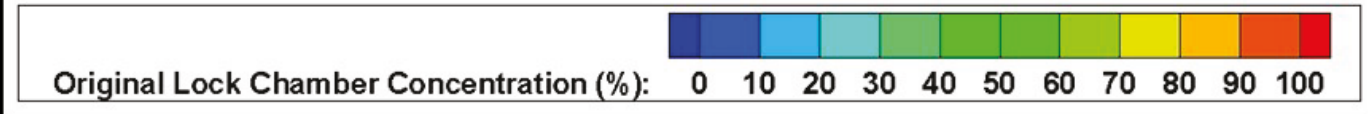

Type 3 Lock Flushing Concept

4, 4-ft Gate Sill Pipes

Original Lock Chamber Concentration Three Feet from Chamber Floor

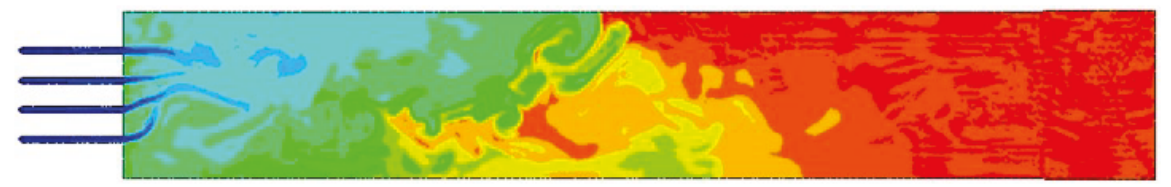

Flushing Time $(\mathrm{min})=5$

Flow $\longrightarrow$

\begin{tabular}{|lllllllllllll|l|}
\hline & & & & & & & & & & & & \\
\hline Original Lock Chamber Concentration (\%): & 0 & 10 & 20 & 30 & 40 & 50 & 60 & 70 & 80 & 90 & 100 \\
\hline
\end{tabular}

Type 3 Lock Flushing Concept 4, 4-ft Gate Sill Pipes

Original Lock Chamber Concentration Three Feet from Chamber Floor

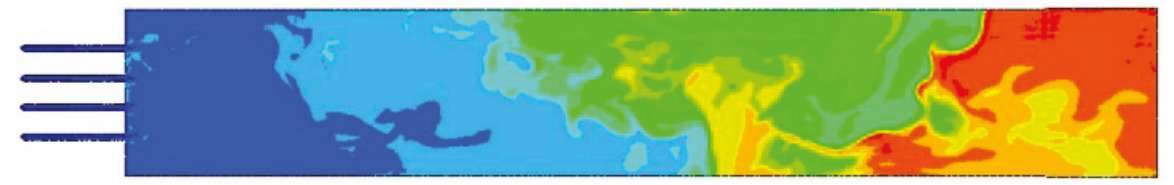

Flushing Time $(\mathrm{min})=10$

Flow $\longrightarrow$ 
Figure 39. Type 3 original lock chamber water concentration contours at $10 \mathrm{ft}$ from chamber floor.

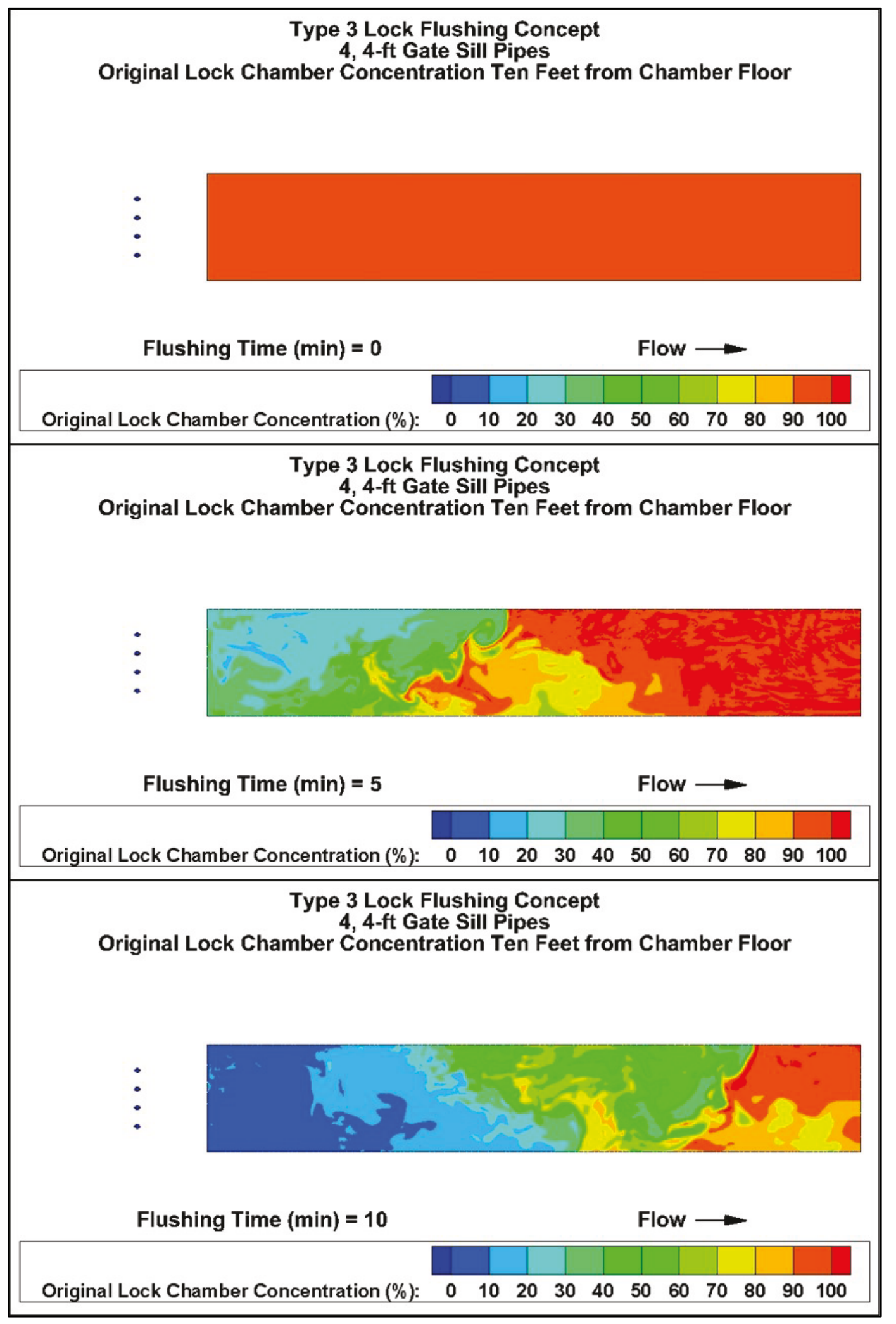


Figure 40. Type 3 original lock chamber water concentration contours at lock chamber surface.

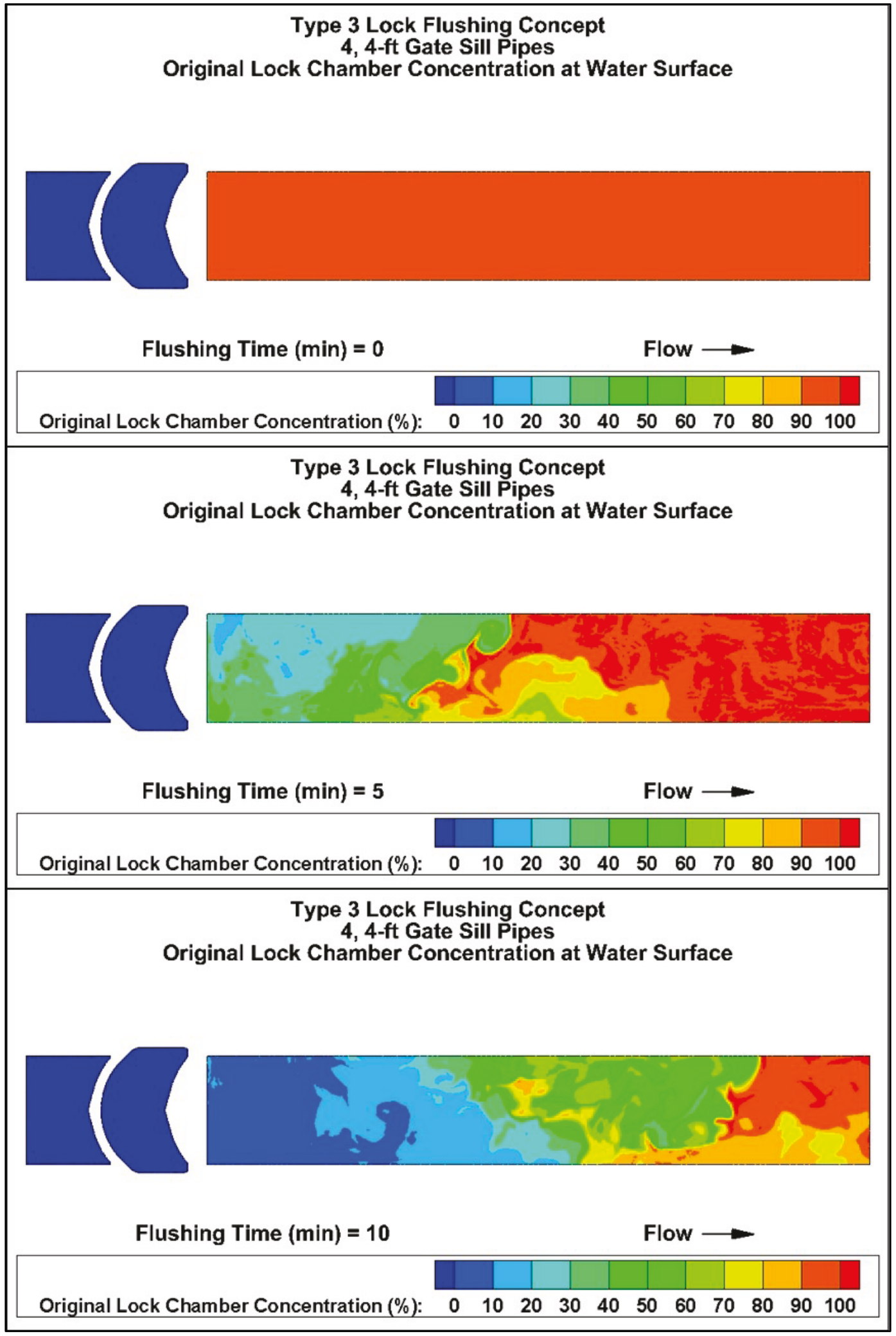


The flushing effectiveness and efficiency for Type 3 are shown in Figure 41 and Table 9. In the figure, the original lock water concentration is plotted against the flushing time. The different curves indicate how much of the lock chamber has been flushed to different levels of original lock chamber water concentration during a flushing operation with red indicating at most a $10 \%$ reduction in the original lock chamber concentration, green indicating at most a 50\% reduction, and dark blue indicating a $99.9 \%$ reduction (essentially portions of the chamber where the water has been completely replaced by flushing water).

The curves corresponding to at least $70 \%$ dilution show a slow volume change initially, a period of rapid volume change, and finally a return to a slow volume change as the curves approach $100 \%$ of the lock chamber. Essentially complete flushing ( $99.9 \%$ reduction) as indicated by the dark blue line farthest to the right in the figure is only achieved in over $1 \%$ of the lock chamber after 20 min of flushing. However, $90 \%$ reduction of the original lock chamber concentration has occurred in $44 \%$ of the lock chamber after 15 min of flushing (indicated by the dashed black line). Lock chamber volume percentages at 5 min increments of flushing are listed in Table 9. The values listed correspond to values that can be read directly from Figure 41, but the table values provide more precision in the percent volumes. 
Figure 41. Type 3 lock chamber flushing performance.

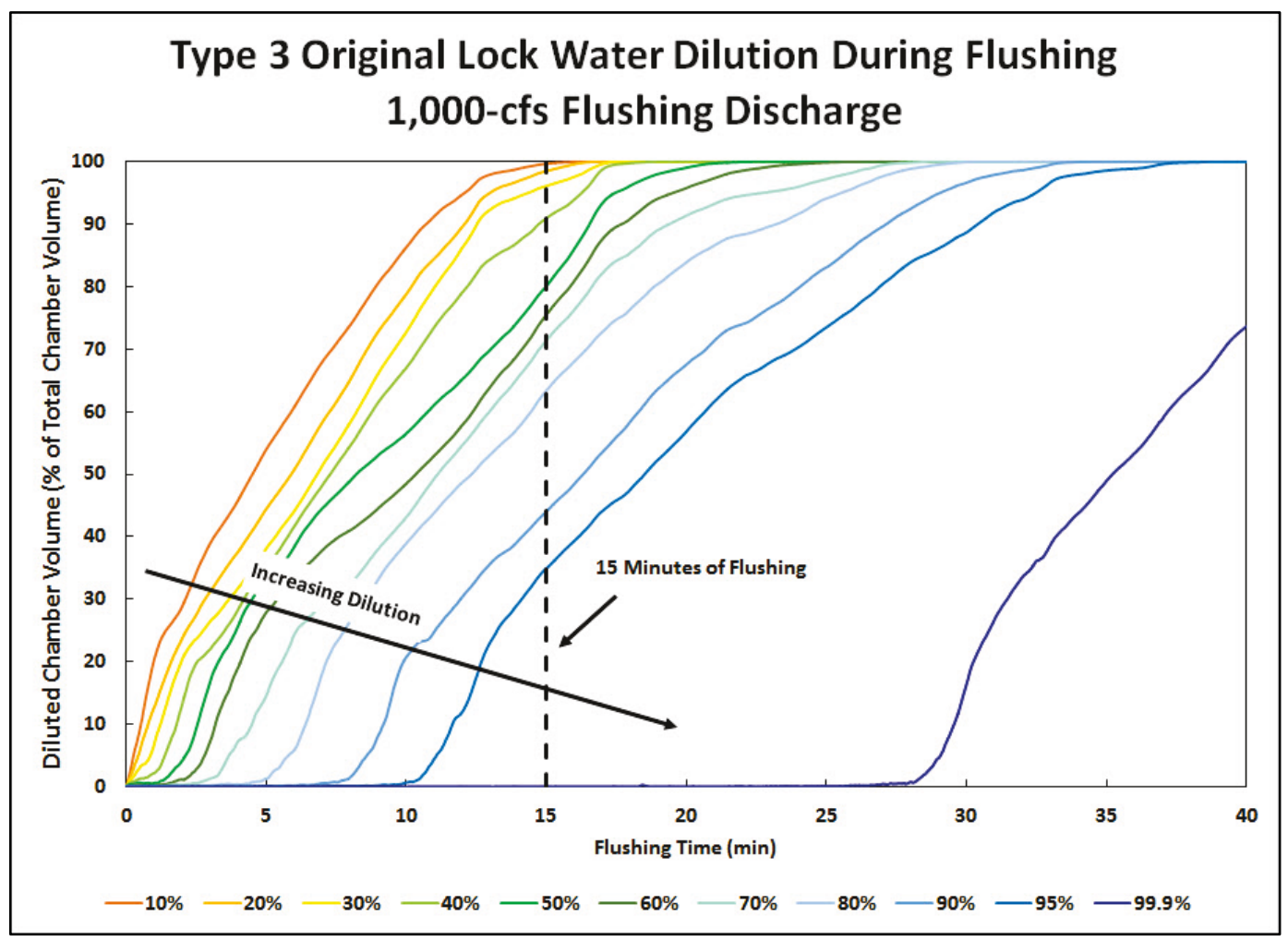

Table 9. Type 3 chamber flushing performance -5 min intervals.

\begin{tabular}{|c|c|c|c|c|c|c|c|c|c|}
\hline \multirow{2}{*}{\multicolumn{2}{|c|}{ Flushing Time (minute) }} & \multicolumn{8}{|c|}{ Flushed Chamber Volume (\% of total lock chamber volume) } \\
\hline & & 5 & 10 & 15 & 20 & 25 & 30 & 35 & 40 \\
\hline \multirow{10}{*}{ 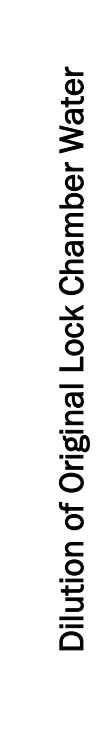 } & $99.9 \%$ & $<1$ & $<1$ & $<1$ & $<1$ & $<1$ & 16 & 49 & 74 \\
\hline & $90 \%$ & $<1$ & 21 & 44 & 68 & 83 & 97 & 100 & 100 \\
\hline & $80 \%$ & 1 & 39 & 63 & 84 & 94 & 100 & 100 & 100 \\
\hline & $70 \%$ & 15 & 43 & 71 & 91 & 97 & 100 & 100 & 100 \\
\hline & $60 \%$ & 28 & 48 & 75 & 96 & 100 & 100 & 100 & 100 \\
\hline & $50 \%$ & 33 & 56 & 80 & 99 & 100 & 100 & 100 & 100 \\
\hline & $40 \%$ & 35 & 67 & 91 & 100 & 100 & 100 & 100 & 100 \\
\hline & $30 \%$ & 38 & 73 & 96 & 100 & 100 & 100 & 100 & 100 \\
\hline & $20 \%$ & 44 & 79 & 98 & 100 & 100 & 100 & 100 & 100 \\
\hline & $10 \%$ & 54 & 86 & 100 & 100 & 100 & 100 & 100 & 100 \\
\hline
\end{tabular}




\subsection{Type 3r lock flushing concept}

The contour plots of the velocity magnitudes for the Type 3 r lock flushing concept are shown in Figure 42-Figure 44. In each figure, the velocity contours are shown at the beginning of flushing, at 5 min of flushing, and at 10 min of flushing. The flushing discharge is constant throughout the simulation. Flushing flow is introduced into the lock chamber at the upstream end via a rectangular slot through the gate sill. The jet that extends from the rectangular slot has a maximum velocity of approximately $15 \mathrm{ft} / \mathrm{sec}$. Viewing the contours closest to the chamber floor, the velocity magnitudes vary in both time and space in approximately the upstream half of the lock chamber. The flow velocity in the jet halfway down the lock chamber is approximately $7 \mathrm{ft} / \mathrm{sec}$. Farther downstream, the variation of velocity magnitude is much smaller, and the maximum flow velocities are approximately $4 \mathrm{ft} / \mathrm{sec}$. The contours $10 \mathrm{ft}$ from the chamber floor show that the velocity magnitudes are much smaller farther away from the rectangular slot but are still largely restricted to the upstream half of the lock chamber. At that elevation, the maximum velocity magnitude is approximately $7 \mathrm{ft} / \mathrm{sec}$ in the upstream half of the chamber and $4 \mathrm{ft} / \mathrm{sec}$ farther downstream. At the lock chamber surface, the velocity magnitudes vary more than near the center of the lock chamber water column. The jet issuing from the rectangular slot reaches the surface approximately halfway down the lock chamber creating $7 \mathrm{ft} / \mathrm{sec}$ flows at the surface.

Contour plots of the original lock chamber water concentration the Type $3 \mathrm{r}$ are shown in Figure 45-Figure 47. The purpose of these figures is to show how much the concentration in the lock chamber varies in both time and space in the lock chamber during a lock filling operation. At the beginning of flushing (flushing time $=0$ ), the entire lock chamber is orange/red indicating a uniform concentration of $100 \%$ of the original lock chamber water. During flushing, the contours in the lock chamber change from orange/red to green to blue. These changes show that the lock chamber flushing is reducing the concentration of original lock chamber water. Since flushing flow is introduced at the upstream end of the lock chamber, the original lock chamber water concentration is reduced first at the upstream end of the lock chamber. The original lock chamber water concentration is reduced throughout the lock chamber as the flushing flow moves toward the downstream miter gates. There is no strong vertical variation in the original lock chamber water concentration. After 15 min of lock flushing, the original lock chamber concentration at the upstream end of the lock chamber has already been reduced to approximately $10 \%$. 
Figure 42. Type $3 \mathrm{r}$ velocity magnitude contours $3 \mathrm{ft}$ from chamber floor.

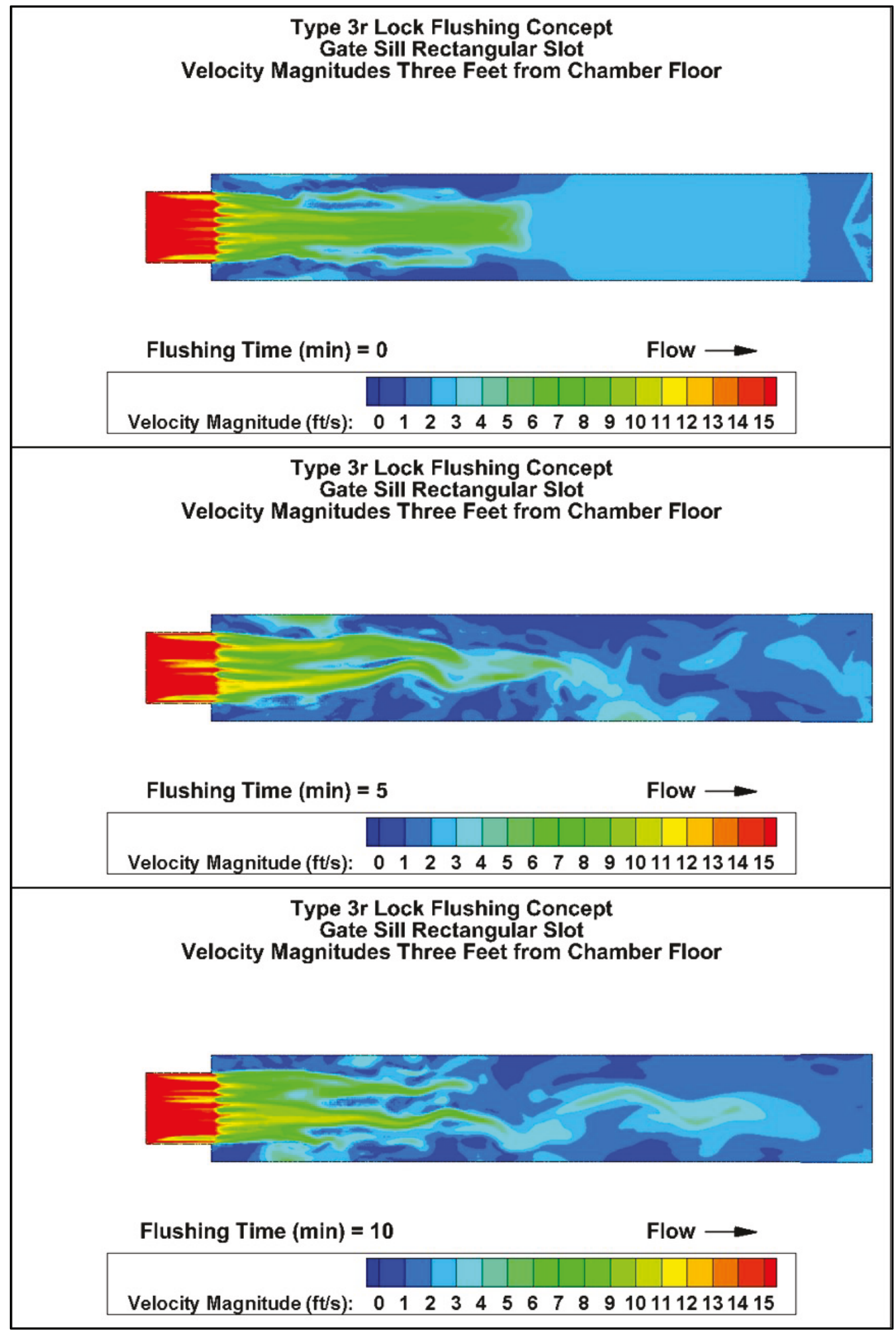


Figure 43. Type $3 r$ velocity magnitude contours $10 \mathrm{ft}$ from chamber floor.

Type 3r Lock Flushing Concept Gate Sill Rectangular Slot

Velocity Magnitudes Ten Feet from Chamber Floor

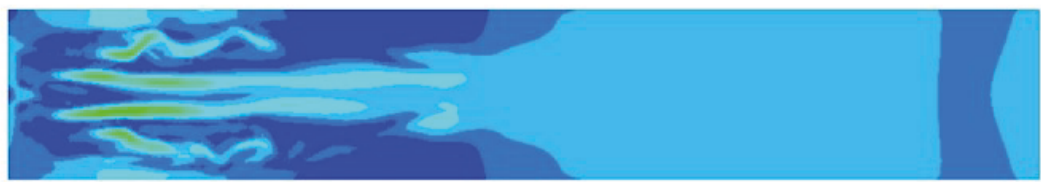

Flushing Time $(\min )=0$

Flow $\longrightarrow$

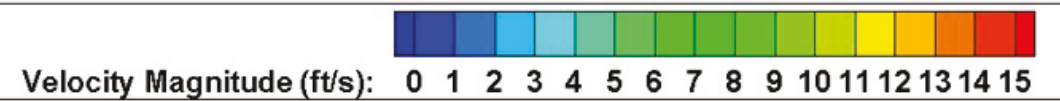

Type 3r Lock Flushing Concept

Gate Sill Rectangular Slot

Velocity Magnitudes Ten Feet from Chamber Floor

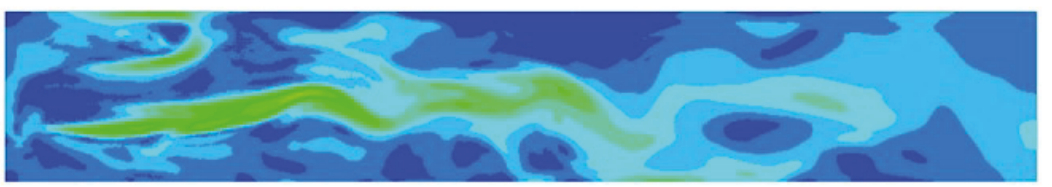

Flushing Time $(\min )=5$

Flow $\longrightarrow$

Velocity Magnitude (ft/s): $\begin{array}{lllllllllll}0 & 1 & 2 & 3 & 4 & 5 & 6 & 7 & 8 & 9 & 101112131415\end{array}$

\section{Type 3r Lock Flushing Concept}

Gate Sill Rectangular Slot

Velocity Magnitudes Ten Feet from Chamber Floor

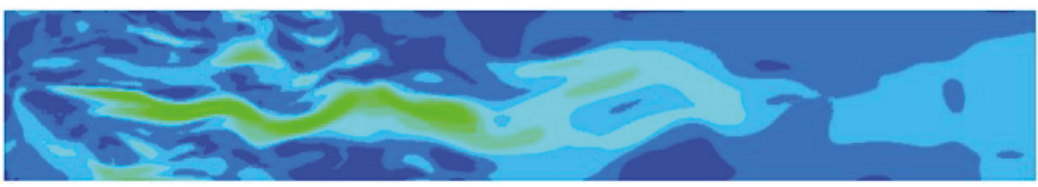

Flushing Time $(\min )=10$

Flow $\longrightarrow$

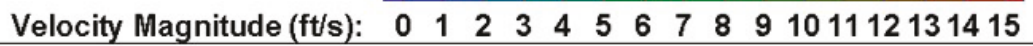


Figure 44. Type $3 r$ velocity magnitude contours at lock chamber surface.

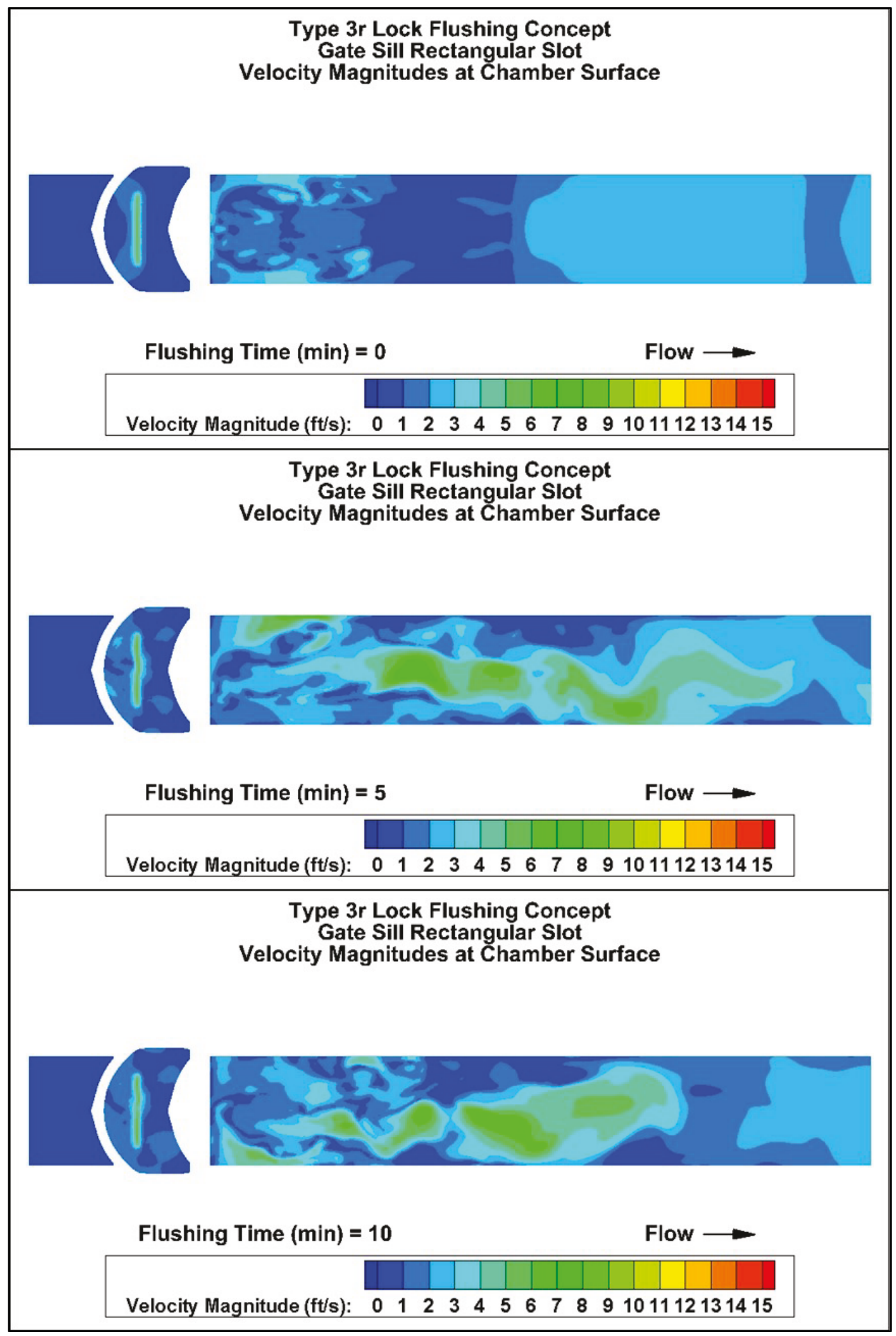


Figure 45. Type $3 \mathrm{r}$ original lock chamber water concentration contours $3 \mathrm{ft}$ from chamber floor.

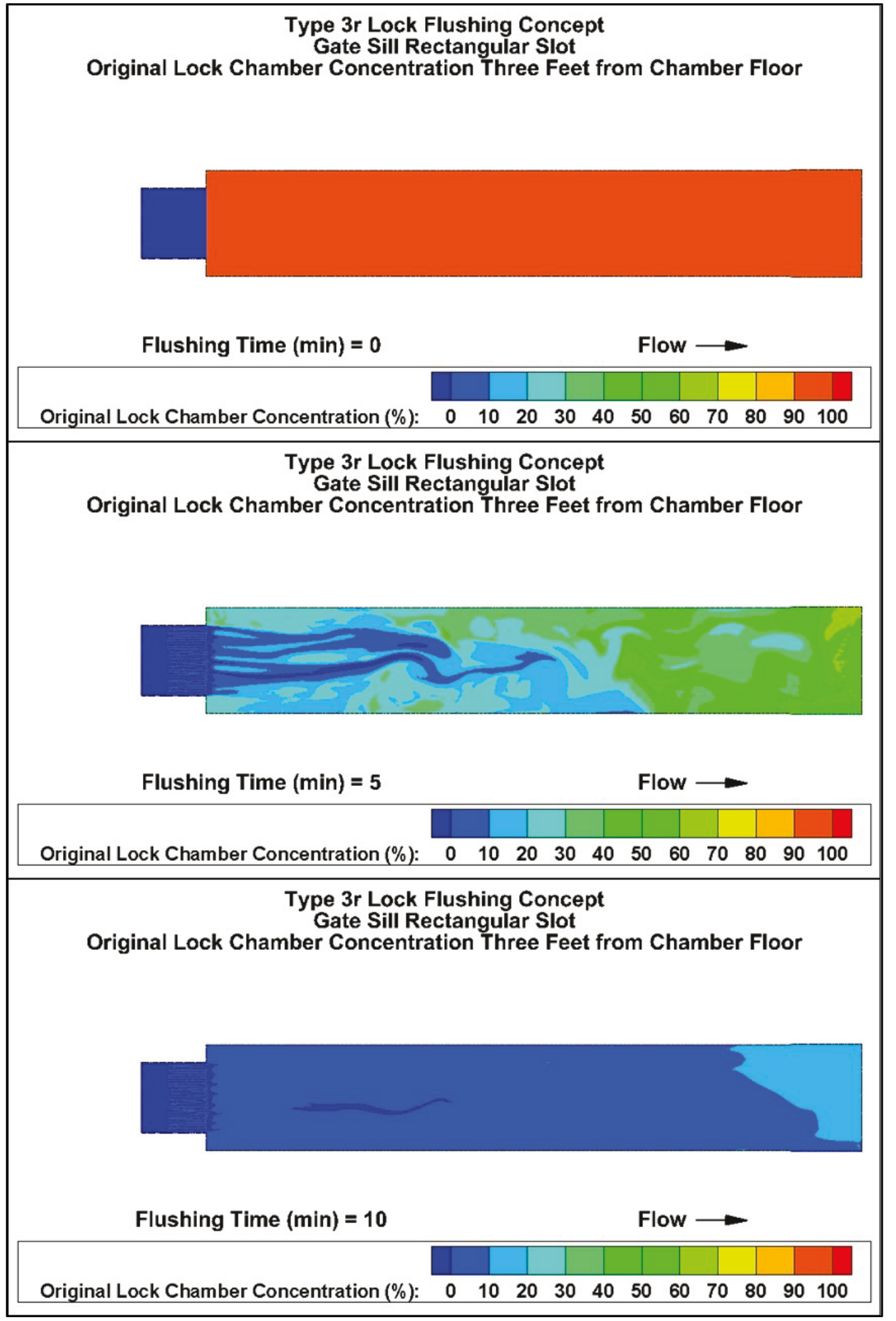


Figure 46. Type $3 r$ original lock chamber water concentration contours $10 \mathrm{ft}$ from chamber floor.

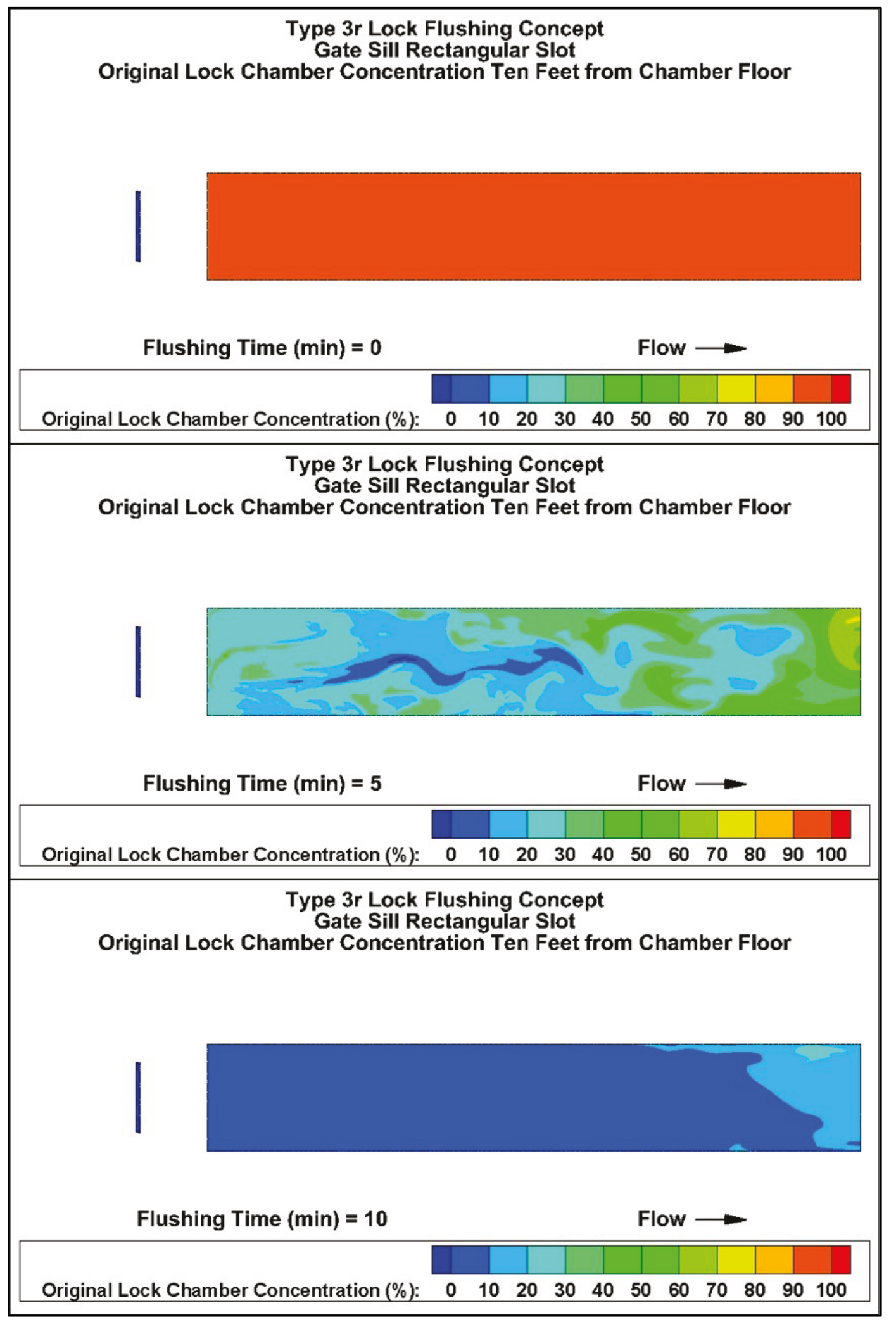


Figure 47. Type 3r original lock chamber water concentration contours at lock chamber surface.

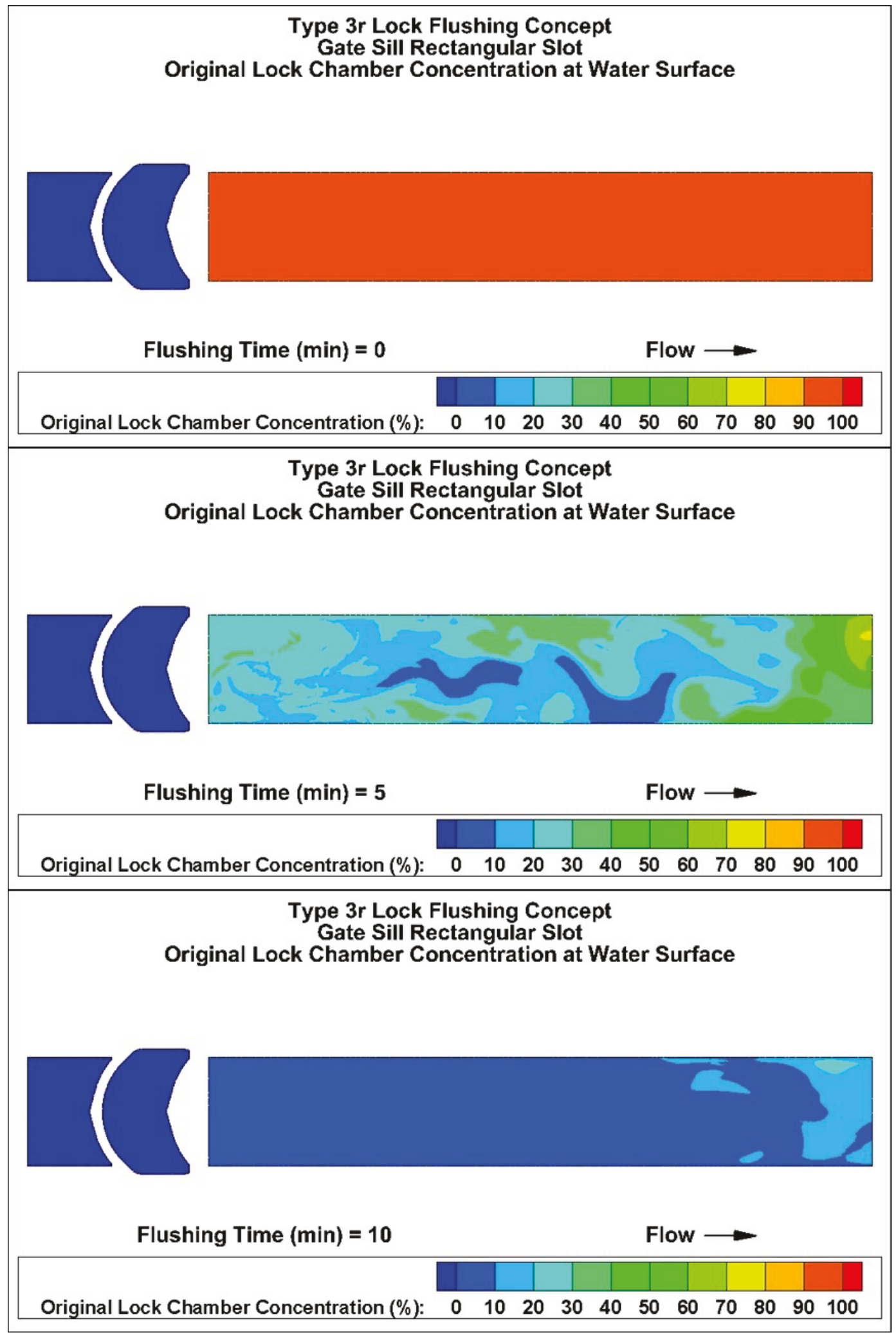


The flushing effectiveness and efficiency for Type $3 \mathrm{r}$ are shown in Figure 48 and Table 10. In the figure, the original lock water concentration is plotted against the flushing time. The different curves indicate how much of the lock chamber has been flushed to different levels of the original lock chamber water concentration during a flushing operation with red indicating at most a $10 \%$ reduction in the original lock chamber concentration, green indicating at most a 50\% reduction, and dark blue indicating a 99.9\% reduction (essentially portions of the chamber where the water has been completely replaced by flushing water).

The curves corresponding to at least $70 \%$ dilution show a slow volume change initially, a period of rapid volume change, and finally a return to a slow volume change as the curves approach $100 \%$ of the lock chamber. Essentially, complete flushing (99.9\% reduction) as indicated by the dark blue farthest to the right has only been achieved in approximately $4 \%$ of the lock chamber after 20 min of flushing, although nearly $80 \%$ of the lock chamber is flushed after $25 \mathrm{~min}$. A 95\% reduction of the concentration has occurred in the entire lock chamber after $15 \mathrm{~min}$ of flushing (indicated by the dashed black line). Lock chamber volume percentages at $5 \mathrm{~min}$ increments of flushing are shown in Table 10. The values listed correspond to values that can be read directly from Figure 48, but the table values provide more precision in the percent volumes.

Figure 48. Type 3r lock chamber flushing performance.

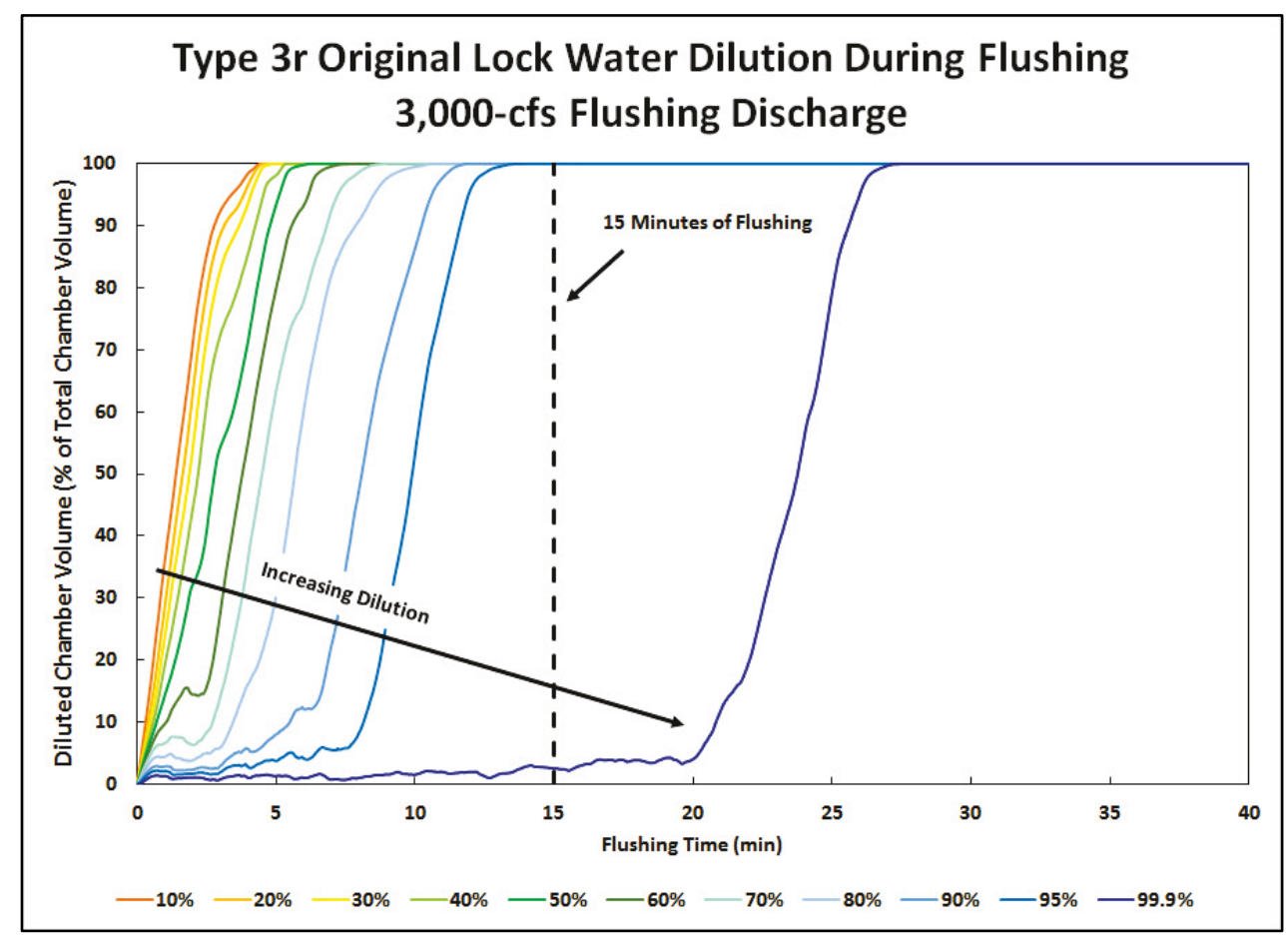


Table 10. Type $3 r$ chamber flushing performance -5 min intervals.

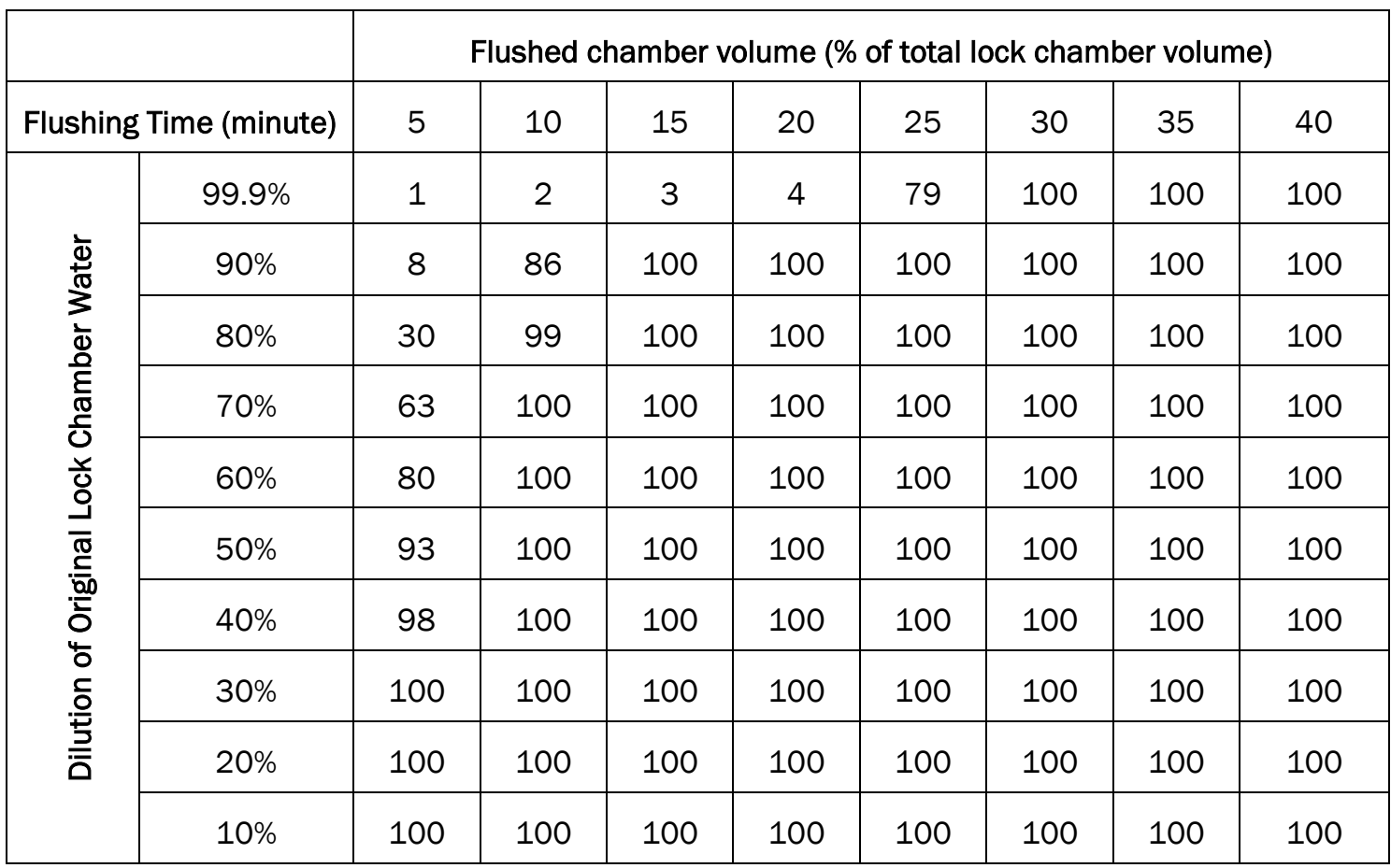

\subsection{Type 5 lock flushing concept}

The contour plots of the velocity magnitudes for the Type 5 lock flushing concept are shown in Figure 49-Figure 51. In each figure, the velocity contours are shown at the beginning of flushing, at 5 min of flushing, and at 10-min of flushing. The flushing discharge remains constant throughout the simulation. Flushing flow is introduced into the lock chamber at several locations via the filling and emptying ports. Viewing the contours closest to the chamber floor, the velocity magnitudes vary in both time and space. The jets that extend from each port have a maximum velocity of approximately $5 \mathrm{ft} / \mathrm{sec}$. Each jet extends approximately halfway across the lock chamber. The jets are directed more toward the downstream miter gates for the ports that are farthest downstream. The flow deflectors on the first four ports on each culvert drastically reduce the distance the corresponding jets extend toward the opposite lock chamber wall. The contours $10 \mathrm{ft}$ from the chamber floor show that the variation in velocity magnitudes is much smaller farther away from the ports. At that elevation, the maximum velocity magnitude is approximately $3 \mathrm{ft} / \mathrm{sec}$. At the lock chamber surface, the velocity magnitudes vary more than near the center of the lock chamber water column. The largest velocity magnitudes at the water surfaces are approximately $3 \mathrm{ft} / \mathrm{sec}$. The velocity magnitudes in the lock chamber for Type 5 are noticeably larger throughout the lock chamber than with Type 1. 
Contour plots of the original lock chamber water concentration for Type 5 are shown in Figure 52-Figure 54. The purpose of these figures is to show how much the concentration in the lock chamber varies in both time and space in the lock chamber during a lock filling operation. At the beginning of flushing (flushing time $=0$ ), the entire lock chamber is orange/red indicating a uniform concentration of $100 \%$ of the original lock chamber water. During flushing, the contours in the lock chamber change from orange/red to green to blue. These changes show that the lock chamber flushing is reducing the concentration of original lock chamber water during flushing. Since flushing flow is introduced at multiple locations in the lock chamber, the original lock chamber water concentration is reduced gradually throughout the lock chamber. At $3 \mathrm{ft}$ from the chamber floor, the effect of the ports is noticeable, and the reduction in chamber concentration varies dramatically in both time and space. Moving farther up the water column, the reduction in concentration is more gradual. Note that after 15 min of lock flushing, the concentration of original lock chamber water for each elevation is approximately $30 \%$ for the entire chamber. Upstream of the flushing port and upstream of the filling ports, the original lock chamber concentration is even higher. 
Figure 49. Type 5 velocity magnitude contours $3 \mathrm{ft}$ from chamber floor.

Type 5 Lock Flushing Concept

Redesigned Filling and Emptying System

Velocity Magnitudes Three Feet from Chamber Floor

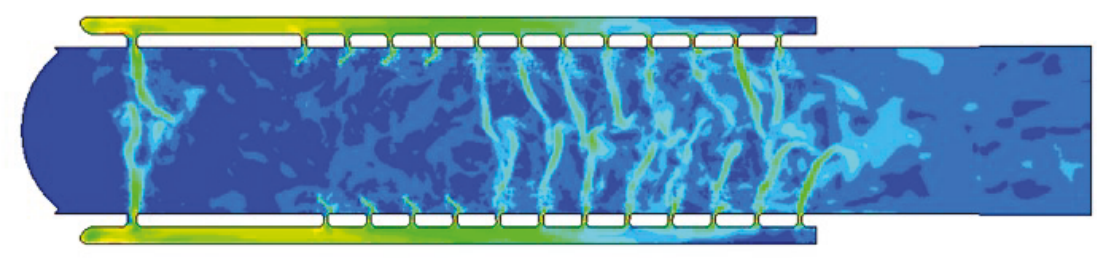

Flushing Time $(\min )=0$

Flow $\longrightarrow$

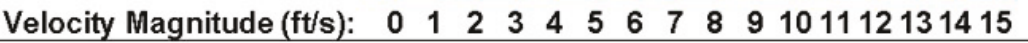

Type 5 Lock Flushing Concept

Redesigned Filling and Emptying System Velocity Magnitudes Three Feet from Chamber Floor

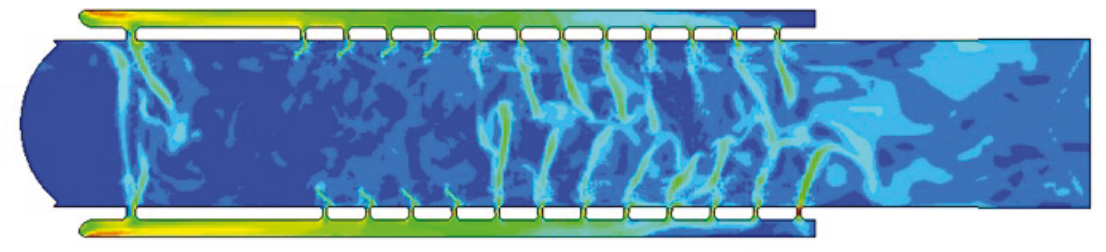

Flushing Time $(\min )=5$

Flow $\longrightarrow$

Velocity Magnitude (ft/s): $\quad \begin{array}{lllllllllll}0 & 1 & 2 & 3 & 4 & 5 & 6 & 7 & 8 & 9 & 1011121314\end{array}$

Type 5 Lock Flushing Concept

Redesigned Filling and Emptying System

Velocity Magnitudes Three Feet from Chamber Floor

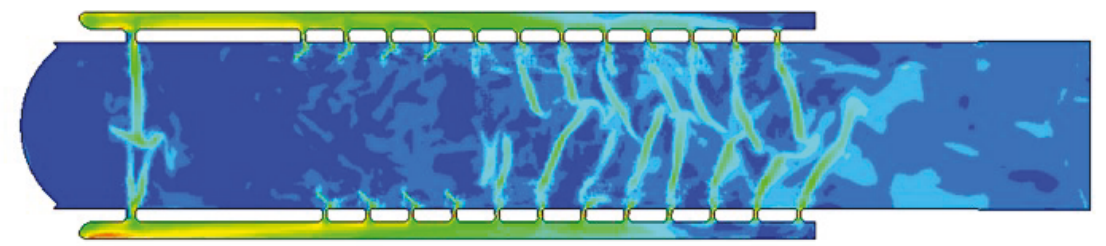

Flushing Time $(\mathrm{min})=10$

Flow $\longrightarrow$

Velocity Magnitude (ft/s): $\quad \begin{array}{lllllllllll}0 & 1 & 2 & 3 & 4 & 5 & 6 & 7 & 8 & 9 & 1011121314\end{array}$ 
Figure 50. Type 5 velocity magnitude contours $10 \mathrm{ft}$ from chamber floor.

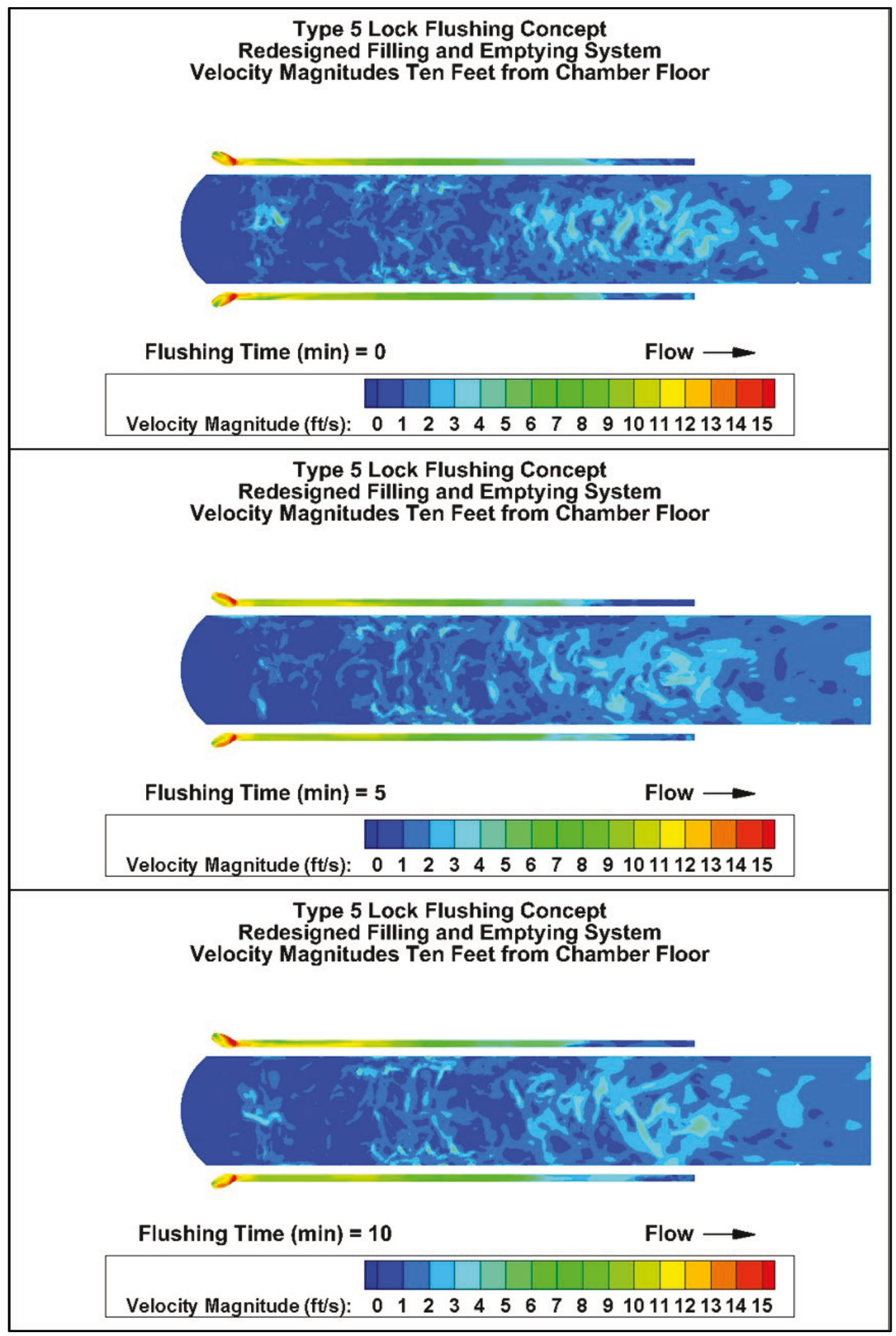


Figure 51 . Type 5 velocity magnitude contours at lock chamber surface.

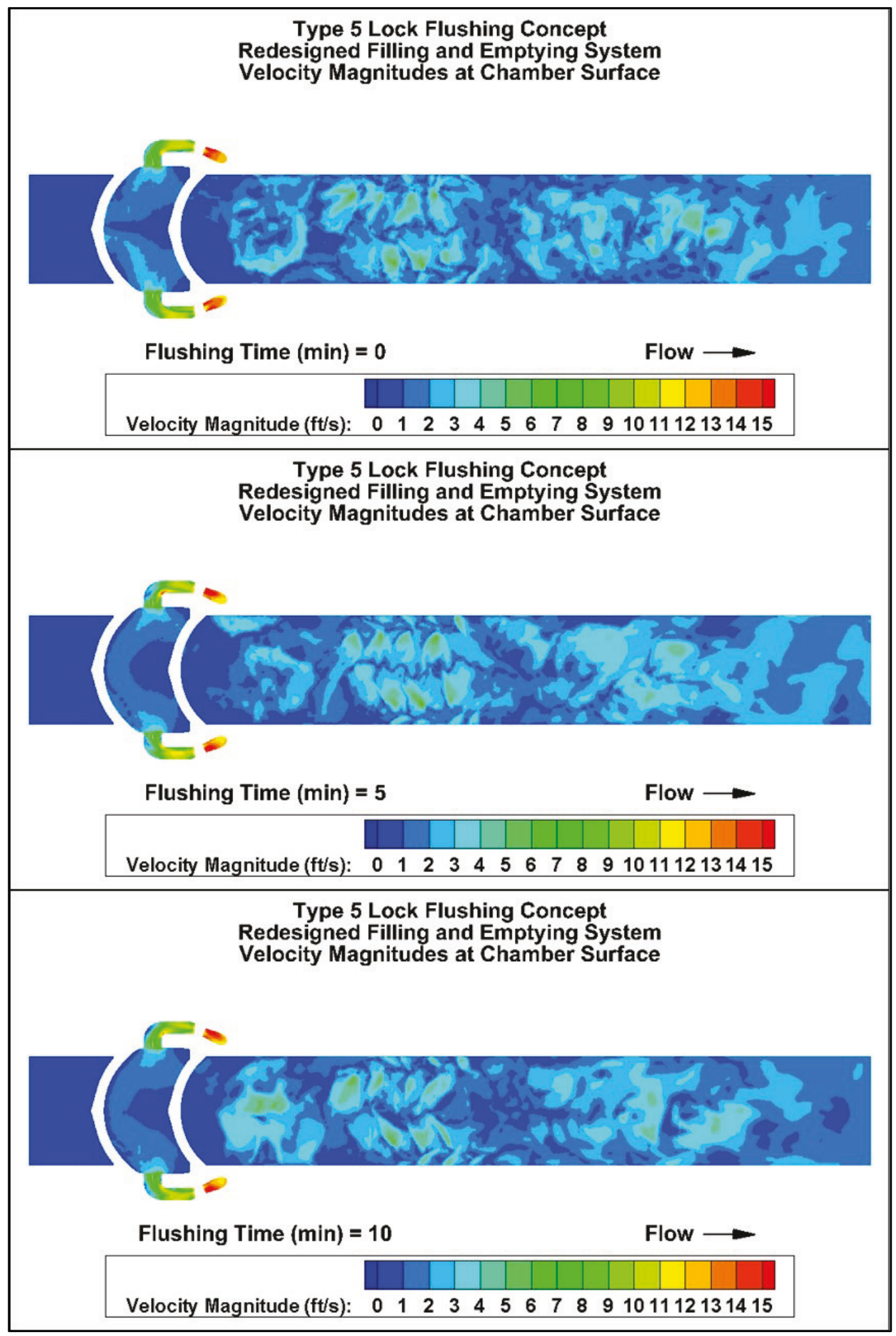


Figure 52. Type 5 original lock chamber water concentration contours $3 \mathrm{ft}$ from chamber floor.

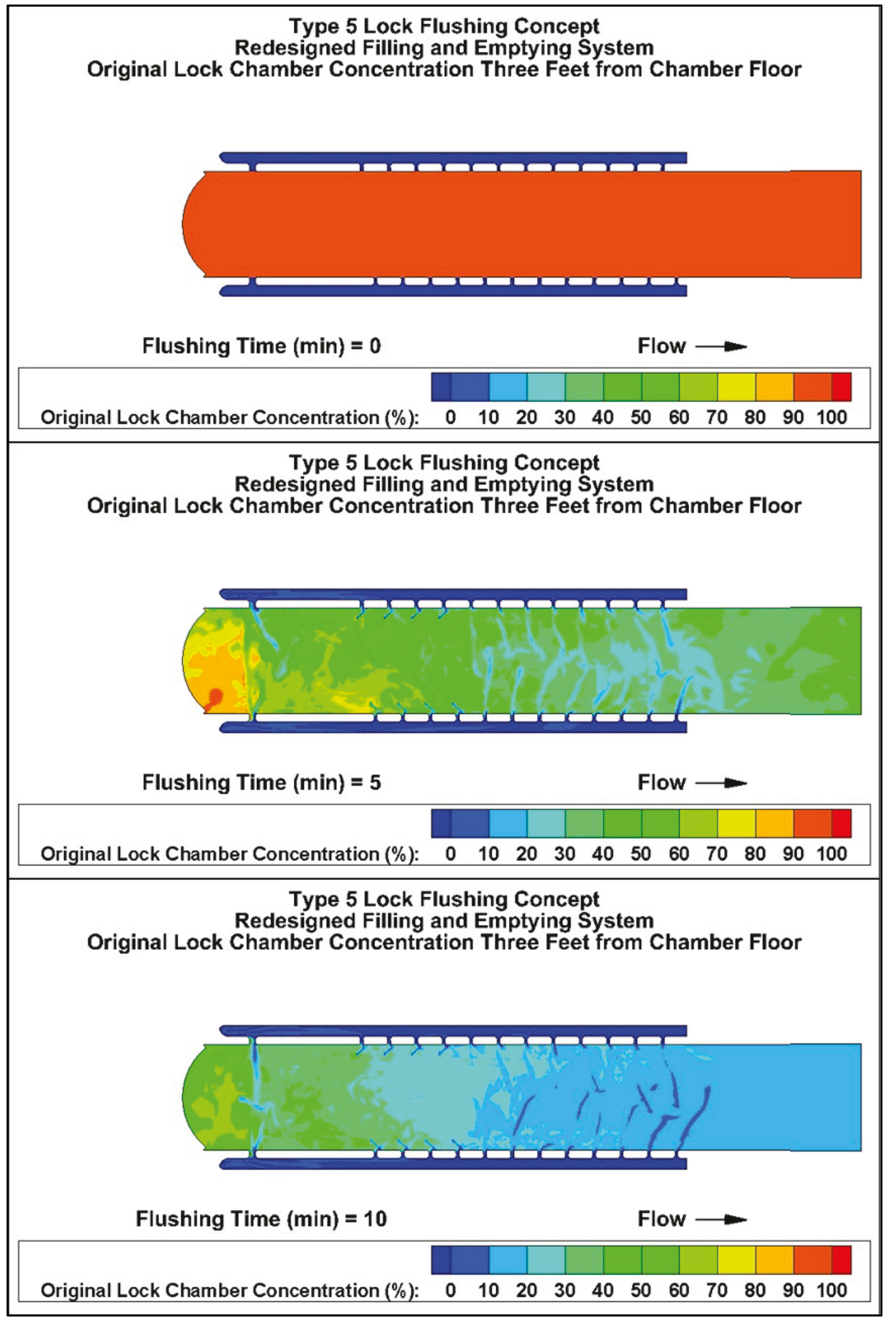


Figure 53. Type 5 original lock chamber water concentration contours $10 \mathrm{ft}$ from chamber floor.

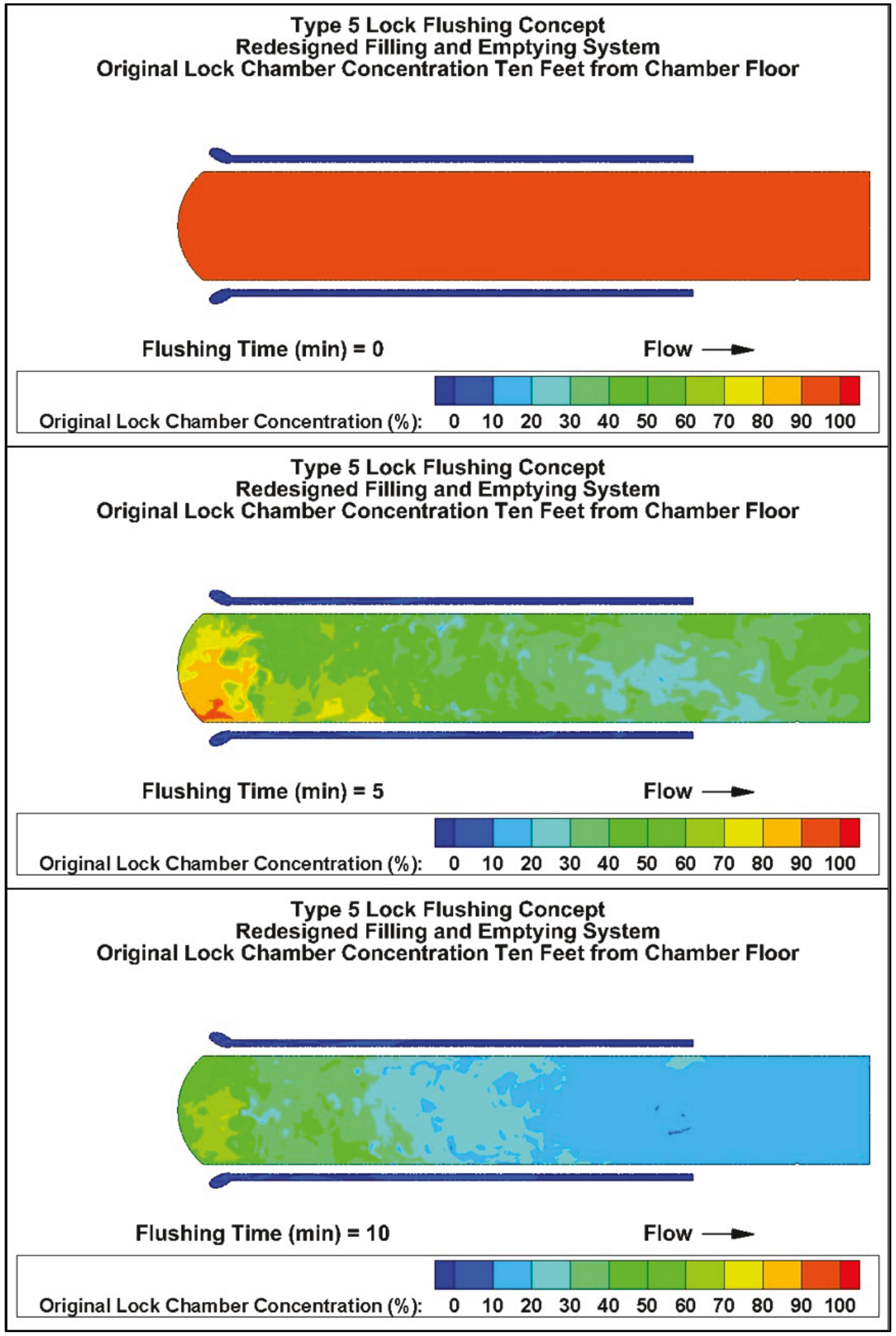


Figure 54. Type 5 original lock chamber water concentration contours at lock chamber surface.

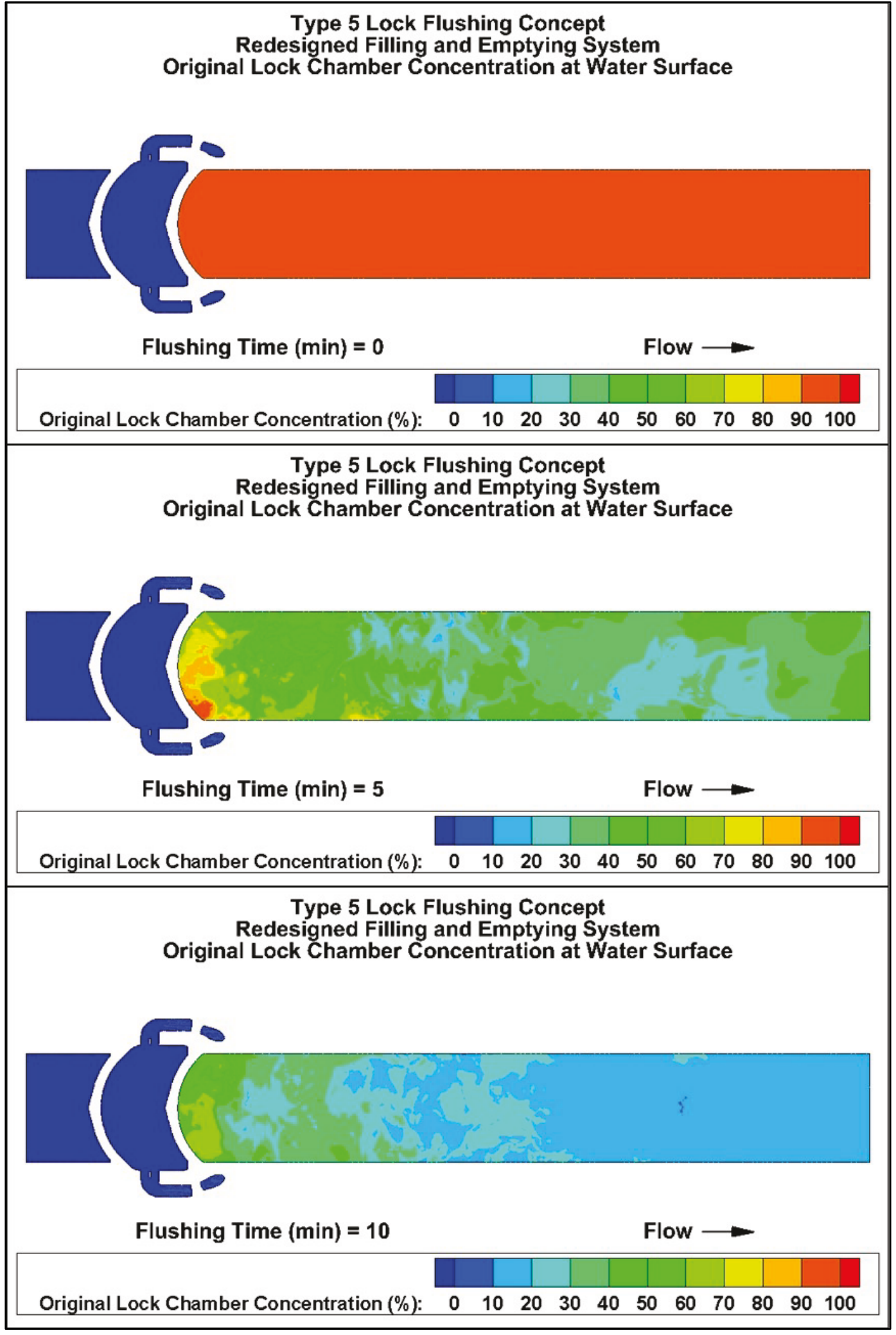


The flushing effectiveness and efficiency for Type 5 are shown in Figure 55 and Table 11. In the figure, the original lock water concentration is plotted against the flushing time. The different curves indicate how much of the lock chamber has been flushed to different levels of the original lock chamber water concentration during a flushing operation with red indicating at most a $10 \%$ reduction in the original lock chamber concentration, green indicating at most a 50\% reduction, and dark blue indicating a 99.9\% reduction (essentially portions of the chamber where the water has been completely replaced by flushing water).

The curves corresponding to at least a reduction of $50 \%$ of the original lock chamber concentration show a slow volume increase initially, a period of rapid volume increase, and finally a return to a slow volume increase as the curves approach $100 \%$ of the lock chamber. This improvement in efficiency is indicated in the concentration volume solution (Figure 52 through Figure 54) lying farther to the left and above the analogous curves for Type 1 (Figure 34). The desired amount of flushing (99.9\% reduction) as indicated by the dark blue line that is essentially on top of the horizontal axis is not attained even in 40 min of flushing. After 15 min (indicated by the dashed black line) $90 \%$ reduction of the flow has only occurred in $45 \%$ of the lock chamber. Lock chamber volume percentages at $5 \mathrm{~min}$ increments of flushing are shown in Table 11. The values listed correspond to values that can be read directly from Figure 55, but the table values provide more precision in the percent volumes. 
Figure 55. Type 5 lock chamber flushing performance.

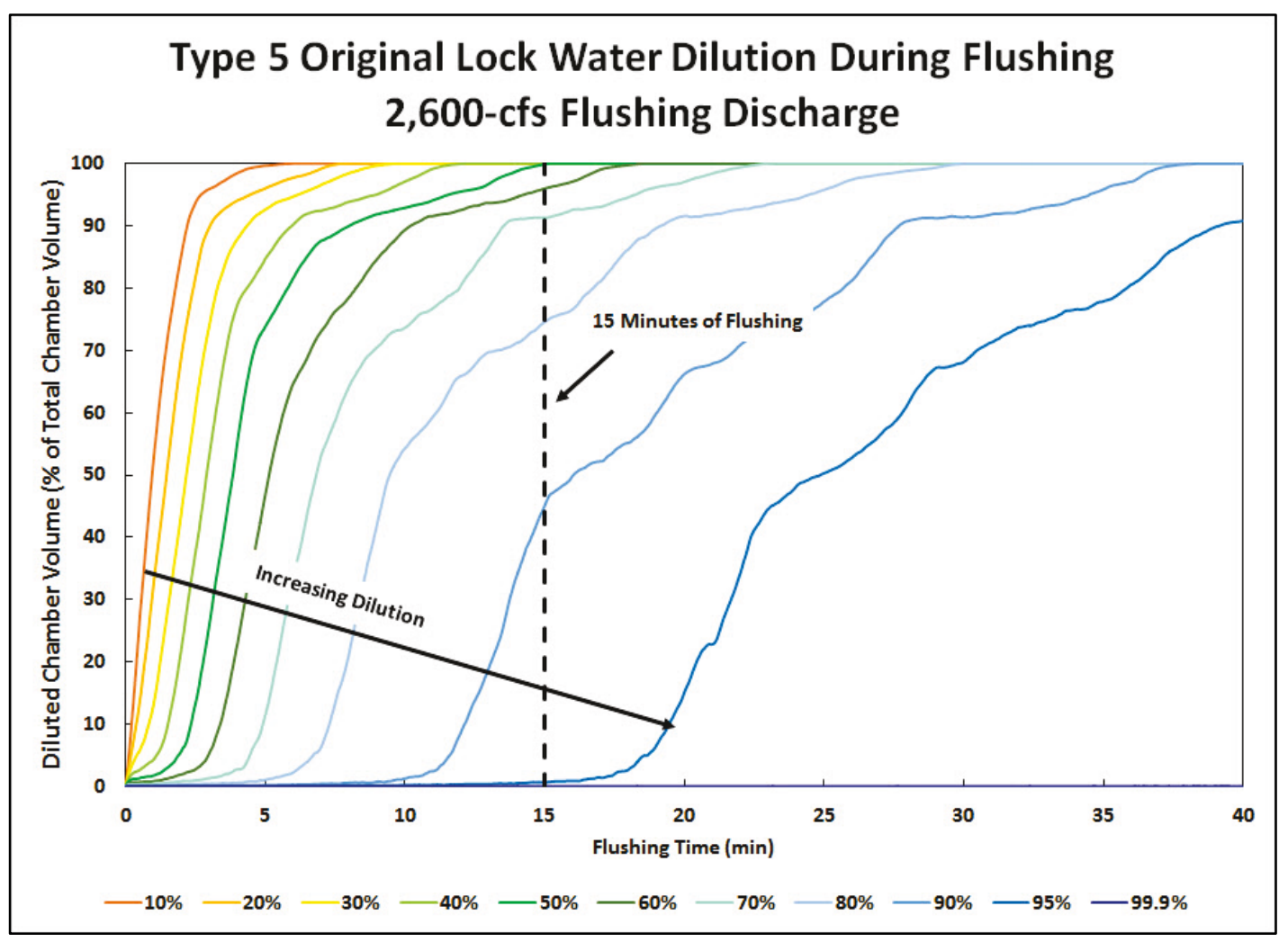

Table 11. Type 5 chamber flushing performance -5 min intervals.

\begin{tabular}{|c|c|c|c|c|c|c|c|c|c|}
\hline & & \multicolumn{8}{|c|}{ Flushed Chamber Volume (\% of total lock chamber volume) } \\
\hline \multicolumn{2}{|c|}{ Flushing Time (min) } & 5 & 10 & 15 & 20 & 25 & 30 & 35 & 40 \\
\hline \multirow{10}{*}{ 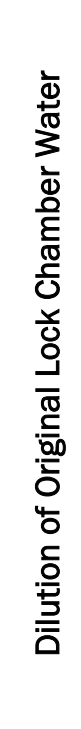 } & $99.9 \%$ & $<1$ & $<1$ & $<1$ & $<1$ & $<1$ & $<1$ & $<1$ & $<1$ \\
\hline & $90 \%$ & $<1$ & 1 & 45 & 66 & 78 & 91 & 96 & 100 \\
\hline & $80 \%$ & 1 & 54 & 75 & 92 & 96 & 100 & 100 & 100 \\
\hline & $70 \%$ & 12 & 74 & 91 & 97 & 100 & 100 & 100 & 100 \\
\hline & $60 \%$ & 47 & 89 & 96 & 100 & 100 & 100 & 100 & 100 \\
\hline & $50 \%$ & 74 & 93 & 100 & 100 & 100 & 100 & 100 & 100 \\
\hline & $40 \%$ & 85 & 97 & 100 & 100 & 100 & 100 & 100 & 100 \\
\hline & $30 \%$ & 93 & 100 & 100 & 100 & 100 & 100 & 100 & 100 \\
\hline & $20 \%$ & 96 & 100 & 100 & 100 & 100 & 100 & 100 & 100 \\
\hline & $10 \%$ & 100 & 100 & 100 & 100 & 100 & 100 & 100 & 100 \\
\hline
\end{tabular}




\subsection{Lock flushing numerical model results summary}

The numerical models provide information that can be used to make some direct comparisons of the relative performance of the lock flushing concepts. Two graphical representations of the performance of each flushing concept are shown: contour plots showing the spatial variation concentration during a flushing operation and lock chamber flushing performance scatter plots (Figure 28 through Figure 55).

The contour plots of concentration show how each type of system introduces water into the chamber. The convection-dominated systems gradually reduce concentration throughout the lock chamber during a flushing operation. However, the advection-dominated systems reduce the concentration of the upstream end of the lock chamber (where the flushing flow enters the chamber) and pushes the original lock chamber water downstream and out of the chamber. The contour plots also give a qualitative indication of how well each system flushes the lock chamber.

The lock chamber flushing performance plots provide a more macroscopic perspective of the lock chamber performance throughout a flushing operation. Viewed separately, the lock chamber flushing performance plots (Figure 34, Figure 41, Figure 48, and Figure 48Figure 55) indicate how effectively and how efficiently each flushing concept performs. For each plot, a shift in any curve to the left ( $x$-axis, higher flushing efficiency) and upward ( $y$-axis, larger portion of the lock chamber) indicates better lock flushing performance. Viewed together, those plots show which flushing concepts provide the most feasible option for flushing the lock chamber of ANS. Another insight from the lock flushing performance plots is whether a convection-dominated system (like Type 1 or Type 5) or an advection-dominated system (like Type 3 or Type 3r) would flush the lock chamber most effectively and efficiently.

The Type 1 performance results (Figure 34) show how well the Brandon Road Lock can be flushed with the existing F/E system. These results can be used to determine if using the existing structure sufficiently satisfies the goal of the lock flushing portion of GLMRIS. These results also serve as the point of comparison for any lock flushing concept that requires a change to Brandon Road Lock. The Type 1 concept does not fully flush the lock chamber (at least $99.9 \%$ concentration reduction) in 40 min of flushing. 
The Type 5 performance results (Figure 41) show that the Type 5 lock flushing concept does perform significantly more effectively and efficiently than Type 1. The improved performance is largely due to the increase in the flushing discharge allowed by the resizing and new placement of the $\mathrm{F} / \mathrm{E}$ ports. While the performance of the Type 5 concept is significantly better than the Type 1, the Type 5 still does not fully flush the lock chamber (at least $99.9 \%$ concentration reduction) in 40 min of flushing. Implementing the Type 5 concept would also yield a significantly shorter lock chamber filling and emptying time. This expectation is taken from the filling and emptying times of locks that are designed according to the current USACE guidelines (HQUSACE 2006).

The Type 3 performance results show that the advection-dominated concepts perform differently than the convection-dominated concepts. Beginning after approximately $11 \mathrm{~min}$ of lock flushing, the original concentration in the lock chamber is reduced by $95 \%$ in more than $5 \%$ of the lock chamber. For Types 1 and 5, 95\% reduction is not achieved in 5\% of the lock chamber until after approximately $32 \mathrm{~min}$ and $17 \mathrm{~min}$, respectively. Another important aspect of the Type 3 performance is that noticeable portions of the lock chamber are fully flushed after approximately $27 \mathrm{~min}$ of flushing. Note that the flushing discharge that produces the improved flushing performance for Type 3 requires a lower flushing discharge (1,000 cubic feet per second [cfs]) than both Types 1 and 5 (1,350 cfs and 2,600 cfs, respectively).

The Type $3 \mathrm{r}$ indicate how well an advection-dominated flushing system could work if the maximum allowable discharge could be introduced in a way that did not produce excessively high velocities that would cause severe variations in the lock-chamber water surface. Over $5 \%$ of the lock chamber would reach at least $95 \%$ original concentration reduction after 7 min of flushing. Also, noticeable portions of the lock chamber are fully flushed after approximately 20 min of flushing, and $100 \%$ of the lock chamber is fully flushed after approximately $27 \mathrm{~min}$ of flushing. The Type $3 \mathrm{r}$ configuration is not feasible because the slot (as presented in Figure 23) will not fit through the upstream gate sill because of another (mechanical) components of the lock in the area. The Type $3 \mathrm{r}$ models were produced as an indication of flushing performance of the advection-dominated case when only the system hydraulics were considered. 


\section{Physical Model Considerations}

A complete evaluation of the structural and hydraulic modifications of Brandon Road Lock cannot be performed using solely a numerical model. Further, current USACE policy does not allow construction of a modification to a navigation lock that is outside of current design guidance without a physical model study that investigates the ramifications of the design changes - particularly to safety related to vessels that would traverse the lock. Therefore, the construction of a physical model of the Brandon Road Lock with its existing F/E system and at least one of the lock flushing concepts has been proposed to follow the numerical modeling efforts. This physical model would provide the necessary information on the hydraulic performance of the lock related to vessels (hawser forces) and navigation safety that is required before any modifications could be made to Brandon Road Lock. This chapter outlines the considerations for designing the physical model and how to use the information gained from the physical model study to inform the GLMRIS team on how Brandon Road Lock would perform if one of the lock flushing concepts is implemented.

The primary similitude consideration in hydraulic modeling of navigation locks is that the scale is large enough to reduce the scale effects to an understandable level. A 1:25-scale model is the current practice for evaluating the performance of a lock chamber (HQUSACE 2006).

\subsection{Kinematic similitude}

Kinematic similarity is an appropriate method of modeling free-surface flows in which the viscous stresses are negligible. Kinematic similitude requires that the ratios of the inertial forces $\left(\rho V^{2} L^{2}\right)$ to the gravitational forces $\left(\rho g L^{3}\right)$ in the model are equal to those of the prototype. Here, $\rho=$ fluid density, $V=$ fluid velocity, $L=$ a characteristic length, and $g=$ acceleration due to gravity. This ratio is generally expressed as the Froude number, Fr.

$$
F r=\frac{V}{\sqrt{g L}}
$$

Here, $L$, the characteristic length, is usually taken as the flow depth in open-channel flow. 
The Froude number can be viewed in terms of the flow characteristics. Because a surface disturbance travels at the celerity of a gravity wave, $\sqrt{g h}$ where $h=$ flow depth, the Froude number describes the ratio of advection speed to the gravity wave celerity. Evaluation of the lock chamber performance generally focuses on modeling the hawser forces on moored barges during filling and emptying operations. During normal locking operations, the skin friction drag on the vessel is insignificant because horizontal fluid velocities are small. Hawser forces are generated primarily by slopes of the lock chamber water surface. The tow's bow-tostern water-surface differentials are the result of long period seiches in the lock chamber. Seiching is the process of gravity waves traveling in the longitudinal direction from the upper service gates to the lower service gates. Therefore, equating Froude numbers in the model and prototype is an appropriate means of modeling the lock chamber to ensure that the model measurements accurately describe (and can be scaled up to) the behavior of the prototype.

\subsection{Dynamic similitude}

Physical models are often used to model forces. Appropriate scaling of viscous forces requires the model be dynamically similar to the prototype. Dynamic similarity is accomplished when the ratios of the inertia forces to viscous forces $(\rho v V L)$ of the model and the prototype are equal. Here, $v$ is the kinematic viscosity of the fluid. This ratio of inertia to viscous forces is usually expressed as the Reynolds number

$$
R e=\frac{V L}{v}
$$

and in pressure flow analysis, the culvert hydraulic diam is usually chosen as the characteristic length, $L$. The Reynolds number quantifies the flow's viscous forces relative to advection forces. As the Reynolds number increases, the flow is less affected by viscous shear (friction). ${ }^{1}$

\subsection{Similitude for lock models}

Modeling lock filling and emptying systems is not entirely quantitative. The system is composed of pressure flow conduits and open-channel flow components. Further complicating matters, the flow is unsteady.

${ }^{1}$ See Section 8.3 for further information on why reducing the effect of shear in a scaled model of a navigation model is important. 
Discharges (therefore $R e$ and $F r$ ) vary from no flow at the beginning of an operation to peak flows within a few minutes and return to no flow at the end of the cycle. Current physical model studies of lock designs employ 1:25-scale Froudian models in which the viscous differences (between the model and the prototype) are small and can be estimated based on previously reported model-to-prototype comparisons. Setting the model and prototype Froude numbers equal yields the relations between the dimensions and hydraulic quantities shown in Table 12, assuming a 1:25 length scale relationship.

Table 12. Model-prototype scale relations.

\begin{tabular}{|l|c|c|}
\hline \multicolumn{1}{|c|}{ Characteristic } & Dimension & $\begin{array}{c}\text { Scale Relation } \\
\text { Model:Prototype }\end{array}$ \\
\hline Length & $\mathrm{L}_{r}=\mathrm{L}_{r}$ & $1: 25$ \\
\hline Pressure & $\mathrm{P}_{r}=\mathrm{L}_{r}$ & $1: 25$ \\
\hline Area & $\mathrm{A}_{r}=\mathrm{Lr}^{2}$ & $1: 625$ \\
\hline Velocity & $\mathrm{V}_{r}=\mathrm{Lr}_{r}^{1 / 2}$ & $1: 5$ \\
\hline Discharge & $\mathrm{Q}_{r}=\mathrm{L}_{r}{ }^{5 / 2}$ & $1: 3,125$ \\
\hline Time & $\mathrm{Tr}_{r}=\mathrm{Lr}_{r}{ }^{1 / 2}$ & $1: 5$ \\
\hline Force & $\mathrm{F}_{r}=\mathrm{Lr}^{3}$ & $1: 15,625$ \\
\hline Reynolds number & $\mathrm{Re}_{r}=\mathrm{Lr}^{3 / 2}$ & $1: 125$ \\
\hline
\end{tabular}

These relations are used to transfer model data to prototype equivalents and vice versa.

Complete similitude in a physical model is attained when geometric, kinematic, and dynamic similitudes are satisfied. Physical models of hydraulic structures with both internal flow (pressure flow) and external flow (free-surface flow) typically are scaled using kinematic (Froudian) similitude at a large enough scale that the viscous effects in the scaled model can be neglected.

Boundary friction losses in lock culverts are empirically described using the smooth-pipe curve of the Darcy-Weisbach friction factor where the head loss is expressed as

$$
H_{f}=f \frac{L}{D} \frac{V^{2}}{2 g}
$$


where:

$$
\begin{aligned}
H_{f} & =\text { head loss due to boundary friction } \\
f & =\text { Darcy-Weisbach friction factor } \\
L & =\text { culvert length } \\
D & =\text { culvert diam. }
\end{aligned}
$$

The Darcy-Weisbach friction factor for turbulent flow in smooth pipes is given in an implicit form as (Vennard and Street 1982)

$$
\frac{1}{\sqrt{f}}=2.0 \log (\operatorname{Re} \sqrt{f})-0.8
$$

The USACE has investigated more than 50 model and 10 prototype studies of lock filling and emptying systems (Pickett and Neilson 1988). The majority of these physical model studies were conducted at a scale of 1:25, although early studies sometimes used a 3:100 scale. Lock models constructed to a scale of 1:25 have maximum Reynolds numbers at peak discharges on the order of $10^{5}$ while the corresponding prototype values are on the order of 107. This difference is illustrated in results from physical model (Ables 1978) and field (McGee 1989) experiments on the Whitten (Bay Springs) Lock presented on the filling curves in Figure 56. Because the friction factor decreases with increasing Reynolds number, the model is hydraulically too rough as compared to the prototype. The scaled friction losses in the model will therefore be larger than those experienced by the prototype structure. Consequently, the scaled velocities (and discharges) in the model will be lower, and the scaled pressures within the culverts will be higher than those of the prototype. Lower discharges result in longer filling and emptying times in the model than the prototype. Prototype filling and emptying times for similar designs will be smaller than those measured in a 1:25-scale lock model. 
Figure 56. Whitten (Bay Springs) Lock filling curves.

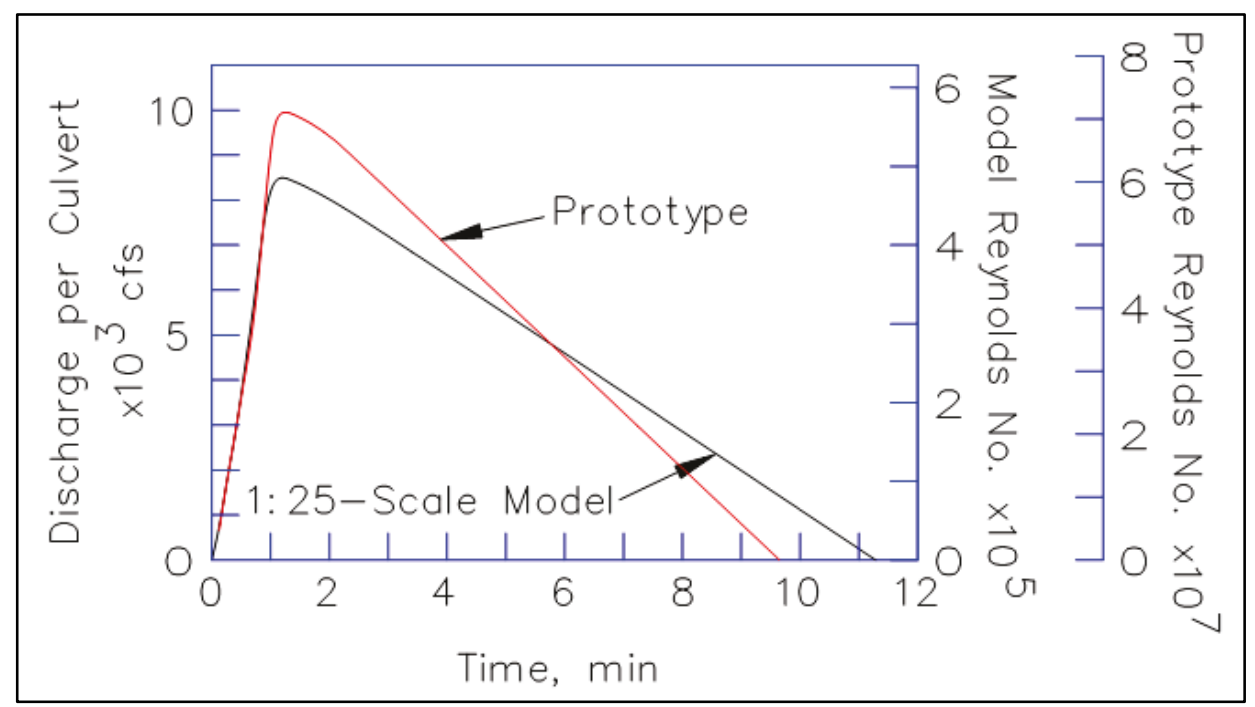

Boundary friction decreases with increasing Reynolds number. As mentioned previously, lock model velocities scaled using kinematic similitude (model Froude number equal to prototype Froude number) in a 1:25-scale model have maximum Reynolds numbers at peak discharges on the order of $10^{5}$, yet the corresponding prototype values are on the order of 107. Therefore, scaled friction losses in the model are larger than those experienced by the prototype structure. (The model is said to be hydraulically too rough.) Consequently, the scaled velocities (and discharges) in the model are smaller, and the scaled pressures within the culverts are higher than those of the prototype. Even in lock systems in which low pressures are not a particular concern, the lower discharges cause longer scaled filling and emptying times in the model than those experienced by the prototype.

Even though a prototype lock filling-and-emptying system is normally more efficient than predicted by its hydraulic model, EM 1110-2-1604 (HQUSACE 2006) states that the difference in efficiency is acceptable as far as most of the modeled quantities are concerned (hawser forces, for example) and can be accommodated empirically for others (filling time and overtravel, specifically).

\subsection{Model-prototype comparison}

Direct component-to-component comparison of differences in model and prototype performance is difficult due to the lack of accurate data of the turbulent, unsteady flow. However, comparison of the overall lock 
coefficient, $C_{L}$, for model and prototype structures provides a dimensionless parameter that describes the hydraulic efficiency integrated over the flow cycle of locking operations. The nondimensional term is also convenient because rarely do data exist for the same pools in model and prototype. The lock coefficient is defined by the relation commonly referred to as the Pillsbury equation (Pillsbury 1915):

$$
T-k_{v} t_{v}=\frac{2 A_{L}}{\sqrt{2 g} C_{L} A_{c}}(\sqrt{H+d}-\sqrt{d})
$$

or

$$
C_{L}=\frac{2 A_{L}}{\sqrt{2 g} A_{c}\left(T-k_{v} t_{v}\right)}(\sqrt{H+d}-\sqrt{d})
$$

where:

$$
\begin{aligned}
C_{L}= & \text { overall lock coefficient } \\
A_{L}= & \text { plan area of the lock chamber } \\
H= & \text { initial head or lift } \\
d= & \text { lock-chamber water level over-travel (undertravel for lock } \\
& \text { emptying) } \\
A_{c}= & \text { sum of culvert area at each operation valve } \\
T= & \text { filling or emptying time } \\
t_{v}= & \text { valve operation time } \\
k_{v}= & \text { valve coefficient (which generally ranges from } 0.45 \text { to } 0.55 \text { and } \\
& \text { is taken as } 0.5 \text { for the present study. }
\end{aligned}
$$

The lock coefficient for existing locks ranges from about 0.45 for relatively slow operation to approximately 0.90 for very efficient systems that provide rapid operation (HQUSACE 2006).

Physical model and field data suggest that the coefficient from a 1:25-scale model can range from $11 \%$ to $17 \%$ less than the prototype equivalent during filling and $12 \%$ to $19 \%$ less during emptying. As previously discussed, the prototype structures are relatively more efficient because of the differences in viscous forces. Some examples from studies listed in the references are presented in Table 13. Equation 32 shows that the lock coefficient quantifies a lock's filling and emptying performance using several lock parameters that, in turn, are related to other lock 
characteristics. These "hidden" lock parameters, particularly the viscous effects, are a primary driver in the value of the lock coefficient. The lock coefficient should not be used to determine a proper scale for a physical model study.

Table 13. Lock coefficient, $C_{L}$, for various projects.

\begin{tabular}{|l|c|c|c|c|c|c|}
\hline \multirow{2}{*}{ Lock Project } & \multicolumn{3}{|c|}{ Filling Operations } & \multicolumn{3}{c|}{ Emptying Operations } \\
\cline { 2 - 7 } & Model & Prototype & Difference & Model & Prototype & Difference \\
\hline Bankhead & 0.66 & 0.78 & $15 \%$ & 0.56 & 0.69 & $19 \%$ \\
\hline Lower Granite & 0.77 & 0.93 & $17 \%$ & 0.66 & 0.78 & $15 \%$ \\
\hline Bay Springs & 0.63 & 0.75 & $16 \%$ & 0.52 & 0.59 & $12 \%$ \\
\hline Bonneville & 0.61 & 0.72 & $15 \%$ & 0.47 & 0.56 & $16 \%$ \\
\hline Barkley* & 0.75 & 0.84 & $11 \%$ & N/A & 0.62 & N/A \\
\hline Greenup* & 0.57 & 0.62 & $8 \%$ & 0.51 & 0.59 & $14 \%$ \\
\hline
\end{tabular}

*Barkley and Greenup locks were tested in 3:100- (1:33. 3 )-scale models.

\subsection{Similitude for mixing models}

Hydraulic modeling of mixing requires not only geometric and kinematic similitude but also dynamic similitude so that model observations are representative of prototype behavior. The most important phenomenon that must be modeled is the interplay between momentum of the issuing jet and the ambient fluid. This behavior dominants the flow both near and to some distance from the discharge point. To achieve dynamic similitude, the values of Reynolds number and Froude numbers in the model and prototype must be the same. This cannot be achieved unless the model is full scale (1:1-scale) or a different fluid is used in the model. The Reynolds number is always delegated to secondary importance with the provision that its value in the model is sufficiently large to achieve turbulent flow (Fischer et al. 1979). This turbulent flow requirement means that the Reynolds number of the discharge jet based on the jet flushing velocity and diam should be at least 2,000 (Fischer et al. 1979). This Reynolds number would produce a turbulent jet in the model. Therefore, a 1:25-scale Froude-scaled model with Reynolds number of 100,000 - well above the turbulent threshold - will be large enough to provide a reasonable representation of prototype mixing. 


\subsection{Hawser forces during flushing}

Navigation locks are designed and operated to ensure safety for vessel operators and project personnel. Safety is viewed in terms of lock chamber performance, which is evaluated based on surface currents and turbulence. Conditions in a lock chamber cannot be hazardous to small craft but must not cause excessive forces the mooring line forces required to hold the design vessel in place. Those mooring forces, referred to as hawser forces, are limited to 5 tons by USACE lock design criteria (HQUSACE 1995, 2006).

The hawser forces can be determined if the motion of a moored system (barge tow or other vessel) is known. If the buoyant force balances the barge weight and if the pitch motion is assumed negligible, then the singledegree-of-freedom equation of motion for such a moored system is

$$
\left(1+C_{a}\right) m_{v} \ddot{s}+C_{h} \dot{s}+\left(K_{0}+k\right) s=F
$$

where:

$$
\begin{aligned}
s= & \text { surge displacement of the barge } \\
C_{a}= & \text { added mass coefficient } \\
m_{v}= & \text { mass of the barge tow } \\
C_{h}= & \text { hydrodynamic damping coefficient } \\
K_{o}= & \text { initial tension in the hawser } \\
K= & \text { hawser spring constant } \\
F= & \text { the total force acting on the barge }\left(F_{s}+F_{\tau}+F_{p}\right) \\
F_{s}= & \text { difference in hydrostatic force between the bow and stern } \\
F_{\tau}= & \text { force due to shear stress } \\
F_{p}= & \text { hydrodynamic response (force required to accelerate the fluid) } \\
& \text { (Kalkwijk 1973). }
\end{aligned}
$$

The overscript dot indicates differentiation with respect to time.

Steady-state forces acting on a moored vessel can be determined from the right-hand side of Equation 33, which is the sum of the external forces acting on the system. In equation form

$$
F_{s}=\rho g b d l S_{s}
$$




$$
\begin{gathered}
F_{r}=\frac{1}{2} C_{f} \rho A V|V| \\
F_{p}=\frac{1}{2} \rho b d C_{p} V|V|
\end{gathered}
$$

where:

$$
\begin{aligned}
b & =\text { beam width of barge } \\
d & =\text { barge draft } \\
l & =\text { barge length } \\
S_{s} & =\text { slope of the water surface } \\
g & =\text { acceleration due to gravity } \\
\rho & =\text { fluid density } \\
C_{f} & =\text { friction coefficient } \\
A & =\text { wetted area of the hull } \\
C_{p} & =\text { pressure coefficient } \\
V & =\text { mean velocity of fluid relative to the vessel. }
\end{aligned}
$$

Although this single-degree-of-freedom model only simulates the vessel's surge, Natale and Savi (1994) demonstrate its accuracy in modeling barges moored in a lock chamber. The single-degree-of-freedom equation of motion (Equation 33) is a second-order, nonhomogeneous, ordinary differential equation for a damped system with external forcing. In mooring applications, the system is generally underdamped, and the displacement of the moored vessel oscillates with an exponential decay in amplitude.

A model of forces exerted in hawsers mooring a vessel in a lock chamber has been used in conjunction with a numerical flow model of lock filling systems to optimize lock operations (Natale and Savi 1994, 2000). Information on such parameters as the hawser spring constant is available from sources such as Naval Facilities Engineering Command (1986a,b). Added mass and hydrodynamic damping coefficients needed to model the mooring of a barge tow in a lock chamber are given in Stockstill (2003).

Often, the only force considered is the hydrostatic force since it is much larger than the shear due to friction or the hydrodynamic response. However, using the equation of motion provides a more accurate answer. Equation 33 can be used in conjunction with a numerical flow solution to estimate the forces exerted during flushing operations when a tow is moored in the chamber. This modeling system could also be used to 
estimate hawser forces on vessels moored downstream of the lock in the lower approach during flushing. This process would require values for the added mass and damping coefficients, which could be determined using physical model experiments. This one-dimensional modeling approach in conjunction with numerical modeling could provide estimates of the hawser forces, but a physical model would still be required for any modeling with a vessel inside a lock chamber.

If the inertia is neglected, then the longitudinal flow is uniform from one end of the chamber to the other. The water-surface slope in the lock chamber can be estimated using the Darcy-Weisbach equation.

$$
\frac{H_{L}}{L}=S_{f}=S_{s}=\frac{f}{8 R} \frac{Q^{2}}{g A^{2}}
$$

where:

$$
\begin{aligned}
S_{f}= & \text { friction slope of the water surface } \\
Q= & \text { discharge } \\
A= & \text { flow area }=B h \\
R= & \text { hydraulic radius of the channel cross-section; flow area } \\
& \text { divided by wetted perimeter }\left(R=\frac{B h}{2 h+B}\right) .
\end{aligned}
$$

The dimensions of Brandon Road Lock are included in Table 1 and Table 2 in Section 2.3.

The water-surface slope can also be estimated using the Manning's equation:

$$
S_{s}=\frac{n^{2}}{C_{m} R^{\frac{4}{3}}}\left(\frac{Q}{A}\right)^{2}
$$

where:

$$
\begin{aligned}
n= & \text { Manning's roughness coefficient } \\
C_{m}= & \text { a dimensional constant ( } C_{m}=1 \text { for SI units and 2.208 for U.S. } \\
& \text { customary units). }
\end{aligned}
$$


A reasonable value of Manning's coefficient for a lock chamber with concrete walls and rock floor is 0.015, depending on the roughness of the lock floor.

The information provided in this chapter summarizes the aspects of the lock flushing system that must be considered for and during a physical model study. Without a physical model study of the lock flushing system, the navigation safety concerns for vessels in the lock chamber during flushing cannot be addressed. 


\section{Further Research - Prototype and Physical Model Testing}

\subsection{Prototype tests}

A field study of Brandon Road Lock has been proposed by the U.S. Geological Survey. The field study would provide data on the flow distribution in the lock chamber for the existing F/E system. These field data will be used to validate future numerical and physical models. The prototype test plan includes measuring velocities in the lock chamber during steady flow conditions through the filling system, similar to the Type 1 lock flushing concept. To avoid any safety issues, these experiments will be conducted without tows in the lock chamber. If the validation results find that the physical model reproduces field conditions with an empty chamber, then experiments with a tow present in the chamber can be conducted with confidence.

\subsection{Physical model experiments}

A physical model is required for the lock flushing concept that is being considered for implementation after the numerical modeling phase. Before a final decision is made on the lock flushing concept to be constructed at Brandon Road Lock, a physical model would be needed to answer questions related to safety, because of existing USACE regulations, and uncertainties that currently exist in the numerical modeling of navigation locks and the related flow situations.

\subsubsection{Safety}

Vessel movement within the lock chamber during flushing is the primary safety concern. Fluid and vessel forces are derived from many sources including hydraulic forces acting on the vessel and mooring line forces. The processes involved in calculating vessel movement within the lock chamber during flushing are very complex and include poorly constrained parameters (e.g., added mass, hydraulic damping coefficients, turbulence intensity, scales of motion). Further research is needed, especially with regard to large vessels operating in confined spaces as well as vessel displacement sensitivities to some input parameters, to determine appropriate values for use in analytical and numerical models. 
Hawser criteria are based on the hydrodynamic vessel forces and are designed to provide a high degree of safety during lock operations. The vessel is expected to experience the maximum safe forces for an extended period during the flushing process. Flushing produces a longitudinal water surface slope that will generate substantial forces on vessels. Since the hawser forces must be known for safe lock operation when vessels are in the chamber, the only way to develop safe operating criteria is to measure these forces in a physical model.

\subsubsection{U.S. Army Corps of Engineers (USACE) regulations}

USACE regulations require physical models for lock designs that do not follow the design criteria directly. EM 1110-2-1604 Hydraulic Design of Navigation Locks (HQUSACE 2006) and EM 1110-2-2602 Planning and Design of Navigation Locks (HQUSACE 1995) describe the USACE requirements for lock design and construction including navigation criteria. EM1110-2-1604 (HQUSACE 2006) defines the criteria for maximum hawser forces on moored vessels based on physical model studies. Therefore, USACE guidance standards require a physical model to determine the maximum safe force. EM 1110-2-2602 (HQUSACE 1995) states that "physical model studies... are a traditional and necessary part of the planning and design phase for most navigation facilities." While the document mentions the use of numerical models, they currently cannot sufficiently reproduce the flow conditions and subsequent physical quantities to address new designs or extensive modifications to existing projects. The hydraulic engineering community does not have a thoroughly validated modeling system capable of providing the accuracy required to meet the USACE hawser safety criteria prescribed in EM 1110-2-1604 (HQUSACE 2006). Existing numerical models are appropriate for low-level screening to determine relative differences (not absolute) between some design alternatives but are inappropriate for exploring the extensive modifications proposed in the Brandon Road lock flushing study.

\subsubsection{Numerical modeling uncertainties}

Numerical models (including those presented in this report) can include a tracer or particle tracking feature to simulate chamber flushing, but the numerical model results are only as good as the values of the empirical constants that appear in the equation governing longitudinal dispersion in a flowing fluid (Equations 1 and 25). The tracer algorithms are based on turbulent diffusion theory that includes diffusion coefficients that are 
derived from turbulence closure methods. These diffusion coefficients are subject to some degree of uncertainty as the mixing algorithm is specific to a particular set of equations, which are discretized in a particular manner. These equations include empirically determined coefficients and scaling parameters that are calculated from physical model or field data and often must be adjusted when applied in a new situation. There is no real randomness in the numerical model, so the result is an average or synthetic representation of the physical system. Furthermore, the added complexity of the alternative flushing systems combined with the presence of a vessel in the chamber has not been explored previously. Numerical model results cannot be verified to be representative of Brandon Road Lock until the values of parameters such as the diffusion coefficient for the flushing flows are determined in either a field study or a physical model study. Because of the uncertainty associated with the known diffusion coefficients for the flow situation encountered with navigation locks, tracer and dye studies are the only practical method to quantify lock flushing with higher certainty than $3 \mathrm{D}$ numerical models.

\subsubsection{Physical model tests}

A physical model can be constructed at the ERDC such that a suite of filling and emptying tests will be conducted to determine flushing rates for the lock chamber. A 1:25-scale physical model of Brandon Road Lock filling and emptying system can be used to measure flushing with and without tows to directly determine residence time within the lock chamber and the culverts. This will unequivocally establish the lock operation procedures required to reduce the lock ANS concentration to various dilution levels (e.g., 95\%, 99\%). In addition to emptying and filling without vessels, experiments using a remote-controlled tow with different barge configurations can determine the effects of vessel lockage on exchange. Vessel blockage during the locking process can either increase (exiting) or decrease (entering) the volume within the lock. Localized mixing along the hull as well as propeller wash can further complicate the exchange mechanism, so the case with tows is significantly more complex and critical to understanding the role of navigation in lock flushing. Questions of vessel effects such as (1) "What is the role of vessels during the locking process in enhancing/hindering the exchange flow," (2) "How does vesselinduced turbulence and propeller wash modify residence time," and (3) "What role does vessel blockage play in modifying the exchange flow rate" can be quantified. Experiments can explore the consequences of upbound and downbound tows with different barge configurations. 
Rhodamine dye can be used to track the water mass within the lock chamber to quantify turbulent dispersion coefficients and flushing rates. Rhodamine dye has been used extensively in the marine environment as a water mass tracer, and accurate methodologies to measure the mixing rates and dispersion are well developed. Rhodamine fluorescence can be easily measured using inexpensive fluorometers, thus providing residence time and flushing efficiency within the lock chamber and culvert. Confetti can be used to measure surface water exchange and flow visualization techniques, such as high-speed digital photography, provide direct measurements of particle velocity and rotation to evaluate water mass exchange dynamics.

Particular attention can be paid to evaluating the Type 1 concept (existing filling and emptying system). If Brandon Road Lock can serve as the necessary barrier using the existing filling and emptying system, then the project modification expenses will be limited to ensuring that the filling valves can close under flowing conditions and that the lower miter gates are secured open during flushing. The barrier expense will then be limited to the additional flushing time required prior to each filling operation, which is common to each design alternative considered.

The effectiveness of the Type 4 concept (continuous flushing downstream of the lock) can be evaluated in the same physical model if it is constructed to include a sufficient reach of the lower approach. Experiments with tows passing over the Type 4 concept manifold can determine how the flushing currents interact with the tow's return currents and propeller wash for both upbound and downbound tows, thus indicating possible impacts to navigation.

\subsection{Tow effects}

The currents generated as an upbound tow enters a lock chamber are illustrated in Figure 57. As the vessel enters the chamber, the displacement forces the same volume of water from the chamber. The resulting flow is referred to as the return current. A barge tow leaving the lock draws water into the chamber to replace the vessel's displacement volume (Figure 58). Vessel speed and squat, and thus the return currents, are influenced by the depth over the sill and chamber floor (Maynord 2000). These return currents provide a means for ANS contamination through Brandon Road Lock. The flows near a barge tow as it transits into Brandon Road Lock should be considered when developing or evaluating a lock flushing concept or during any physical model study. 
Figure 57. Currents generated as an upbound tow enters a lock chamber.

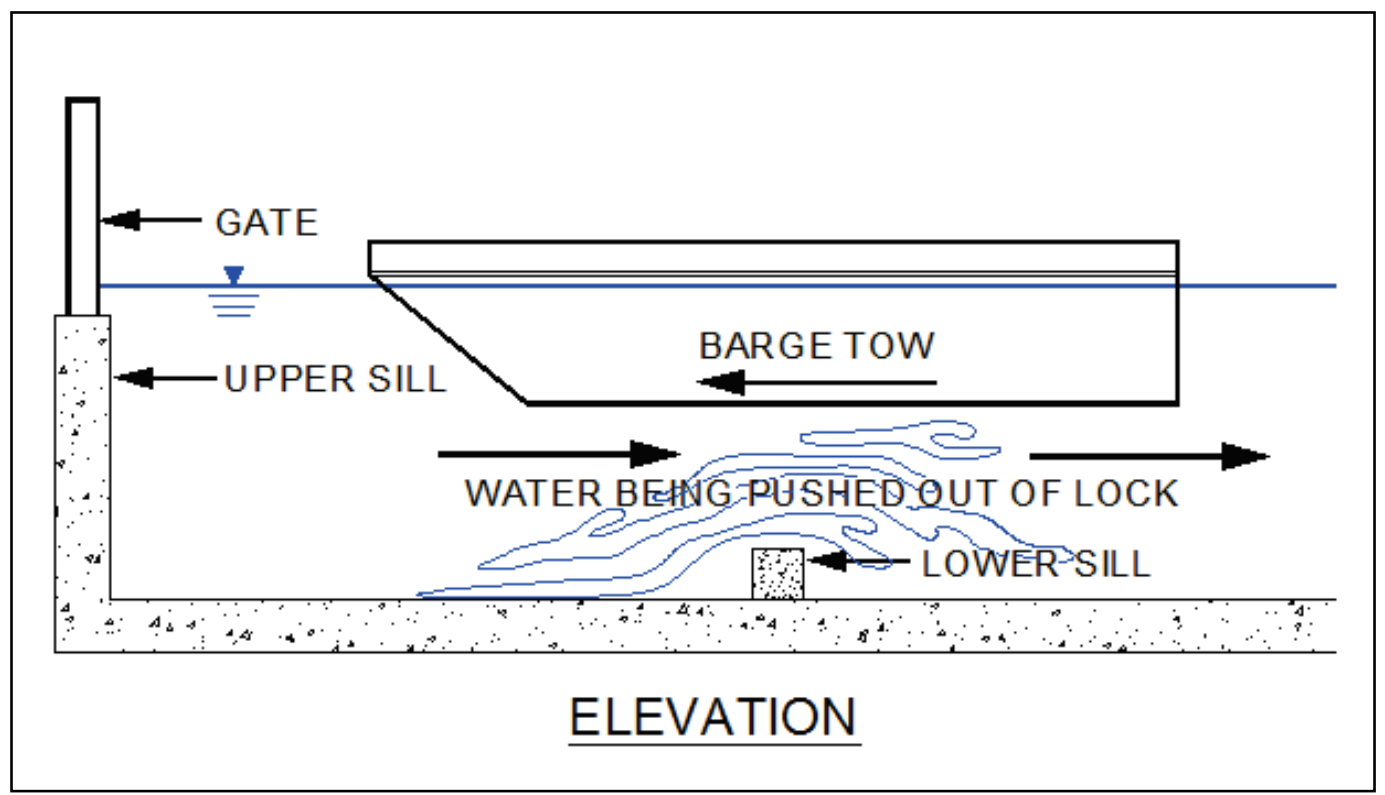

Figure 58. Currents generated as a downbound tow leaves a lock chamber.

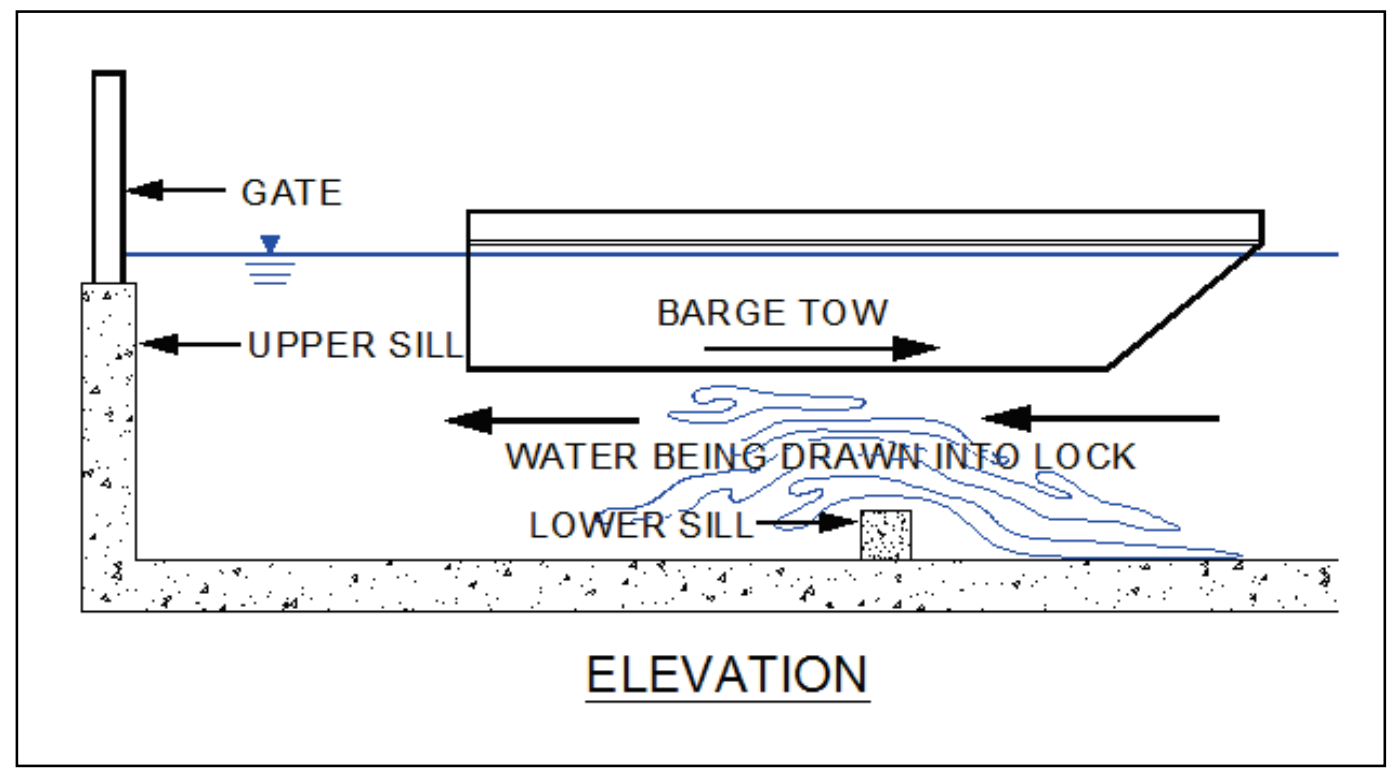

For the case where the vessel is exiting the lock into ANS-contaminated water, a rough approximation is to assume that the volume of water initially displaced by the tow will be replaced by ANS-contaminated water as the tow exits the chamber. In practice, the propeller wash will contribute significantly to mixing and increase the risk of ANS-contaminated water entering the chamber, particularly as the tow exits the chamber. 
The work completed during this study and presented herein provides a good tool for determining the most likely lock flushing concepts for reducing ANS concentration in at prevent transfer of ANS upstream of Brandon Road Lock. However, the analytical and numerical model results provided in this report must be supplemented by a physical model study of the lock flushing system to ensure that the USACE lock operation and navigation safety concerns are met. 


\section{Summary and Recommendations}

Ideas and preliminary hydraulic calculations have been presented as part of the development of an ANS flushing system for Brandon Road Lock. Five flushing system designs and operations have been drafted. The Type 1 lock flushing concept uses the existing culvert system. Types 2 and 3 lock flushing concepts require modifications to the lock structure. The Type 4 concept is not actually a lock flushing concept but rather a design that provides a continuous supply of clean water in the lower lock approach, thus preventing ANS from ever reaching the lock chamber. The Type 5 lock flushing concept is a redesigned $\mathrm{F} / \mathrm{E}$ system.

Five lock flushing concepts (Types 1, 2, 3, 3r, and 5) have been tested in a 3D numerical model. Each model has a lock chamber without tows only. The Type 1 lock flushing concept shows highly unsteady flow fields. Original lock chamber water dilution happens throughout the lock chamber. The area upstream of the first filling and emptying ports flushes considerably faster than the other areas of the chamber.

The Type 2 flushing concept was simulated in the first phase of modeling work but was removed from further consideration because of construction and cost concerns. The numerical models of this concept did not include direct calculation of original lock dilution.

In the Type 3 lock flushing concept, flow is introduced at the upstream end of the chamber, and lock flushing occurs generally upstream to downstream. Because of lock chamber surface drawdown, the flushing discharge for the Type 3 concept must be significantly reduced from what flushing discharge is possible given the head differential between the upper and lower pools. If tows are not present in the lock chamber during flushing, the flushing discharge could remain at the maximum possible value. Flushing flow is also introduced in the upstream end of the lock chamber for the Type $3 \mathrm{r}$ concept. The conduit through which this flushing flow is introduced into the chamber is much larger than with the Type 3 concept to reduce the flushing velocities inside the chamber. The flushing behavior for this concept is also generally upstream to downstream. However, the flushing is much faster for Type $3 \mathrm{r}$ due predominantly to the higher flushing discharge. The introduction of flushing flow over a larger area of the upstream end of the lock chamber also increases the flushing efficiency. The main drawback 
to the Type $3 \mathrm{r}$ design is that structural, mechanical, and construction considerations may significantly limit how much space is available for the flushing conduit through the upstream gate sill.

The Type 5 flushing concept behaves similarly to the Type 1 concept in that flushing flow is introduced through the filling and emptying system ports at multiple areas of the lock chamber. In the Type 5 concept, the filling and emptying system conforms to current USACE hydraulic design guidance standards. The ports have been resized and repositioned. The only deviation in this flushing concept from current design guidance is the inclusion of a flushing port on each culvert upstream of the filling and emptying ports. These flushing ports are located at the same station as the first filling and emptying port in the Type 1 concept. The sole purpose of these ports is to increase the flushing rate in the upstream end of the lock chamber. The Type 5 concept flushes the lock chamber more efficiently than the Type 1 concept but not as efficiently or effectively as either the Type 3 or Type $3 \mathrm{r}$ flushing concepts. The Type 5 concept has the benefit of reducing the lock filling time due to the improved filling and emptying system performance. Such a reduction in filling time would at least partially offset any lockage time increases due to flushing and would be a benefit to navigation.

The Type 1 lock flushing concept should be tested in a physical model. This concept would be the most economical one to implement because it will not require modifications to the lock structure and should be tested to determine the flushing efficiency using the existing filling system. A decision should be made whether the Type 3 (or some variation) or the Type 5 lock flushing concept should be tested. This decision should be based primarily on structural, mechanical, and cost engineering considerations. Placing pipes through the gate sill may require lower construction costs, but this concept (Type 3) may require flow control valves being submerged.

The Type 4 idea (lateral manifold downstream of lock) could be refined once information on the lock approach bathymetry and engineered channel is developed. The physical model should be designed to accommodate experiments to evaluate the Type 4 concept. Experiments can determine the effectiveness of the Type 4 concept as tows pass over it.

The numerical models that have been created and discussed in this report provide insight into how the different lock flushing concepts will flush the 
lock chamber. However, much information for the flushing concepts related to vessel traffic including safety, vessel forces, and vessel motion cannot be adequately addressed in a numerical model with the current state of numerical model in the engineering community. If a lock flushing concept is chosen for implementation at Brandon Road Lock, a physical model study must be performed to evaluate the safety concerns to navigation traffic during the flushing operation before a final decision is made. 


\section{References}

Ables, J. H. 1978. Filling and Emptying System for Bay Springs Lock, TennesseeTombigbee Waterway, Mississippi, Hydraulic Model Investigation. Technical Report HL-78-19. Vicksburg, MS: U.S. Army Engineer Waterways Experiment Station.

Ables, J. H., Jr. 1979. Vortex Problem at Intake Lower St. Anthony Falls Lock and Dam, Mississippi River, Minneapolis, Minnesota. Technical Report HL-79-9. Vicksburg, MS: U.S. Army Engineer Waterways Experiment Station.

Abraham, G., V. D. Burgh, and D. Vos. 1973. Pneumatic Barriers to Reduce Salt Intrusion through Locks. Rijkswaterstaat Communications No. 17. The Hague: Government Publishing Office.

Albertson, M. L., Y. B. Dai, R. A. Jensen, and H. Rouse. 1950. "Diffusion of Submerged Jets.” Transactions of the American Society of Engineers 115: 639-664.

Bastian, D. F. 1971. Calcasieu Saltwater Barrier Prototype Sector Gate Tests. Miscellaneous Paper H-71-4. Vicksburg, MS: U.S. Army Engineer Waterways Experiment Station.

Boggess, D. H. 1970. A Test of Flushing Procedures to Control Salt-Water Intrusion at the W. P. Franklin Dam near Ft. Myers, Florida and the Magnitude and Extent of Salt-Water Contamination in the Caloosahatchee River between La Belle and Olga, Florida. Information Circular No. 62. Tallahassee, FL: Florida Department of Natural Resources, Bureau of Geology.

Deng, Z. Q., L. Bengtsson, V. P. Singh, and D. D. Adrian. 2002. "Longitudinal Dispersion Coefficient in Single-Channel Streams.” Journal of Hydraulic Engineering 128(10): 901-916.

Fernando, H. J. S. 2013. Handbook of Environmental Fluid Dynamics, Volume Two: Systems, Pollution, Modeling, and Measurements. Boca Raton: CRC Press.

Fischer, H. B., E. J. List, R. C. Y. Koh, J. Imberger, and N. H. Brooks. 1979. Mixing in Inland and Coastal Waters. San Diego: Academic Press, Inc.

Headquarters, U.S. Army Corps of Engineers (HQUSACE). 2006. Hydraulic Design of Navigation Locks. EM 1110-2-1604. Washington, DC.

1995. Planning and Design of Navigation Locks. EM 1110-2-2602. Washington, DC.

1988. Corps of Engineers Hydraulic Design Criteria, Vol 2. Washington, DC. http://www.dtic.mil/docs/citations/ADA092238.

Hite, J. E., Jr. 1999. Model Study of Marmet Lock Filling and Emptying System, Kanawha River, West Virginia. Technical Report CHL-99-8. Vicksburg, MS: U.S. Army Engineer Waterways Experiment Station. 
Hite, J. E., Jr. 200o. New McAlpine Lock Filling and Emptying system, Ohio River, Kentucky. ERDC/CHL TR-oo-24. Vicksburg, MS: U.S. Army Engineer Research and Development Center.

Hite, J. E., Jr., and A. M. Tuthill. 2005. New Lock for Soo Locks and Dam, Sault Ste. Marie, Michigan, St. Mary's River. ERDC/CHL TR-05-08. Vicksburg, MS: U.S. Army Engineer Research and Development Center.

Hite, J. E., Jr., and C. Bislip-Morales. 2012. New Lock for Soo Locks and Dam, Model Investigations during 2006-2010, Sault Ste. Marie, Michigan, St. Mary's River. ERDC/CHL TR-12-1. Vicksburg, MS: U.S. Army Engineer Research and Development Center.

Kalkwijk, J. P. T. 1973. Hydrodynamic Forces and Ship Motions Induced by Surges in a Navigation Lock. Rep. No. 73-1. Delft, The Netherlands: Delft University of Technology.

Kumar, A., D. K. Jaiswal, and N. Kumar. 2012. “One-Dimensional Solute Dispersion along Unsteady Flow through a Heterogeneous Medium, Dispersion Being Proportional to the Square of Velocity." Hydrological Sciences Journal 57(6): 1223-1230.

Mausshardt, S., and G. Singleton. 1995. "Mitigating Salt-Water Intrusion through Hiram M. Chittenden Locks." Journal of Waterway, Port, Coastal, and Ocean Engineering 121(4): 224-227.

Maynord, S. T. 2000. Effects of Lock Sill and Chamber Depths on Transit Time of Shallow Draft Navigation. ERDC/CHL TR-00-13. Vicksburg, MS: U.S. Army Engineer Research and Development Center.

McCartney, B. L., J. George, B. K. Lee, M. Lindgren, and F. Neilson. 1998. Inland Navigation: Locks, Dams, and Channels. Volume 94 of ASCE Manuals and Reports on Engineering Practice. Reston, VA: American Society of Engineers.

McGee, R. G. 1989. Prototype Evaluation of Bay Springs Lock, Tennessee-Tombigbee Waterway, Mississippi. Technical Report HL-89-15. Vicksburg, MS: U.S. Army Engineer Waterways Experiment Station.

Miller, D. S. 1990. Internal Flow Systems, 2nd edition. Cranfield, Bedford, UK: BHRA (Information Services).

Murphy, T. E. 1975. Lock Design, Sidewall Port Filling and Emptying System. Miscellaneous Paper H-75-7. Vicksburg, MS: U.S. Army Engineer Waterways Experiment Station.

Natale, L., and Savi, F. 1994. "Dynamics of barges in navigation locks." In Proc., IASTED Int. Conf. on Modelling and Simulation, edited by M. H. Hamza, 237-240. Anaheim, CA.

Natale, L., and Savi, F. 200o. "Minimization of Filling and Emptying Time for Navigation Locks." Journal of Waterway, Port, Coastal, and Ocean Engineering 126(6): 274-280. 
Naval Facilities Engineering Command. 1986a. Fixed Moorings. Design Manual 26.4. Alexandria, VA.

Naval Facilities Engineering Command. 1986b. Mooring Design, Physical and Empirical Data. Design Manual 26.6. Alexandria, VA.

Oswalt, N. R. 1976. Ice Flushing from St. Lawrence Seaway Locks. Technical Report H76-9. Vicksburg, MS: U.S. Army Engineer Waterways Experiment Station.

Parchure, T. M., S. C. Wilhelms, S. Sarruff, and W. H. McAnally. 2000. Salinity Intrusion in the Panama Canal. ERDC/CHL TR-0o-4. Vicksburg, MS: U.S. Army Engineer Research and Development Center.

Pickett, E. B., and F. M. Neilson. 1988. Lock Hydraulic System Model and Prototype Study Data. Miscellaneous Paper HL-88-1. Vicksburg, MS: U.S. Army Engineer Waterways Experiment Station.

Pillsbury, G. B. 1915. "Excess Head in the Operation of Large Locks through the Momentum of the Column of Water in the Culverts." Professional Memoirs: Corps of Engineers, United States Army, and Engineer Department at Large 7(31) 206-212. U.S. Army Engineer School, Army Corps of Engineers.

Runkel, R. L. 1996. "Solution of the Advection-Dispersion Equation: Continuous Load of Finite Duration.” Journal of Environmental Engineering 122(9): 830-832.

Seo, J. W., and T. S. Cheong. 1998. "Longitudinal Dispersion Coefficient in Straight Rivers.” Journal of Hydraulic Engineering 127(11): 919-927.

Socolofsky, S. A., and G. H. Jirka. 2005. "CVEN 489-501 Special Topics in Mixing and Transport Processes in the Environment." Engineering - Lectures, $5^{\text {th }}$ edition. College Station, TX: Coastal and Ocean Engineering Division, Texas A and M University.

Stockstill, R. L. 2003. "Mooring Model Coefficients for Barge Tows in a Navigation Lock." Journal of Waterway, Port, Coastal, and Ocean Engineering 129(5): 233-236.

Tuthill, A. M. 2003. Ice and Debris Passage for Innovative Lock Designs. ERDC/CRREL TR-03-2. Vicksburg, MS: U.S. Army Engineer Research and Development Center.

Tuthill, A., and G. Gooch. 1997. "Modeling Ice Passage at Starved Rock Lock and Dam on Illinois Waterway." Journal of Cold Regions Engineering 11(3): 232-243.

Tuthill, A., L. Liu, and H. T. Shen. 2004. "Modeling Ice Passage at Navigation Locks." Journal of Cold Regions Engineering 18(3): 89-109.

Vennard, J. K., and R. L. Street. 1982. Elementary Fluid Mechanics, $6^{\text {th }}$ edition. New York: John Wiley and Sons.

Wood, I. R. 1970. “A Lock Exchange Flow.” Journal of Fluid Mechanics 42, part 42: 671-687. 


\section{Appendix A: Eisenhower Lock Flushing System Drawings}

Figure 59. Plan and section of ice flushing system added to Eisenhower Lock, St. Lawrence Seaway.

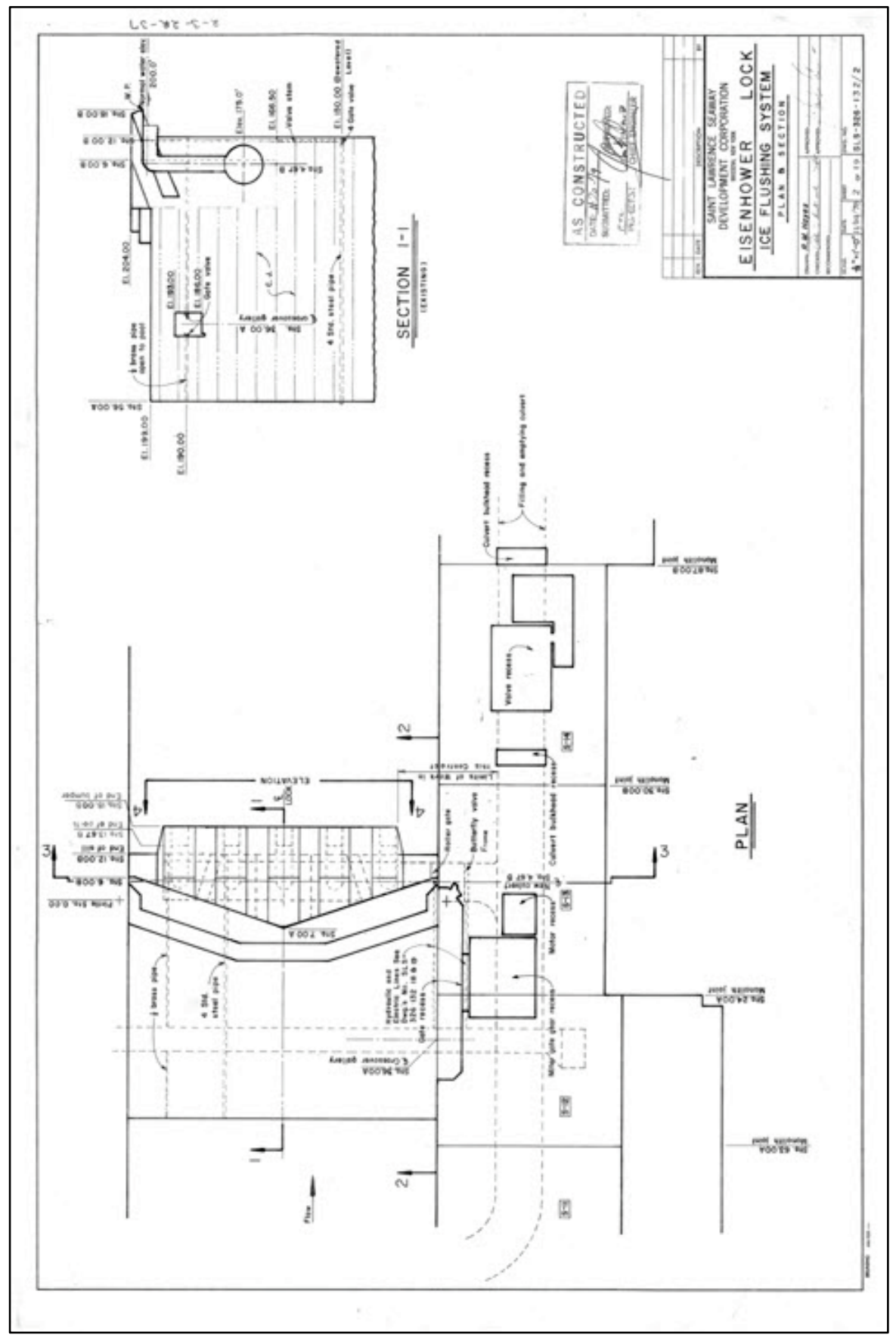


Figure 60. Section and elevation of ice flushing system added to Eisenhower Lock, St. Lawrence Seaway.

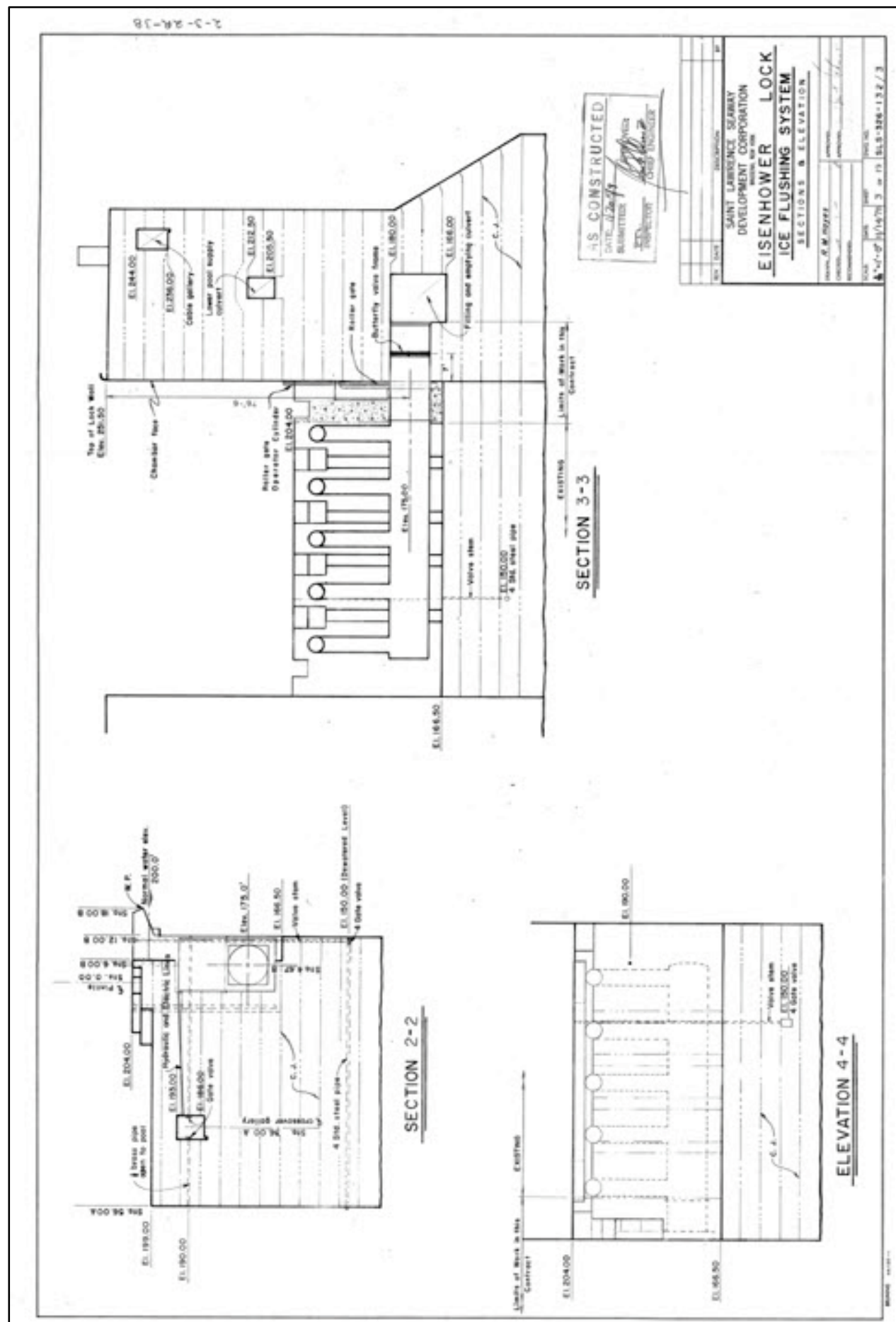




\section{Appendix B: Computational Meshes}

Before the lock flushing numerical simulations can be conducted, the geometry defined by the $\mathrm{CAD}$ model of each lock flushing concept has to be divided into a computational mesh. Each geometry is divided into meshes that are composed of tetrahedral elements. The sizes of these elements differ throughout the flow domain for each geometry. Generally, the size of the element depends on the complexity and size of the component in that area of the geometry. For instance, the filling and emptying ports and culverts require smaller elements to define the wall curvatures than elements in the lock chamber and areas upstream of the upstream gate sill. The geometry and the computation mesh for each lock flushing concept are shown in Figure 61 - Figure 75. The number of nodes and tetrahedral elements for each mesh is listed in Table 14.

Table 14. Computational mesh sizes

\begin{tabular}{|c|c|c|}
\hline Flushing Concept & Nodes & Elements \\
\hline Type 1 & 366,669 & $1,874,851$ \\
\hline Type 2 & 226,285 & $1,138,554$ \\
\hline Type 3 & 244,785 & $1,291,184$ \\
\hline Type 3r & 324,006 & $1,741,038$ \\
\hline Type 5 & 365,312 & $1,865,316$ \\
\hline
\end{tabular}


Figure 61. Type 1 geometry and computational mesh.

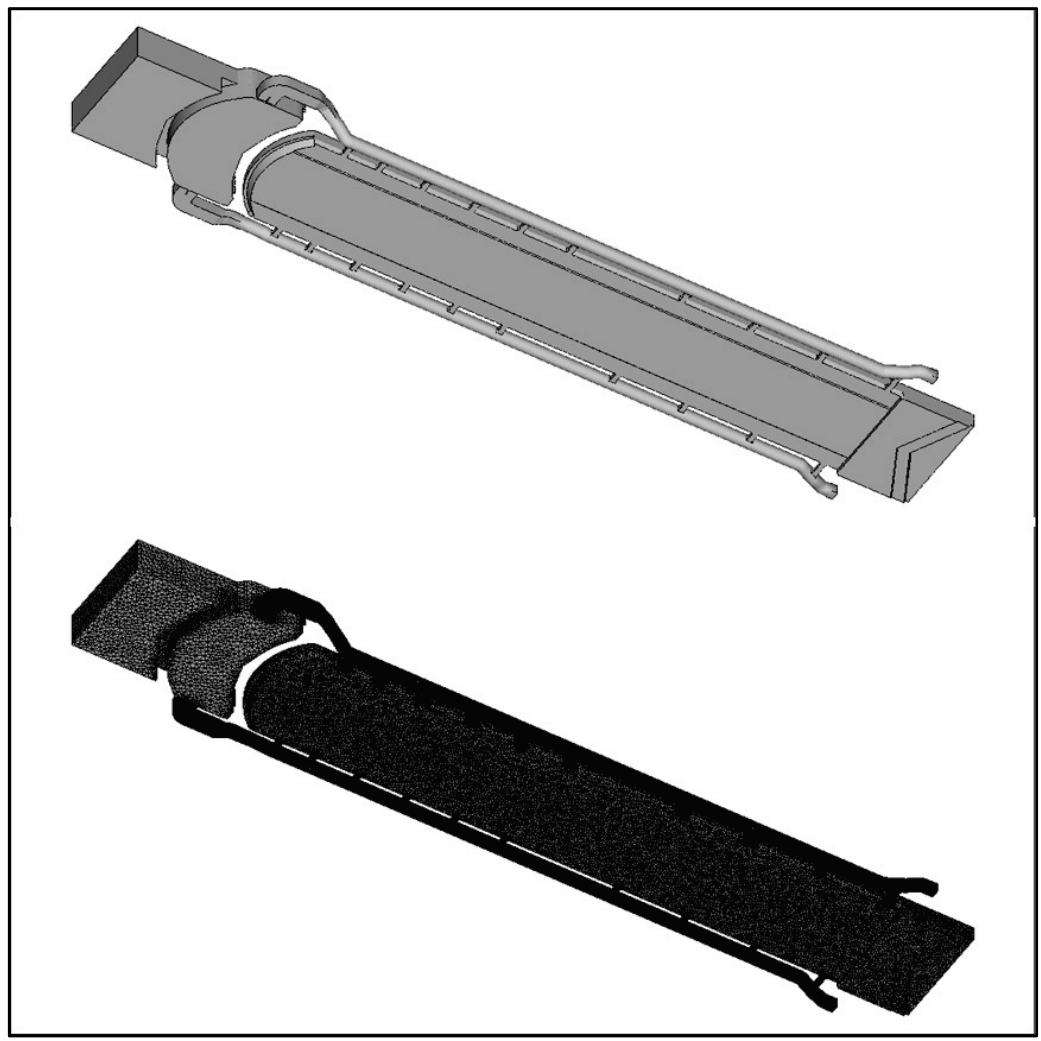

Figure 62. Type 1 geometry and computational mesh - Zoom 1.

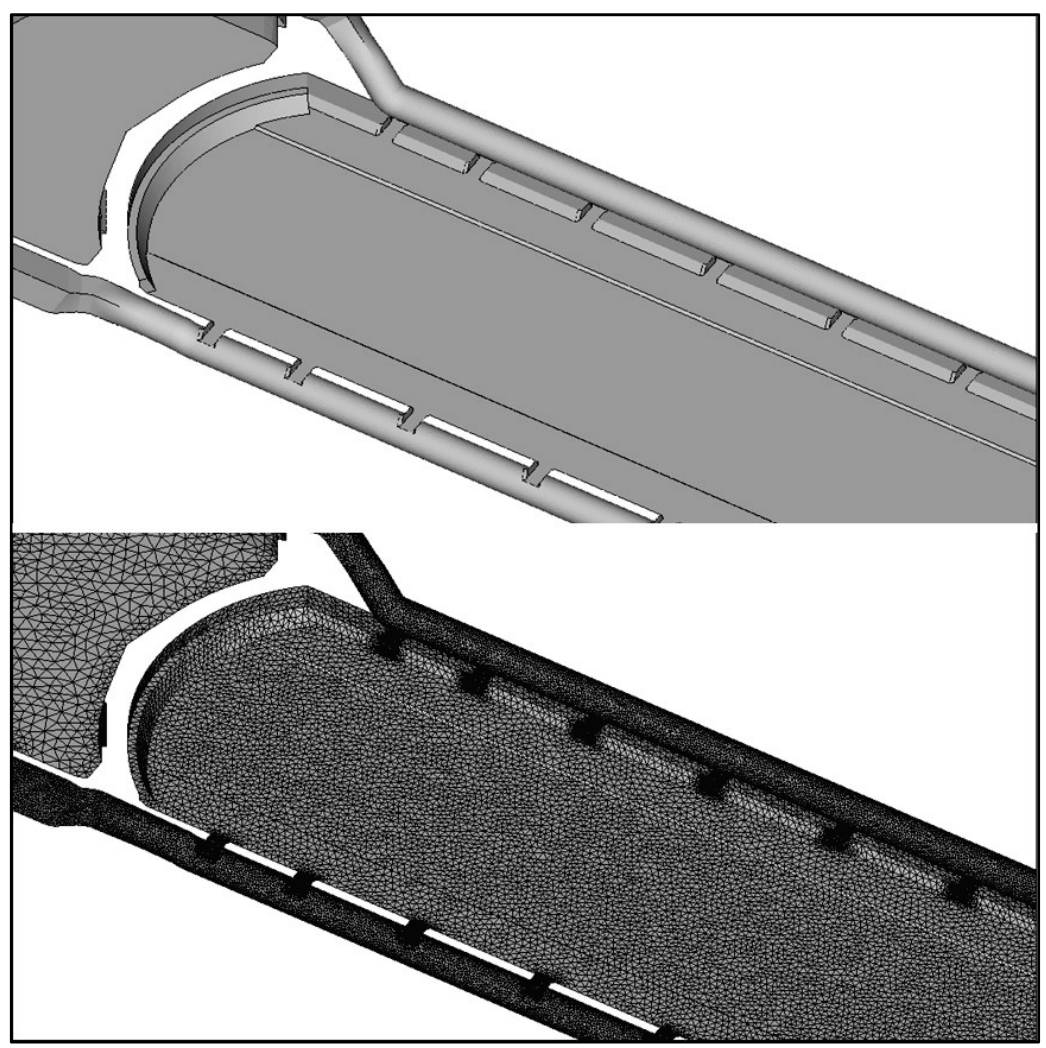


Figure 63. Type 1 geometry and computational mesh - Zoom 2.

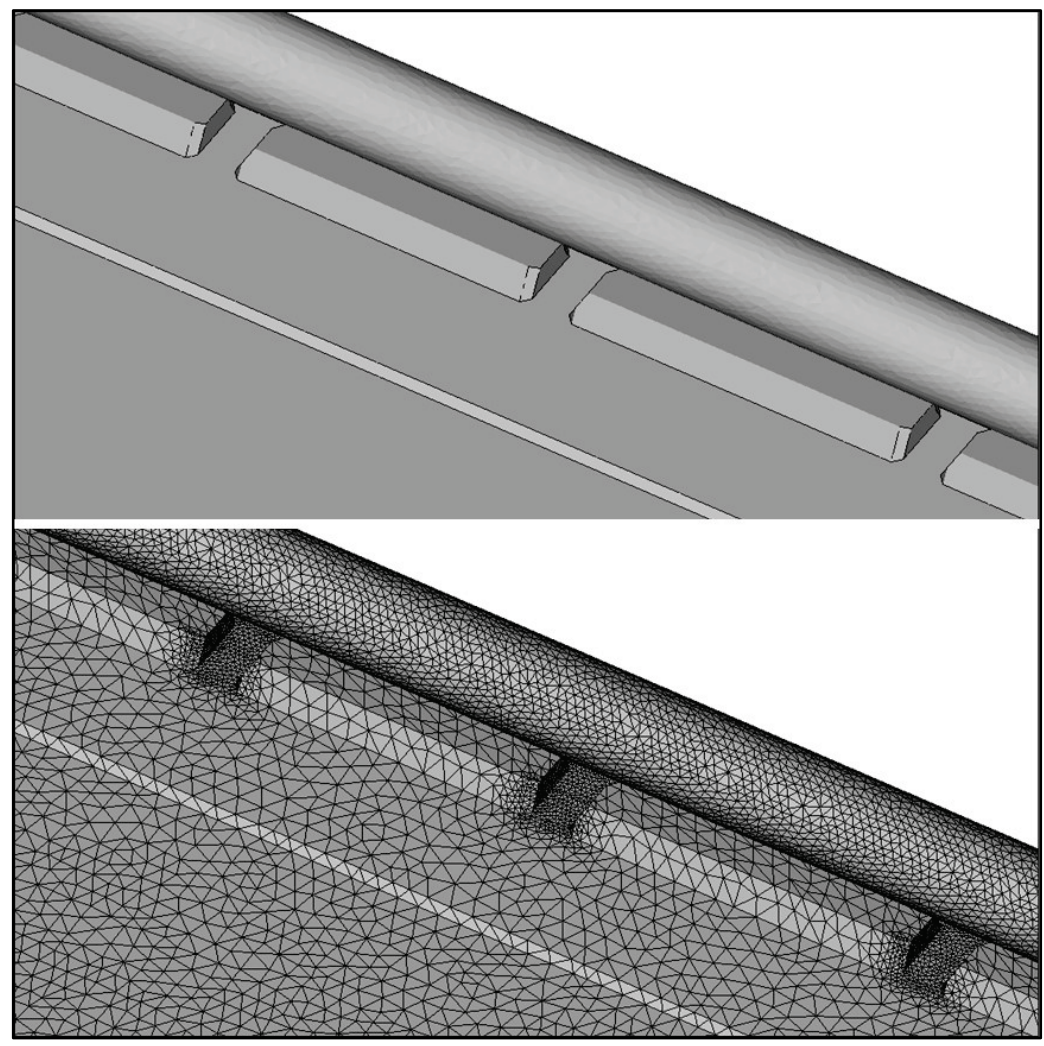

Figure 64. Type 2 geometry and computational mesh.

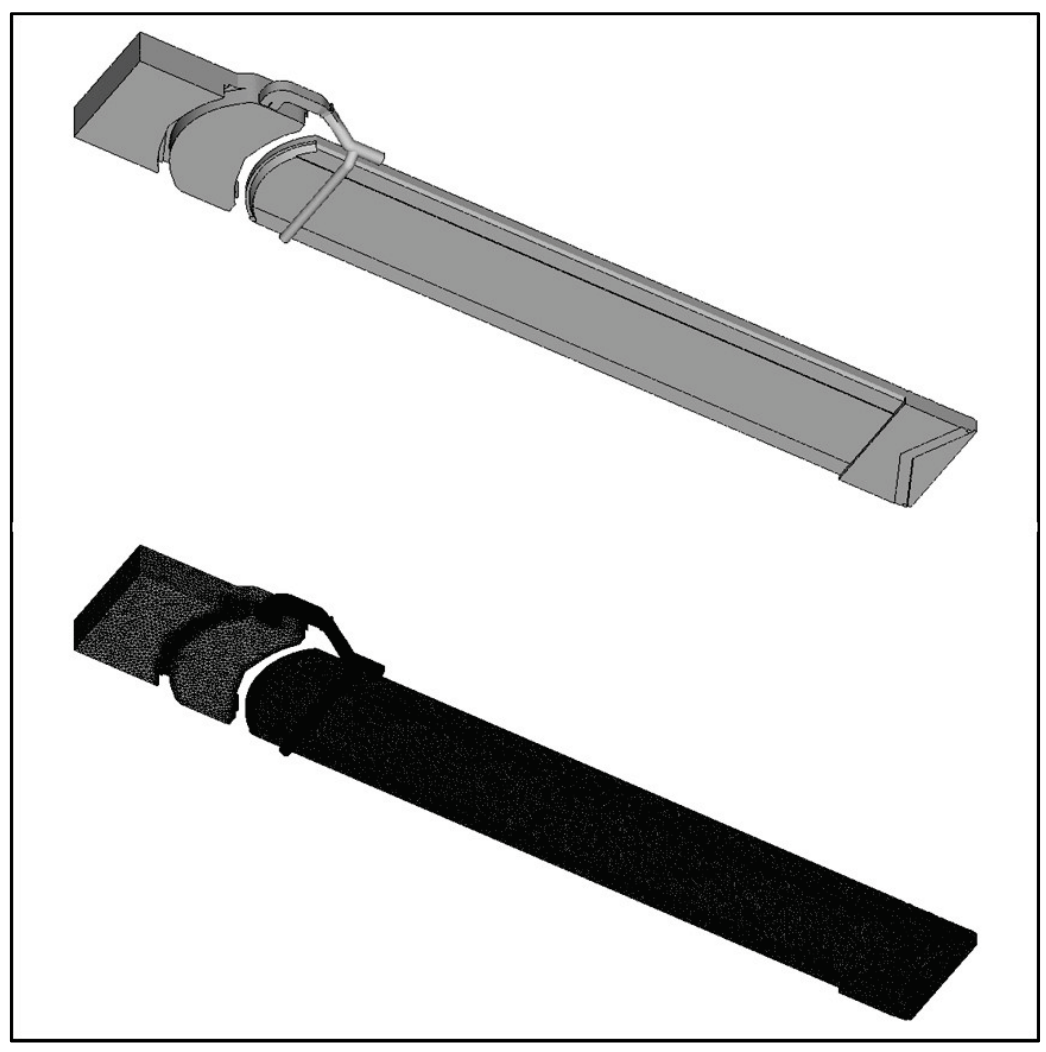


Figure 65. Type 2 geometry and computational mesh - Zoom 1.

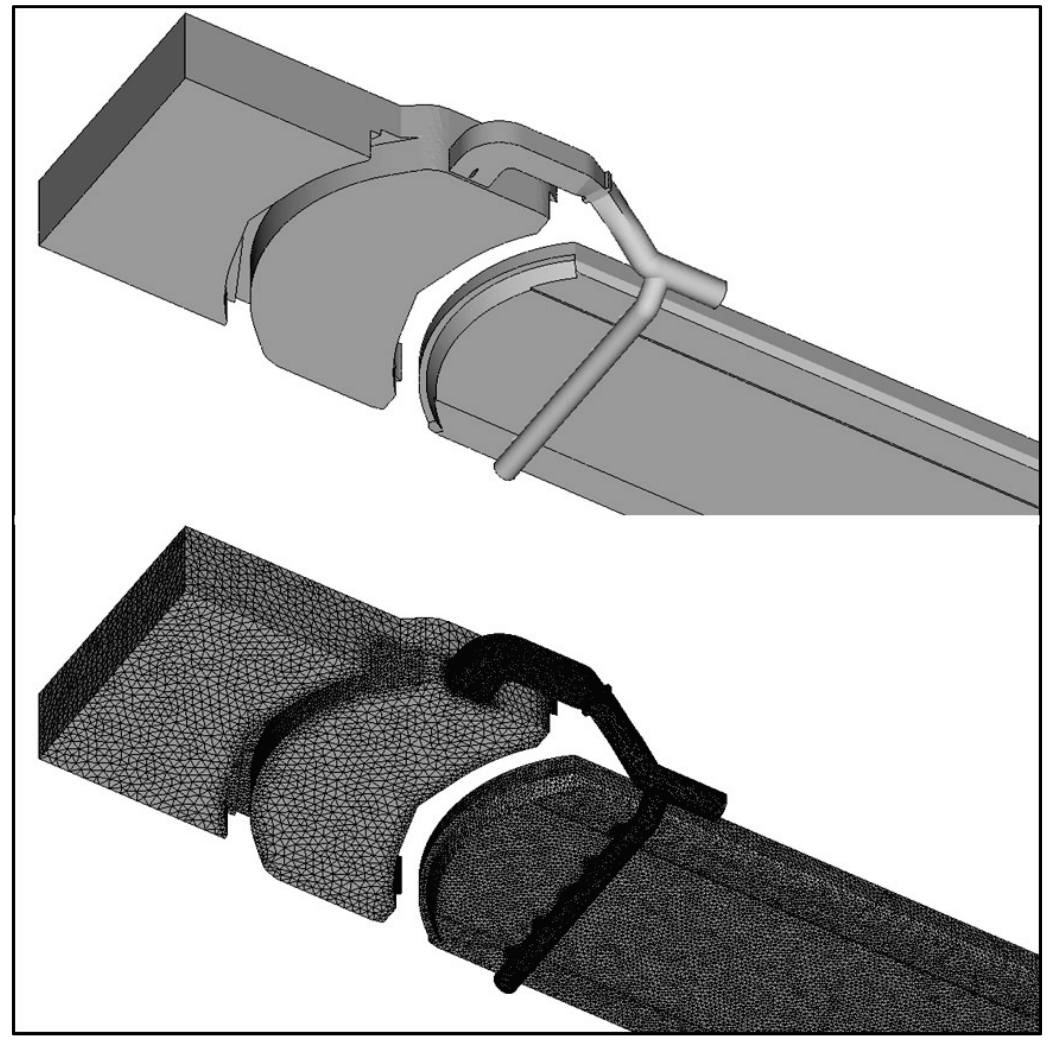

Figure 66. Type 2 geometry and computational mesh - Zoom 2.

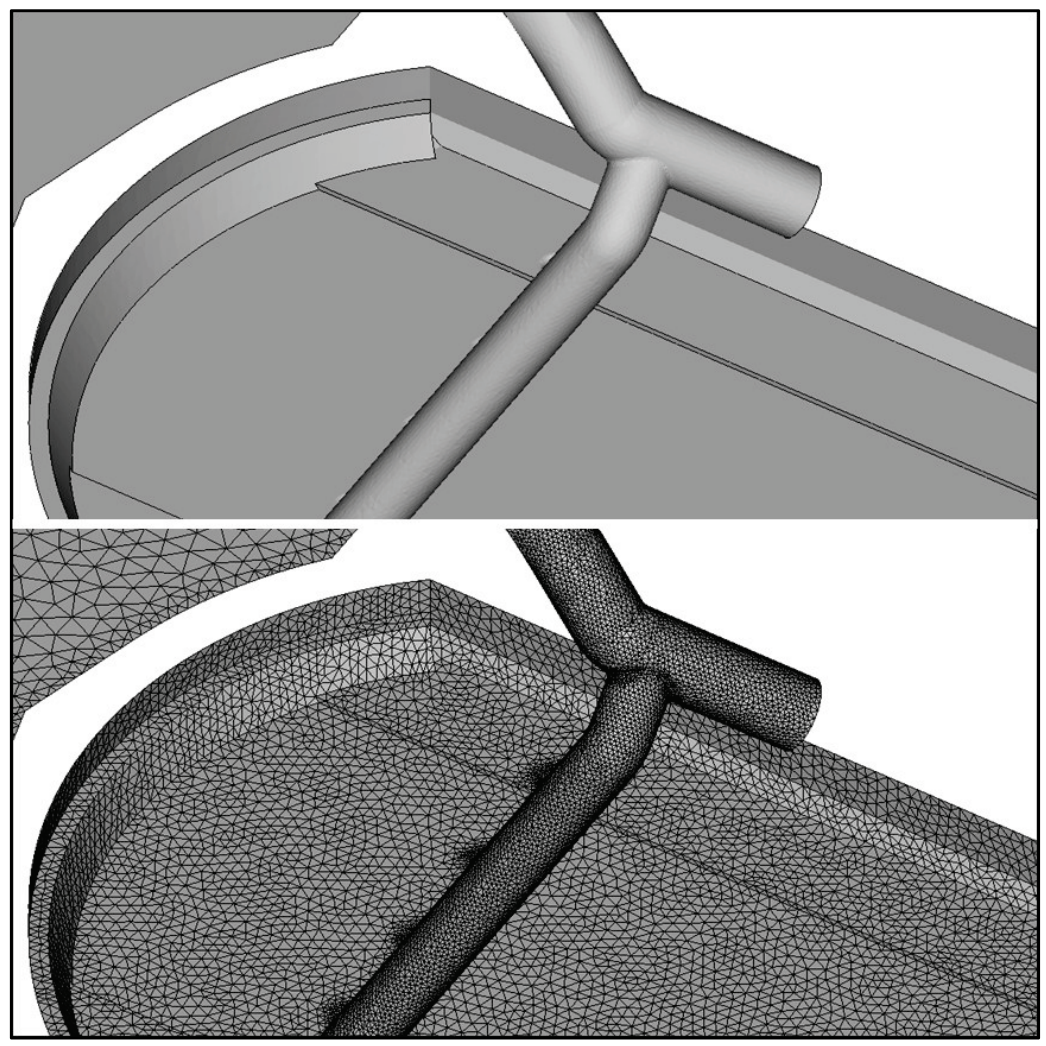


Figure 67. Type 3 geometry and computational mesh.

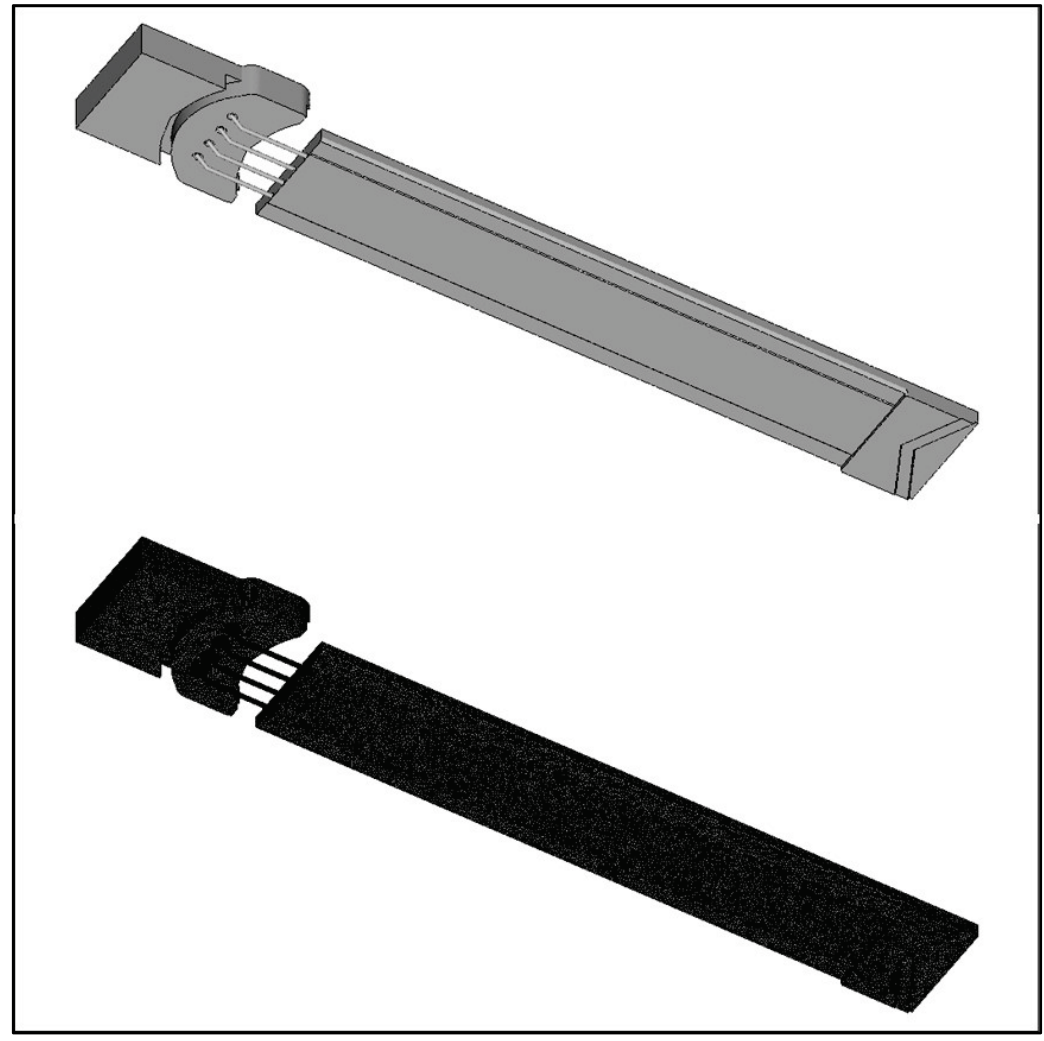

Figure 68. Type 3 geometry and computational mesh - Zoom 1.

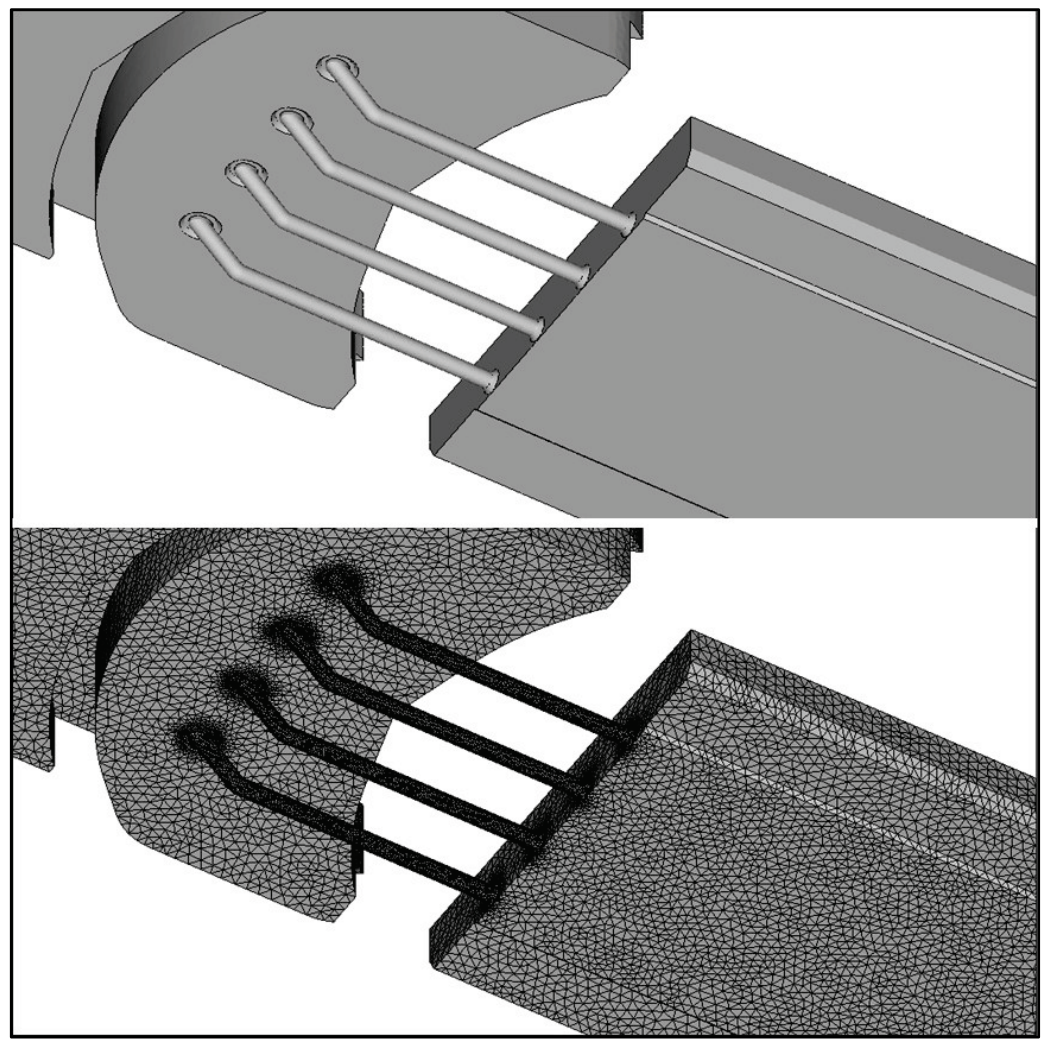


Figure 69. Type 3 geometry and computational mesh - Zoom 2.

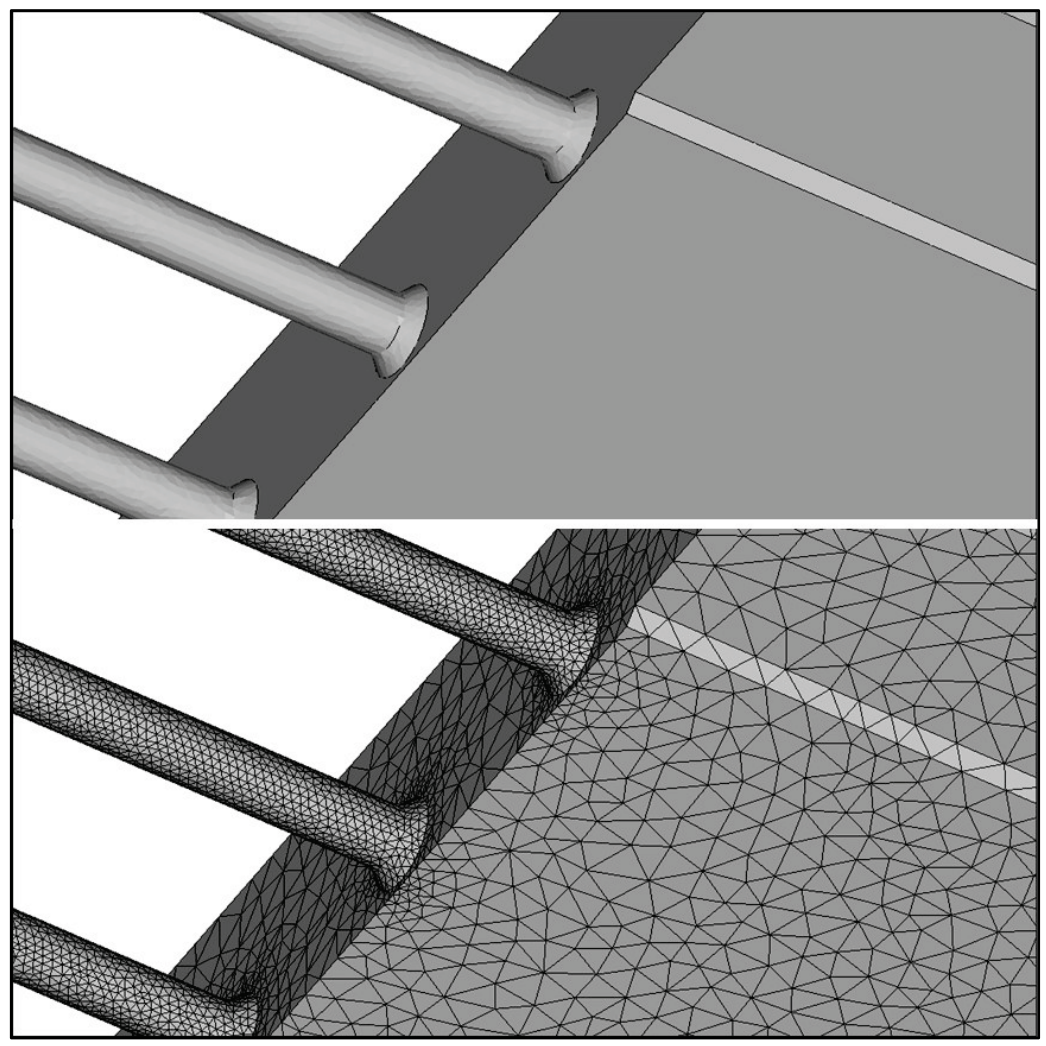

Figure 70. Type $3 r$ geometry and computational mesh.

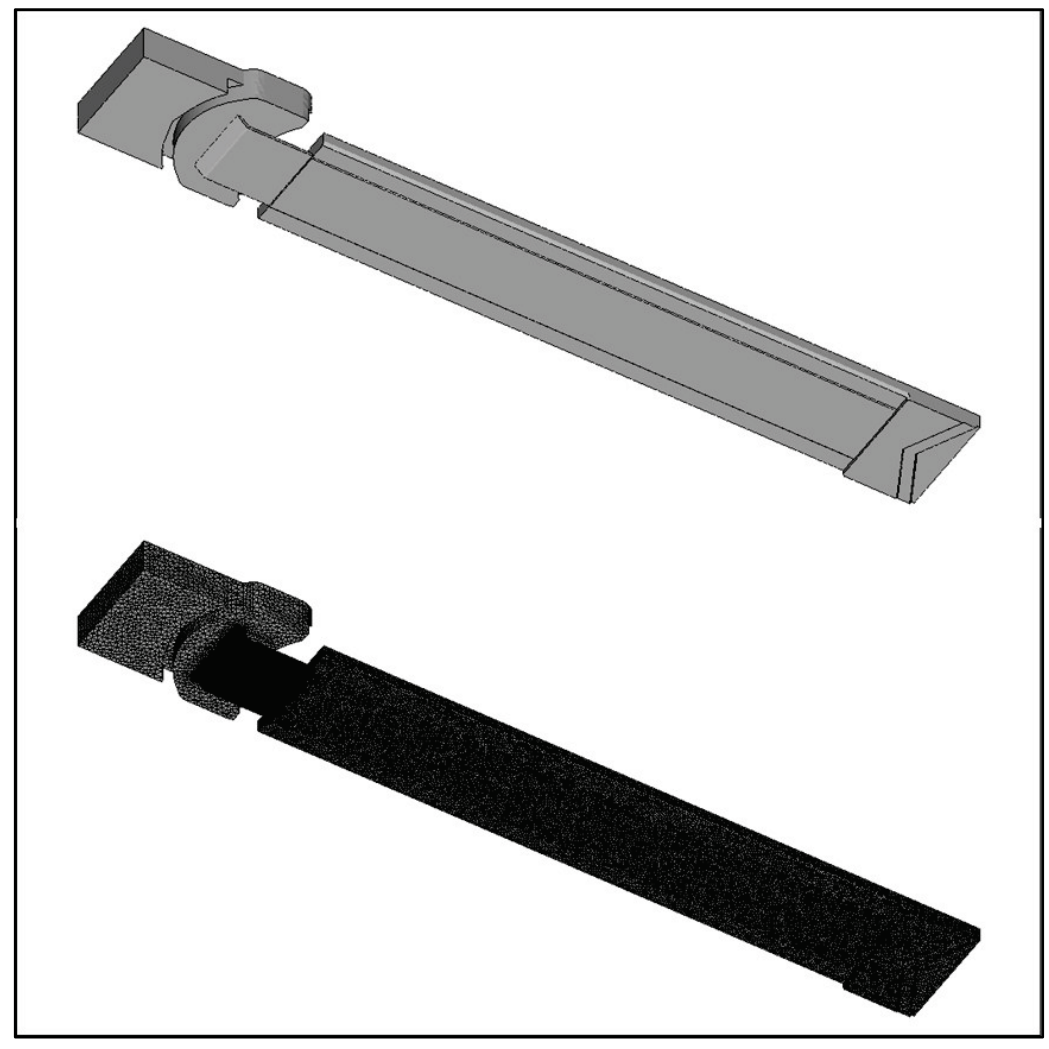


Figure 71. Type $3 r$ geometry and computational mesh - Zoom 1.

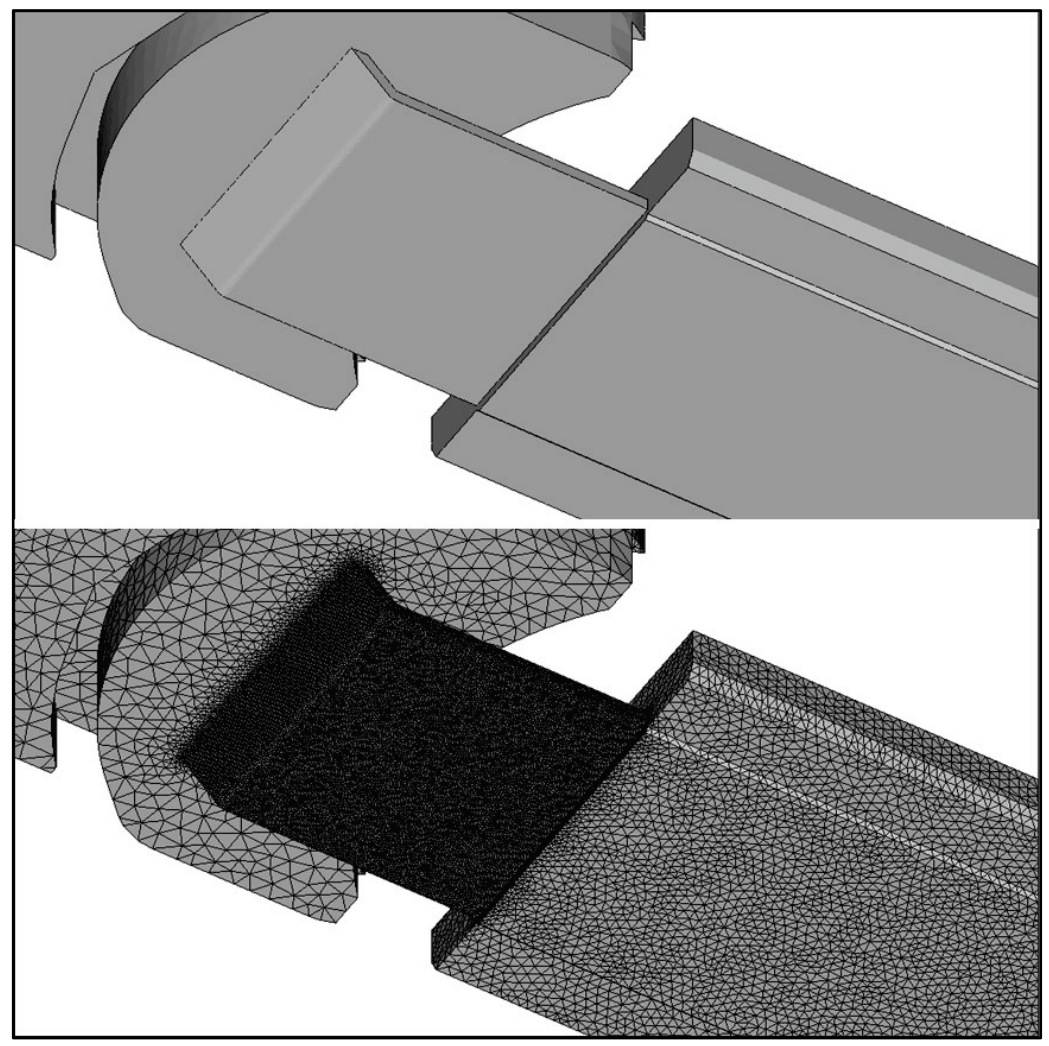

Figure 72. Type $3 r$ geometry and computational mesh - Zoom 2.

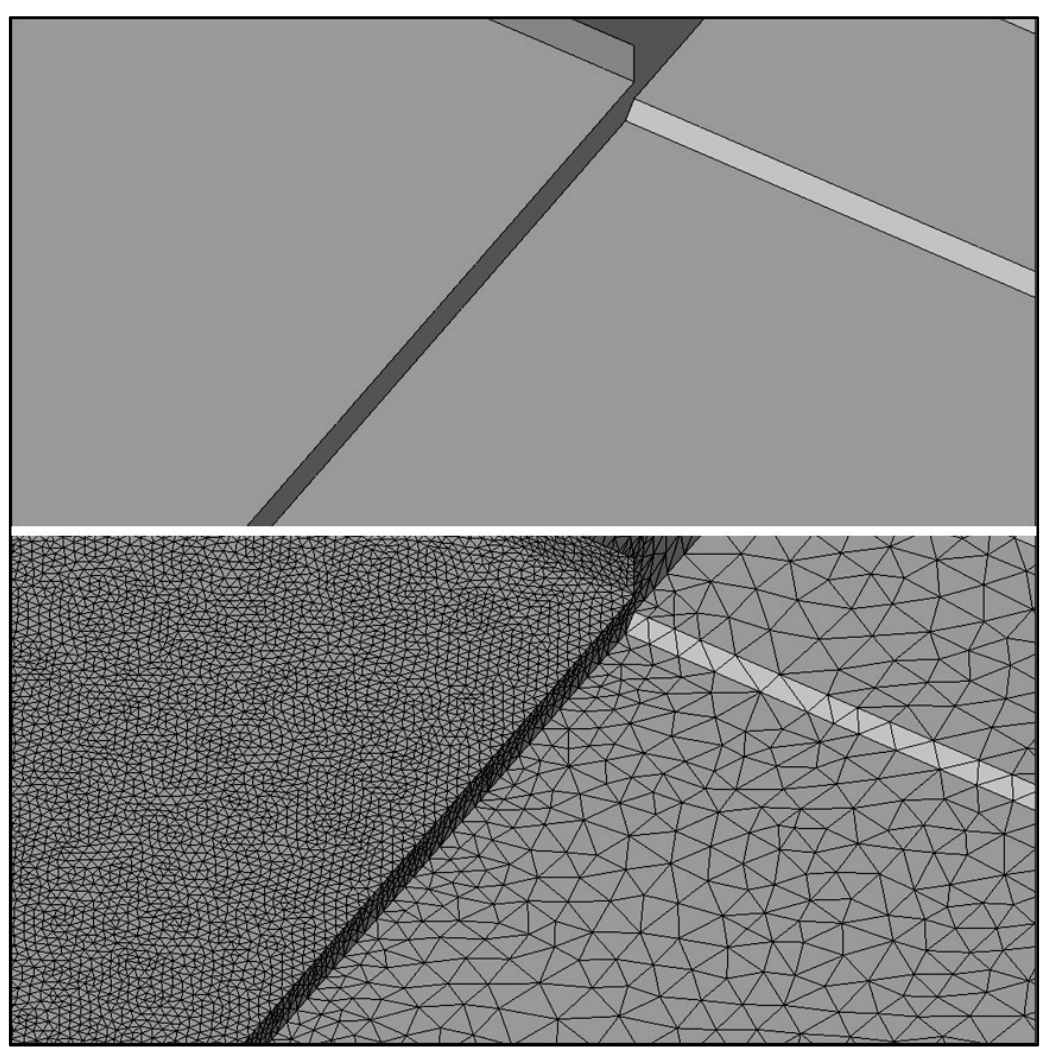


Figure 73. Type 5 geometry and computational mesh.

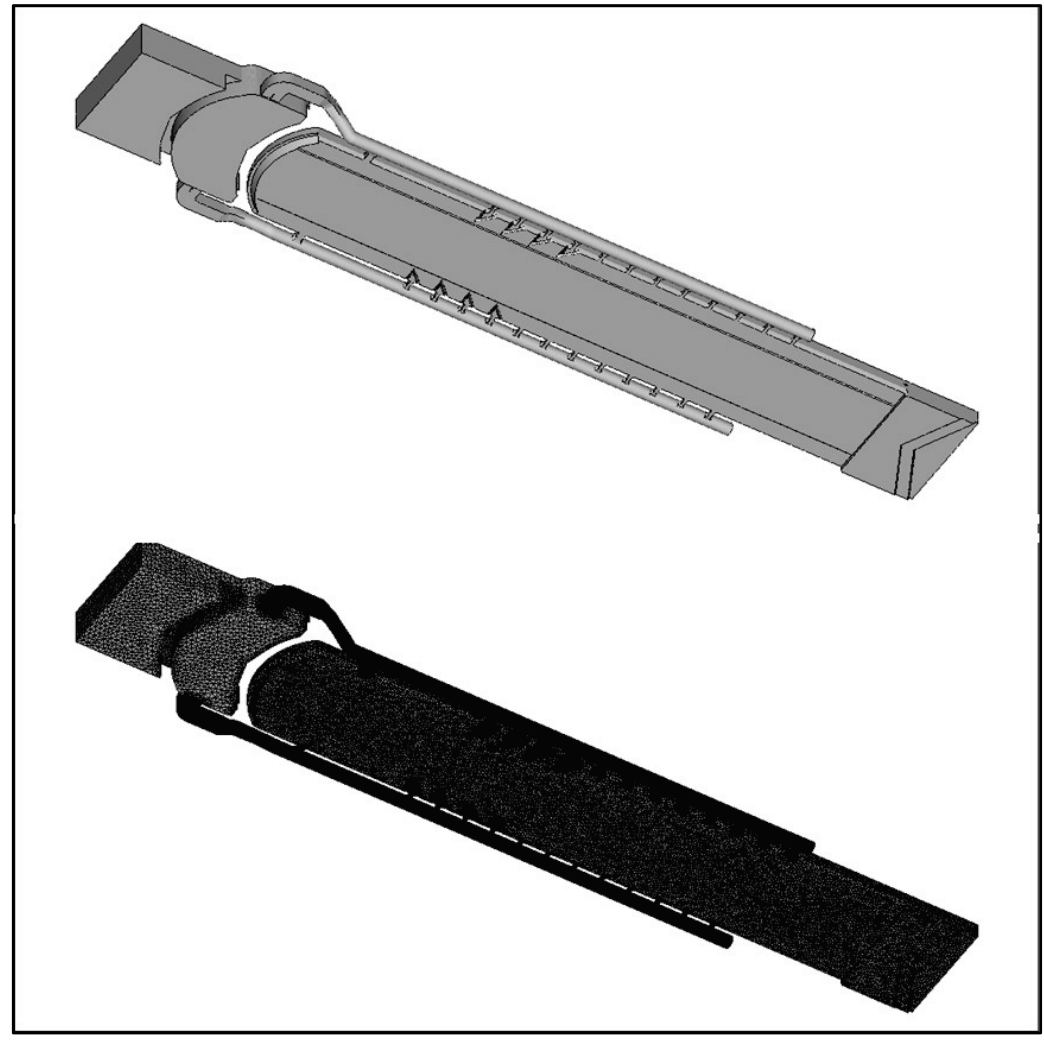

Figure 74. Type 5 geometry and computational mesh - Zoom 1.

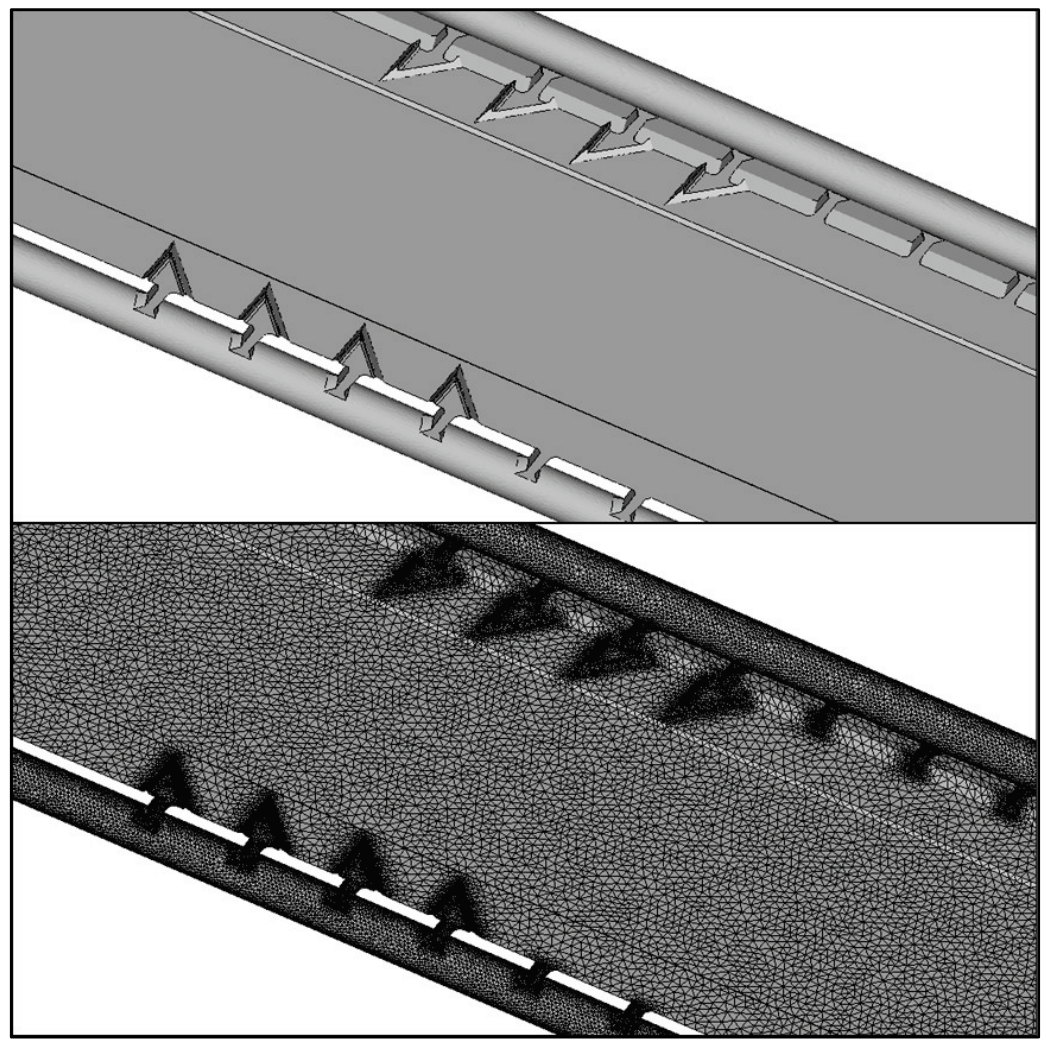


Figure 75. Type 5 geometry and computational mesh - Zoom 2.

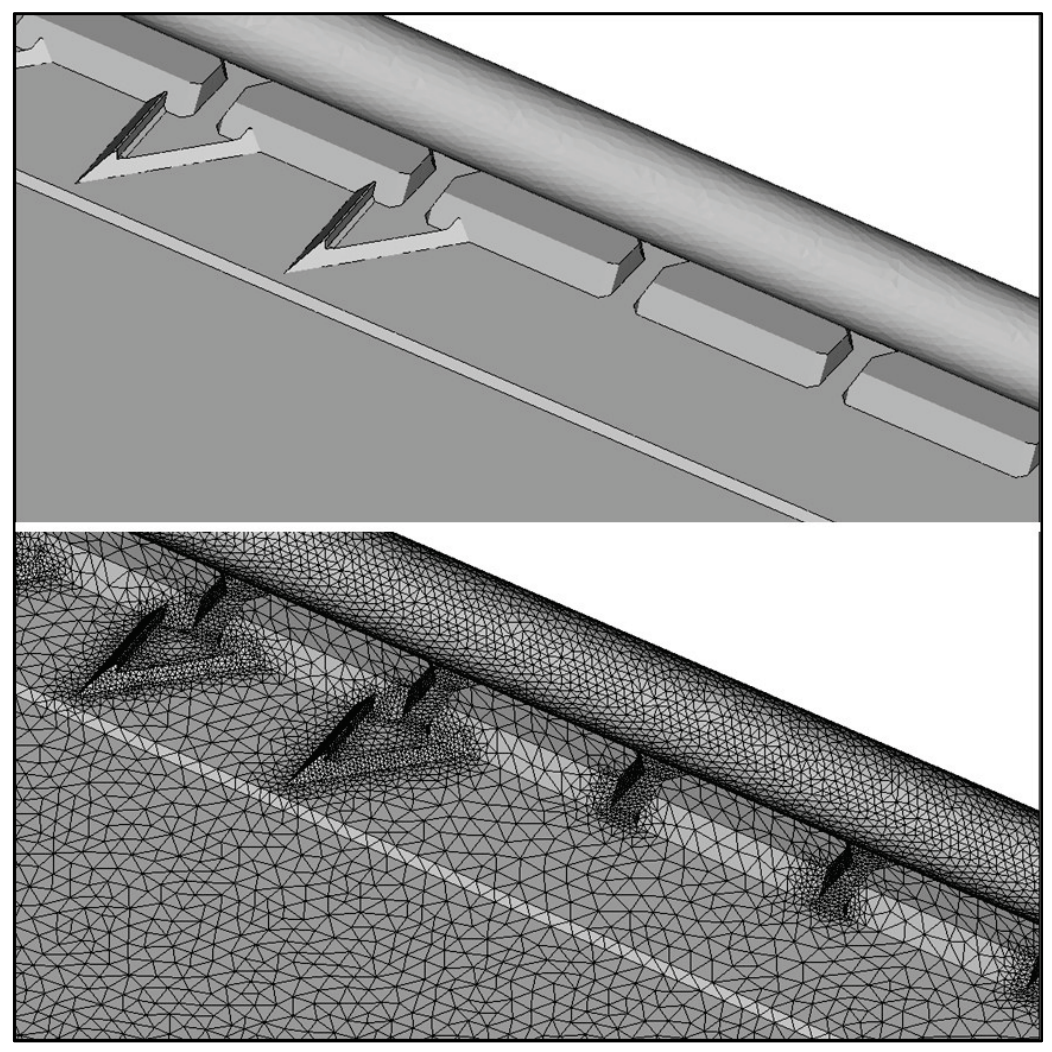




\section{Appendix C: Type 2 Fixed Lid Model Results}

The Type 2 lock flushing concept was simulated in a previous phase of numerical modeling work for the GLMRIS project. The numerical modeling process during that phase included fixed lid models of the lock flushing concepts with no direct calculation of original lock water concentration. The velocity magnitude contour plots (Figure 76 and Figure 77) are included in this appendix to give an idea of how the Type 2 concept would perform, but these results should not be used as a direct comparison with the results shown in Chapter 7 of this report because the displacement and velocity of the water surface were included in those models, which can significantly affect the flow solution. 
Figure 76. Type 2 velocity magnitude contours at el 494.6.

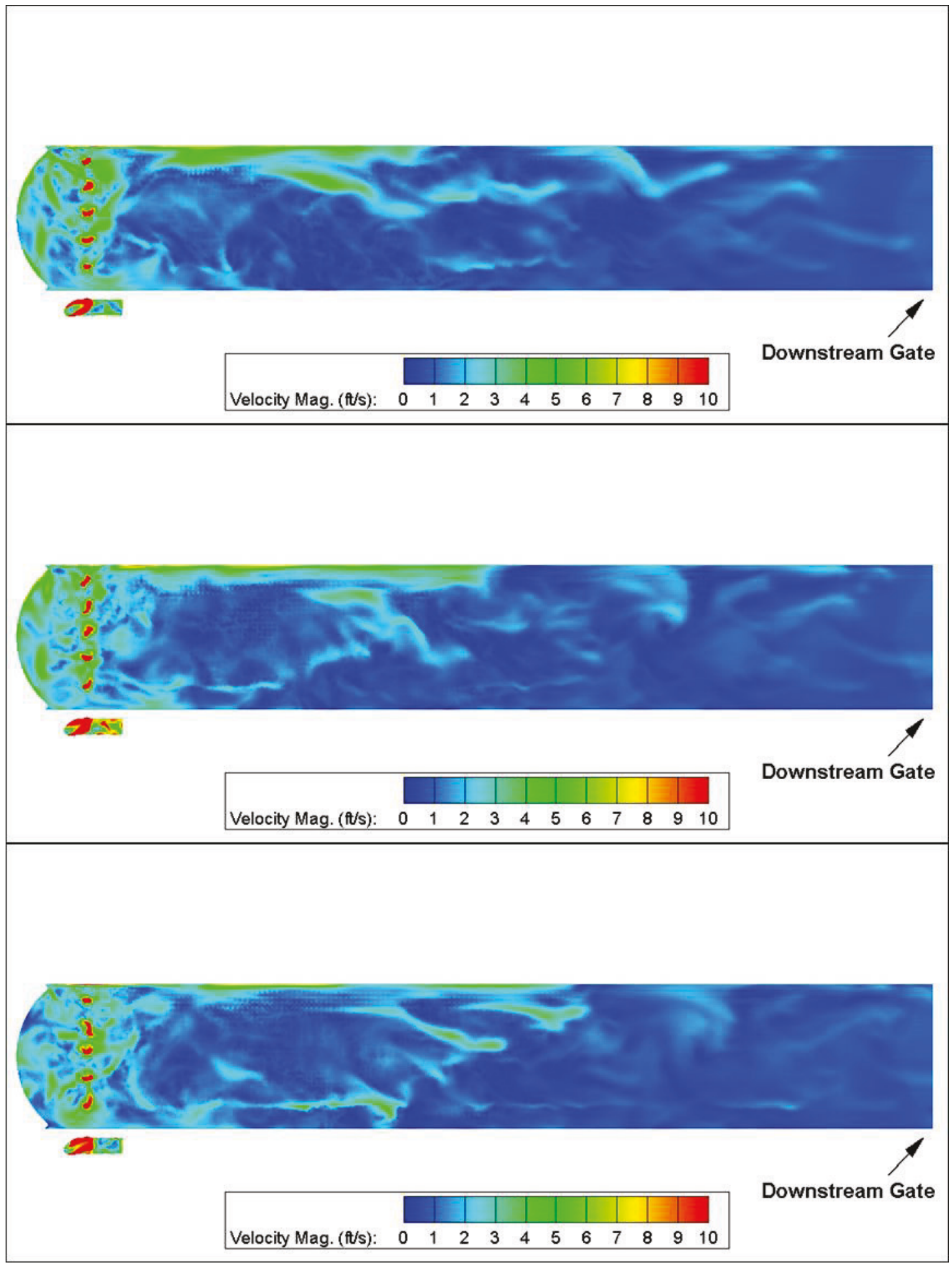


Figure 77 . Type 2 velocity magnitude contours at el 499.6 .

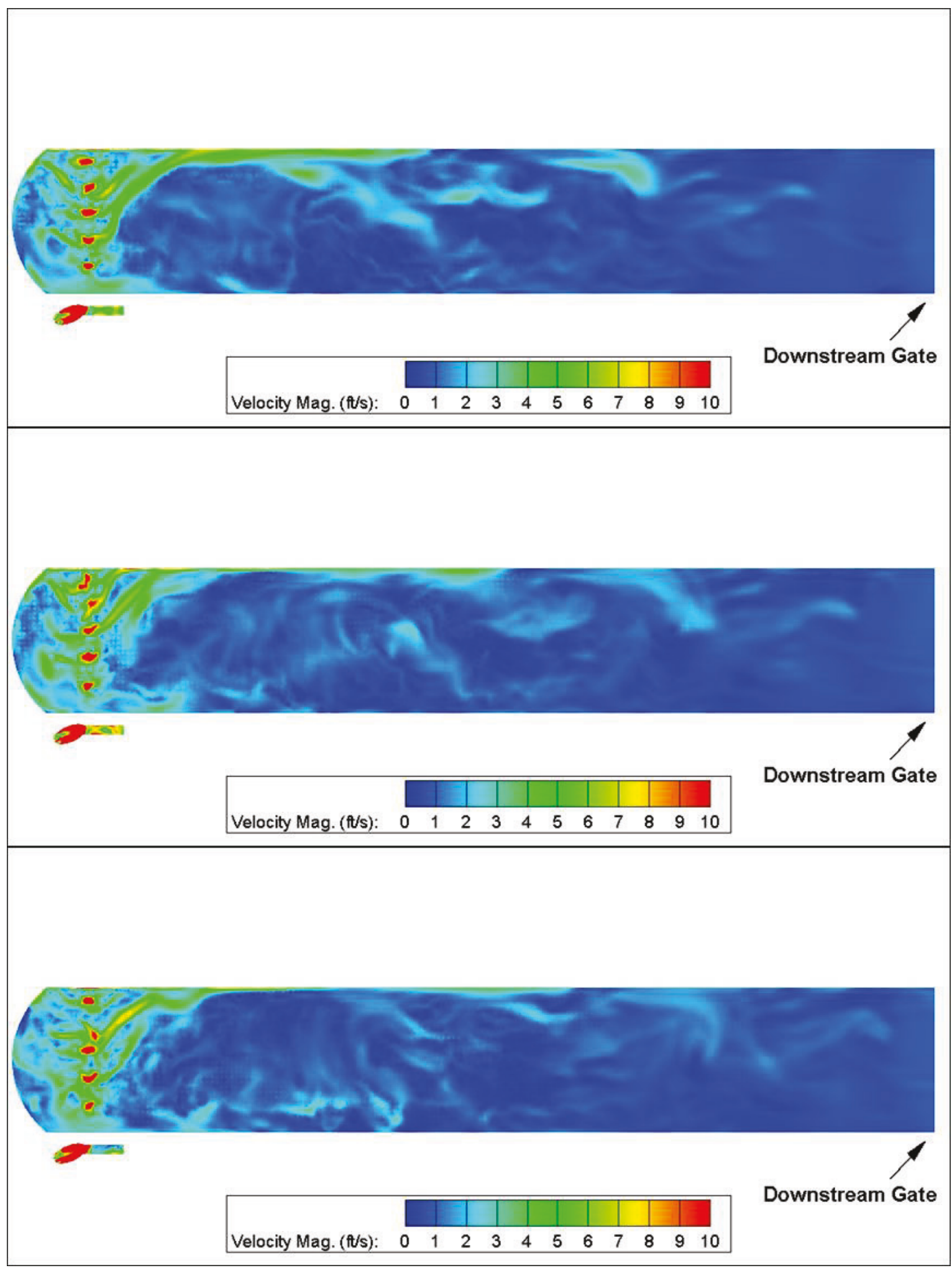




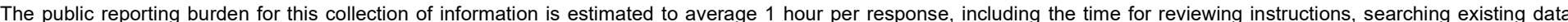

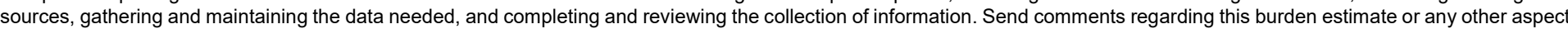

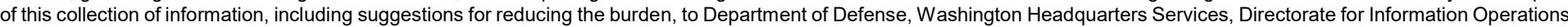

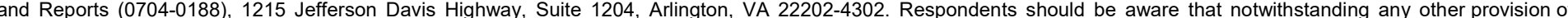
law, no person shall be subject to any penalty for failing to comply with a collection of information if it does not display a currently valid OMB control number.

PLEASE DO NOT RETURN YOUR FORM TO THE ABOVE ADDRESS.

\begin{tabular}{|l|l|l|l}
\hline 1. REPORT DATE & 2. REPORT TYPE & 3. DATES COVERED (FrOm - TO)
\end{tabular}

July 2018

Final Report

\section{TITLE AND SUBTITLE}

Analytical and Numerical Model Study on Reducing the Risk of Aquatic Nuisance Species

Transfer through Brandon Road Lock 5a. CONTRACT NUMBER

5b. GRANT NUMBER

5c. PROGRAM ELEMENT NUMBER

5d. PROJECT NUMBERS

451647, 451617, 114597,

5e. TASK NUMBER

5f. WORK UNIT NUMBER

8. PERFORMING ORGANIZATION REPORT NUMBER

ERDC/CHL TR-18-10

10. SPONSOR/MONITOR'S ACRONYM(S)

USACE LRC

USACE MVR

11. SPONSOR/MONITOR'S REPORT NUMBER(S)
1500 Rock Island Dr., Rock Island, IL 61201

U.S. Army Corps of Engineers, Rock Island

District

231 S LaSalle St. \#1500, Chicago, IL 60604

12. DISTRIBUTION/AVAILABILITY STATEMENT

Approved for public release; distribution is unlimited.

\section{SUPPLEMENTARY NOTES}

\section{ABSTRACT}

The Great Lakes and Mississippi River Interbasin Study (GLMRIS) is a U.S. Army Corps of Engineers study to evaluate methods of preventing the movement of aquatic nuisance species (ANS) movement between the Great Lakes and Mississippi River basins through aquatic connections. This report is an assemblage of ideas, preliminary hydraulic calculations, and numerical model evaluations that serve as part of the development of an ANS flushing system for Brandon Road Lock on the Illinois Waterway. Four flushing system designs and operations are presented. An analytical description of each lock flushing system design and numerical model results of those designs when applied to Brandon Road Lock are presented. Further, justifications and considerations of a physical model study of any lock flushing design that is chosen for construction are presented. This report is an overall commentary on design ideas and considerations for modeling the flushing rate of the lock chamber. The hydraulic details of lock flushing are outlined with the significant parameters of each lock flushing alternative highlighted. Numerical model results are presented to quantify the effectiveness of each lock flushing concept considered in this study.

\section{SUBJECT TERMS}

Hydraulic structures, Illinois Waterway (Ill.), Introduced organisms, Locks (Hydraulic engineering), nonindigenous aquatic pests

\section{SECURITY CLASSIFICATION OF:}

a. REPORT

Unclassified

\section{b. ABSTRACT}

Unclassified

\section{c. THIS PAGE}

Unclassified
17. LIMITATION OF ABSTRACT

SAR
18. NUMBER OF

\section{PAGES}

135 19a. NAME OF RESPONSIBLE PERSON

E. Allen Hammack

19b. TELEPHONE NUMBER (Include area code) 601-634-3628 